\title{
Postnatale Entwicklung des GABAergen Systems im Gehirn der Maus
}

\author{
Dissertation \\ zur Erlangung des Doktorgrades \\ der Mathematisch-Naturwissenschaftlichen Fakultäten \\ der Georg-August-Universität Göttingen
}

vorgelegt von

\section{Barbara Ritter}

aus Waltrop

Göttingen 2001 
D7

Referent: Herr Prof. Dr. F.-W. Schürmann

Koreferent: Herr Prof. Dr. R. Hustert

Tag der mündlichen Prüfung: 27.06.2001 


\section{INHALTSVERZEICHNIS}

$1 \quad$ Zusammenfassung

$2 \quad$ Einleitung 7

2.1 GABAerge Inhibition im zentralen Nervensystem der Säugetiere 7

2.1.1 $\mathrm{GABA}_{\mathrm{A}}$-Rezeptor - Aufbau, Funktion und Lokalisation __ 7

2.1.2 $\mathrm{GABA}_{\mathrm{B}}$-Rezeptor - Aufbau, Funktion und Lokalisation___ 9

2.2 Rezeptorgenese und intrazellulärer Transport von Rezeptoren ___ 13

2.3 Inhibition in neuronalen Netzwerken: Beispiel Respiration___ 14

2.3.1 An der Respiration sind unterschiedliche Strukturen beteiligt___ 15

2.3.2 Der Rhythmusgenerator des respiratorischen Netzwerkes ___ 16

2.3.3 Inhibition im respiratorischen System ___ 18

2.4 Plastizität in neuronalen Netzwerken

2.4.1 Ontogenetische Änderung der Rezeptorexpression ___ 19

2.4.2. Ontogenetische Änderung der Rezeptorfunktion____ 19

2.4.3 Ontogenetische Änderung der Inhibition im respiratorischen Netzwerk ___ 21

2.5 Fragestellung und Zielsetzung___ 21

$3 \quad$ Material und Methoden __ 23

3.1 Experimentelle Vorgehensweise ___ 23

3.2 Elektrophysiologie — 25

3.2.1 Präparation des isolierten, rhythmisch-aktiven Hirnstammschnittes ___ 25

3.2.2 Versuchsaufbau und Datenaufnahme___ 27

3.2.3 Meßtechniken _ـ 29

3.3 Immunohistochemie __ 32

3.3.1 Eingesetzte Erst- und Zweitantikörper____ 35

3.3.2 Färbung mit Avidin-Biotin-gekoppeltem Zweitantikörper durch Umsetzung von Diaminobenzidin ___ 35

3.3.3 Färbung durch Markierung mit fluoreszenzgekoppelten Zweitantikörpern

3.4 Molekularbiologische Methoden 39

3.4.1 Immunopräzipitation _ـ 39

4 Ergebnisse

4.1 GABA moduliert die rhythmische Aktivität des respiratorischen Netzwerkes der Maus ab der Geburt 44

4.1.1 Endogen erhöhtes GABA reduziert die Frequenz des respiratorischen Rhythmus 44

4.1.2 Endogenes GABA aktiviert hauptsächlich $\mathrm{GABA}_{\mathrm{B}}$-Rezeptoren in der perinatalen und $\mathrm{GABA}_{\mathrm{A}}-\mathrm{und}_{\mathrm{GABA}}-$ Rezeptoren in der spätpostnatalen Phase 45

4.2 $\mathrm{GABA}_{\mathrm{A}}$-Rezeptoren vermitteln perinatal eine chloridgetragene Depolarisation 46 
4.3 Entwicklungsabhängige Funktionsänderungen sind begleitet von Veränderung in der zellulären Verteilung der GABA $\mathbf{G}_{\mathrm{B}}$-Rezeptoren

4.3.1 Expression des $\mathrm{GABA}_{\mathrm{B}}$-Rezeptors ab der Geburt nachweisbar _ـ 55

4.3.2 Die intrazelluläre Verteilung des $\mathrm{GABA}_{\mathrm{B}}$-Rezeptors unterliegt einer postnatalen Veränderung ___ 58

4.4 Die intrazelluläre Komplex-Bildung zwischen ATF4 und GABA $A_{B}$-Rezeptor ändert sich während der postnatalen Entwicklung _ 62

4.5 Auswirkungen der Entwicklung des GABAergen Systems auf der Ebene von neuronalen Netzwerken 66

4.5.1 $\mathrm{GABA}_{\mathrm{A}}$-Rezeptoren reduzieren die respiratorische Frequenz erst ab dem Eintritt ihrer hyperpolarisierenden Wirkung 66

4.5.2 Blockade des $\mathrm{GABA}_{\mathrm{B}}$-Rezeptors zeigt eine grundlegend unterschiedliche Wirkung in perinatalen und in älteren Mäusen 70

5 Diskussion 74

5.1 Inhibition in der frühpostnatalan Phase 74

5.1.1 Die Funktion $\mathrm{GABA}_{\mathrm{A}}$-Rezeptor vermittelter Depolarisation in neuronalen Netzwerken 75

5.1.2 $\mathrm{K}^{+}$- vermittelte Inhibition während der frühpostnatalen Phase 77

5.2 Entwicklungsbedingte Veränderungen des $\mathrm{GAB}_{\mathrm{B}}-$ Rezeptors 77

5.2.1 Unterschiedliche intrazelluläre Verteilung des $\mathrm{GABA}_{\mathrm{B}}$-Rezeptors in der Ontogenese: ein Phänomen des Rezeptor-Transportes oder der Rezeptor-Internalisierung? 78

5.3 Interaktion von GABA $\mathrm{A}_{\mathrm{B}}$-Rezeptoren mit ATF4 80

5.4 Ausblick 83

6 Literatur 84

7 Danksagung 92

8 Lebenslauf 94 


\section{ZUSAMMENFASSUNG}

In der vorliegenden Arbeit wurde die ontogenetische Veränderung im GABAergen Sytem anhand des rhythmisch aktiven Hirnstammpräparates der NMRI Maus während der frühpostnatalen Entwicklung (P0-P15) untersucht. Meine Ergebnisse zeigten eine umfassende Veränderung sowohl auf der Netzwerkebene als auch in der zellulären Funktion und in der intrazellulären Rezeptorverteilung und Protein-Interaktion.

Auf der Netzwerkebene bewirkt eine Akkumulation von endogenem GABA eine Verlangsamung des respiratorischen Rhythmus. Dieser Effekt wurde zwischen P0-3 weitgehend von GABA $_{\mathrm{B}^{-}}$ Rezeptoren vermittelt, eine Blockade der $\mathrm{GABA}_{\mathrm{A}}$-Rezeptoren hatte keine Wirkung auf die Frequenz der rhythmischen Aktivität. Ab P4 spielten sowohl $\mathrm{GABA}_{\mathrm{A}}$ - als auch $\mathrm{GABA}_{\mathrm{B}}-$ Rezeptoren eine funktionelle Rolle in der Rhythmusmodulation, wobei $\mathrm{GABA}_{\mathrm{A}}$-Rezeptoren mit zunehmenden Alter einen immer dominanteren Effekt ausübten. Diese Veränderung $\mathrm{GABA}_{\mathrm{A}}$-Rezeptor vermittelter Modulationen auf der Netzwerkebene ging mit einer Verschiebung des ChloridEquillibriumpotentials von $-13.7 \pm 9.8 \mathrm{mV}$ an $\mathrm{P} 0 \mathrm{zu}-71.5 \pm 7.1 \mathrm{mV}$ nach $\mathrm{P} 4$ einher.

Die funktionellen Veränderungen wurden begleitet von einer intrazellulären Umverteilung des $\mathrm{GABA}_{\mathrm{B}}$-Rezeptors. Seine Immunoreaktivität war in den Neuronen des Hirnstamms bis P4 diffus in Soma und Dendriten verteilt, während ab P5 in zunehmender Anzahl intensiv immunopositive Granula im Zellplasma auftraten. Im Elektronenmikroskop konnten sie als $\mathrm{GABA}_{\mathrm{B}}$-haltige Vesikel identifiziert werden. Das Auftreten dieser Vesikel blieb nicht auf den Hirnstamm begrenzt sondern stellte ein im ZNS der Maus weitverbreitetes Phänomen dar. Der Zeitpunkt ihres Auftretens spiegelte die in der Ontogenese später stattfindende Reifung höherer Hirngebiete wieder (CA1: P7; Cortex: P8). In 5-10\% dieser Vesikel wurde eine Kolokalisation von GABA $A_{B}$-Rezeptoren mit ATF4 gezeigt. Mit Ko-immunopräzipitation wurde nachgewiesen, daß die Entwicklung der Interaktion der $\mathrm{GABA}_{\mathrm{B}}$-Rezeptor Untereinheiten R1 und R2 mit ATF4 unterschiedlich verläuft.

Die hier dargestellte Ontogenese des GABAergen Systems erlaubt interessante Einblicke in grundsätzliche Wirkungsmechanismen des ZNS. So wurde die Hypothese gestellt, daß das perinatalphysiologische Fehlen oder eine pathologisch bedingte Fehlfunktion der Chlorid-getragenen Inhibition in einem neuronalen Netzwerk durch funktionelle Kationen-getragene Inhibition kompensiert werden kann. Darüber hinaus deutet die direkte Interaktion des $\mathrm{GABA}_{\mathrm{B}}$-Rezeptors mit ATF4 auf einen neuen Mechanismus in der Signal-Transduktion und im Transport von GABA $_{B^{-}}$ Rezeptoren hin. 


\section{Ergebnisse dieser Doktorarbeit wurden/werden in folgenden Originalarbeiten publiziert:}

Ritter, B; Zhang, W (2000); Early postnatal maturation of $\mathrm{GABA}_{\mathrm{A}}$-mediated inhibition in the brainstem respiratory rhythm-generating network of the mouse; Eur. J. Neurosci.; 12; 2975 2984

Zhang W, Barnbrock A, Gajic S, Pfeiffer A, Ritter B (2001) Differential ontogenie of GABA receptor-mediated pre- and postsynaptic inhibition in respiratory rhythm generating network of mouse. The Journal of Physiology, revised

Ritter, B; Zhang, W; Richter, DW; Ponimaskin, EG; The GABA $B$ Rezeptor subunits R1 and R2 interact differentially with the activation factor ATF4 in mouse brain during the postnatal development; in preparation

Ritter, B.; Ochojski, M; Kühn, T; Schwarzacher, S; Zhang, W; Differential cellular and subcellular distribution of $\mathrm{GABA}_{\mathrm{B}} \mathrm{R} 1 \mathrm{a}$ and $\mathrm{b}$ receptors in mouse brain during postnatal development; in preparation

\section{Teilergebnisse dieser Doktorarbeit wurden als publizierte Kongressbeiträge veröffentlicht:}

Ritter, B., D. W. Richter and W. Zhang (1998). The effect of $\mathrm{GABA}_{\mathrm{A}}$ antagonist bicuculline changes during early postnatal development in the respiratory network of mouse. Eur $J$ Neurosci 10 Suppl 10, 185

Ritter, B., A. Barnbrock and W. Zhang (1999). GABAA-mediated postsynaptic potentials become inhibitory within three postnatal days in respiratory rhythm-generating network. Proceedings of the 27th Göttingen Neurobiology Conference 1999, Vol. 2, Thieme, Stuttgart, New York, p. 244

Ritter, B., A. Barnbrock, A. Pfeiffer and W. Zhang (1999). The role of $\mathrm{GABA}_{\mathrm{A}^{-}}$and $\mathrm{GABA}_{\mathrm{B}^{-}}$ mediated inhibition changes in respiratory rhythm-generating network markedly during early postnatal stage. Soc. Neurosci. Abstr. 25 (1), p694

Ritter, B., M. Ochojski, T. Kühn, A. Pfeiffer, A. Barnbrock, S. Gajic and W. Zhang (2000) The role of $\mathrm{GABA}_{\mathrm{B}}$ receptor and its cellular distribution change during early postnatal development. Pflügers Archiv 439 (Suppl 6): R429 


\section{EINLEITUNG}

\subsection{GABAerge Inhibition im zentralen Nervensystem der Säugetiere}

Der Neurotransmitter $\gamma$-Aminobuttersäure (GABA) ist neben Glycin der wichtigste inhibitorische Neurotransmitter im zentralen Nervensystem (ZNS) der Säugetiere. Die von ihm ausgelösten Effekte werden durch unterschiedliche Rezeptoren vermittelt. Zum einen gibt es die ionotropen

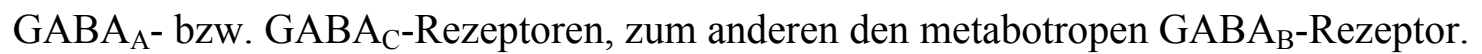

\subsection{1 $\quad$ GABA $_{A}$-Rezeptor - Aufbau, Funktion und Lokalisation}

Der GABA $_{A}$-Rezeptor ist ein Heteromer aus fünf Polypeptid-Untereinheiten s. Abb. 1 A von denen jede vier Mal die Zellmembran durchspannt s. Abb. 1 B. Diese fünf Untereinheiten bilden zusammen eine wassergfüllte Pore (Enna \& Bowery, 1997). Die Pore ist im Grundzustand geschlossen und wird nach extrazellulärer Anlagerung zweier GABA Moleküle durch eine Konformationsänderung geöffnet. Im Innern der Pore befinden sich an exponierter Stelle positiv geladene Aminosäurereste, die als Selektivitätsfilter dienen und nur einfach negativ geladene Chloridionen $\left(\mathrm{Cl}^{-}\right)$und in geringerem Maße Bicarbonationen $\left(\mathrm{HCO}_{3}{ }^{-}\right)$und andere Anionen

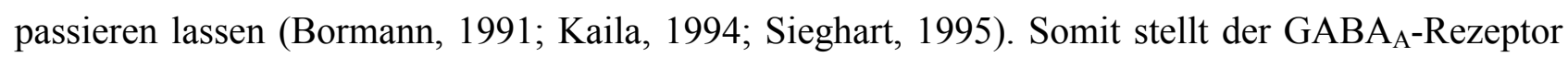
einen ligandengesteuerten, ionotropen $\mathrm{Cl}^{-}$-Kanal dar. Grundsätzlich können die Ionen bei einer Öffnung des Kanals die Membran in beide Richtungen passieren. In welcher Richtung der Ionenfluß bei einem festgelegten Membranpotential stattfindet, wird von dem chemischen Gradienten der Ionen über der Membran bestimmt (s. Abb. 1 C). Die Kopplung von Rezeptor und Kanal in einem Protein ermöglicht eine schnelle Auslösung des postsynaptischen Potentials (PSP) nach der Neurotransmitterausschüttung. Die Funktionsweise von GABA $_{\mathrm{A}}$-Rezeptoren kann durch intrazelluläre Phosphorelierung und Bindung von allosterischen Liganden wie $\mathrm{Zn}^{+}$oder Barbituraten modifiziert werden (Review s. Mohler et al., 1996). Es sind unterschiedliche Pharmaka bekannt, die die Wirkung des $\mathrm{GABA}_{\mathrm{A}}$-Rezeptors beeinflussen, wie z.B. Barbiturate und Benzodiazepine. In dieser Arbeit wurden Bicucullin und Picrotoxin als Antagonisten und Muscimol als Agonist verwendet (Krogsgaard-Larsen et al., 1997).

Da die Bindung von GABA an den Rezeptor nicht permanent ist, löst sich der Transmitter nach einer gewissen Zeit und diffundiert aus dem synaptischen Spalt oder wird aktiv in Neurone und Gliazellen wiederaufgenommen. Dies wird über spezifische Transporter bewerkstelligt, die pharmakologisch, z.B. durch Nipekotinsäure, blockierbar sind (Borden, 1996; Krogsgaard-Larsen et al., 1998). 

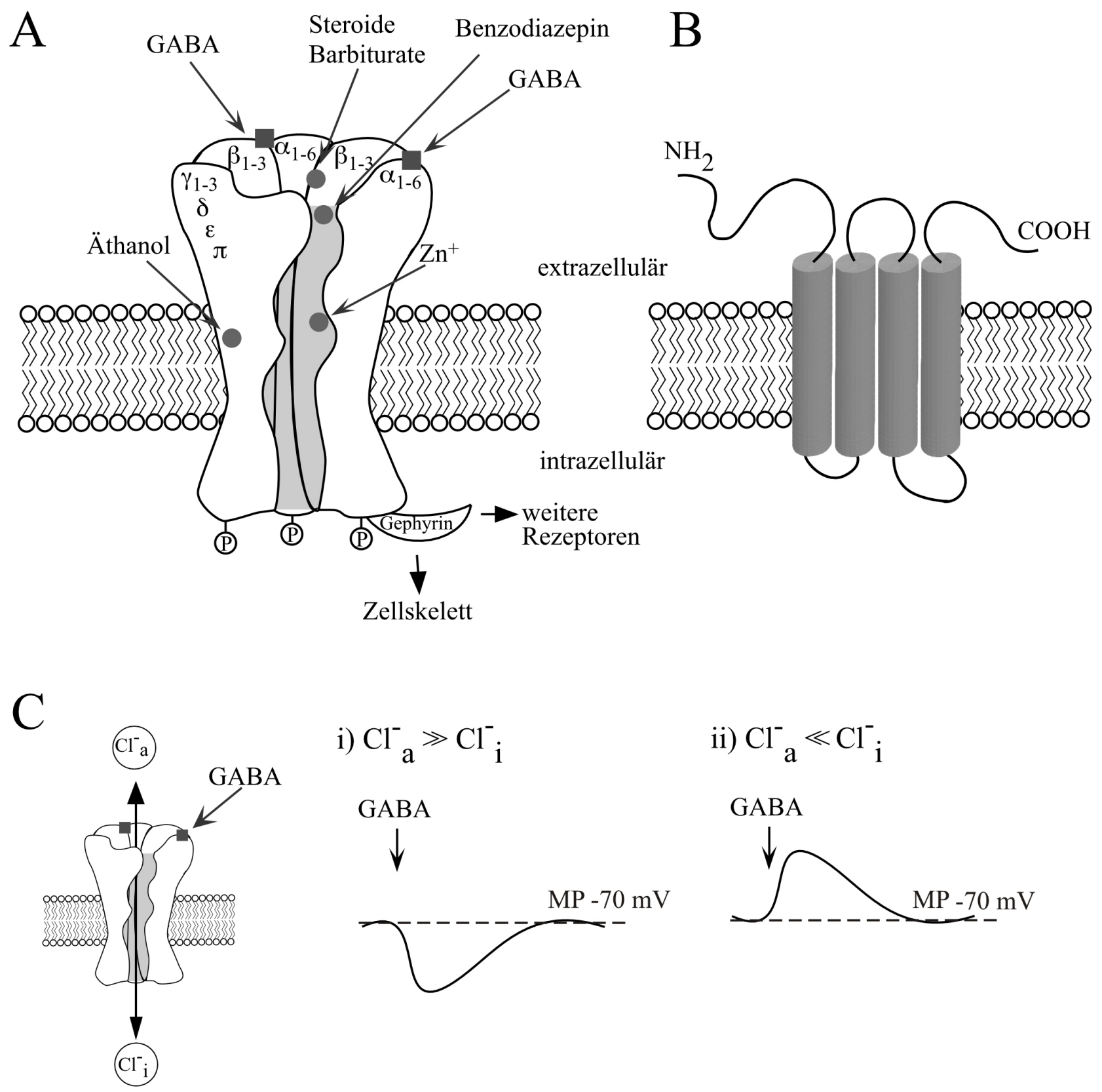

i) $\mathrm{Cl}^{-} \mathrm{a} \gg \mathrm{Cl}^{-}$i

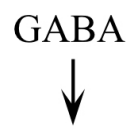

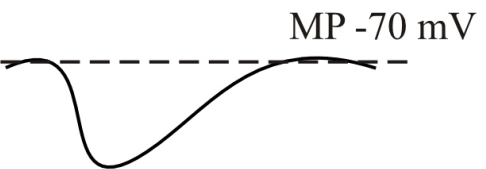

ii) $\mathrm{Cl}_{\mathrm{a}}^{-} \ll \mathrm{Cl}^{-}$i

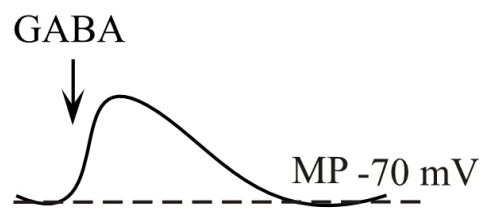

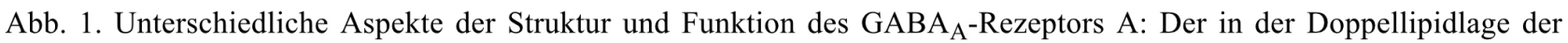
Membran gelegene $\mathrm{GABA}_{\mathrm{A}}$-Rezeptor ist ein Pentamer aus verschiedenen Untereinheiten $\left(\alpha_{1-3}\right.$ bis $\left.\pi\right)$ die eine wassergefüllte Pore (grau schattiert) bilden. GABA $\mathrm{A}^{-R e z e p t o r e n ~ w e r d e n ~ d u r c h ~ d a s ~ A n k e r p r o t e i n ~ G e p h y r i n ~ m i t e i n a n d e r ~ u n d ~ m i t ~ d e m ~}$ Zellskelett verbunden. An den Rezeptor können zwei GABA-Moleküle (Bindungsstellen mit grauem Kästchen markiert) und unterschiedliche Modulatoren (graue Kreise) binden. $\alpha$ - und $\gamma$-Untereinheiten können darüber hinaus phosphoreliert werden. $\mathrm{B}$ : Jede Untereinheit des GABA $\mathrm{A}$-Rezeptors hat 4 transmembrane Helices (graue Zylinder) und extrazellulär gelegene aminound carboxyterminale Endigungen. C: Die Bindung von GABA (Pfeil) und die daraus folgende Erhöhung der Leitfähigkeit des Rezeptorkanales für Chloridionen $\left(\mathrm{Cl}^{-}\right)$ermöglicht den Ionenfluß in beide Richtungen (Doppelpfeil). i) Bei hoher extrazellulärer $\mathrm{Cl}^{-}$-Konzentration $\left(\mathrm{Cl}^{-}{ }_{\mathrm{a}}\right)$ und geringer intrazellulärer $\left(\mathrm{Cl}^{-}{ }_{\mathrm{i}}\right)$ löst $\mathrm{GABA}$-Applikation (Pfeil) bei einem Neuron mit einem Membranpotential (MP) von $-70 \mathrm{mV}$ eine Hyperpolarisation durch $\mathrm{Cl}^{-}$-Einstrom aus. ii) Bei einer umgekehrten Ionenverteilung erfolgt eine Depolarisation durch $\mathrm{Cl}^{-}$-Ausstrom. 
Die verschiedenen Untereinheiten des im Zentralen Nervensysstem ubiquitär exprimierten $\mathrm{GABA}_{\mathrm{A}^{-}}$ Rezeptors (Fritschy et al., 1994; Taguchi et al., 1989; Xia \& Haddad, 1992) werden $\alpha-\delta$, $\varepsilon \rho$ und $\pi$ genannt. Jede dieser Untereinheiten wird in unterschiedlich vielen Splicevarianten exprimiert $\left(\alpha_{1-6}\right.$, $\left.\beta_{1-3}, \gamma_{1-3}, \delta, \pi, \varepsilon \rho_{1-3}\right)$. Es wird angenommen, daß ein funktioneller $\mathrm{GABA}_{\mathrm{A}}$-Rezeptor die Zusammensetzung $1 \alpha_{\mathrm{x}}, 1 \beta_{\mathrm{y}}, 1 \gamma_{\mathrm{x}}$ zuzüglich zweier beliebiger anderer Untereinheiten besitzt (Paysan \& Fritschy, 1998). Jede Untereinheit bzw. deren Splicevarianten moduliert die Eigenschaften des Rezeptors, so daß unterschiedlich zusammengesetzte Rezeptoren unterschiedliche Eigenschaften wie Bindungsaffinitäten zu GABA oder anderen Drogen, verschiedene Kinetiken oder Leitfähigkeiten aufweisen (s. Tabelle 1, Maric et al., 1999; Nusser et al., 1998).

Tabelle 1: Vorkommen und Funktion von GABA $_{A}$-Rezeptor Untereinheiten

\begin{tabular}{|c|c|c|}
\hline Untereinheit & Vorkommen & Funktion \\
\hline$\alpha_{1-6}$ & Ubiquitär & $\begin{array}{l}\text { Bindet GABA, } \\
\text { Determiniert Untereinheitenkomposition } \\
\text { (Fritschy et al., 1997), } \\
\text { Definiert Benzodiazepintyp (Mertens et } \\
\text { al., 1993) }\end{array}$ \\
\hline$\beta_{1-3}$ & Ubiquitär & $\begin{array}{l}\text { Bindet GABA und Gephyrin (Kirsch et al., } \\
\text { 1995; Kneussel et al., 1999), } \\
\text { Benötigt zum Proteintransport zur Zell- } \\
\text { membran (Connolly et al., 1996) }\end{array}$ \\
\hline$\gamma_{1-6}$ & Ubiquitär, besonders häufig $\gamma_{2}$ & $\begin{array}{l}\text { Bindet Gephyrin, (Kirsch et al., 1995; } \\
\text { Kneussel } \text { et al., 1999) } \\
\text { Beeinflußt u.a. die Kanalkinetik, Pharma- } \\
\text { kologie (Gunther et al., 1995) }\end{array}$ \\
\hline$\delta$ & $\begin{array}{l}\text { Extrasynaptisch, } \\
\text { Cerebellum, Thalamus, olfaktori- } \\
\text { scher Bulbus (Fritschy \& Mohler, } \\
\text { 1995) }\end{array}$ & $\begin{array}{l}\text { Transport zu definierten Zellkompartimen- } \\
\text { ten (Nusser } \text { et al., 1998), } \\
\text { Kinetik (Nusser } \text { et al., 1998) }\end{array}$ \\
\hline$\varepsilon \rho_{1-3} ; \pi$ & selten & unbekannt \\
\hline
\end{tabular}

Neben dem $\mathrm{GABA}_{\mathrm{A}}$-Rezeptor ist ein weiterer GABA sensitiver, ligandengesteuerter $\mathrm{Cl}^{-}$-Kanal bekannt, der $\mathrm{GABA}_{\mathrm{C}}$-Rezeptor. Dieser unterscheidet sich lediglich in seiner Pharmakologie vom $\mathrm{GABA}_{\mathrm{A}}-\mathrm{Rezeptor}_{\mathrm{n}}$ und wisher ausschließlich im optischen System detektiert (Johnston, 1996).

\subsubsection{GABA $_{B}$-Rezeptor - Aufbau, Funktion und Lokalisation}

Im Gegensatz zu den $\mathrm{GABA}_{\mathrm{A} / \mathrm{C}}$-Rezeptoren gehört der $\mathrm{GABA}_{\mathrm{B}}$-Rezeptor $\mathrm{zu}$ der Familie der metabotropen Rezeptoren (Bowery et al., 1983; Deisz et al., 1997). Er besitzt einen extrazellulären Aminoterminus, sieben transmembrane Helices und einen intrazellulären Carboxyterminus $\mathrm{s}$. Abb.

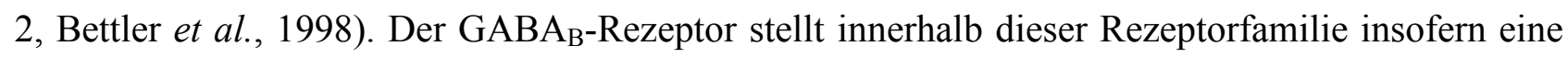
Ausnahme dar, als er nach derzeitigem Wissensstand in der Zellmembran als Heterodimer vorliegen muß, um die bisher beobachteten elektrophysiologischen Wirkungen entfalten zu können. Dieses 
Heterodimer besteht aus zwei strukturell ähnlichen Untereinheiten, GABA $\mathrm{B} 1$ und GABA $\mathrm{B} 2$, die von unterschiedlichen Genen kodiert werden. Es ist nur für die R1-Untereinheit erwiesen, daß sie GABA binden und bei künstlicher Koexpression mit einem $\mathrm{K}^{+}$-leitenden Referenzkanal in Oozyten des Krallenfrosches (Xenopus laevis) ein elektrophysiologisch nachweisbares Signal initiieren kann (Couve et al., 1998; Kaupmann et al., 1998b). Allerdings ist dieses Signal um Größenordnungen kleiner als der in Neuronen bei Aktivierung des GABA $_{B}$-Rezeptors beobachtete Effekt. Die Funktion der R2 Untereinheit wurde bisher dahingehend gedeutet, daß sie den Einbau des heterodimeren Rezeptors in die Neuronenmembran ermöglicht, indem sie sich an eine spezifische Sequenz im C-Terminalen Bereich der R1 Untereinheit durch 'coiled-coil' Wechselwirkung anlagert (Jones et al., 1998). Durch die Maskierung dieser Sequenz wird der Transport des Rezeptors zur neuronalen Membran initiiert (Marshall et al., 1999). Ohne gleichzeitige Expression der R2 Untereinheit verbleibt ein Großteil der R1 Untereinheit im endoplasmatischen Retikulum. Werden beide Untereinheiten zusammen mit dem $\mathrm{K}^{+}$-Referenzkanal in Krallenfrosch Oozyten exprimiert, kann ein Signal ähnlich dem in Neuronen ausgelöst werden (Marshall et al., 1999). Von der erst 1997 von Kaupmann et al. geklonten R1 Untereinheit sind inzwischen 4 Splicevarianten mit einem Molekulargewicht zwischen 100 bis $130 \mathrm{kDa}$ (a-d, Isomoto et al., 1998; Kaupmann et al., 1997) bekannt. Von der 1998 gleichzeitig von drei Arbeitsgruppen nachgewiesenen R2 Untereinheit von 100 kDa (Jones et al., 1998; Kaupmann et al., 1998a; White et al., 1998) sind bisher keine Varianten charakterisiert worden. Allerdings gibt es pharmakologische Hinweise darauf, daß weitere $\mathrm{GABA}_{\mathrm{B}}$-Rezeptor Untereinheiten existieren (Kerr \& Ong, 1995).

Metabotrope Rezeptoren sind mit ihrem Carboxyterminus an G-Proteine gekoppelt und wirken indirekt über intrazelluläre Signaltransduktionswege auf Ionenkanäle. Der GABA $\mathrm{B}_{\mathrm{B}}$ Rezeptor ist mit der Pertussistoxin-sensitiven, inhibitorischen G-Protein Variante $\left(\mathrm{G}_{\mathrm{i}}\right)$ verbunden. Aktiviert GABA den Rezeptor, bewirkt dies die Bindung von Guanosin-Diphosphat (GDP) an die $\alpha_{\mathrm{i}}$-Untereinheit und nachfolgend die Auftrennung des aus drei Untereinheiten bestehenden G-Proteins. Auf diese Weise wird seine $\alpha_{\mathrm{i}}$-Untereinheit in das Zellplasma freigesetzt, und initiiert eine Inhibition der Adenylatcyclase (Wojcik \& Neff, 1984), was über eine Verringerung der Konzentration von cyclischem Adenosinmonophosphat (cAMP) und der verminderten Aktivität der Proteinkinase A (PKA) die Leitfähigkeit von $\mathrm{Ca}^{2+}$-Kanälen beeinflußt s. Abb. 2). Die $\beta \gamma$-Untereinheiten verbleiben in der Membran, in der sie frei diffundieren und ihrerseits eine vermehrte Öffnung von $\mathrm{K}^{+}$-leitenden Kanälen bewirken (Kaupmann et al., 1998b; Sodickson \& Bean, 1996).

Aktivierung der postsynaptischen $\mathrm{GABA}_{\mathrm{B}}$-Rezeptoren bewirkt eine Erhöhung der einwärtsgleichrichtenden $\mathrm{K}^{+}$-Leitfähigkeit der Membran ebenso, wie eine Reduktion des $\mathrm{Ca}^{2+}$-Einstroms durch nieder- und hochschwellige $\mathrm{Ca}^{2+}$-Kanäle (Deisz \& Lux, 1985; Gahwiler \& Brown, 1985; 
Misgeld et al., 1995; Newberry \& Nicoll, 1984; Zhang et al., 1999). Da die Erhöhung der $\mathrm{K}^{+}-$ Ströme eine Hyperpolarisation ('slow inhibitory postsynaptic potential' IPSP, Misgeld et al., 1995) auslöst bzw. reduzierte $\mathrm{Ca}^{2+}$-Ströme eine Depolarisation erschweren, bewirkt eine Aktivierung postsynaptischer $\mathrm{GABA}_{\mathrm{B}}$-Rezeptoren eine kationengetragene Inhibition.

Präsynaptisch lokalisierte $\mathrm{GABA}_{\mathrm{B}}$-Rezeptoren (Billinton et al., 1999; Bowery et al., 1983; Deisz et al., 1997) reduzieren den durch spannungsabhängige Kanäle vermittelten $\mathrm{Ca}^{2+}$-Einstrom beim Einlaufen eines Aktionspotentials in die präsynaptische Nervenendigung (Misgeld et al., 1995). Durch diese präsynaptische Inhibition wird der Transmitterausstoß verringert und somit die Effektivität der synaptischen Übertragung reduziert. Es werden zwei weitere GABA $\mathrm{B}_{\mathrm{B}}$ Rezeptor vermittelte Mechanismen diskutiert, die ebenfalls die Transmitterausschüttung modulieren könnten. Dies sind zum einen eine Erhöhung der $\mathrm{K}^{+}$-Leitfähigkeit und somit eine Hyperpolarisation der präsynaptischen Nervenendigung (Jarolimek et al., 1994), zum anderen eine von der Leitfähigkeit der Membran unabhängige Beeinflussung der Transmitterfreisetzung, deren genauer Mechanismus noch ungeklärt ist (Jarolimek \& Misgeld, 1992). Eine besondere Situation stellen die GABAerge Autorezeptoren dar. Wenn $\mathrm{GABA}_{\mathrm{B}}$-Rezeptor-vermittelte präsynaptischen Inhibition die Freisetzung des Transmitters GABA reduziert (Anderson \& Mitchell, 1985) wird postsynaptisch eine Verminderung der $\mathrm{GABA}_{\mathrm{A}}$-Rezeptor-vermittelten Inhibition bewirkt (Ben-Ari et al., 1989). Es wurde gezeigt, daß $\mathrm{GABA}_{\mathrm{B}}$-Rezeptoren in der Regulation rhythmisch oszillierender Thalamuskerne, Schmerzverarbeitung, Absense-Epilepsie, entzündungsfolgender Spastizität und der Induktion synaptischer Langzeitpotentierung (long term polarisation, LTP) eine modulatorische Rolle einnehmen (Castro-Lopes et al., 1995; Crunelli \& Leresche, 1991; Davies et al., 1991; Enna et al., 1998; Misgeld et al., 1995; Snead, 1994).

Verschiedene Techniken wie z.B. Bindungsstudien mit radioaktiven Liganden (Turgeon \& Albin, 1994) oder radioaktiven Boten-Ribonukleinsäuren (in situ Hybridisierung, Bischoff et al., 1999) zeigten die Expression des $\mathrm{GABA}_{B}$-Rezeptors in fast allen Regionen des Zentralen Nervensystems in unterschiedlicher Stärke. Diese Methoden eignen sich allerdings nicht für die Darstellung der Rezeptorverteilung auf zellulärem und subzellulärem Niveau. Erst 1999 gelang der Arbeitsgruppe Fritschy et al. eine immunohistochemische Färbung des $\mathrm{GABA}_{\mathrm{B}}$-Rezeptors. Sie dokumentierte das Vorkommen von $\mathrm{GABA}_{\mathrm{B}}$-Rezeptoren in der extrasynaptischen Neuronenmembran. Diese war besonders intensiv in den cerebellaren Purkinjezelldendriten. Aus technischen Gründen lassen die bisherigen Daten allerdings die Frage unbeantwortet, in welchen synaptischen Strukturen die synaptischen $\mathrm{GABA}_{\mathrm{B}}$-Rezeptoren lokalisiert sind (persönliche Mitteilung Fritschy, Fritschy et al., 1999). Außerdem ist bisher unklar, welche Funktion extrasynaptische $G_{A B A}$-Rezeptoren ausüben. 
Pharmakologisch finden inzwischen unterschiedliche Agonisten und Antagonisten für den $\mathrm{GABA}_{\mathrm{B}^{-}}$ Rezeptor Anwendung. Bereits seit langem ist der Blut-Hirn-Schranken-gängige Agonist Baklofen bekannt (Bowery et al., 1984). Ihm gegenüber stehen die klassischen Antagonisten Phaklofen und Saklofen. Erst seit kürzerer Zeit kommen speziell entwickelte Pharmaka, wie zum Beispiel der Agonist CGP 44532 und der Antagonist CGP 55845A zum Einsatz (Bittiger et al., 1993).

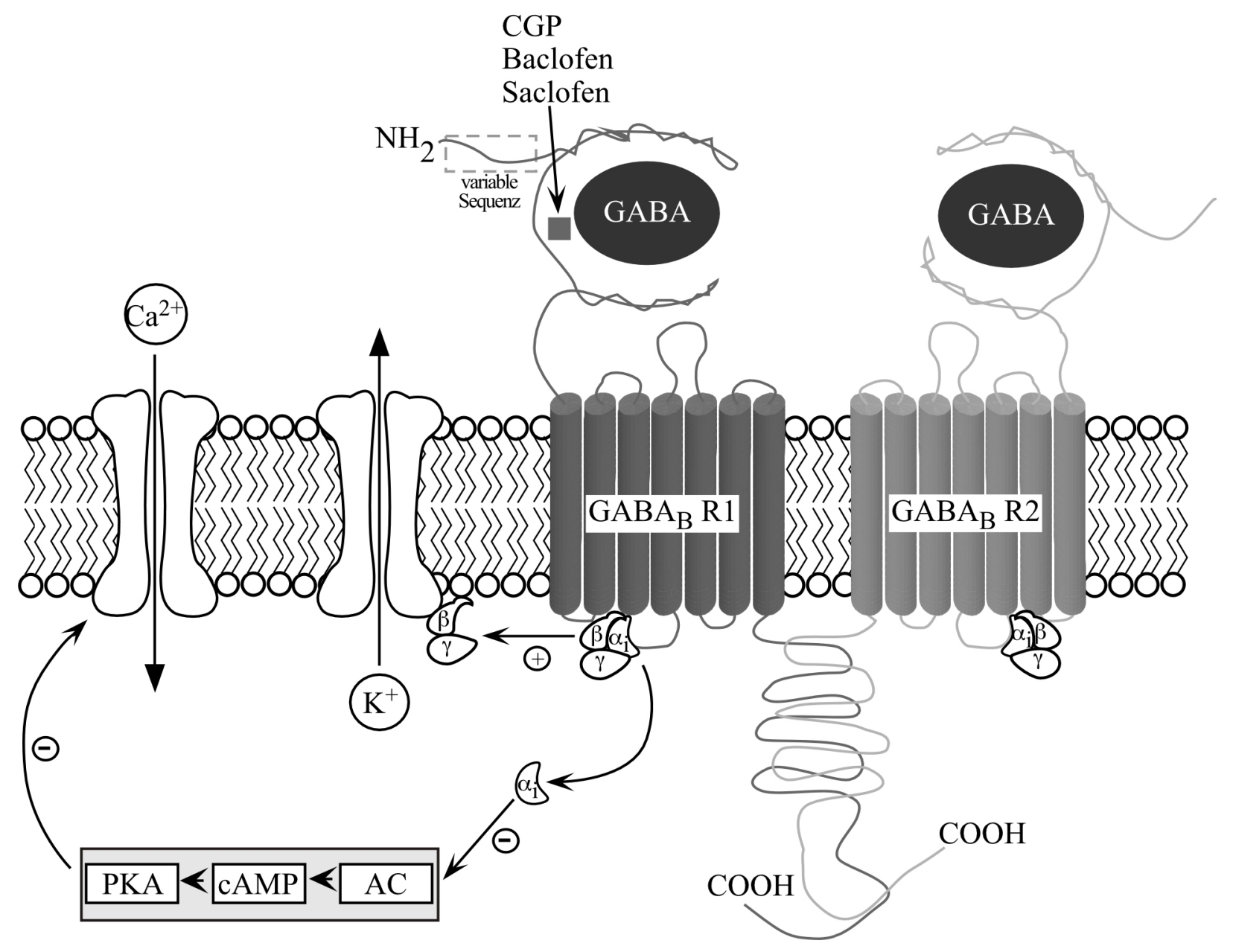

Abb. 2. Unterschiedliche Aspekte der Struktur und Funktion des $G_{A B A}$-Rezeptors. Der GABA $A_{B}$-Rezeptor besteht aus zwei Untereinheiten $\left(G_{A B A}\right.$ R1, GABA $A_{B}$ R2) die jeweils sieben Mal die Membran durchspannen und eine extrazelluläre aminoterminale und eine intrazelluläre carboxyterminale Endigung besitzen. Die Bindungsstellen für GABA, die kompetetiven Ago- und Antagonisten (Kästchen) und die $\alpha-\gamma$-Untereinheiten des gekoppelten Gi Proteins sind angegeben. Die Bindung von GABA löst mindestens zwei Effekte aus. Zum einen inhibiert die $\alpha$ Untereinheit die Adenylatcyclase (AC) und reduziert so über Veränderungen im Spiegel des cyclischen Adenosinmonophosphates (cAMP) und der Aktivität der Protein-KinaseA (PKA) die Leitfähigkeit von $\mathrm{Ca}^{2+}$. Kanälen. Zum anderen aktiviert die $\beta \gamma$-Untereinheit $\mathrm{K}^{+}$-Kanäle. Das gestrichelte Rechteck markiert die in den Splicevarianten a und b variierte Sequenz. 


\subsection{Rezeptorgenese und intrazellulärer Transport von Rezeptoren}

Transmembrane Proteine wie Neurotransmitterrezeptoren werden am rauhen ER synthetisiert. Es wird angenommen, daß bereits bei der Synthese eine Faltung des Proteins erfolgt. Die Anzahl und Orientierung seiner transmembranen Sequenzen wird dabei durch Signalsequenzen innerhalb der Aminosäuresequenz geregelt. Danach werden proteinhaltige Vesikel vom ER abgeschnürt und nach ihrer Prozessierung im Golgi-Apparat zur Membran transportiert, wo ihr Einbau durch Verschmelzung des Vesikels mit der Membran erfolgt. Dieser Transport verläuft zellkompartimentspezifisch durch sogenannten schnellen, Mikrofilament-gebundenen Transport. Die genauen Mechanismen für den gerichteten Transport zu definierten Zellkompartimenten sind allerdings unbekannt. Beim $\mathrm{GABA}_{\mathrm{A}}$-Rezeptor sorgt die Expression der $\delta$-Einheit eine Insertation des Rezeptors in die extrasynaptische Membran, ohne daß genau erklärbar ist, wie sie diesen Effekt

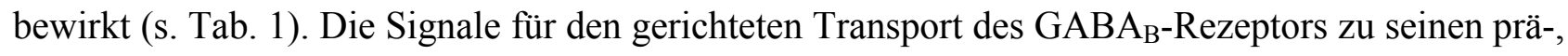
post- und extrasynaptischen Lokalisationen sind nicht bekannt. Es wurde lediglich beobachtet, daß einzeln exprimierte Untereinheiten zu einem hohen Maße im ER verbleiben und nicht zur Zellmembran transportiert werden (s. 2.1.2).

extrazellulär
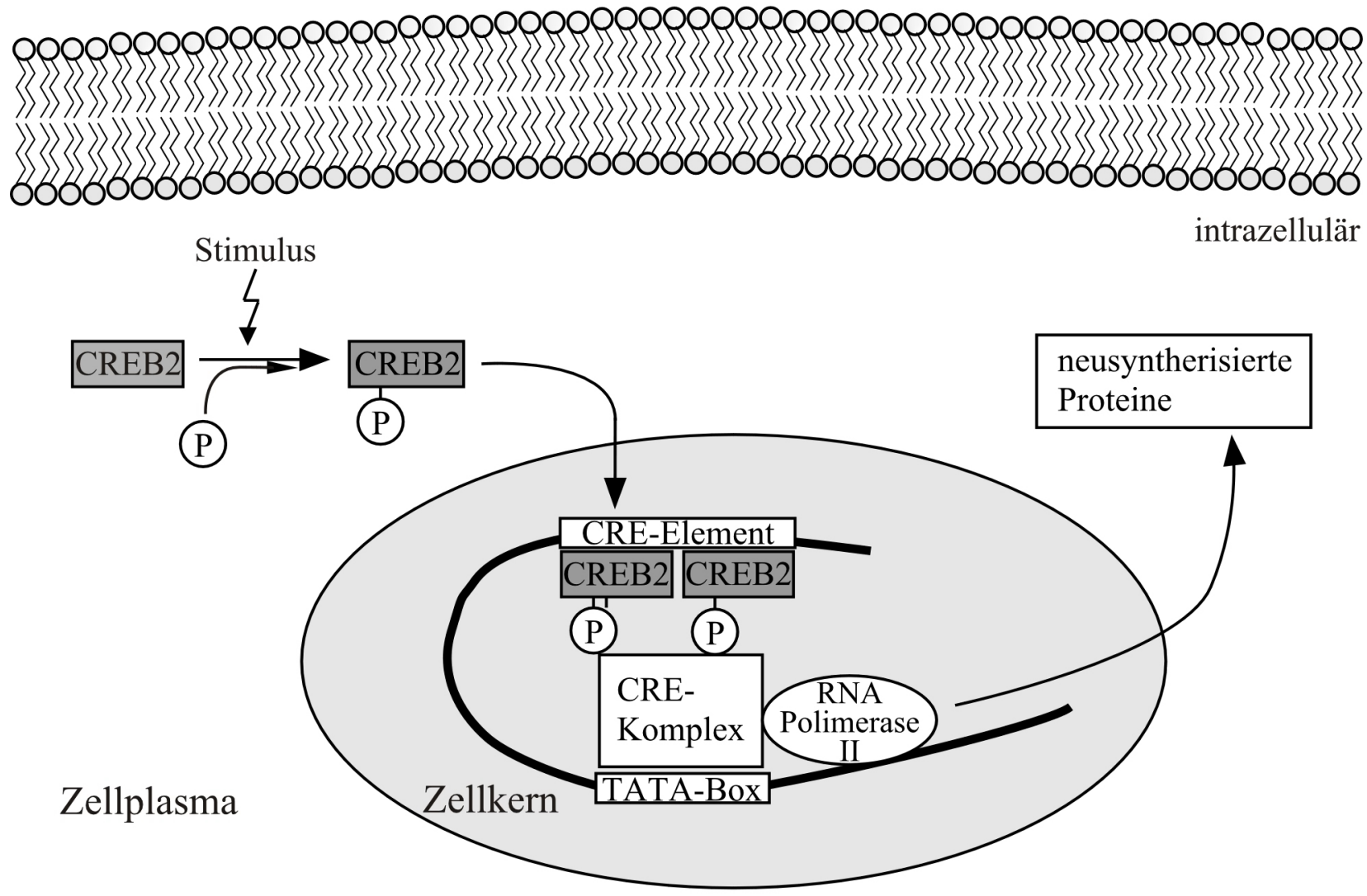

Abb. 3. Wirkungsweise von CREB2 (ATF4). Bei einem entsprechenden Stimulus wird zunächst die Phosphorelierung (P) und dann die Translokation von CREB in den Zellkern initialisiert. Dort binden jeweils zwei CREB an die cyclische Adenosinmonophosphat sensitive Sequenz (CRE-Element) in der Desoxyribonuklein säurehelix und ermöglichen die Anlagerung eines Proteinkomplexes (CRE-Komplex) an die Start-Box (TATA-Box) bestimmter Gene. Dies erleichtert die initiale Bindung der translatierenden RNA-Polimerase II und somit die Synthese neuer Proteine außerhalb des Kerns. 
Innerhalb der postsynaptischen Membran können Proteine frei beweglich vorliegen. Bei Neurorezeptoren findet man allerdings häufig festgelegte Lokalisationen in Gruppen ('cluster') an den entsprechend spezialisierten Membranabschnitten. So sind Gruppen von $\mathrm{GABA}_{\mathrm{A}}$-Rezeptoren durch ein Ankerprotein namens Gephyrin untereinander und mit dem Zellskelett verbunden (s. auch Abb. 1A, Tab. 1). Dies verhindert eine freie Bewegung in der Membran und führt zur Bildung von clustern an postsynaptischen Spezialisierungen. Wird Gephyrin nicht exprimiert, verbleibt der Rezeptor in Transportvesikeln innerhalb des Zellplasmas, und es erfolgt eine Anreicherung im ER (Kirsch et al., 1995). Da noch keine Färbungen von synaptisch lokalisierten $\mathrm{GABA}_{\mathrm{B}}$-Rezeptoren gelang, ist deren Organisation an diesen Spezialisierungen unbekannt. Ein verknüpfendes Ankerprotein für $\mathrm{GABA}_{\mathrm{B}}$-Rezeptoren konnte bisher nicht nachgewiesen werden.

Neurotransmitterrezeptoren sind, wie viele andere Proteine, in ihrer Synthese induzierbar (Archibald et al., 1999). Das bedeutet, daß sie bei einem entsprechenden Stimulus, wie z.B. erhöhter neuronaler Aktivität, in größerer Menge verfügbar sind. Diese Regulation verläuft häufig über die Aktivierung der genetischen Transkription durch entsprechende Transkriptionsfaktoren. So binden zum Beispiel Mitglieder der Familie der Cyclo-Adenosinmonophosphat sensiblen Faktoren (cyclicAMP r responding element binding proteins, CREB; auch activating transcription factors, ATF in Mäusen), wie z.B. CREB2 (in Mäusen ATF4), nach ihrer über intrazelluläre Signaltransduktionwege initiierte Phosphorelierung und ihrer verstärkten Translokation in den Zellkern an die Promotorregion unterschiedlicher Gene (s. Abb. 3). Auf diese Weise kann deren Synthese sowohl abgeschwächt als auch verstärkt werden (Jungling et al., 1994; Karpinski et al., 1992; Liang \& Hai, 1997). Für die $\mathrm{GABA}_{\mathrm{A}^{-}}$bzw $\mathrm{GABA}_{\mathrm{B}}$-Rezeptoren ist nicht bekannt, ob sie bei erhöhter neuronaler Aktivität in stärkerem Maße in der Membran detektierbar sind. Allerdings gibt es in neuester Zeit Hinweise darauf, daß $\mathrm{GABA}_{\mathrm{B}}$-Rezeptoren direkt an den Transkriptionsfaktor CREB2 binden. Bei einer Aktivierung des Rezeptors in transfektierten Zellinien konnte CREB2 verstärkt im Kern nachgewiesen werden, was zu einer Expressionsveränderung von Reporterproteinen führt (Nehring et al., 2000; White et al., 2000). Die Interaktion von $\mathrm{GABA}_{\mathrm{B}}$ Rezeptoren und ihrer Funktion bei der Regulierung der Zellfunktion in nativem Gewebe ist bisher noch nicht untersucht worden.

\subsection{Inhibition in neuronalen Netzwerken: Beispiel Respiration}

Die Wirkung von GABA auf ein postsynaptisches Neuron kann unterschiedlich sein. Zum einen kann die Aktivierung des $\mathrm{GABA}_{\mathrm{A}}$-Rezeptors der Exzitation durch ein hyperpolarisierendes postsynaptisches Potential (PSP) entgegenwirken. Allerdings bewirkt diese Hyperpolarisation nicht ausschließlich eine Hemmung. Sie führt in einigen Neuronentypen zur De-inaktivierung spannungsabhängiger Ionenkanäle, welche ihrerseits eine Depolarisation verursachen und folglich die Auslösung eines Aktionspotential begünstigen können. Ebenso kann eine Aktivierung des 
$\mathrm{GABA}_{\mathrm{A}}$-Rezeptors die Leitfähigkeit der postsynaptischen Membran so stark erhöhen, daß gleichzeitige depolarisierende Ströme keine genügend große Potentialänderung mehr erzeugen können, um ein Aktionspotential auszulösen. Diese Wirkungsweise ist unter dem Namen ,shunting ‘ bekannt. Neben diesen postsynaptischen Effekten kann GABA über den GABA -Rezeptor eine präsynaptische Hemmung [s. 2.1.2. bewirken, bei der die Neurotransmitterfreisetzung beeinflußt wird und so sowohl die inhibitorische als auch die exzitatorische Transmission abgeschwächt werden kann. Postsynaptisch vermitteln $\mathrm{GABA}_{\mathrm{B}}$-Rezeptoren eine kationengetragene Hyperpolarisation und die Regulation spannungsabhängiger $\mathrm{Ca}^{2+}$-Kanäle.

Die unterschiedlichen Aspekte der Inhibition spielen in der Funktion vieler neuronaler Netzwerke eine wichtige Rolle. So ist sie u.a. essentiell für die Generierung der regelmäßigen Aktivität von Rhythmus-erzeugenden Netzwerken wie z.B. einigen Thalamuskernen (Steriade \& Deschenes, 1984), dem Rhythmusgenerator der Lokomotion (Grillner et al., 1998) und dem respiratorischen Netzwerk der Medulla oblongata (Richter, 1995). Dies soll im Folgenden anhand des respirativen Systems kurz verdeutlicht werden.

\subsubsection{An der Respiration sind unterschiedliche Strukturen beteiligt}

Atmung ist eine Vitalfunktion, die bei jedem Lebewesen von der Geburt bis zum Tod funktionieren muss. Der Atemrhythmus bei Säugern wird in der Medulla oblongata generiert und von anderen Hirngebieten modulatorisch beeinflusst (Bianchi et al., 1995). Man unterscheidet bei der Atmung drei verschiedene Phasen. Während die Inspirations- und die passive Exspirationsphase für den Gasaustausch unerläßlich sind, ermöglicht die aktive Exspiration zusätzliche Atemmodulation wie z.B. beim Husten (Richter, 1995). An der Atmung sind verschiedene Muskelgruppen essentiell beteiligt. Die Wichtigsten sind das vom Nervus phrenicus innervierte Zwerchfell, die Interkostalmuskulatur und die Bauchmuskulatur (Thews, 1995).

Über den direkten Vorgang der Lungenventilation hinaus müssen viele andere Vorgänge mit der Atmung koordiniert werden. Ein Beispiel ist die atemsynchrone Bewegung des Zungengrundes, um die Verlegung des Luftweges zu vermeiden. Aus diesem Grund ist die Aktivität des Zungengrundes über den zwölften Hirnnerves ( $N$. hypoglossus, XII) bzw. den Nucleus hypoglussus (Ncl. hypoglossus) mit dem respiratorischen Netzwerk gekoppelt. 


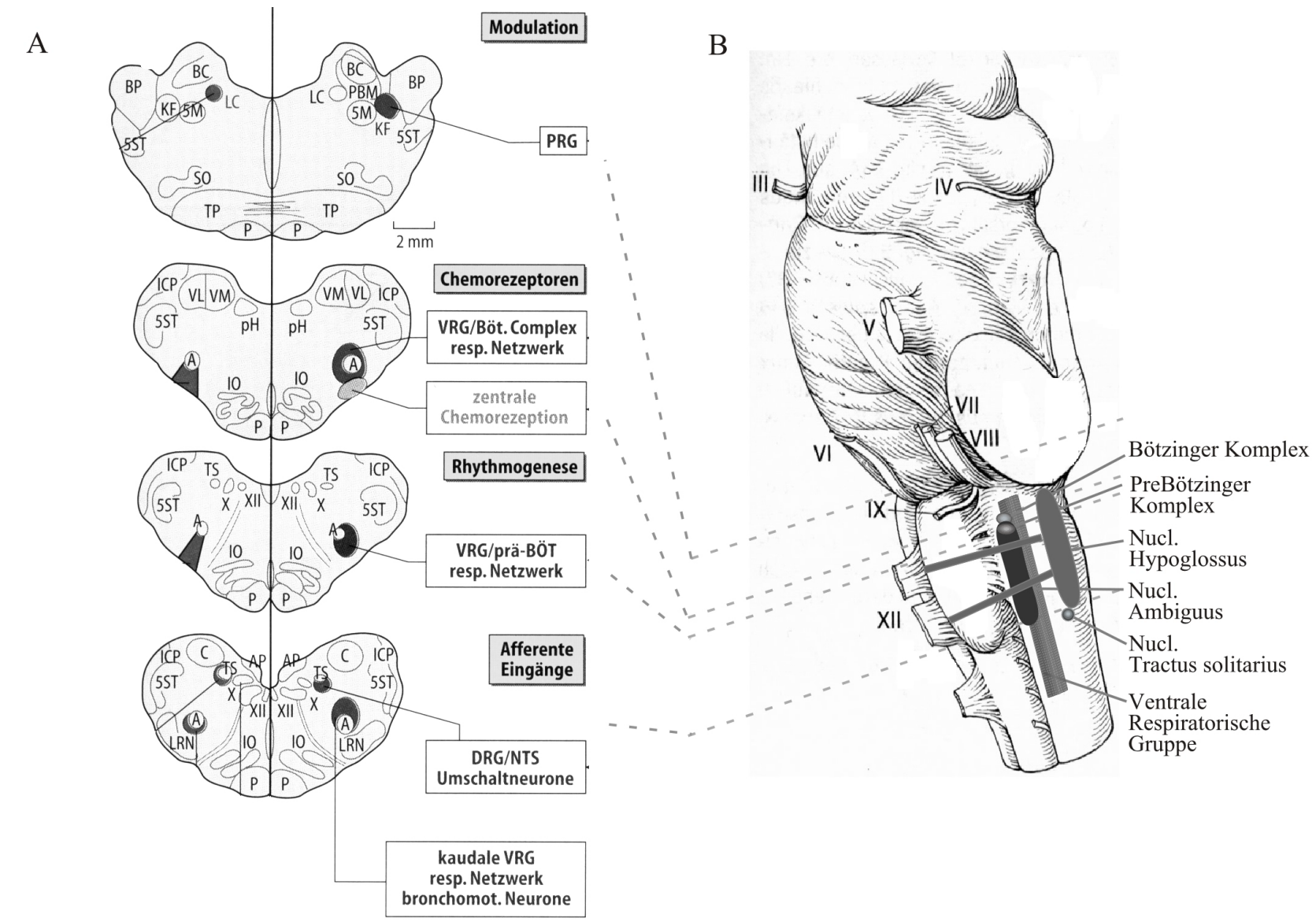

Abb. 4. Schematische Darstellung der Lokalisation des Atemzentrums im Hirnstamm. A: Transversale Schnitte durch den Hirnstamm in Höhe des Prä-Bötzinger/Bötzinger Komplexes (modifiziert nach Richter 1995, S. 595). B: Eine anatomische Darstellung des Hirnstammes beim Menschen mit den Abgängen der Hirnnerven (Lateinische Zahlen). Eingezeichnet sind die für die Atmung wichtigen Kerngebiete. $P R G=$ pontine respiratorische Gruppe, $V R G=$ ventrale respiratorische Gruppe, prä BÖT = Prä-Bötzinger Komplex, DRG = dorsale respiratorische Gruppe, NTS = Nucleus tractus solitarius.

In der Medulla sind mehrere Neuronengruppen an der Generation, Modulation und der Kontrolle der Atmung beteiligt. Diese sind in erster Linie die dorsale respiratorische Gruppe (DRG) des Nucleus ventrolateralis des Tractus solitarius und die ventrale respiratorische Gruppe (VRG). Letztere wird unterteilt in einen kaudalen, einen intermediären und einen rostralen Teil. Der rostrale Teil der VRG teilt sich in den Bötzinger und den Prä-Bötzinger Komplex (PBC) auf. Smith et al. (1991a) wiesen mit Hilfe von Hirnstammpräparationen der Ratte nach, daß für die Generierung des Atemrhythmus der PBC essentiell ist. Der PBC befindet sich auf der Höhe des unteren Drittels des vierten Hirnventrikels und schließt sich kaudal an den Nucleus ambiguus und den Nucleus retrofacialis an. Die genaue Lage der beschriebenen Neuronengruppen zeigt Abbildung 4. Zu bemerken ist, daß der PBC zwar eine funktionelle Einheit bildet, aber anatomisch nicht von anliegenden Hirngebieten zu unterscheiden ist. Neben den rhythmusgenerierenden Neuronen enthält er ebenso propriobulbäre Motoneurone.

\subsubsection{Der Rhythmusgenerator des respiratorischen Netzwerkes}

Im PBC wurden sechs funktionell unterschiedliche Neuronengruppen anhand ihres Entladungsmusters und der zeitlichen Abfolge ihrer Aktivität relativ zu der des Nervus phrenicus charakterisiert (Bianchi et al., 1995; Richter et al., 1992): 
1) Die prä-inspiratorische Neurone (prä-I)

2) Die früh-inspiratorisch Neurone (früh-I)

3) Die Rampen-inspiratorisch Neurone (Rampen-I)

4) Die spät-inspiratorisch Neurone (Spät-I)

5) Die post-inspiratorisch Neurone (PI)

6) Die expiratorische Neurone (E2)

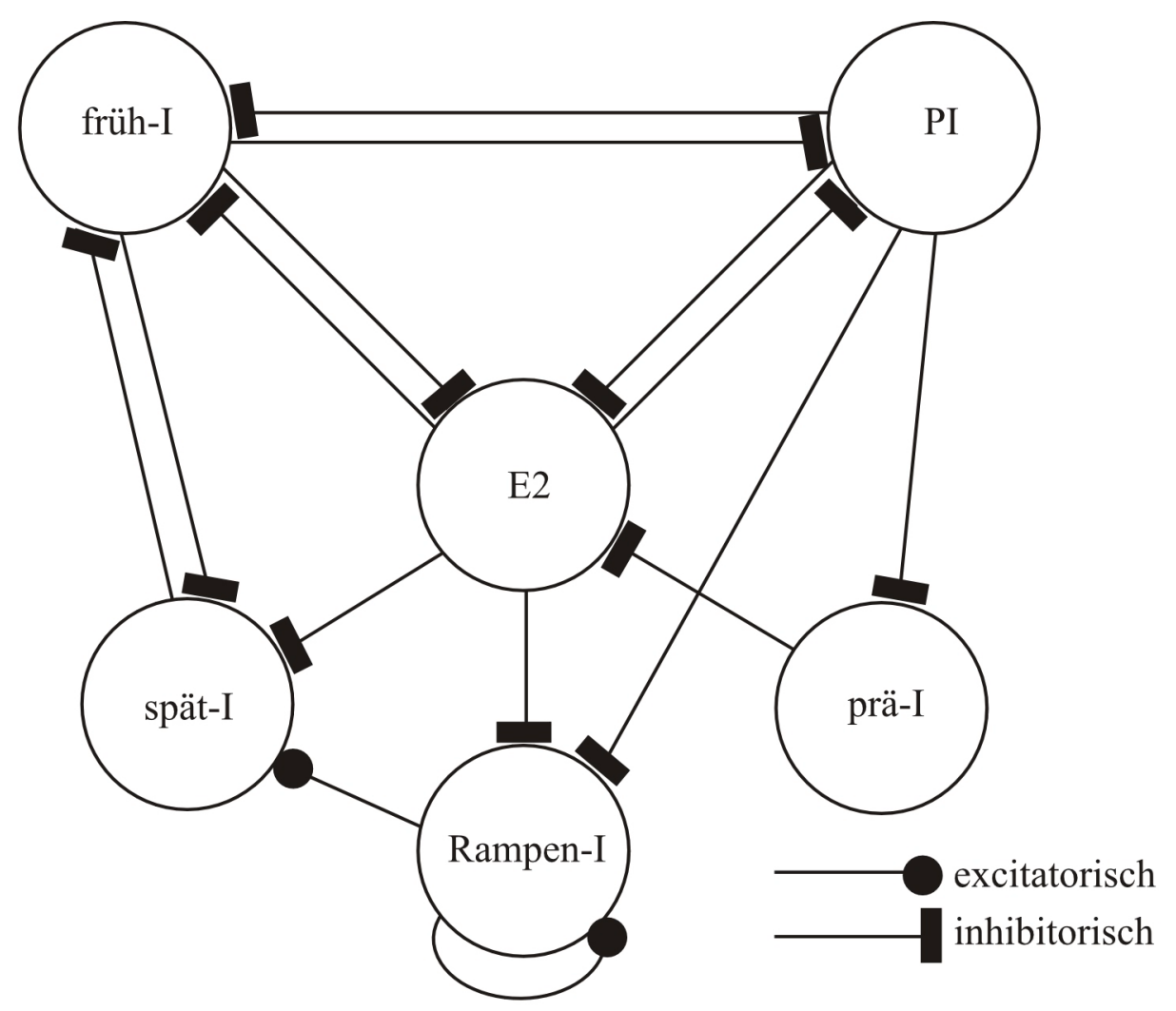

Abb. 5. Schematische Darstellung der inhibitorischen und exzitatorischen Verschaltung der Neurone im respiratorischen Netzwerk (modifiziert nach Richter 1996). Prä-I: Prä-inspiratorisches Neuron; Früh-I: frühinspiratorisches Neuron; Rampen-I: Rampen-inspiratorisches Neuron; Spät-I: spätinspiratorisches Neuron; PI: post-inspiratorisches Neuron; E2: exspiratorisches Neuron.

Das momentane Verständnis der zellullären Verknüpfungen innerhalb des respiratorischen Netzwerkes wurde hauptsächlich durch in vivo Experimente an Katzen erarbeitet s. Abb. 5; Richter 1999, Funk 1995). In diesen Verknüpfungen spiegeln sich ebenso wie in den intrinsichen Eigenschaften der Neurone (Ramirez \& Richter, 1996) wichtige Eigenschaften der prinzipiellen Rhytmogenese in neuronalen Netzwerken wider (Review s. Selverston \& Moulins, 1985). So bilden die sich reziprok inhibierenden Neuronengruppen der früh-I und PI den primäreren Oszillator. Sie besitzen aufgrund ihrer zellulären Eigenschaften und synaptischen Verschaltungen die Fähigkeit, rhythmische Aktionspotentialsalven (bursts) zu erzeugen. Der während dieser bursts erfolgende $\mathrm{Ca}^{2+}$-Einstrom sorgt für die Aktivierung von $\mathrm{K}^{+}$-Kanälen, die zusammen mit der einsetzenden Inhibition durch andere Neuronengruppen die Salve beenden (automatische Terminierung). Die danach länger anhaltende Inhibition de-inaktiviert Kationenkanäle und ermöglicht so nach ihrer 
Beendigung das weitere Auftreten eines bursts (Rebound-Depolarisation). In dieser burst-Aktivität wechseln sich früh-I und PI aufgrund ihrer reziproken Inhibition gegenseitig ab. Die weiteren Neuronengruppen modulieren und stabilisieren den respiratorischen Rhythmus.

\subsubsection{Inhibition im respiratorischen System}

Auch im respiratorischen Netzwerk wird Inhibition vorwiegend durch die Neurotransmitter Glyzin bez. $\gamma$-Aminobuttersäure $(\mathrm{GABA})$ und über die Glyzin- bzw. GABA $\mathrm{A}$-Rezeptoren vermittelt (s. Review Ramirez \& Richter, 1996). Experimentelle Daten haben gezeigt, daß eine Blockade der beiden genannten Rezeptoren bei intakten Säugetieren zum Atemstillstand führt (Hayashi \& Lipski, 1992). Durch in vivo Experimente konnten Schmid et al. (1989) nachweisen, daß Glycin induzierte Inhibition sowohl tonisch als auch phasisch stattfindet und somit die Form der elektrischen Entladungsmuster der verschiedenen respiratorischen Neurone entscheidend mitbestimmt. GABA hat eine komplexe Wirkung, da es verschiedene, prä- und postsynaptisch lokalisierte Rezeptoren aktivieren kann. Für die von dem $\mathrm{GABA}_{\mathrm{A}}$-Rezeptor vermittelte Inhibition wird eine tonische (Haji et al., 1990; Haji et al., 1992) und eine phasische Wirkung (Ramirez \& Richter, 1996) angenommen.

Die Wirkungen des $\mathrm{GABA}_{\mathrm{B}}$-Rezeptors konnten in Experimenten mit der Katze (Champagnat \& Richter, 1994; Taveira da Silva et al., 1987) und der Ratte demonstriert werden (Brockhaus \& Ballanyi, 1998; Hayashi \& Lipski, 1992). So zeigte sich, daß die Aktivierung des $\mathrm{GABA}_{\mathrm{B}^{-}}$ Rezeptors mit dem Rezeptoragonisten Baklofen sowohl die Frequenz als auch die Amplitude der Entladung des Nervus phrenicus reduziert bzw. blockiert. Zhang et al zeigten 1999 (Zhang et al., 1999), daß in inspiratorischen Neuronen des PBC unterschwellige $\mathrm{Ca}^{2+}$-Ströme (low voltage activating, LVA) ebenso durch $\mathrm{GABA}_{\mathrm{B}}$-Rezeptor vermittelte Signale moduliert werden wie hochschwellige (high voltage activating, HVA). Des weiteren wird eine Modulation der postsynaptischen, einwärtsgerichteten $\mathrm{K}^{+}$-Kanäle und der präsynaptischen Transmitterfreisetzung vermutet.

\subsection{Plastizität in neuronalen Netzwerken}

Die bisher beschriebenen Funktionen der Rezeptoren bei synaptischen Übertragungen stellen kein starres Gefüge in neuronalen Netzwerken dar, sondern besitzen ein hohes Maß an Plastizität. Diese ermöglicht ihnen zum einen die Anpassung an physiologisch oder pathophysiologisch geänderte Bedingungen und zum anderen längerfristige Umstrukturierungen wie sie zum Beispiel in der Ontogenese auftreten. Plastizität ist unter anderem bei der Modulation von Kanälen oder Rezeptoren, der Verstärkung oder Schwächung einer einzelnen Synapsen und beim Umbau gesamter Netzwerke zu beobachten. 


\subsubsection{Ontogenetische Änderung der Rezeptorexpression}

Die Expression und der Einbau der GABA Rezeptoren und ihrer Untereinheiten sind entwicklungsbedingten Kontrollen unterworfen. Diese Prozesse sind innerhalb des zentralen Nervensystems region- und zelltypspezifisch. So ist das Vorkommen des GABA A $_{\mathrm{A}}$-zeptors in den Großhirngebieten der Ratte in adulten Tieren stark ausgeprägt, wo hingegen sie perinatal nur in sehr geringer Anzahl exprimiert werden. Ihre Häufigkeit steigt in den ersten drei postnatalen Wochen bis um das dreifache an um zum adulten Expressionsgrad leicht wieder abzufallen. Eine völlig andere Entwicklung ist dagegen im Hirnstamm zu beobachten. Hier ist das Vorkommen des $\mathrm{GABA}_{\mathrm{A}^{-}}$ Rezeptors bei der Geburt recht hoch, wächst bis zu Mitte der zweiten. postnatalen Woche etwas an und fällt bis zur Reife (zweiter. Lebensmonat) stark ab (Xia \& Haddad, 1992).

Die ontogenetisch veränderte Expression der $\mathrm{GABA}_{\mathrm{A}}$-Rezeptor Untereinheiten ist in mehreren Spezies ausführlich dokumentiert (s. Review Paysan \& Fritschy, 1998). Im Gegensatz dazu ist über die ontogenetische Expression des $\mathrm{GABA}_{\mathrm{B}}$-Rezeptors relativ wenig bekannt. Wie Fritschy et al. (1999) in Ratten zeigten, ist die $\mathrm{GABA}_{\mathrm{B}}$ R1a Splicevariante in Extrakten des gesamten Hirngewebes stärker vertreten als die $\mathrm{GABA}_{\mathrm{B}} \mathrm{R} 1 \mathrm{~b}$ Variante. Dieses Verhältnis verschiebt sich bis zur Mitte der zweiten postnatalen Woche. $\mathrm{Zu}$ diesem Zeitpunkt sind beide Splicevarianten in gleicher Menge vertreten. In adulten Tieren ist die Häufigkeit der R1b Variante in den meisten Hirngebieten sogar höher als die der R1a. Ausnahmen stellen lediglich der olfaktorische Bulbus und das Striatum dar. Die Funktion einer solchen Verschiebung in der Expression der Untereinheiten bleibt bis dato ungeklärt.

\subsubsection{Ontogenetische Änderung der Rezeptorfunktion}

Auch die Funktionsweise der Neurotransmitterrezeptoren kann sich während der Ontogenese stark verändern, wie die Arbeiten verschiedener Forschungsgruppen anhand der $\mathrm{GABA}_{\mathrm{A}}$-Rezeptorvermittelten synaptischen Potentiale eindrucksvoll demonstrieren konnten. 


\section{A) Perinatal}

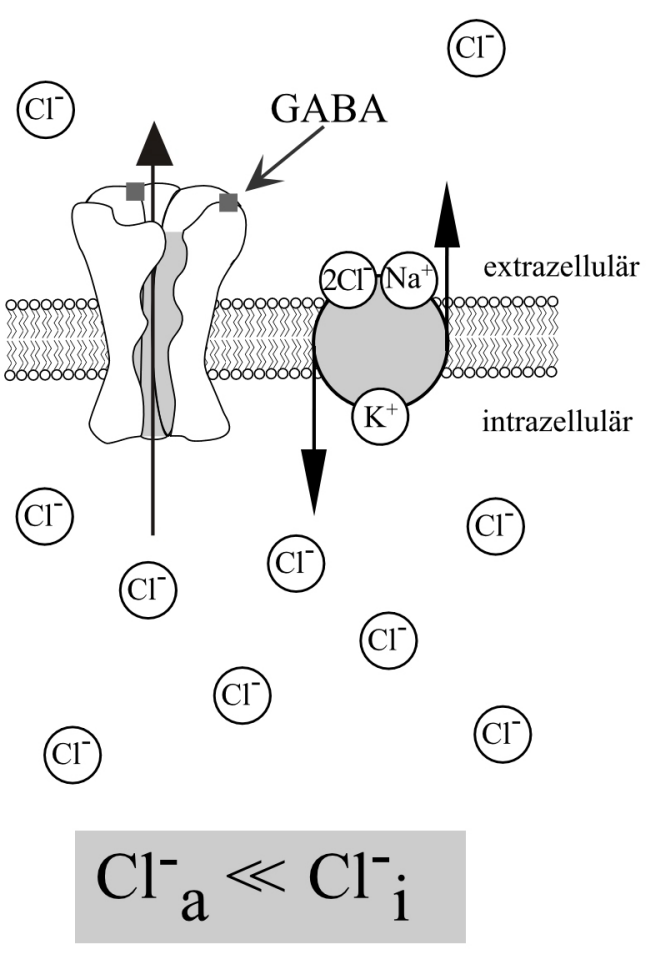

\section{B) Adult}
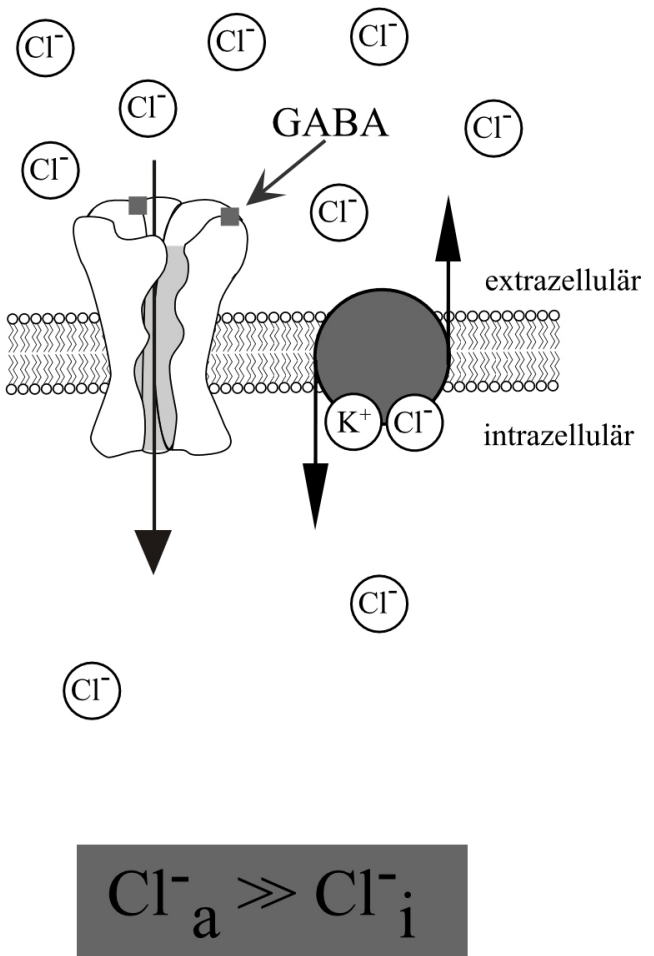

Abb. 6. Einfluß von altersabhängig expremierten Ionenpumpen auf $\mathrm{GABA}_{\mathrm{A}}$-Rezeptor vermittelte $\mathrm{Cl}^{-}-\mathrm{Ströme}$.

A: Perinatal wird die Na-K-2Cl-Pumpe in Neuronen exprimiert, die zwei Cl-- und ein $\mathrm{Na}^{+}-$Ion im Austausch gegen ein $\mathrm{K}^{+}$-Ion in die Zelle transportiert. Dies geschieht unter Ausnutzung des $\mathrm{Na}^{+} / \mathrm{K}^{+}$-Gradienten über der Neuronenmembran als treibender Kraft. Als Folge daraus ist der intrazelluläre $\mathrm{Cl}^{-}-\mathrm{Gehalt}\left(\mathrm{Cl}^{-}\right)$gegenüber dem extrazellulären $\left(\mathrm{Cl}_{\mathrm{a}}^{-}\right)$erhöht, und bei einer Aktivierung von $\mathrm{GABA}_{\mathrm{A}}$-Kanälen findet ein $\mathrm{Cl}^{-}$-Ausstrom statt. B: In adulten Neuronen wird stattdessen der KCC2-Transporter exprimiert, der gleichzeitig ein $\mathrm{K}^{+}$- und ein $\mathrm{Cl}^{-}$-Ion aus der Zelle pumpt. Dies resultiert in einer erniedrigten intrazellulären $\mathrm{Cl}^{-}$-Konzentration und einem $\mathrm{GABA}_{\mathrm{A}}$

Rezeptor vermittelten $\mathrm{Cl}^{-}$-Einstrom.

Wie eingangs ausführlich beschrieben wurde, stellt der $\mathrm{GABA}_{\mathrm{A}}$-Rezeptor einen $\mathrm{Cl}^{-}$-Kanal dar. In adulten Neuronen sorgt ein speziell in Nervenzellen exprimierter $\mathrm{K}^{+} / \mathrm{Cl}^{-}$-Kotransporter (KCC2) für eine gegenüber dem Extrazellulärmedium deutlich verringerte intrazelluläre Cl-Konzentration, wobei ein $\mathrm{Cl}^{-}$und ein $\mathrm{K}^{+}$-Ion unter Ausnutzung des aktiv erzeugten $\mathrm{K}^{+}$-Konzentrationsgefälles über der Membran aus der Zelle hinaustransportiert werden (s. Abb. 6 B. Rivera et al. (1999) haben gezeigt, daß die Expression dieses $\mathrm{K}^{+} / \mathrm{Cl}^{-}$-Kotransporters (KCC2) in vielen Bereichen des Großhirns erst postnatal, mit einer regionspezifischen Verzögerung von bis zu drei Wochen stattfindet (Lu et al., 1999; Rivera et al., 1999). Gleichzeitig führt die Aktivität eines weiteren, $\mathrm{Na}^{+}$ und $\mathrm{K}^{+}$-abhängigen Transporters $(\mathrm{Na}-\mathrm{K}-2 \mathrm{Cl})$, der nur perinatal exprimiert wird, zu einem aktiven $\mathrm{Cl}^{-}$-Einstrom in neonatale Neurone s. Abb. 6A, Plotkin et al., 1997). Bei Aktivierung des GABA $\mathrm{A}^{-}$ Rezeptors kommt es deshalb zu einem depolarisierenden $\mathrm{Cl}^{-}$-Ausstrom s. auch Abb. 1). Perinatale $\mathrm{GABA}_{\mathrm{A}}$-Rezeptor-vermittelte Depolarisation wurde in der Ratte im Hippocampus (Ben-Ari et al., 
1997; Cherubini et al., 1991; Cherubini et al., 1990; Staley \& Mody, 1992), Hypothalamus (Chen et al., 1996), auditorischem Hirnstamm (Kandler \& Friauf, 1995), spinalen Hinterhorn (Reichling et $a l ., 1994)$ und in spinalen Motoneuronen (Wu et al., 1992) nachgewiesen. Da GABA $\mathrm{A}_{\mathrm{A}}$-Rezeptoren in nur geringeren Mengen ebenfalls $\mathrm{HCO}_{3}^{-}$-Ionen leiten, liegt das Äquilibriumpotential von ihnen vermittelter Ströme $\left(\mathrm{E}_{\mathrm{GABA}}\right)$ meist nahe des Äquilibriumpotentials von $\mathrm{Cl}^{-}$-Strömen $\left(\mathrm{E}_{\mathrm{Cl}}{ }^{-}\right)$.

\subsubsection{Ontogenetische Änderung der Inhibition im respiratorischen Netzwerk}

Betrachtet man die vielfältigen möglichen Veränderungen der GABA-Rezeptoren während der Ontogenese in ihrer Zusammensetzung, Lokalisation und Funktion, so stellt sich die Frage, wie sich diese auf neuronale Netzwerke auswirken. Als Beispiel für den momentanen Wissensstand soll hier wieder das respiratorische Netzwerk dienen. Einerseits muß das respiratorische System aus vitalen Gründen vom ersten Moment nach der Geburt funktionstüchtig sein. Andererseits ist es sehr wahrscheinlich, daß auch das respiratorische Netzwerk einer wesentlichen postnatalen Umstrukturierung unterliegt. Wie diese beiden Umstände miteinander zu vereinbaren sind, wurde bisher sehr kontrovers diskutiert.

Die bisherigen Forschungsergebnisse zur postnatalen Entwicklung der GABA vermittelten Effekte stammen in erster Linie aus der Ratte. Anders als in adulten Tieren, führt eine Blockade der $\mathrm{Cl}^{-}-$ getragenen Inhibition in neonatalen Ratten nicht zu einer Beendigung des Rhythmus (Brockhaus \& Ballanyi, 1998; Feldman \& Smith, 1989; Onimaru et al., 1990; Ramirez \& Richter, 1996; Zhang et al., 1999). Die Forschungsarbeiten der Arbeitsgruppen Feldmann (Shao \& Feldman, 1997) und Brockhaus \& Ballanyi (1998) haben im respiratorischen Netzwerk der neonatalen Ratte ein im Vergleich zum Membranpotential negatives $\mathrm{E}_{\mathrm{GABA}}$ ermittelt. Dies entspricht nicht der Situation in anderen Hirngebieten dieser Spezies s. 2.3.2.). Zusammen werden diese beiden Befunde dahingehend interpretiert, $\mathrm{da} \beta$ die $\mathrm{GABA}_{\mathrm{A}}$-Rezeptor-vermittelte Inhibition im respiratorischen Netzwerk der perinatalen Ratte zwar vorhanden, allerdings noch nicht essentiell ist. Es wird darüber hinaus auch postuliert, daß in dieser Spezies der Atemrhythmus in der perinatalen Phase von Schrittmacher-Neuronen ohne wesentliche Beteiligung der Inhibition erzeugt werden kann (Onimaru \& Homma, 1987).

\subsection{Fragestellung und Zielsetzung}

Die obige Einleitung macht deutlich, daß unsere Erkenntnis über das GABAerge System in adulten Tieren in den letzten zwei Dekaden exponentiell zunahm. Im Kontrast dazu wissen wir noch sehr wenig darüber, wie das GABAerge System in der peri- und frühpostnatalen Entwicklung heranreift. Die Frage der Ontogenese des GABAergen Systems ist insbesondere deswegen von Brisanz, weil Berichte bekannt wurden, daß die Chlorid-vermittlte Inhibition während der ersten postnatalen Woche in den meisten Hirngebieten nicht funktionsfähig ist. Es stellt sich die Frage, wie sich das 
heranwachsende Gehirn auf das Fehlen der im adulten Gehirn essentiellen Chlorid-vermittlten Inhibition einstellt.

In der vorliegenden Arbeit soll anhand des respiratorischen Netzwerkes der neonatalen Maus diese wichtige Frage untersucht werden. Da das respiratorischen Netzwerk vom ersten Moment nach der Geburt an funktionieren muß, erscheinen uns die folgenden konkreten Fragen von Bedeutung:

a) Existiert eine funktionelle $\mathrm{GABA}_{\mathrm{A}}$-Rezeptor-vermittelte Inhibition im respiratorischen Netzwerk der Maus von Geburt an?

b) Spielt $\mathrm{GABA}_{\mathrm{B}}$-Rezeptor-vermittelte Inhibition bereits bei der Geburt eine funktionelle Rolle im respiratorischen Netzwerk der Maus?

c) Wie verändert sich die zelluläre Verteilung und Interaktion des $G_{A B A}$-Rezeptors während der ersten postnatalen Wochen im Hirnstamm der Maus? 


\section{MATERIAL UND METHODEN}

\subsection{Experimentelle Vorgehensweise}

Wie in der Einleitung ausführlich erläutert, könnten sich die ontogenetischen Entwicklungen des GABAergen Systems sowohl auf der Netzwerk-Ebene, als auch auf den zellulären, subzellulären und molekularen Ebenen abspielen. Das Ziel der hier vorliegenden Arbeit ist es, diese mehrschichtige Ontogenese des GABAergen Systems in NMRI Mäusen zu charakterisieren.

Um die Vielfalt der möglichen, entwicklungsbedingten Veränderungen untersuchen zu können, sind unterschiedliche Versuchsansätze erforderlich. So sollte die funktionelle Entwicklung des GABAergen Systems mit Hilfe elektrophysiologischer Techniken erarbeitet werden (s. Abb. 7 A). Diese Untersuchungen wurden am rhythmisch aktiven Hirnstammpräparat als experimentelles Modell durchgeführt. Das rhythmisch aktive Hirnstammpräparat erlaubt die gleichzeitige Messung der funktionellen Aktivität des Netzwerkes und einzelner Neuronen unter in vitro Bedingungen. Weiterhin sollte eine immunohistochemische Detektion der zellulären und subzellulären Verteilung der $\mathrm{GABA}_{\mathrm{B}}$-Rezeptoren auf licht- und elektronenmikroskopischem Niveau durchgeführt werden. Dies erfolgte nicht nur in Hirnstammschnitten, sondern auch in Sagitalschnitten des gesamten Mäusehirns, um die Entwicklungen unterschiedlicher Hirnregionen miteinander vergleichen zu können s. Abb. 7 B . Um die Kolokalisation von GABA S $_{B}$-Rezeptoren mit dem Transkriptionsfaktor ATF4 zu dokumentieren, wurden Fluoreszenzdoppelfärbungen an fixiertem neuronalen Gewebe der Maus ebenso wie an primären Hippocampuszellneuronen vorgenommen Abb. $7 \mathrm{C}$ ). Letztere waren leichter $\mathrm{zu}$ handhaben und ermöglichten qualitativ überlegene Färbungen. Da eine Kolokalisation nur begrenzt Aussagen über die tatsächliche Interaktion der Proteine zuläßt und eine exakte Quantifizierung der beteiligten Proteinmengen nicht möglich ist, sollte zuletzt die intrazelluläre Interaktion zwischen $\mathrm{GABA}_{\mathrm{B}}$-Rezeptor und ATF4 durch einen molekarlarbiologischen Ansatz über Immunopräzipitation charakterisiert werden s. Abb. 7 D). 


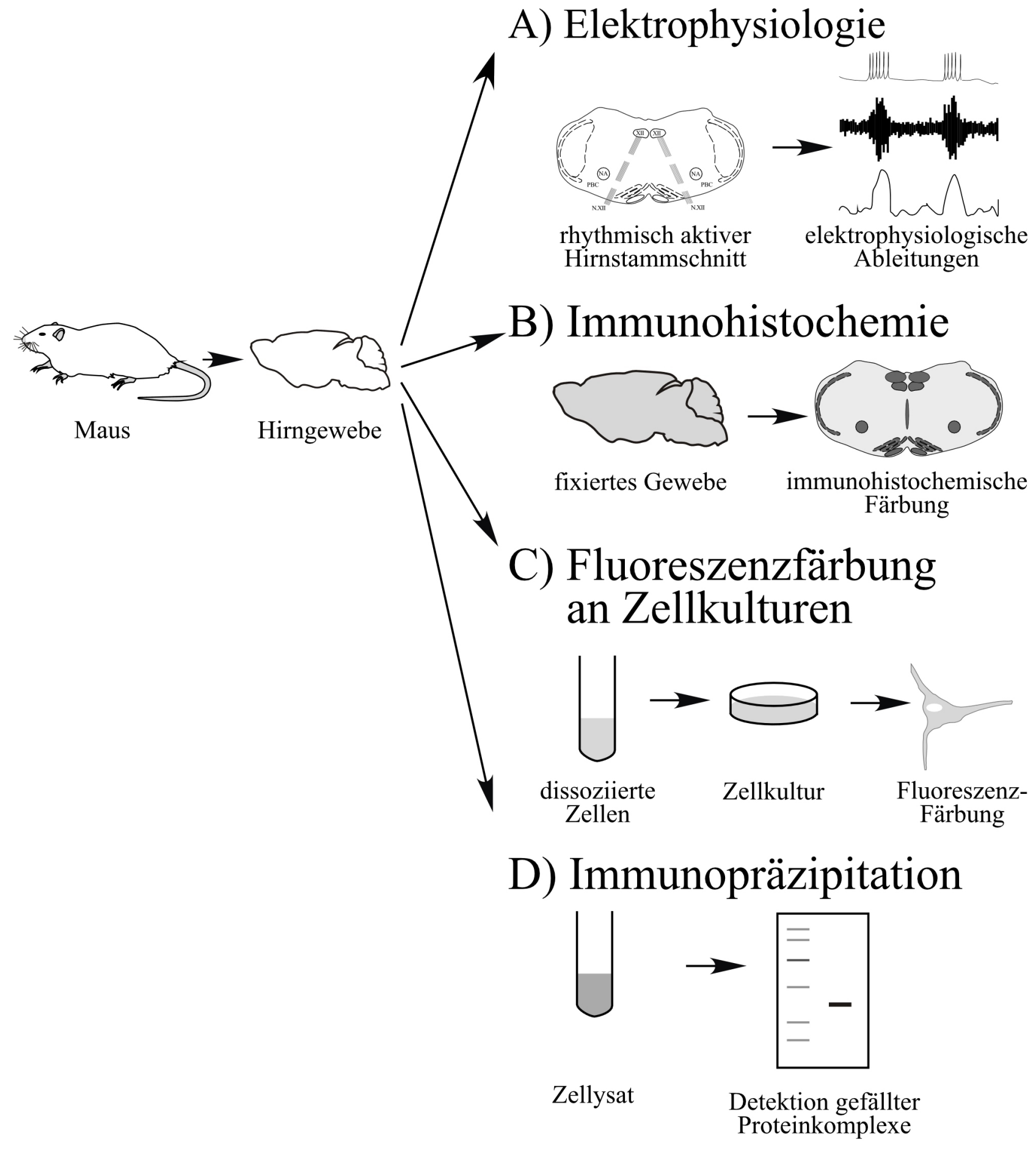

Abb. 7. Übersicht der verwendeten Methoden. Aus Mäusen gewonnenes Hirngewebe wird auf unterschiedliche Weisen weiterverarbeitet. A: Erstellung eines rhythmisch aktiven Hirnstammschnittes zur Durchführung unterschiedlicher, elektrophysiologischer Ableitungen. PBC = Prä-Bötzinger Komplex; XII = Nucleus hypoglossus, NA = Nucleus ambiguus, N.XII =Wurzel des zwölften Hirnnerven; B: Fixation des Gewebes und anschließende, immunohistochemische Färbung. C: Erstellung einer Zellsuspension und Anzüchtung von Zellen in Kultur, nachfolgend Weiterverarbeitung in Fluoreszenzfärbung oder Immunopräzipitation (s. D.). D: Auftrennung von aus einem Zellysat spezifisch ausgefällten Proteinkomplexen und anschließende Detektion durch lichtemittierende Antikörper. 


\subsection{Elektrophysiologie}

\subsubsection{Präparation des isolierten, rhythmisch-aktiven Hirnstammschnittes}

Bei dem Hirnstammschnitt handelt es sich um ein $700 \mu \mathrm{m}$ dickes Präparat, welches sowohl den PräBötzinger Komplex (PBC), als auch den Nucleus hypoglossus und einen Teil der Wurzel des $N$. hypoglossus (N.XII, s. Abb. 8) enthält. Zur Herstellung dieses Präparates wurden NMRI-Mäuse verschiedener postnataler Stadien (Tag der Geburt (P0) bis postnataler Tag 15 (P15)) mit Äther narkotisiert und auf Höhe des 4. Rückenmarknerven dekapitiert. Die Schädelkalotte wurde entfernt, so daß das Gehirn von oben frei zugänglich wurde. Das Gehirn wurde, von rostral nach caudal, vorsichtig aus dem Schädel gehoben und mit einer Federschere wurden die Hirnnerven möglichst nah an der Schädelbasis abgetrennt. Der Hirnstamm wurde von Groß- und Kleinhirn abgetrennt und mittels Cyanoacrylat (Loctite, Deutschland $\mathrm{GmbH}$ ) mit der dorsalen Seite auf einem Agarblock befestigt, der seinerseits auf einer $24^{\circ}$ schrägen Ebene fixiert war. Die schiefe Ebene mit dem Präparat wurde so in ein Vibratom eingespannt, daß die Kippung in rostro-caudaler Linie erfolgte. Die Präparation wurde möglichst zügig und unter dauernder Kühlung des Gehirngwebes in eiskalter carbogenbegaster artifizieller cerebrospinaler Lösung (ACSF, s. Tabelle 2) vollzogen, um Hypoxieschäden zu vermeiden.

\section{Tabelle 2: Extrazellulärlösungen}

\begin{tabular}{l|l||l} 
& $\begin{array}{l}\text { Artificielle cerebrospinale Lösung } \\
\text { (ACSF) }\end{array}$ & $\begin{array}{l}\text { carbonatfreie } \\
\text { ACSF }\end{array}$ \\
\cline { 2 - 3 } Substanz & Konzentration $(\mathrm{mM})$ & Konzentration $(\mathrm{mM})$ \\
\hline $\mathrm{NaCl}$ & 118 & 118 \\
\hline $\mathrm{KCl}$ & 3 & 3 \\
\hline $\mathrm{CaCl}$ & 1.5 & 1.5 \\
\hline $\mathrm{MgCl}_{2}$ & 1 & 1 \\
\hline $\mathrm{NaHCO}_{3}$ & 25 & - \\
\hline $\mathrm{NaH}_{2} \mathrm{PO}_{4}$ & 1 & - \\
\hline $\mathrm{HEPES}$ & - & 25 \\
\hline Glukose & 5 & 5
\end{tabular}

Die Lösungen wurden mit $\mathrm{NaOH}$ auf einen pH-Wert von 7.4 eingestellt. Die ACSF wurde mit Carbogen $\left(95 \% \mathrm{O}_{2}, 5 \% \mathrm{CO}_{2}\right)$, die carbogenfreien ACSF mit 100\% $\mathrm{O}_{2}$ begast. 


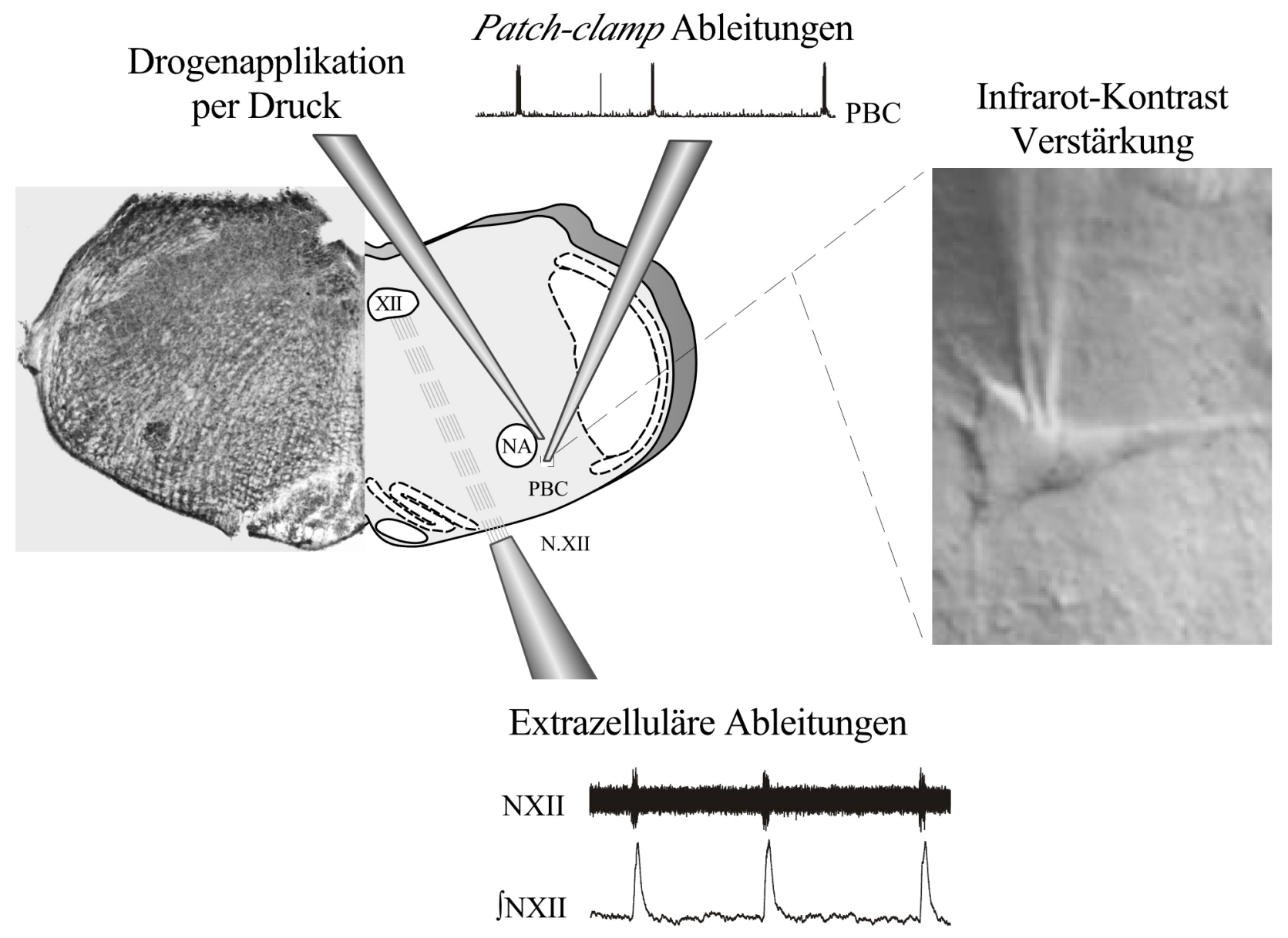

Abb. 8. Schematische Darstellung der elektrophysiologischen Methoden. Am als Gewebe (linke Hälfte) und schematisch (rechte Hälfte) gezeigtem, rhythmisch aktiven Hirnstammschnitt werden zeitgleich unterschiedliche Applikationen und Ableitungen durchgeführt. Neben der systemischen Applikation über die umspülende Badlösung ist Drogenapplikation per Druck auf Einzelzellen möglich. Die extrazellulären Ableitungen werden an der austretenden Nervenwurzel durchgeführt und das gemessene Summenpotential (NXII) und dessen Integral ( $($ NXII) dokumentiert. Unter Infrarotsicht ermöglicht eine patch clamp Elektrode weiterhin die Ableitung eines einzelnen Neurons. In dieser und allen weiteren Abbildungen: $\mathrm{PBC}=$ Prä-Bötzinger Komplex; NA = Nucleus ambiguus; $\mathrm{N}$. XII $=$ Wurzel des zwölften Hirnnervenwurzel; NXII $=$ Ableitung des Summenpotentials der zwölften Hirnnervenwurzel; $\int \mathrm{NXII}=$ Integral des Summenpotentials der zwölften Hirnnervenwurzel

Die rostrale Schnittebene des vertikalen Hirnstammschnittes lag auf dem Niveau des Nucleus facialis. Von ihr aus wurde ein $700 \mu \mathrm{m}$ dicker Schnitt entnommen und sofort in die Meßkammer überführt. Bei einigen Experimenten wurden stattdessen mehrere $200 \mu \mathrm{m}$ dicke Schnitte derselben Region hergestellt. Die nicht sofort zur Messung benutzten Schnitte wurden in begaster ACSF bei Raumtemperatur (RT) gelagert.

Innerhalb der Meßkammer wurde der Schnitt auf eine Plexiglaslochplatte gelegt und mit einem mit Nylonfäden umspannten Aluminiumrahmen fixiert. Die Lochplatte diente dazu, das Präparat nicht nur von oben, sondern auch von unten zu umspülen und die Sauerstoffversorgung des Präparates ausreichend zu gewährleisten. Der Sauerstoffpartialdruck $\left(\mathrm{pO}_{2}\right)$ betrug $200 \pm 50 \mathrm{mmHg}$ in einer Gewebetiefe von $100 \mu \mathrm{m}$ (Mironov et al., 1998). Die rostrale Ebene des Schnittes sollte von oben für die elektrophysiologischen Messungen zugänglich sein. Durch die Meßkammer zirkulierte die 
carbogenbegaste ACSF, deren Flußgeschwindigkeit und Temperatur kontrollierbar war. Die ACSF wurde in ca. 15 Minuten auf $27-29^{\circ} \mathrm{C}$ erwärmt und danach der Kaliumgehalt schrittweise von $3 \mathrm{mM}$ auf $8 \mathrm{mM}$ angehoben. Dies bewirkte eine tonische Depolarisation der Hirnstammneurone, die die spontane rhythmische Aktivität des Hirnstammschnittes stabilisierte (Greer et al., 1992; Smith et al., 1991b).

Die Neurone des Prä-Bötzinger Komplexes (PBC) wurden anhand ihrer Lage ventrolateral zu der Pars compacta des Nucleus ambiguus identifiziert. Um eine Schädigung des Gewebes durch Gramicidin möglichst gering zu halten, wurde für jede durchgeführte Versuchsreihe ein neuer Schnitt benutzt.

\subsubsection{Versuchsaufbau und Datenaufnahme}

Die Meßkammer (s. Abb. 9) war fest auf einem bewegbaren Tisch eines aufrechten Mikroskopes (Axioscope, Zeiss) montiert, welches mit einem Axoplan Wasserimmersionsobjektiv mit 40facher Vergrößerung ausgestattet war. Der Kontrast des Präparates wurde durch einen Infrarot-KontrastEnhancer (C2400, Hamamatsu Photonics Deutschland GmbH, Herrsching) verstärkt. Die InfrarotKontrast-Verstärkung und die Piezo-Steuerung (P-263, Physik Instrumente) der patch clamp Elektrode ermöglichten eine Ableitung der PBC-Neurone unter Sicht.

Die Meßkammer war so plaziert, daß sie gleichzeitig für Meß- und Applikationselektroden zugänglich war. Alle Elektroden waren zur genauen Positionierung an Mikromanipulatoren montiert, die patch clamp Elektrode zusätzlich an einen Piezo-gesteuerten Mikromanipulator. Sie war weiterhin direkt mit einem Impedanzwandler verbunden. Auf sie konnte ebenso wie auf die Druckapplikationselektrode über ein Schlauchsystem Druck ausgeübt werden. Mit letzterer wurde der $\mathrm{GABA}_{\mathrm{A}}$-Rezeptor spezifische Agonist Muscimol in einer Konzentration von $0.1 \mathrm{mM}$ in ACSF appliziert. Wenn nicht anders erwähnt, erfolgte dies durch einen auf die Flüssigkeitssäule der Applikationspipette ausgeübten Druck von 0.5 mbar für $100 \mathrm{~ms}$.

Die gesamte bisher beschriebene Meßeinheit war zur Abschirmung gegen elektromagnetische Störungen mit einen Faraday-Käfig umgeben und zur Vermeidung hochfrequenter Schwingung auf einem hydraulisch stoßgedämpften Tisch gelagert. Sie war mit den außerhalb des Käfigs gelegenen, zur Aufarbeitung und Darstellung der Signale und zu Steuerung der Messprotokolle benutzten Apparaturen verbunden. Ein gleichfalls außerhalb des Käfigs befindliches Pump- und Thermostatsystem erlaubte die Kontrolle von Temperatur (in Messkammer $28^{\circ} \mathrm{C}$ ) und Durchflußgeschwindigkeit ( $15 \mathrm{ml} / \mathrm{min}$ ) der Extrazellulärflüssigkeit. In ihr konnten je nach Versuch eine oder mehrere Pharmaka gelöst werden, um sie extrazellulär im Bad zu applizieren.

Die mit der patch clamp Elektrode gemessenen Signale wurden mit einem Axopatch 200 Verstärker (Axon Instrument Inc.) registriert und mit einem vierpoligen Besselfilter bei einer Grenzfrequenz von $2 \mathrm{kHz}$ gefiltert. Die Daten wurden während der Messung mit einer Frequenz von $10 \mathrm{kHz}$ von 
einem Analog/Digital-Wandler (DigiData 1200) digitalisiert und auf einem Computer mit Hilfe von pClamp 6.0 Programmen aufgezeichnet und später analysiert. Diese Programme erlaubten weiterhin das Anlegen von Strom- und Spannungsprotokollen an die patch clamp Elektrode.

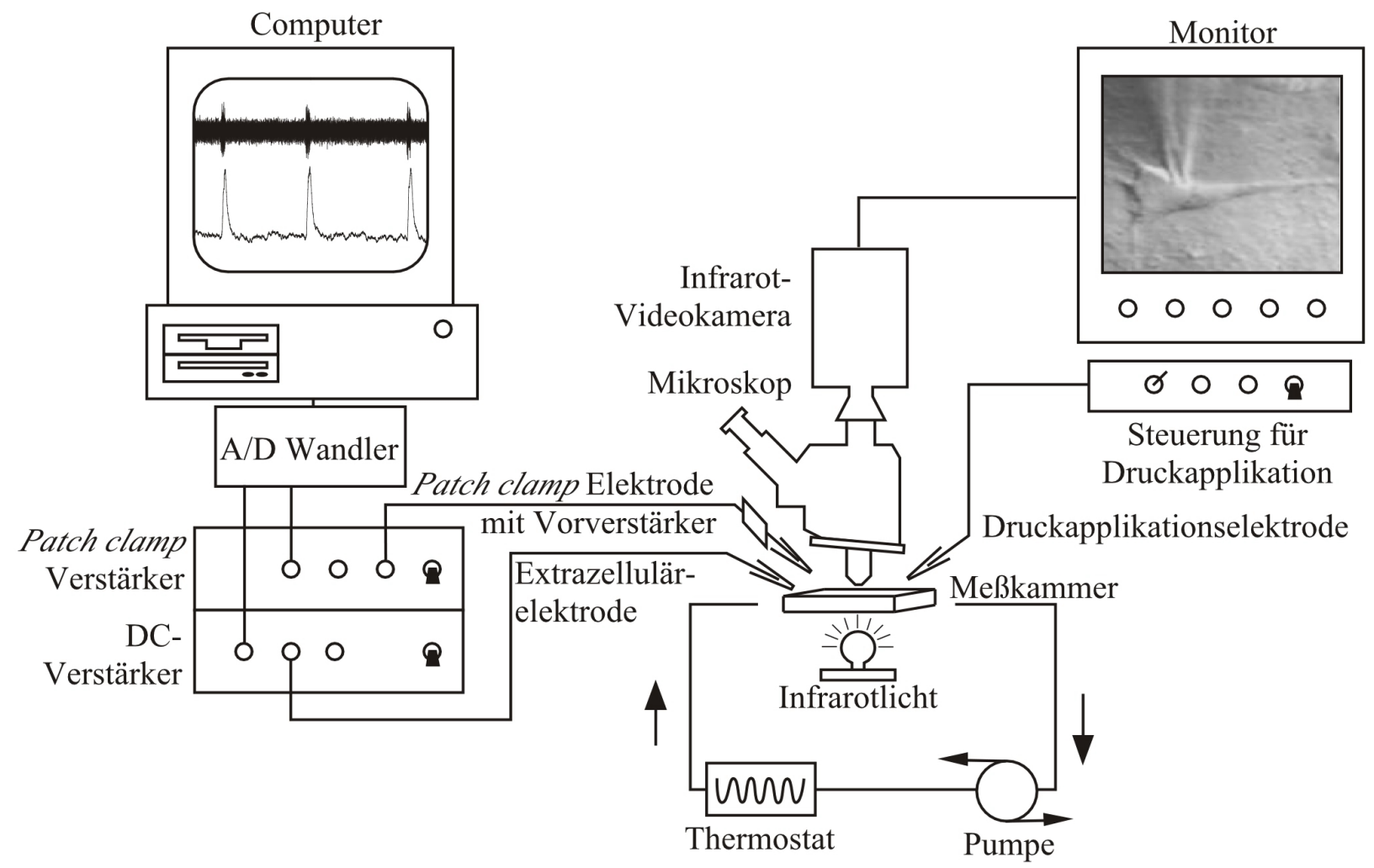

Abb.9. Schematische Darstellung des Meßplatzaufbaus. Das Hirnstammpräparat in der Meßkammer wird über eine zirkulierende Badlösung umspült, die von einer Pumpe betrieben und über ein Wärmebecken mit Thermostat erwärmt wird. Es existiert ein getrennter Zu- und Ablauf. Über Extrazellulär- und Patch clamp Elektrode werden Daten vom Präparat detektiert, über ein Verstärkersystem geleitet und als analog-digitale Signale in den Computer übertragen. Über eine Druckelektrode können gelöste Drogen unter definierten Bedingungen appliziert werden. Eine Infrarot-Videokamera und ein Monitor ermöglichen Einzelzellableitungen unter Sicht.

Das mit der extrazellulären Saugelektrode gemessene Summenpotential des N. hypoglossus wurde 20000 fach verstärkt, gefiltert (Hochpaßfilter 1,5 kHz; Tiefpaßfilter $250 \mathrm{~Hz}$ ) und zusätzlich in einem weiteren Verarbeitungsschritt rektifiziert, erneut gefiltert (Tiefpaßfilter, Paynter Filter) und mit einer Zeitkonstante von 20-30 ms intregriert.

Bei den durchgeführten Messungen kamen verschiedene Elektrodentypen zur Anwendung. Alle wurden aus Borosilikat-Glas (Clark Elektromedical Instruments) mit einem Pipettenziehgerät (P87, Sutter Instrument Co., Navato) hergestellt. Für patch clamp Elektroden bei Messungen im whole cell Modus s.u. wurden Glaskapilaren mit innerem Filament verwendet. Sie besaßen durchschnittlich einen Spitzendurchmesser von $1 \mu \mathrm{m}$ und einen Widerstand von 4-6 M $\Omega$. Für extrazelluläre Saug- und Druckapplikationselektroden sowie für patch clamp Elektroden zur Messung mit Gramicidin wurden Glaskapillaren ohne Filament verwendet. Während der Spitzendurchmesser der zur Messung mit Gramicidin bestimmten Elektroden ebenfalls $1 \mu \mathrm{m}$ 
entsprach, variierte er zwischen 5-10 $\mu \mathrm{m}$ für Druckapplikationselektroden und wurde bei Extrazellulärelektroden der Größe des abzuleitenden Nerves angepaßt.

\subsubsection{Meßtechniken}

\section{Extrazelluläre Ableitungen}

Die im Präparat enthaltenen Wurzeläste des $N$. hypoglossus wurden durch leichten Unterdruck vollständig in die mit Extrazellulärlösung gefüllte Elektrode gesaugt. Der elektrische Kontakt wurde über einen chlorierten Silberdraht hergestellt und die detektierten Signale, wie unter 2.2.2. beschrieben, verarbeitet und gespeichert. Eine weitergehende Analyse ermöglichte das Axo-graph 4.0 Programm der Firma Axon Instruments, mit dem die Frequenz des Atemrhythmus sowie Amplitude und Zeitverlauf des integrierten Signals ausgewertet wurden.

\section{Messungen im whole-cell Modus der patch clamp Technik}

Die patch clamp Methode wird angewandt, um Zellen durch Applikation von Strom und Spannung in einem definierten elektrischen Zustand zu halten, sie sozusagen zu 'klemmen' (clamp). Obwohl es unterschiedliche patch clamp Konfigurationen gibt, soll in dieser Arbeit nur die sogenannte Ganzzell- oder 'whole cell' Konfiguration und eine ihrer Varianten, die Messung an Gramicidin perforierten Zellen, beschrieben werden (Numberger \& Draguhn, 1996).

Zum Erreichen der whole cell Konfiguration wurde die Elektrode an das Präparat unter leichtem Überdruck auf die Flüssigkeitssäule der Pipette $(30 \mathrm{mmHg})$ angenähert, um Verschmutzungen der Elektrodenspitze zu vermeiden. Der Widerstand der Meßelektrode konnte über einen Testpuls von $10 \mathrm{mV}$ und die sich daraus ergebenen Ströme errechnet werden. Da die Badlösung über eine Badelektrode geerdet war, wurde ihr Potential als $0 \mathrm{mV}$ definiert. Kurz bevor die Elektrodenspitze auf der Zellmembran des abzuleitenden Neurons aufsaß, zeigte sich dies durch eine Erhöhung des Widerstandes um bis zu $1 \mathrm{M} \Omega$. Nun wurde der Druck abgelassen und der Zelle im voltage clamp Modus s.u. eine Spannung von $-70 \mathrm{mV}$ gegenüber der Badlösung vorgegeben. In den meisten Fällen erhöhte sich der Widerstand nun spontan durch das Anlagern der Zellmembran an die Pipetteninnenwände. Dann wurde ein vorsichtiger Sog appliziert, bis sich die Ströme über der Membran soweit verringert hatten, daß sich ein Widerstand von mehreren Gigaohm (G $\Omega$ ) ergab (Ausbildung des 'Gigasaels'). Danach wurden die kapazitiven Ströme, die zum Umladen der Elektrode benötigt wurden, durch ein zum Vorverstärker parallel geschalteten WiderstandKapazität-Einheit mit regelbarem Widerstand kompensiert. Durch ruckartigen Unterdruck wurde die Membran unter der Elektrodenspitze aufgebrochen und die whole cell Konfiguration erreicht. Der Serienwiderstand, der den an der Elektrodenspitze und beim Eintritt in die Zelle auftretenden Spannungsabfall charakterisiert, wurde nun durch eine positive Rückopplung zu ca 80-85\% kompensiert. Ebenso wurden die kapazitiven Ströme der Zellmembran ausgeglichen. An Neuronen 
(Membranpotential von $-70 \mathrm{mV}$ ) von Leckströmen über $100 \mathrm{pA}$ wurden keine Messungen durchgeführt.

In der whole cell Konfiguration sind zwei unterschiedliche Meßmodi möglich. Im Spannungsklemm-Modus (voltage clamp) wird der Zelle durch entsprechende Kompensationsströme ein bestimmtes Potential vorgegeben. Diese Ströme sind meßbar und entsprechen den bei der vorgegebenen Spannung über die Zellmembran fließenden Ionenströmen, die sie ausgleichen. Bei verzweigten Neuronen tritt in diesem Meßmodus das Problem auf, daß bereits in den Soma-nahen Bereichen der Dendriten zu viel Spannung abfällt, um die Bedingungen innerhalb der Soma-fernen Dendriten festlegen zu können. Genaue Aussagen lassen sich also nur über Ströme in somalen oder soma-nahen Bereichen des Neurons treffen. Im Stromklemm-Modus (current clamp) wird ein konstanter Strom vorgegeben, während das Potential der Zelle variabel bleibt.

Bei der whole cell Konfiguration erfolgt innerhalb von Minuten ein Austausch des physiologischen Zellinhaltes mit der Pipettenlösung. Infolgedessen werden zelleigene Stoffe wie Metabolite oder intrazelluläre Botenstoffe ausgewaschen. Diese Eigenschaft der whole cell Ableitung kann genutzt werden, um intrazelluläre Bedingungen weitgehend über die Pipettenlösung vorzugeben s. Abb. 10 A). Bei den durchgeführten Messungen wurden Pipetten-Lösung mit niederiger $\mathrm{Cl}^{-}$-Konzentration (InLow, in mM: K-Glukonat 140; $\mathrm{KCl} 1 ; \mathrm{CaCl}_{2}$ 1; EGTA 10; $\mathrm{MgCl}_{2} 2 ; \mathrm{Na}_{3} \mathrm{GTP}$ 0.5; $\mathrm{Na}_{3} \mathrm{ATP} 4$; HEPES 10) benutzt.

\section{Messungen an Gramicidin-perforierten Neuronen}

Bei der Messung an Gramicidin-perforierten Neuronen wurde der elektrische Kontakt zum Zellinneren nach Ausbildung des Gigaseals dadurch erreicht, daß sich einzelne Gramicidinmoleküle nach und nach in die Zellmembran einlagern und so eine kationen-leitende Pore entsteht S. Abb. $10 \mathrm{~B}$.

In dieser Arbeit wurde eine modifizierte Methode nach Kyrozis et al. verwendet (Kyrozis \& Reichling, 1995). Die GramicidinD-Stammlösung (5 mg/ml in Dimethylsulfoxid) konnte 12 Stunden auf Eis gelagert werden und wurde direkt vor der Messung zu der in whole cell Ableitungen benutzten Pipettenlösung in einer Konzentration von $20 \mu \mathrm{g} / \mathrm{ml}$ gegeben. Vor den Messungen wurde das Potential bestimmt, daß sich zwischen einer mit Gramicidin-haltiger Lösung gefüllten Elektrode und der Badlösung ergibt. Ein solches Potential bezeichnet man als Grenzflächenpotential (liquid junction potential). Das von der Gramicidin-haltigen Pipette zur Badlösung gebildete Grenzflächenpotential wurde mit dem zwischen Bad und einer mit InLow gefüllter Pipette entstehendem Potential verglichen. In 5 Messungen ergab sich eine durchschnittliche Differenz von $-8.5 \pm 1.3 \mathrm{mV}$ (siehe auch Brockhaus \& Ballanyi, 1998). Um die in 
Gramicidin-perforierten patch clamp Modus gemessenen Potentiale mit den im whole cell Modus mit InLow gemessenen vergleichen zu können, wurden sie um $-8.5 \mathrm{mV}$ korrigiert.

A)

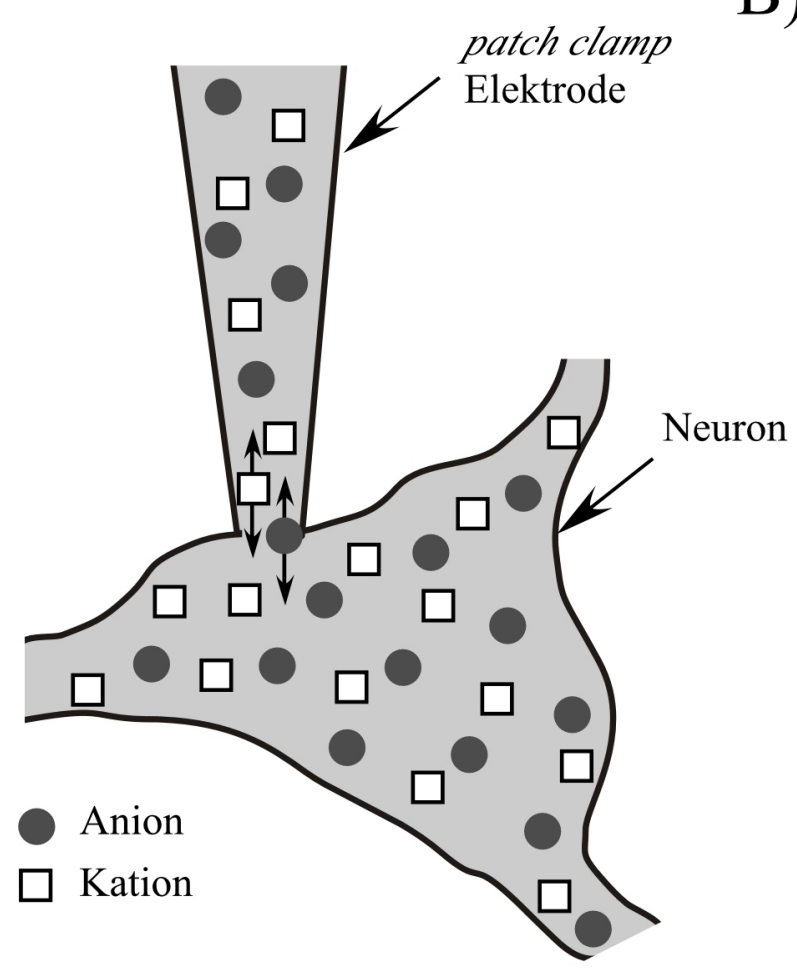

Ableitung an Neuronen in whole cell Konfiguration
B)

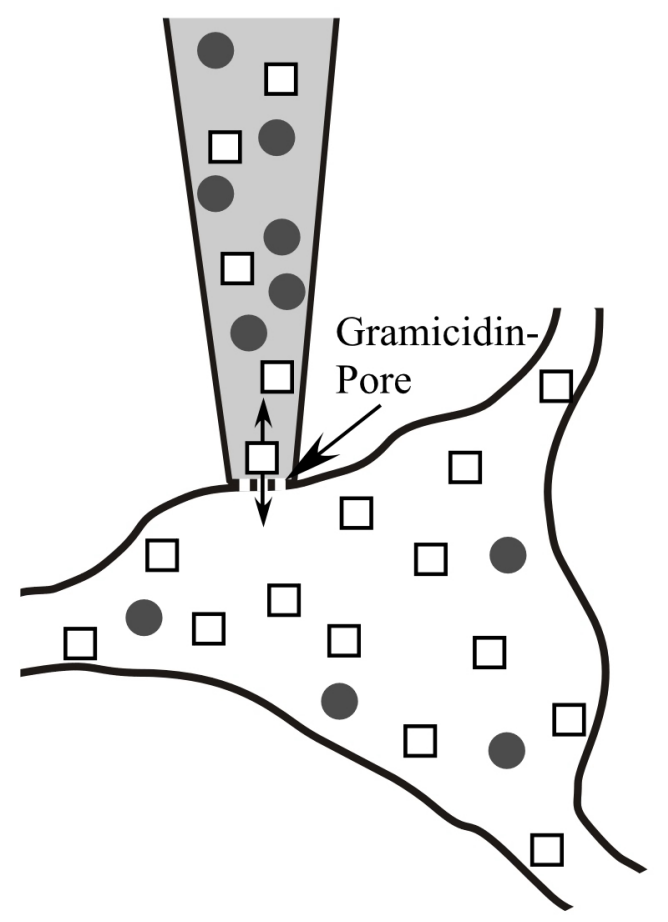

Ableitung an Gramicidin-perforierten Neuronen

Abb. 10. Vergleich unterschiedlicher patch clamp Methoden. A: Bei einem im whole cell Modus abgeleiteten Neuron (Dendriten nicht vollständig abgebildet) wird das Zellplasma durch die Pipettenlösung (grau) äquilibriert, da der erzeugte Durchbruch durch die Membran keinerlei Selektivität besitzt und sowohl Anionen als auch Kationen hindurchwandern (Doppelpfeil). B: Bei der Ableitung an Gramicidin-perforierten Neuronen sind die gebildeten Poren ausschließlich leitend für Kationen. Dies verhindert einen Ausstauch von Anionen oder anderen Inhaltsstoffen des Zellplasmas (weiß) mit der Pipettenlösung (grau).

Die Elektroden wurden mit ca. $2 \mu$ Gramicidin-freier Pipettenlösung vorgefüllt, um Kontaminationen des Präparates während der Suche nach geeigneten Neuronen zu vermeiden. Aus demselben Grund wurde kein Überdruck auf die patch clamp Elektrode angelegt bis sie sich in direkter Nähe des abzuleitenden Neurons befand. Nach Ausbildung des Gigaseals fiel der Eingangswiderstand innerhalb von 5-20 Minuten auf 40-100 M 2 . Nur Neurone, in denen im current clamp Modus deutlich ausgeprägte Aktionspotentiale erzeugt werden konnten, wurden weiter untersucht. Um eine Schädigung der Neurone durch Gramicidin so gering wie möglich zu halten, wurde pro Gewebeschnitt nur eine Zelle untersucht. In einigen Zellen kam es nach einer gewissen Zeit zum spontanen Durchbruch der Zellmembran. Die Membran konnte durch ruckartigen Sog ebenfalls bewußt durchbrochen werden, um die whole cell Konfiguration zu erreichen. In diesem Fall konnten vergleichende Messungen im whole cell Modus durchgeführt werden. 
Bei einer Messung an Gramicidin-perforierten Neuronen vermeidet man eine Äquilibrierung des Zellinhaltes mit der Pipettenlösung (s. Abb. 10 B). Es wandern lediglich Kationen - in erster Linie $\mathrm{K}^{+}$und $\mathrm{Na}^{+}$- über die Membran. Andere Ionengradienten, wie z.B. der $\mathrm{Cl}^{-}$-Gradient, werden nicht direkt beeinflußt (Ebihara et al., 1995). Wird das Gleichgewichtspotential Rezeptor-vermittelter Ströme gemessen, d.h. das Potential, bei dem trotz Kanalöffnung keine meßbaren Ionenströme erfolgen, so kann aus der Nernst-Gleichung die Konzentration des stromtragenden Ions innerhalb der Zelle errechnet werden.

$$
V_{m}=\frac{R T}{z F} * \ln \left(\frac{[C]_{a}}{[C]_{i}}\right)
$$

Leitet ein Kanal mehrere Ionen, so wird Goldmann-Hodgkin-Katz Gleichung verwendet:

$$
V_{m}=\frac{R T}{F} * \ln \left(\frac{\sum P_{\text {Kation }}[\text { Kation }]_{a}+\sum P_{\text {Anioo }}[\text { Anion }]_{i}}{\left.\sum P_{\text {Kation }}[\text { Kation }]_{i}+\sum P_{\text {Anion }} \text { Anion }\right]_{a}}\right)
$$

$$
\begin{array}{cll}
\text { Mit } \mathrm{V}_{\mathrm{m}}=\text { Membranpotential } & \mathrm{R}=\text { allgemeine Gaskonstante } & \mathrm{T}=\text { Temperatur } \\
\mathrm{F}=\text { Faraday-Konstante } & \mathrm{P}=\text { Permeabilität der Membran } & {[\mathrm{C}]=\text { Konzentration }} \\
\mathrm{Z}=\text { Wertigkeit des Ions } &
\end{array}
$$

\section{Statistik}

Um die Signifikanz von Unterschieden einer Datengruppe zu einer anderen zu ermitteln, wurden gepaarte oder ungepaarte Student-t-tests durchgeführt. Hierzu wurde das Programm InStat

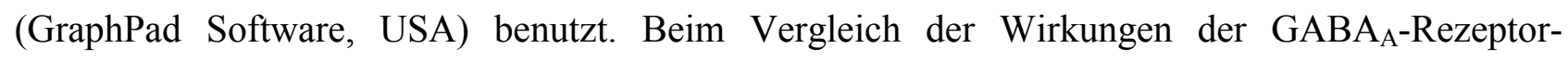
Blockade auf unterschiedliche Aspekte des respiratorischen Rhythmus kam der zweiwegige ANOVA Test zur Anwendung (Excel, Microsoft, USA). Zwei Datengruppen wurden als signifikant verschieden von einander betrachtet und mit einem Stern markiert $\left(^{*}\right)$, wenn die Wahrscheinlichkeit des Fehlers erster Ordnung unter 5\% lag $(\mathrm{p}<0.05)$. Sank die Überschreitungswahrscheinlichkeit unter $1 \%(\mathrm{p}<0.01)$ galt ihre Unterschiedlichkeit als deutlich $(* *)$, unter $0.1 \%$ als extrem signifikant $(* * *)$.

Statistische Daten wurden \pm ihrer Standardabweichung dargestellt. Als Maß für die Homogenität einer Datengruppe wurde der Koeffizient der Variation als prozentualer Anteil der Standardabweichung am Durchschnittswert der Daten ermittelt. Die Anzahl der durchgeführten Experimente wurde mit $n=A n z a h l$ angegeben.

\subsection{Immunohistochemie}

Obwohl elektrophysiologische Messungen indirekte Rückschlüsse über die prä- oder postsynaptische Lokalisation funktioneller Rezeptoren erlauben, sind sie doch unzureichend für eine umfassende Darstellung ihrer Lokalisation. Eine Möglichkeit, das Vorkommen eines Proteins 
in unterschiedlichen Strukturen eines Organismus oder einer Zelle nachzuweisen, ist die Immunohistochemie. In ihr nutzt man die hohe Bindungsaffinität von Antikörpern zu ihren spezifischen Antigenen aus. Normalerweise kommen die im Serum vorhandenen, löslichen Immunoglobuline (IgG) zur Anwendung. IgG bestehen aus zwei schweren Ketten und zwei leichten Ketten. Teile dieser Ketten sind in ihrer Aminosäuresequenz speziesspezifisch konstant, andere sind

A

Fixierte Zellen

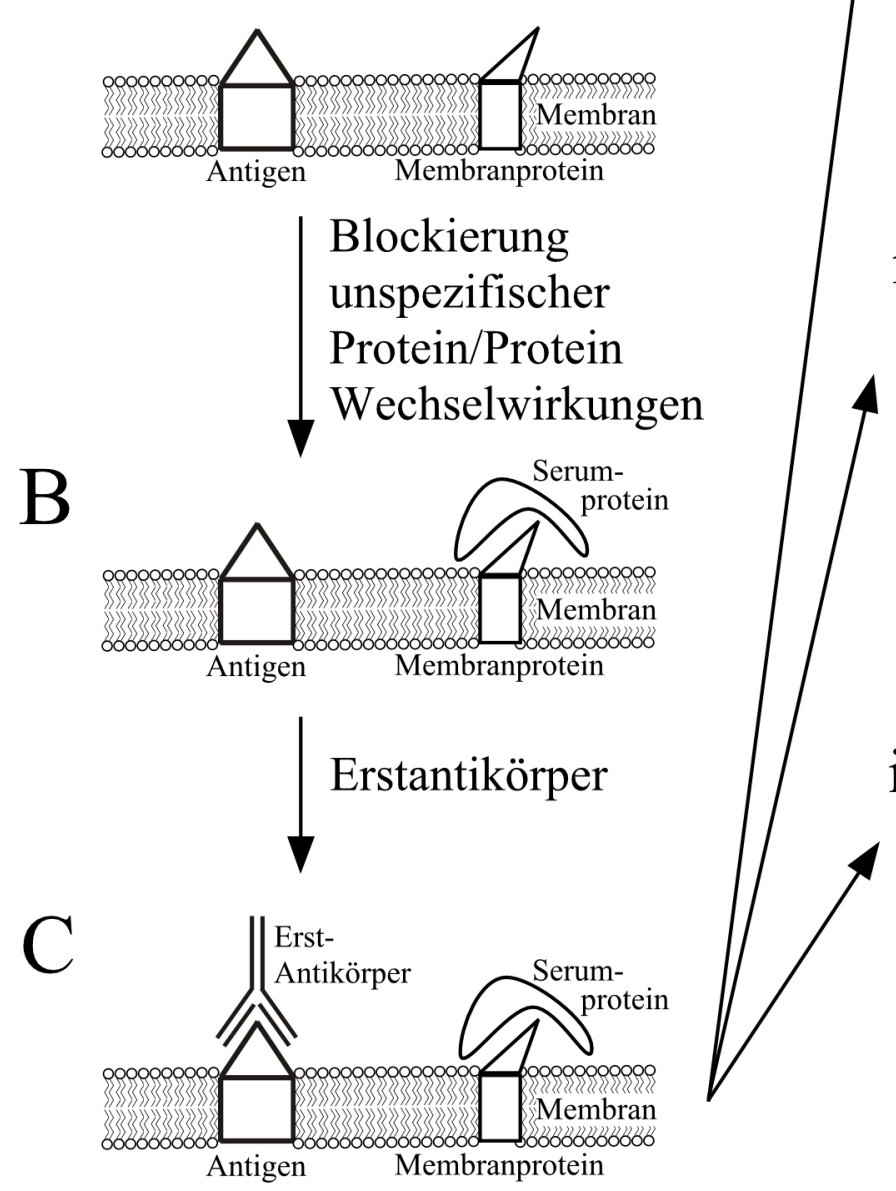

\section{$\mathrm{D}_{\text {i) Färbung durch Umsatz von }}$ Diaminobenzidin (DAB)}

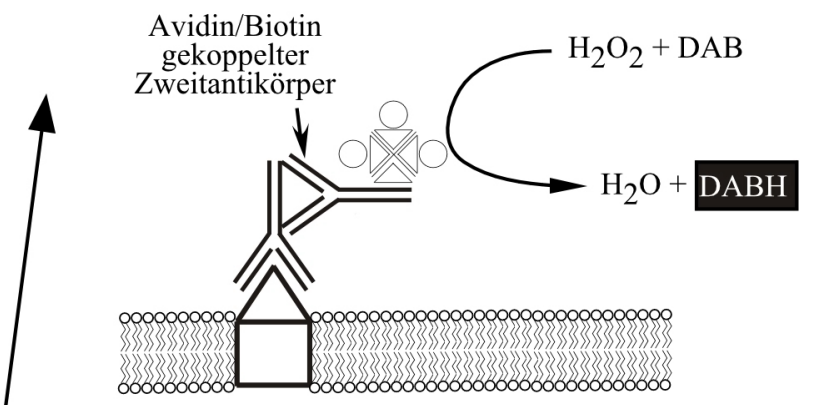

ii) Färbung durch Fluoreszenz

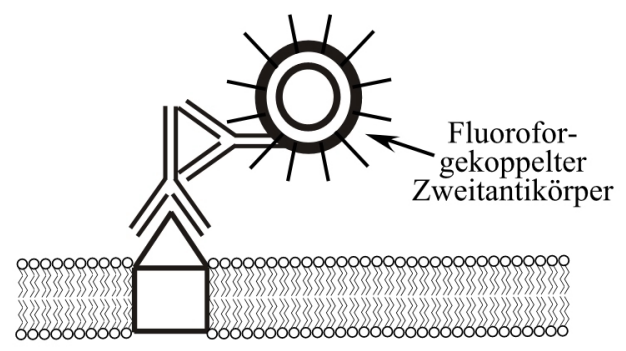

iii) Doppelfluoreszenzfärbung

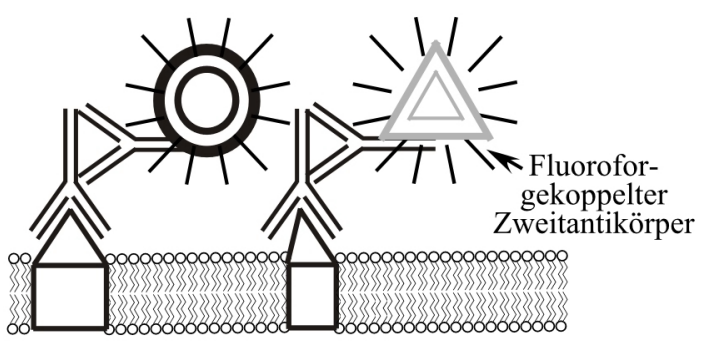

Abb. 11. Ablauf immunohistochemischer Färbungen. A: Im ersten Schritt werden unspezifische Wechselwirkungen mit anderen Membranproteinen chemisch fixierter Zellen durch Zugabe von Serumproteinen abgesättigt. B: Zugabe des Antigen-erkennenden Erstantikörpers. C: Nach der Bindung des Erstantikörpers an das zu detektierende Antigen kann dessen konstante Region durch Zweitantikörper mit unterschiedlichen Signalsystemen erkannt werden. D: i) Färbung mit Diaminobenzidin (DAB): Zweitantikörper ist mit einem Biotin-Avidin Komplex verbunden, der DAB zu einem bräunlichen Niederschlag (DABH) umsetzt. ii) Fluoreszenzfärbung: Zweitantikörper ist an Fluofor gekoppelt. iii) Doppelfluoreszenzfärbung: Färbung zweier Antigene mit jeweils unterschiedlichen Erst- und unterschiedlich fluoreszierenden Zweitantikörpern. Sind zwei unterschiedliche Zweitantikörper räumlich nah genug, ergibt sich bei der Addition ihrer Emissionen eine neue Farbe. 
hochvariabel, denn sie kleiden den Teil des IgG aus, der für die Antigenerkennung und Bindung zuständig ist.

Bei der Bindung an Antigene ist zu bedenken, daß die meisten Antigene groß genug sind, um unterschiedliche Strukturen zu beinhalten, die gleichzeitig von IgG erkannt werden können. Eine solche, von IgG erkennbare Struktur nennt man Epitop. An ein bestimmtes Epitop können wiederum verschiedene IgG mit unterschiedlicher Affinität binden, je nachdem wie gut ihre variable Region zur Epitopstruktur paßt.

Das zu untersuchende Gewebe wird in der Immunhistochemie zunächst chemisch fixiert, um dessen Zell- und Gewebestruktur zu erhalten s. Abb. 10 A). Dieses geschieht meist durch Quervernetzung von Proteinen. $\mathrm{Zu}$ bedenken ist allerdings, daß eine zu starke Vernetzung Epitope für Antikörper unzugänglich machen kann. Vor der eigentlichen Färbeprozedur sollten unspezifische Protein/Protein-Wechselwirkungen abgesättigt werden, um unspezifische Anlagerung der IgG zu vermeiden s. Abb. 11 B). Danach bindet ein entsprechend zugegebener IgG das gewünschte Epitop s. Abb. 11 C). Diesen IgG nennt man auch Erstantikörper. Bei der hier eingesetzten indirekten Färbung wird dieser durch einen sogenannten Zweitantikörper sichtbar gemacht s. Abb. 11 D. Solche Zweitantikörper werden in einer zweiten Erzeugertierspezies hergestellt und erkennen die identischen Sequenzen der Erstantikörper-Ketten aller im ersten Wirtstier erzeugten IgG. Außerdem ist der Zweitantikörper an ein Detektionssystem gekoppelt. Dieses Detektionssystem kann entweder ein Fluorofor sein oder ein Enzymkomplex, der mit einer entsprechenden Umsetzung einen lichtmikroskopisch sichtbaren Farbstoff am Ort des gesuchten Epitops produziert.

In dieser Arbeit wurden sowohl die Fluoreszenz- als auch die enzymatische indirekte Färbung eingesetzt. Bei der enzymatischen Färbung wurden an Biotin gebundene Zweitantiköper verwendet. Diese banden einen an Avidin gekoppelten Komplex, der drei Peroxidase-Moleküle enthielt. Bei Zugabe von Diaminobenzidin (DAB) und $\mathrm{H}_{2} \mathrm{O}_{2}$ bildete diese einen unlöslichen, braunen Farbstoff s. Abb. 11 D, i) . Geschah diese Umsetzung in Beisein von Nickelammoniumsulfat, nahm der Niederschlag eine schwärzliche Färbung an und war so auch in geringeren Mengen leichter zu detektieren. Die enzymatische Färbung ist zwar komplizierter und somit auch fehleranfälliger als die Fluoreszenzfärbung, sie enthält allerdings einige signalverstärkende Schritte. So werden z.B. drei Enzymmoleküle an einen Zweitantikörper angelagert, die jeweils viele DAB Moleküle umsetzen können. Somit ist die enzymatische Färbung zur Detektion geringer Epitopkonzentrationen geeignet.

Bei der Fluoreszenzfärbung kamen Zweitantikörper zum Einsatz, die entweder an den rot fluoreszierenden $\mathrm{Cy} 3{ }^{\mathrm{TM}}$ Fluorofor oder an den grün fluoreszierenden Alexa488 gekoppelt waren (s. Abb. 11 D, ii) . Die Färbung mit fluoreszierenden Zweitantikörpern eignet sich gut für sogenannte Doppelfärbungen s. Abb. 11 D, iii). Hier werden gleichzeitig oder aufeinanderfolgend 
Erstantikörper gegen verschiedene Antigene eingesetzt, die in unterschiedlichen Erzeugertieren hergestellt wurden. Gegen die unterschiedlichen konstanten Regionen dieser Erstantikörper konnten nun an $\mathrm{Cy}^{\mathrm{TM}}$ (Dianova, Deutschland) oder an Alexa488 (Alexa, Niederlande) gekoppelte Zweitantikörper gerichtet werden. Addierte man die erhaltenen roten bzw. grünen Färbungen so erhielt man an Orten, an denen beide Epitope kolokalisiert waren, eine gelbe Färbung. Das Ergebnis der Färbungen wurde u.a. durch konfokale Laserscan-Mikroskopie sichtbar gemacht. Diese erlaubt durch ein entsprechendes Anregungs- und Detektionsverfahren dünne optische Sektionen durch das Präparat und minimiert so die Addition von Lichtsignalen aus nichtfokussierten Ebenen.

Immunohistochemische Färbungen können ebenso durch Elektronenbeschuß in der Elektronenmikroskopie detektiert werden. Auf diese Weise wird allgemein elektronendichtes Material erkannt. Da es sich bei dem DAB-Umsetzungsprodukt um ein solches handelt, können nach der oben beschriebenen Färbung die Lipidstrukturen der Zelle mit Osmium kontrastiert, das Gewebe in Polyharze wie Epoxid eingebettet und ultradünne Schnitte erstellt werden. Diese zeigen unter dem Elektronenmikroskop die Lokalisation angefärbter Strukturen auf der Ebene von Zellorganellen. Die elektronenmikroskopischen Studien wurden von Frau Monika Ochojski im Rahmen ihrer Dissertation durchgeführt.

\subsubsection{Eingesetzte Erst- und Zweitantikörper}

\section{Tabelle 3: Eingesetzte Erstantikörper}

\begin{tabular}{|c|c|c|c|}
\hline \multirow[b]{2}{*}{ Epitop } & \multirow[b]{2}{*}{ Erzeugertier } & \multicolumn{2}{|c|}{ EingesetzteVerdünnungen } \\
\hline & & $\begin{array}{l}\text { Färbung: } \\
\text { DAB-Umsatz }\end{array}$ & $\begin{array}{l}\text { Färbung: } \\
\text { Fluoreszenz }\end{array}$ \\
\hline $\mathrm{GABA}_{\mathrm{B}}-\mathrm{R} 1 \mathrm{a}$ und $\mathrm{b}$ (Chemicon) & Meerschwein & $1: 10.000$ & $1: 1.000$ \\
\hline GABA $_{B}-\mathrm{R} 2$ (Chemicon) & Meerschwein & $1: 1000$ & $1: 1.000$ \\
\hline $\mathrm{GABA}_{\mathrm{B}}-\mathrm{R} 1 \mathrm{~b}^{*}$ & Kaninchen & $1: 500$ & $\begin{array}{ll}------ \\
\end{array}$ \\
\hline CREB II (Santa-Cruz) & Kaninchen & $\begin{array}{l}------ \\
\end{array}$ & $1: 50$ \\
\hline
\end{tabular}

Tabelle 4: Eingesetzte Zweitantikörper

\begin{tabular}{l|l|l|c|c|c} 
Färbung & Epitop & Firma & Fluorofor & $\begin{array}{l}\text { Erzeuger- } \\
\text { tier }\end{array}$ & $\begin{array}{l}\text { Eingesetzte } \\
\text { Verdünnungen }\end{array}$ \\
\hline $\begin{array}{l}\text { DAB- } \\
\text { Umsatz }\end{array}$ & Meerschwein IgG & Vector & ------ & Ziege & $1: 200$ \\
\hline \hline Fluoreszenz & Meerschwein IgG & Dianova & CY3 & Ziege & $1: 250$ \\
\cline { 2 - 6 } & Kaninchen IgG & Molekular Probes & $\begin{array}{c}\text { Alexa } \\
488\end{array}$ & Ziege & $1: 100$
\end{tabular}

\subsubsection{Färbung mit Avidin-Biotin-gekoppeltem Zweitantikörper durch Umsetzung von Diaminobenzidin}

\section{Präparation}

Mäuse verschiedener Altersstufen (P0-P60) wurden mit Äther narkotisiert, der Brustkorb, die linke Herzkammer und die rechte Herzvorkammer eröffnet und eine Kanüle passenden Durchmessers in 
die aorta ascendens eingeführt. Die Tiere wurden mit einer 0.9\%iger NaCl-Lösung (s.u.) entblutet und mit Fixationslösung ca. 20 Minuten perfundiert. Die Flußgeschwindigkeit der Lösungen wurde über den hydrostatischen Druck reguliert. Das Gehirn wurde entnommen, 3-5 h in Fixierlösung, weitere $3 \mathrm{~h}$ in 10\% Saccharoselösung und für mindestens $12 \mathrm{~h}$ in 30\% Saccharoselösung zur Kryoprotektion inkubiert. In letzterer konnte das Gewebe bei $4^{\circ} \mathrm{C}$ bis zu 30 Tagen gelagert werden. Das Gewebe wurde auf einem Gefriermikrotom bei $-24^{\circ} \mathrm{C} \quad 20-40 \mu \mathrm{m}$ dick geschnitten und anschließend freischwimmend gefärbt.

Phosphatpuffer $(0.1 \mathrm{M}): 405 \mathrm{ml} 0.1 \mathrm{M} \mathrm{Na}_{2} \mathrm{HPO}_{4}$ wurden mit $95 \mathrm{ml} 0.1 \mathrm{M} \mathrm{NaH}_{2} \mathrm{PO}_{4}$ gemischt und ein $\mathrm{pH}$ von 7.4 mit $\mathrm{NaOH}$ eingestellt.

NaCl-Lösung: $\quad 0.9 \% \mathrm{NaCl}$ in $0.1 \mathrm{M}$ Phosphatpuffer

Fixationslösung: $\quad 4 \%$ Paraformaldehyd in $0.1 \mathrm{M}$ Phosphatpuffer

Saccharoselösung: $\quad 10 \%$ oder $30 \%$ Saccharose, $0.002 \%$ NaAcid in 0.1 M Phosphatpuffer

\section{DAB-Färbung}

Nach 15 minütigem Waschen in phosphatgepufferter Salzlösung (phosphate buffered saline, PBS) wurden die Schnitte zur Reduktion des restlichen Paraformaldehyds 15 Minuten in Reduktionslösung inkubiert. Nach zweimal 15-minütigem Waschen in PBS wurde die endogene Peroxidaseaktivität durch 30-minütige Inkubation in Phenylhydrazinlösung, die zur Absättigung der unspezifischen Proteinbindungen Ziegenserum enthielt, zerstört. Die Schnitte wurden direkt in die Erstantikörperlösung für $48 \mathrm{~h}$ bei $4^{\circ} \mathrm{C}$ überführt. Wiederum wurde 20 und 40 Minuten in $\boldsymbol{P B S}$ gespült, für 60 Minuten in 3\%iger Serumlösung in PBS überführt und über Nacht bei $4^{\circ} \mathrm{C}$ in Zweitantikörperlösung inkubiert.

Dann wurden nach 20- und 40-minütigem Waschen in $P B S$ und 60 minütiger Inkubation in 1\%iger Tween 20-Lösung in PBS die Schnitte 0.5-6 h in Avidin-Biotin-Komplex Lösung inkubiert. Eine längere Inkubationszeit intensivierte das Signal. Die Schnitte wurden nachfolgend 10, 20 und 30 Minuten in PBS und 15 Minuten in Vorinkubationslösung inkubiert und 2-5 Minuten in Inkubationslösung entwickelt bis eine genügend intensive Färbung sichtbar wurde. Die Reaktion wurde durch Überführung in eiskalte PBS gestoppt, die Schnitte weitere 10 und 20 Minuten in $\boldsymbol{P B S}$ gewaschen und auf gelatinebeschichtete Objektträger aufgezogen. Nach einer mindestens 40minütigem Trocknungphase wurden die Präparate in einer aufsteigenden Alkoholreihe (50\%, 80\%, 2x 99\% Äthanol; 2x Xylol) entwässert und unter DePeX-Kunstharz (Serva, Deutschland) mit Objektgläsern bedeckt. Alle Inkubationsschritte erfolgten, wenn nicht anders angegeben, bei Raumtemperatur unter milder Mischung.

Alle Materialien, die mit DAB in Berührung gekommen sind, müssen vor der Reinigung mehrere Tage in Bleichlauge eingelegt werden, da DAB in dem Verdacht steht, krebserregend zu sein. 
Phosphatgepufferte Salzlösung $140 \mathrm{mM} \mathrm{NaCl}, 3 \mathrm{mM} \mathrm{KCl}, 2 \mathrm{mM} \mathrm{NaH}_{2} \mathrm{PO}_{4}, 6 \mathrm{mM} \mathrm{Na}_{2} \mathrm{HPO}_{4}$; $\mathrm{pH}$

(phosphate buffered saline, PBS): 7.4

Reduktionslösung:

Phenylhydrazinlösung:

Erstantikörperlösung:

Zweitantikörperlösung:

Avidin-Biotin-Komplex Lösung:

Tris-Stammlösung:

Imidazol-Stammlösung:

Vorinkubationslösung:

Inkubationslösung:

\section{Bleichlauge:}

Zur Gelatine-Beschichtung der Wassergemisch von 2:3 gelöst.

$1 \% \mathrm{NaBH}_{4}$ in PBS

Phenylhydrazin (1:2000), 0.1\% Triton X-100, 3\% Ziegenserum in PBS

0.1\% Triton X-100, 3\% Ziegenserum, 0.1\% Natriumazid, 0.01\% Thimerosal in PBS mit entsprechender Konzentration des Erstantikörpers

Triton- und Ziegenserum-haltige (0.1 bzw 3\%ig) PBS wurde 50:1 mit 5\%iger Natriumazidlösung und 1:2000 mit entsprechendem Zweitantikörper gemischt.

Die Lösungen A und B des Elite Kits der Firma Vector 1:1000 (v/v), 1\%igem Tween 20, PBS

$500 \mathrm{mM}$ Tris(hydroxymethyl)aminomethan

$1 \mathrm{M}$ Imidazol in $\mathrm{H}_{2} \mathrm{O}$, pH 7.6

0.05\% 3,3'-Diaminobenzidin-tetrahydrochlorid (DAB), 1:10

Tris-Stammlösung, 1:100 Imidazol-Stammlösung in $\mathrm{H}_{2} \mathrm{O}$

$3 \mathrm{ml}$ Vorinkubationslösung, $180 \mu \mathrm{l}$ 5\% Ammoniumnickelsulfatlösung, die Reaktion durch Zugabe von $1.5 \mu 1$ 30\%igem $\mathrm{H}_{2} \mathrm{O}_{2}$ gestartet.

1:100 Natriumhypochloritlösung (ca. $12 \% \mathrm{Cl}^{-}$aktiv) in $\mathrm{H}_{2} \mathrm{O}$ Objektträger wurden $0.5 \%$ Gelatine in einem Isopropanol-

\subsubsection{Färbung durch Markierung mit fluoreszenzgekoppelten Zweitantikörpern}

Anfärbung des $G A B A_{B}$-Rezeptors in fixiertem Hirngewebe

Die Gewebeschnitte werden wie unter 3.3.2. beschrieben erstellt. Nach dreimal 15-minütigem Waschen in Tris-Saline Puffer wurden die Schnitte über Nacht bei $4^{\circ} \mathrm{C}$ in Erstantikörperlösung inkubiert. Wiederum wurde nachfolgend dreimal 15 Minuten in Tris-Saline Puffer gewaschen und für 30 Minuten in Zweitantikörperlösung überführt. Nach erneut dreimal 15 Minuten in Tris-Saline Puffer wurden die Schnitte auf gelantinebeschichtete Objektträger überführt, luftgetrocknet und in Histosave (Camon, Deutschland) eingedeckt. Alle Inkubationsschritte erfolgten, wenn nicht anders angegeben, bei Raumtemperatur unter milder Mischung. Die Detektion der Fluoreszenz erfolgte für $\mathrm{Cy}^{\mathrm{TM}}$ gkoppelte Zweitantikörper bei einer Anregungswellenkänge von $554 \mathrm{~nm}$ und einer Emissionwellenlänge von 568 bis 574 nm, für Alexa488 gekoppelte entsprechend bei 488 bzw 515 $\mathrm{nm}$. 
Tris-Saline Puffer: $\quad 50 \mathrm{mM}$ Tris(hydroxymethyl)aminomethan, $7.38 \mathrm{~g} / \mathrm{l} \mathrm{NaCl}$ in $\mathrm{H}_{2} \mathrm{O}, \mathrm{pH} 7.4$

Erstantikörperlösung: $\quad 2 \%$ Ziegenserum, $0.1 \%$ Triton X-100, in Tris-Saline Puffer mit entsprechender Erstantikörperkonzentration. Bei einer Doppelfärbung kamen zwei Erstantikörper gleichzeitig zum Einsatz.

Zweitantikörperlösung: $2 \%$ Ziegenserum, $\quad 0.1 \%$ Triton X-100 in Tris-Saline Puffer mit entsprechender Zweitantikörperkonzentration. Bei einer Doppelfärbung kamen zwei Zweitantikörper gleichzeitig zum Einsatz.

Doppelfärbung des $G A B A_{B}$-Rezeptors in primären Zellkulturen von hippocampalen Neuronen Mäuse im Alter von zwei Tagen (P2) wurden dekapitiert und in eisgekühltem $\boldsymbol{P B S}$ die Hippocampi präpariert. Hippocampusgewebe mehrerer Mäuse wurde in $0.5 \mathrm{ml}$ vorgewärmten Trypsin-EDTA Puffer (Gibco, Deutschland) 25 Minuten bei $37^{\circ} \mathrm{C}$ inkubiert und anschließend abzentrifugiert (1000xg, 10 Minuten). Das Pellet wurde in $0.5 \mathrm{ml}$ komplettem DMEM (Dulbecco's modifiziertes Eagle's Medium) resuspendiert und trituriert. Die so entstandene Zellsuspension wurde mit komplettem DMEM auf $0.5 \times 10^{6}$ Zellen pro ml verdünnt, auf collagenbeschichteten Objektgläschen ausplattiert und über Nacht bei $37^{\circ} \mathrm{C}$ unter $5 \% \mathrm{CO}_{2}$-haltiger Atmosphäre inkubiert. Danach wurde der Überstand durch $2 \mu \mathrm{M}$ Cytosin-b-D-Arabinose enthaltendes komplettes DMEM ersetzt, um die Proliferation von Gliazellen zu unterbinden. Für die Färbungen wurden zehn Tage alte Kulturen verwendet.

Auf Objektgläschen kultivierte Hippocampuszellen wurden mit Fixationslösung für 15 Minuten fixiert und 3 mal in $\boldsymbol{P B S}$ gewaschen. Zum Entfernen restlichen Paraformaldehyds wurden die Gläschen für 15 Minuten in Glycin-haltige PBS (50 mM) überführt und zu Permeabilisierung der Zellmembranen 5 Minuten in mit 0.1\% mit Triton $X-100$ versetztem PBS inkubiert. Nach einer weiteren Stunde Inkubation in einer beide Erstantikörper enthaltenden Lösung wurde 3 mal 5 Minuten mit PBS gewaschen. Danach wurde in den beiden Zweitantikörper enthaltende Lösungen sukzessive 1 Stunde inkubiert und wiederum wie oben gewaschen. Die Präparate wurden in 90\%iger Glycerinlösung eingedeckt und durch konfokale Laserscan-Mikroskopie mit entsprechenden Anregungs- und Emisionswellenlängen analysiert.

$\underline{D M E M}$

Komplettiertes DMEM

Fixationslösung
Dulbecco's modifiziertes Eagle's Medium

DMEM mit 10\% Pferdeserum, $50 \mu \mathrm{g} / \mathrm{ml}$ Penicillin/StreptomycinLösung

4\% Paraformaldehyd in 0.1 M Phosphatpuffer 


\section{Erstantikörperlösung}

$\underline{\text { Zweitantikörperlösungen }}$

90\% Glycerinlösung
2\% Rinderserumalbumin, GABA $\mathrm{B}_{\mathrm{B}} \mathrm{R} \mathrm{a} / \mathrm{b}$ Erstantikörper 1:5000, ATF4 Erstantikörper 1:500, in PBS

a) 2\% Rinderserumalbumin, AlexaFluor 488 Ziege gegen Kaninchen IgG (Alexa, Niederlande), in PBS

b) $2 \%$ Rinderserumalbumin, $\mathrm{Cy}^{\mathrm{TM}}-3$ Ziege gegen Meerschweinchen IgG (Dianova, Deutschland), in PBS $90 \%$ (v/v) Glycerin in $\mathrm{H}_{2} \mathrm{O}$

\subsection{Molekularbiologische Methoden}

\subsubsection{Immunopräzipitation}

Wie oben beschrieben ermöglicht die Immunohistochemie durch die Technik der Doppelfärbung eine Detektion kolokalisierter Proteine. Über eine funktionelle Interaktion von Proteinen untereinander trifft jedoch die Methode der Ko-Immunopräzipitation eine genauere Aussage. In der Ko-Immunopräzipitation können intrazelluläre Proteinkomplexe direkt nachgewiesen werden. Dazu findet die Antikörper-Epitopbindung nicht in einem fixierten Gewebe, sondern in einem flüssigen Gewebelysat statt. Um dieses Lysat zu erhalten, wird Gewebe zuerst mechanisch zerkleinert und dann mit Hilfe von Detergenzien alle Lipidmembranen der Zelle solubilisiert. An die sich nun frei in Lösung befindlichen Zell- und Membranpolypeptide s. Abb. 12 A können die Antikörper spezifisch binden s. Abb. 12 B. Diese werden wiederum von dem nachfolgend zugesetzten Protein A (Sigma) erkannt, daß sich spezifisch an die schweren Ketten von Immunoglobulinen anlagert (s. Abb. 12 C). Das Protein A ist chemisch an eine Sepharose-Matrix gekoppelt, die seine Ausfällung durch Zentrifugation ermöglicht. Bei dieser Ausfällung werden Protein A-Erstantikörper-AntigenKomplexe pelletiert. Zusätzlich befinden sich in der gefällten Fraktion allerdings alle weiteren Zellkomponenten, die sich mit dem Antigen zu einem Komplex zusammenbinden. Das Ziel der KoImmunopräzipitation ist es, diese Polypeptide $\mathrm{zu}$ detektieren und so einen Hinweis auf die Bindungspartner eines bestimmten Antigens zu erhalten. Um dies $\mathrm{zu}$ erreichen, werden die ausgefällten Komplexe aufgetrennt $\mathrm{s}$. Abb. 12 D und die enthaltenen Proteine mit Natriumdodecylsulfat (Sodium $\underline{\text { Sodecyls }}$ ulfate, SDS) gesättigt. SDS ist ein zweifach negativ geladenes, lösliches Detergenz, das sich in stöchiometrischem Verhältnis an Aminosäureketten anlagert. Es bewirkt gleichzeitig ihre Denaturierung und überlagert ihre von dem pH-Wert der Umgebung abhängige Eigenladung. Die SDS-Proteinlösung wird auf ein Polyacrylamidgel aufgetragen und einem elektrischen Feld ausgesetzt, indem sich die Proteine entsprechend ihrer Größe aufteilen. In dieser Arbeit wurden Polyacrylamidgele verwendet (SDS-PAGE), deren Vernetzungsgrad steuerbar und somit für die Auftrennung verschieden großer Proteine optimierbar ist. 


\section{A $\quad$ B $\quad$ C}

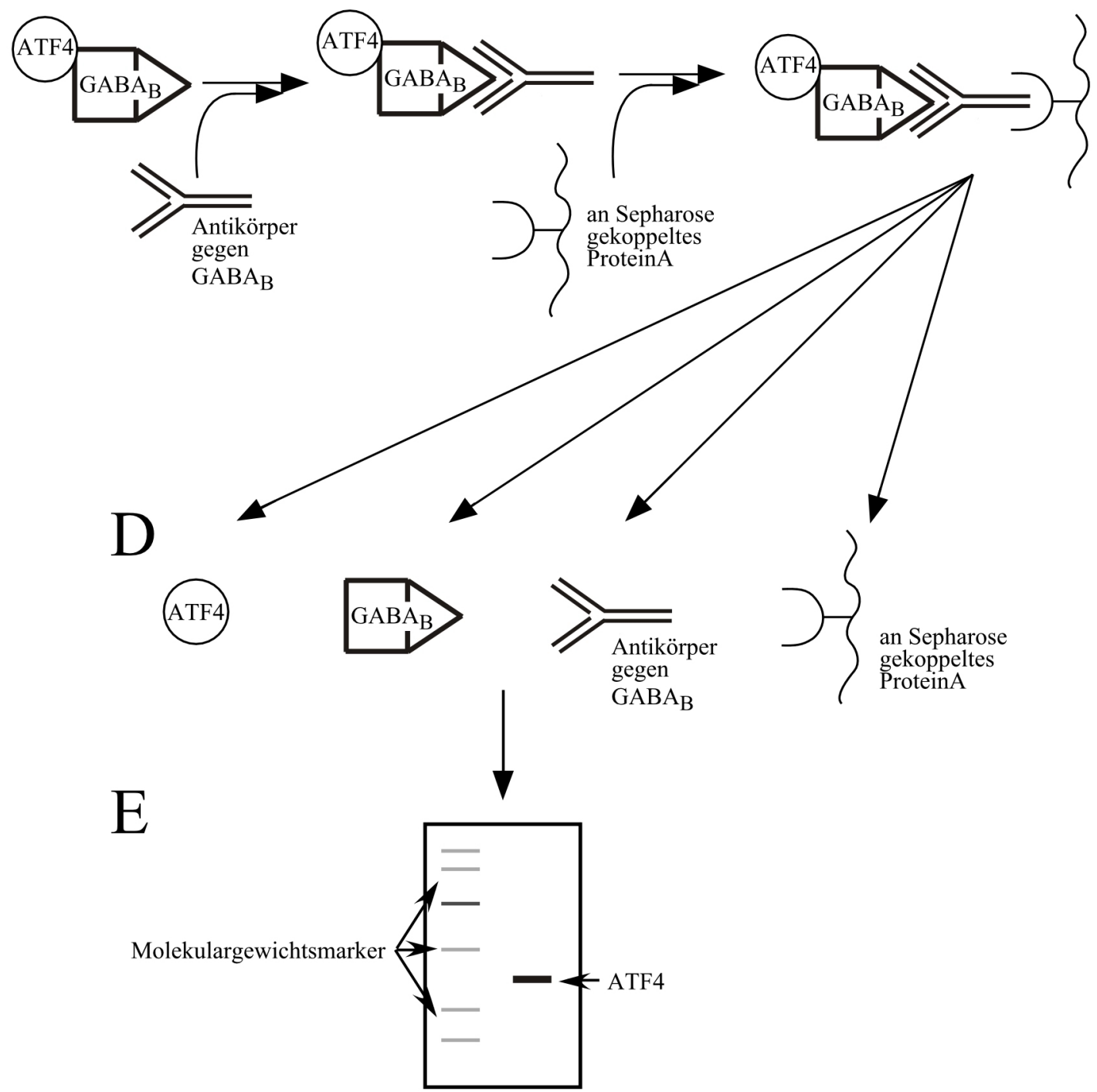

Abb. 12. Ablauf einer Immunopräzipitation. A: Im Zellysat befindet sich gelöstes $G_{A B A}$-Rezeptor-Protein und eventuell daran gebundenes ATF4. B: Der $\mathrm{GABA}_{\mathrm{B}}$-Rezeptor wird durch entsprechend zugegebenen Antikörper gebunden. C: Dieser wird wiederum von zugesetztem, an Sepharose-Matrix gekoppelten ProteinA gebunden. D: Die gebildeten Komplexe fallen aus, werden von noch in Lösung befindlichen abgetrennt und ihre Bindung gespalten. E: Die gefällten Proteine werden auf einem Polyacrylamidgel nach ihrer Größe aufgetrennt und auf eine Nitrozellulose-membran geblottet. ATF4 wird mit entsprechendem Antikörper detektiert.

Die durch SDS-PAGE aufgetrennten Proteine werden mit Hilfe der Western-Blott-Technik detektiert. Hier werden sie in einem elektrischen Feld auf eine Nitrozellulose-Membran überführt. Danach werden sie durch Anlagerung eines epitopspezifischen Erst- und einem mit einem Detektionssystem versehenen Zweitantikörper markiert. In dieser Arbeit wurde als Detektionssystem ein Enzym namens Meerrettich-Peroxidase verwendet. Es erzeugt durch Umsetzung entsprechend zugegebener Substanzen Chemilumineszenz. Diese wird durch einen strahlungssensitiven Fotofilm detektiert s. Abb. 12 E. 
Die Versuche unter Verwendung der Ko-Immunopräzipitation wurden unter Anleitung von Herrn Dr. Ponimaskin, Abteilung Neuro- und Sinnesphysiologie, Physiologisches Institut, Universität Göttingen, durchgeführt.

\section{Erstellung und Vorklärung der Zellysate}

Mit Äther betäubte Mäuse wurden dekapitiert und das Gehirn und in einigen Versuchen ebenfalls die Leber und das Herz in eisgekühltem, carbogenäquilibrierter $\boldsymbol{A C S F}$ entnommen. Das entnommene Gewebe wurde dreimal 15 Minuten lang in begaster, gekühlter $\boldsymbol{A C S F}$ gewaschen, zerschnitten und in ca $0.5 \mathrm{ml} \boldsymbol{A C S F}$ mechanisch mit einem Teflonmörser homogenisiert. Die Proben wurden mit entsprechender Menge doppelt konzentriertem Ripa-Puffer versetzt und unter gelegentlichem Mischen 20 Minuten auf Eis inkubiert. Nicht gelöste Gewebereste wurden abzentrifugiert (10 Minuten, 13000xg) und der Überstand weiter verwendet.

Sollten aus kultivierten Hippocampuszellen Lysate hergestellt werden, so wurde zunächst das Kulturmedium vorsichtig abgenommen und zweimal 15 Minuten lang mit PBS gewaschen. Schließlich wurden die Zellen mechanisch durch Überspülen und Aufsaugen mit PBS vom Schalenboden gelöst und die Suspension mit gleichem Volumen doppelt konzentriertem RipaPuffer versetzt. Nach 15-minütiger Inkubation auf Eis wurden die Zellreste durch Zentrifugation entfernt (10 Minuten, 13000xg).

Um unspezifische Wechselwirkungen mit Protein A zu vermeiden, wurden je $600 \mu 1$ der aus kultivierten Zellen oder Gewebe erstellten Lysate $200 \mu \mathrm{lmit}$ 5\% Präimmunserum vorinkubierte Protein A Suspension (Sigma) zugesetzt und 30 Minuten inkubiert. Das an die Polymermatrix gebundene ProteinA wurde danach durch Zentrifugation (10', 13000xg) pelletiert und verworfen.

\section{\begin{tabular}{ll} 
ACSF: & s. 2.2.1. Tabelle 2 \\
\hline
\end{tabular}}

RIPA-Puffer: $\quad 1 \%$ Triton X-100, 1\% Natrium-Desoxycholat, 0.1\% Natrium-dodecyl-sulfat (SDS), $0.15 \mathrm{M} \mathrm{NaCl}, 20 \mathrm{mM}$ Tris, $10 \mathrm{mM}$ EDTA, $1 \mathrm{mM}$ Phenylmethylsulfoylfluorid (PMSF), 10 mM Jodacetamid in $\mathrm{H}_{2} \mathrm{O}, \mathrm{pH} 7,4$

\section{Komplexfällung}

$\mathrm{Zu} 600 \mu \mathrm{l}$ des vorgeklärten Zellysates wurde nun der gewünschte Antikörper in gewünschter Konzentration s. Tabelle 5 gegeben und über Nacht unter gründlicher Mischungen bei $4^{\circ} \mathrm{C}$ inkubiert. Danach wurde jede Probe mit suspendierter $20 \mu 1$ Sepharose-ProteinA-Matrix versetzt und 2 Stunden unter Mischung inkubiert. Die ausgefällten Protein-Sepharose Komplexe wurde durch 2 minütiges Zentrifugieren bei 6500xg sedimentiert und der Überstand zum großen Teil abgenommen. Die Proben wurden mit $700 \mu 1$ Ripa-Puffer (s.o.) versetzt und gründlich gemischt. Dieser Waschvorgang wurde einmal wiederholt und beim dritten Mal wurde der Überstand nach der Zentrifugation bis auf $20 \mu \mathrm{l}$ abgenommen. 
Tabelle 5: Erstantikörperkonzentrationen bei der Ko-Immunopräzipitation

\begin{tabular}{l|l|l} 
Epitop (Firma) & Erzeugertier & Eingesetzte Verdünnungen \\
\hline $\begin{array}{l}\text { GABA } \\
\text { (Chemicon) }\end{array}$ & Meerschwein & $1: 1200$ \\
\hline $\begin{array}{l}\text { GABA } \\
\text { (Chemicon) }\end{array}$ & Meerschwein & $1: 1000$ \\
\hline $\begin{array}{l}\text { CREB II } \\
\text { (Santa-Cruz) }\end{array}$ & Kaninchen & $1: 100$
\end{tabular}

\section{Proteinauftrennung}

Die ausgefällten Proteinkomplexe wurden in $20 \mu \mathrm{l}$ Restüberstand gelöst, mit $10 \mu 1$ 3xkonzentriertem, nicht reduzierendem Probenpuffer versetzt und für 3 Minuten auf $100^{\circ} \mathrm{C}$ erhitzt. Nach Klärung der Lösungen durch Zentrifugation konnten die Proben entweder sofort auf ein Polyacrylamidgel aufgetragen oder zunächst zum Reduzieren von Cysteinbindungen mit 10\% Mercaptoethanol versetzt, abermals gekocht und abzentrifugiert werden. Bei den Polyacrylamidgelen handelte es sich um SDS-haltige, 10 oder 7,5\%ige Trenngele, die mit einem 5\%igem Sammelgel mit pH-Gradient von 2 pH-Punkten überschichtet waren. Die Proben wurden bei $80 \mathrm{~V}$ und maximal $400 \mathrm{~mA}$ und $10 \mathrm{~W}$ in Laufpuffer aufgetrennt.

10\%iges Trenngel $\quad$ Puffer (4x): 60.5 g/l Tris-HCl, 4 g/l SDS, pH 8.8 in $\mathrm{H}_{2} \mathrm{O}$

Stammlösung: $30 \mathrm{ml} \mathrm{30 \% AA/0.8 \% Bis,} 18.75$ Puffer (4x), $26.25 \mathrm{ml} \mathrm{H}_{2} \mathrm{O}$

Gellösung: $2.5 \mathrm{ml}$ Stammlösung, $4 \quad \mu \mathrm{l}$ TEMED, $20 \quad \mu 1 \quad$ 10\%iges Ammoniumpersulfat

5\%iges Sammelgel: $\quad$ Puffer (4x): 60.5 g/1 Tris-HCl, 4 g/l SDS, pH 6.8 in $\mathrm{H}_{2} \mathrm{O}$

Stammlösung: $7.8 \mathrm{ml}$ 30\%AA/0.8\%Bis, $15 \mathrm{ml} \mathrm{Puffer} \mathrm{(4x),} 36.6 \mathrm{ml} \mathrm{H} \mathrm{H}_{2} \mathrm{O}$

Gellösung: $2.5 \mathrm{ml}$ Stammlösung, $4 \quad \mu \mathrm{l}$ TEMED, $20 \quad \mu 1 \quad 10 \%$ iges Ammoniumpersulfat

Probenpuffer (nicht $62.5 \mathrm{mM}$ Tris- $\mathrm{HCl}, 20 \%$ Glyzerin, 6\% SDS, ca. 0.01\% Bromphynolblau in $\mathrm{H}_{2} \mathrm{O}$, reduzierend): pH6.8

Probenpuffer $62.5 \mathrm{mM}$ Tris-HCl, 20\% Glyzerin, 6\% SDS, 10\% Mercaptoethanol, ca. 0.01\% (reduzierend): Bromphynolblau in $\mathrm{H}_{2} \mathrm{O}$, pH6.8

Laufpuffer: 3.02 g/1 Tris-HCl, 14.4 g/l Glyzin, 1 g/l SDS in $\mathrm{H}_{2} \mathrm{O}$, pH 8.5

Western-Blot

Das Polyacrylamidgel und die Blot-Membran (Hybond-P, Amersham, Germany) wurden zuerst für 15 Minuten in Transferpuffer äquilibriert. Zwischen einem Stapel aus mit Transferpuffer befeuchteten Filterpapieren wurde die Blot-Membran zur Anode, das aufgelegte Polyacrylamidgel zur Kathode der Western-Blot-Apparatur orientiert und die Proteine bei 12 bis 14 V, 400 mA und $10 \mathrm{~W}$ (ca $5 \mathrm{~mA}$ pro $\mathrm{cm}^{2}$ ) für 12 bis 14 Stunden auf die Blot-Membran überführt. 
Transferpuffer: $\quad$ Stammlösung: 30.2 g/1 Tris-HCl, 144 g/l Glyzin, 5 g/l SDS in $\mathrm{H}_{2} \mathrm{O}$

Gebrauchslösung: 10\% Stammlösung, 20\% Methanol in $\mathrm{H}_{2} \mathrm{O}$

Meerrettich-Peroxidase Detektion

Nachdem zunächst unspezifische Protein-Bindungen durch $1 \mathrm{~h}$ Inkubation in Blocking-Lösung abgesättigt worden waren, wurde die Blot-Membran einmal 15 und zweimal 5 Minuten in PBS/Tween gewaschen und für 1 Stunde in Erstantikörperlösung inkubiert, danach gewaschen und für 20-30 Minuten in Zweitantikörperlösung überführt. Nach gründlichem Waschen mit PBS/Tween wurde für 1 Minute mit einer 1:1 Mischung der Entwicklungskomponenten des ECL Western-blot Systems der Firma Amersham (Germany) inkubiert und nach Entfernung der Flüssigkeit die Chemilumineszenz der Meerrettichperoxidasereaktion auf lichtempfindlichen Röntgen-Filmen (Kodak, Sigma) nachgewiesen. Die Quantifikation der Signalbanden wurde mit Hilfe des AGFA Scanners SnapScan1236 und des Gel-Pro Analyzer Version 3.1 Programmes ausgeführt.

PBS/Tween: $\quad 0.05 \%$ Tween in PBS

Blocking-Lösung: $\quad 2 \mathrm{M} \%$ lyophylisiertes Rinderserum in PBS/Tween

Erstantikörperlösung: 1:1000 für Antikörper gegen CREB2, 1:10000 gegen $\mathrm{GABA}_{\mathrm{B}} \mathrm{R} 1 \mathrm{a} / \mathrm{b}$ und $\mathrm{GABA}_{\mathrm{B}} \mathrm{R} 2$ in PBS/Tween

Zweitantikörperlösung: 1:1000 Meerrettichperoxidase-gekoppelten Antikörper gegen die konstante Region des verwendeten Erstantikörpers in PBS/Tween 


\section{ERGEBNISSE}

\subsection{GABA moduliert die rhythmische Aktivität des respiratorischen Netzwerkes der Maus ab der Geburt}

\subsubsection{Endogen erhöhtes GABA reduziert die Frequenz des respiratorischen Rhythmus}

Um die Frage zu beantworten, ab welchem Alter endogen aktivierte GABA-Rezeptoren bei der Modulation der respiratorischen Aktivität von NMRI Mäusen eine funktionelle Rolle spielen, wurden rhythmisch aktive Hirnstammschnitte von Mäusen zwischen P0-15 (Tag der Geburt bis postnataler Tag 15) mit Nipekotinsäure inkubiert. Nipekotinsäure gehört zu den GABATransporterblockern, die die Wiederaufnahme von GABA aus dem synaptischen Spalt reduzieren (Krogsgaard-Larsen et al., 1997). Die Applikation dieser Drogen bewirkt eine Akkumulation von endogen freigesetztem GABA, speziell an GABAergen Synapsen. Anders als bei der systemischen Applikation von GABA wird auf diese Weise in erster Linie die Wirkung der Rezeptoren verstärkt, die auch unter physiologischen Bedingungen durch GABA-Freisetzung aktiviert werden. Die Aktivierung endogen nicht aktiver Rezeptoren wird minimiert. Es wurden fünf unterschiedliche Konzentrationen von Nipekotinsäure getestet $(0.25 ; 0.5 ; 0.75 ; 1$ und $2 \mathrm{mM})$ und die Frequenz der extrazellulär abgeleiteten Aktivität des zwölften Hirnnerven nach jeweils 10-minütiger Inkubation dokumentiert.

Es zeigte sich, daß die Akkumulation von endogen ausgeschüttetem GABA sowohl perinatal (P0-3) als auch in älteren Tieren (P7-15) zu einer Reduktion des Atemrhythmus führte s. Abb. 13, A, C. Diese war abhängig von der Nipekotinsäurekonzentration und in älteren Tieren (P7-15) ausgeprägter als in jüngeren (P0-3). In Präparationen aus P0-3 Mäusen (n=12) wurde ab einer Drogenkonzentration von $0.5 \mathrm{mM}$ eine signifikante Frequenzreduktion beobachtet. Die Frequenz wurde auf $70.1 \pm 3.32 \%$ des Kontrollwertes bei $0.5 \mathrm{mM}$, auf $60.7 \pm 3.03 \%$ bei $0.75 \mathrm{mM}$, auf $50.4 \pm 2.63 \%$ bei $1 \mathrm{mM}$ und auf $25.6 \pm 3.32 \%$ bei $2 \mathrm{mM}$ Nipekotinsäure reduziert.

Bei Tieren zwischen P7-15 $(\mathrm{n}=10)$ erzielten bereits $0.25 \mathrm{mM}$ Nipekotinsäure eine signifikante Reduktion der rhythmischen Frequenz. Sie wurde auf 75.0 $\pm 4.74 \%$ des Kontrollwertes bei $0.25 \mathrm{mM}$, auf $65.0 \pm 3.16 \%$ bei $0.5 \mathrm{mM}$, auf $45.4 \pm 2.47 \%$ bei $0.75 \mathrm{mM}$, auf $22.3 \pm 3.2 \%$ bei $1 \mathrm{mM}$ und auf $20.8 \pm 2.56 \%$ bei $2 \mathrm{mM}$ Nipekotinsäure reduziert. Es ist erwähnenswert, daß auch eine ausgedehnte Inkubationszeit (120 Minuten, $\mathrm{n}=15)$ in keinem der durchgeführten Experimente $\mathrm{zu}$ einer vollständigen Blockade der respiratorischen Aktivität führte. Der durch Nipekotinsäure erzielte Effekt war stets reversibel nach entsprechender Auswaschzeit (30-60 Minuten) mit Kontrollösung s. Abb. 13, B, C).(In Kooperation, Zhang et al., 2001). 


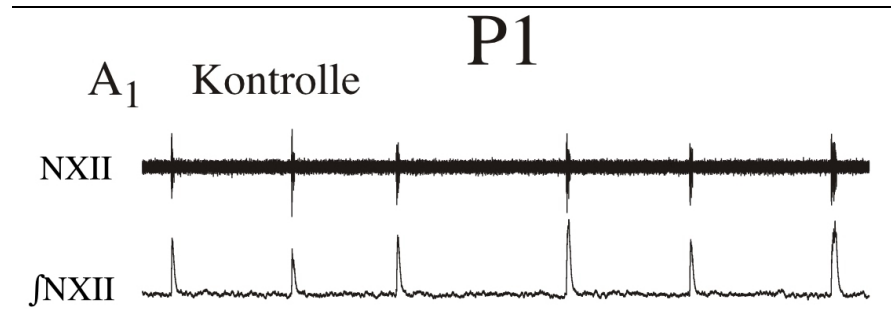

$\mathrm{B}_{1} \quad$ Kontrolle
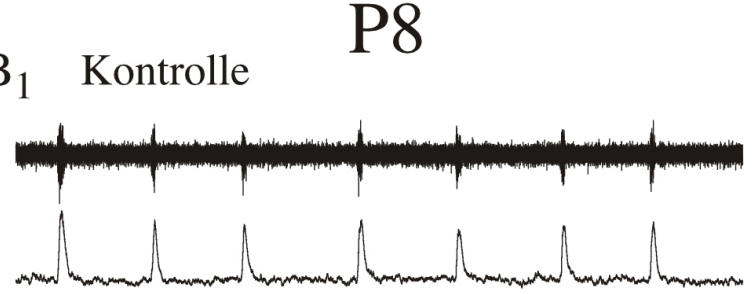

$\mathrm{A}_{2} 1 \mathrm{mM}$ Nipekotinsäure

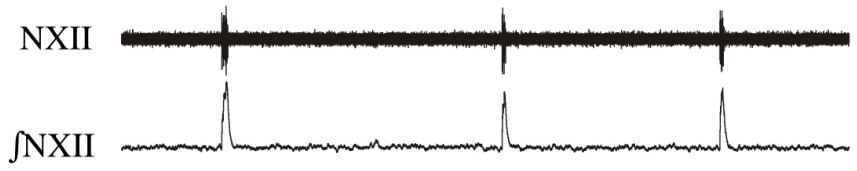

$\mathrm{B}_{2} 1 \mathrm{mM}$ Nipekotinsäure

$\mathrm{A}_{3} \quad 1 \mathrm{mM}$ Nipekotinsäure + 40 nM CGP

$\mathrm{B}_{3} 1 \mathrm{mM}$ Nipekotinsäure + 40 nM CGP
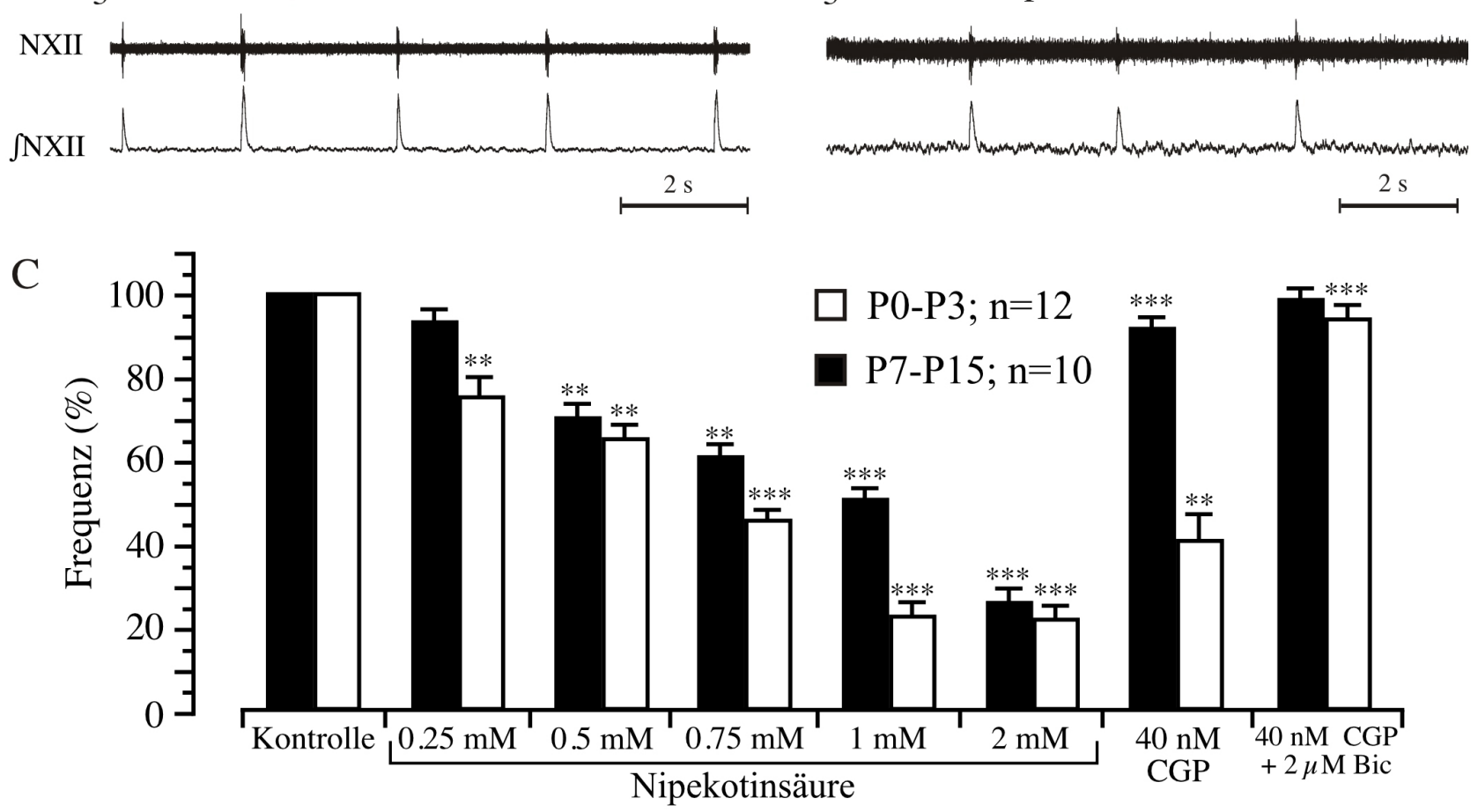

Abb. 13. Endogen freigesetztes GABA reduziert die Frequenz des respiratorischen Rhythmus in jedem untersuchten Alter (P0-15). A: $1 \mathrm{mM}$ Nipekotinsäure reduziert die respiratorische Frequenz einen Tag nach der Geburt (P1). Dieser Effekt kann durch Blockade der GABA $_{\mathrm{B}}$-Rezeptoren mit 40 nM CGP 55845A fast vollständig aufgehoben werden. B: Bei derselben Versuchsdurchführung erhöht CGP die Frequenz bei P8 Tieren nur geringfügig. C: Relativ zum Kontrollwert veränderte Frequenz unter Zugabe unterschiedlicher Nipekotinsäurekonzentrationen. Die in jedem Alter stattfindende Reduktion kann bei Tieren zwischen P0-3 durch Blockade der GABA B -Rezeptoren, bei Tieren zwischen P7-15 nur bei zusätzlicher Blockade der $\mathrm{GABA}_{\mathrm{A}}$-Rezeptoren durch $2 \mu \mathrm{M}$ Bicucullin aufgehoben werden.

Diese Versuche zeigen, daß GABA von Geburt an eine funktionelle Rolle im respiratorischen Netzwerk spielt. Für sich genommen lassen diese Ergebnisse allerdings noch keinerlei Schlüsse darauf zu, von welchem der GABA Rezeptoren diese Reduktion vermittelt wird.

\subsubsection{Endogenes GABA aktiviert hauptsächlich GABA $_{B}$-Rezeptoren in der perinatalen und $\mathrm{GABA}_{\mathrm{A}^{-}}$und $\mathrm{GABA}_{\mathrm{B}}$-Rezeptoren in der spätpostnatalen Phase}

Die Frage, durch welchen Rezeptor endogen akkumuliertes GABA die Reduktion des Atemrhytmus bewirkt, sollte durch spezifische Rezeptorantagonisten geklärt werden. Zur Blockade des $\mathrm{GABA}_{\mathrm{A}^{-}}$

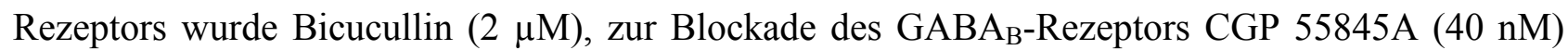
eingesetzt. 
Wie unter 3.1.1. beschrieben, reduzierte ein erhöhter GABA Gehalt an GABAergen Synapsen die Frequenz der rhythmischen Aktivität in allen untersuchten postnatalen Stadien. Bei dem Versuch, diesen Effekt durch Blockade der GABA-Rezeptoren rückgängig zu machen, zeigten sich allerdings entwicklungsbedingte Unterschiede. Nach der Inkubation mit $2 \mathrm{mM}$ Nipekotinsäure (Frequenz auf $25.6 \pm 3.32 \%$ des Kontrollwertes reduziert) bewirkte in Mäusen zwischen P0-3 der GABA $\mathrm{B}^{-}$ Rezeptor Antagonist CGP 55845A (40 nM) eine fast vollständige Aufhebung (98.5 $\pm 2.6 \%$ ) des Nipekotinsäureeffektes s. Abb. 13, C). Eine zusätzliche Blockade des GABA - Rezeptors durch 2 $\mu \mathrm{M}$ Bicucullin resultierte in keinem signifikanten Anstieg der rhythmischen Frequenz. Eine Applikation der Drogen in umgekehrter Reihenfolge erzielten die gleiche Ergebnisse $(n=5)$. Im Gegensatz dazu erhöhte sich in älteren Tieren die Frequenz der Aktivität bei Badapplikation von 40 nM CGP 55845A nur geringfügig (von 20.8 $22.56 \% \mathrm{zu} 40.5 \pm 6.32 \%$ ), während sie durch $2 \mu \mathrm{M}$ Bicucullin nahezu auf den Ausgangswert vor der Einwirkung von Nipekotinsäure angehoben werden konnte (93.8 \pm 3.29 s. Abb. 13, C).

Dieses Resultat spricht dafür, daß der $\mathrm{GABA}_{\mathrm{B}}$-Rezeptor eine dominante Rolle in der Modulation des respiratorischen Rhythmus während der perinatalen Phase einnimmt, welche später vom $\mathrm{GABA}_{\mathrm{A}}$-Rezeptor übernommen wird.

\subsection{GABA $A_{A}$-Rezeptoren vermitteln perinatal eine chloridgetragene Depolarisation}

Die bisher dargestellten Ergebnisse zeigen, daß GABA eine altersabhängige Wirkung auf die Aktivität neuronaler Netzwerke wie dem respiratorischen System der Maus ausübt. Im Folgenden soll geklärt werden, ob die perinatal noch wenig ausgeprägte $\mathrm{GABA}_{\mathrm{A}}$-Rezeptor vermittelte Reduktion des respiratorischen Rhythmus auf Änderungen der Rezeptorfunktion auf zellulärem Niveau zurückzuführen ist.

Hierzu wurde eine Analyse der $\mathrm{GABA}_{\mathrm{A}}$-Rezeptor vermittelten Ströme über die postsynaptische

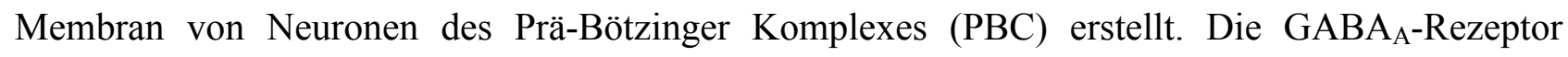
vermittelten Potentialänderungen wurden in der Gramicidin-peforierten patch clamp Technik im current clamp Modus elektrophysiologisch untersucht. Auf diese Weise blieb der $\mathrm{Cl}^{-}$-Gehalt der Zelle während der Ableitung unverändert. Die Neurone wurden aufgrund ihrer Lage, ihrer Form und der zeitlichen Koinzidenz ihrer bursts zu denen des extrazellulär abgeleiteten N. hypoglossus als inspiratorische Neurone identifiziert. Das Membranpotential in den Ruhephasen zwischen den bursts lag bei Mäusen zwischen P0-10 im Durchschnitt bei 56.1 $\pm 5.1 \mathrm{mV}(\mathrm{n}=26)$. Bei diesen Werten wurde das liquid junction potential der Gramicidin-haltigen Pipettenlösung berücksichtigt (s. Methoden. 
Wurde auf ein PBC Neuron einer neonatalen Maus (zwischen P0 und P3) lokal $100 \mu \mathrm{M}$ Muscimollösung druckappliziert, so zeigte sich nicht die erwartete Hyperpolarisation, sondern eine Membrandepolarisation $(\mathrm{n}=5)$. Diese Depolarisation führte $\mathrm{zu}$ einem verlängerten, vom Atemrhythmus unabhängigen burst s. Abb. 14 B. Um die Eigenschaften dieser GABA A $^{-R e z e p t o r-}$ vermittelten Depolarisation und ihre Veränderung während der ersten zwei postnatalen Wochen zu untersuchen wurden 26 PBC Neurone von Mäusen zwischen P0 und P15 getestet.

Zunächst wurden, um das Äquilibriumpotential $\mathrm{GABA}_{\mathrm{A}}$-Rezeptor-vermittelter Ströme ( $\mathrm{E}_{\mathrm{GABA}-\mathrm{A}}$ ) ermitteln zu können, den Neuronen durch entsprechende DC-Ströme unterschiedliche Membranpotentiale vorgegeben. Durch lokale Druckapplikation von $100 \mu \mathrm{M}$ Muscimol in ACSF wurden die $\mathrm{GABA}_{\mathrm{A}}$-Rezeptoren aktiviert und die resultierenden Membranpotentialveränderungen dokumentiert. Die Druckapplikationselektrode wurde hierbei so positioniert, daß kein Druckartefakt erkennbar war. Es zeigte sich, daß der $\mathrm{GABA}_{\mathrm{A}}$-Rezeptor-vermittelte Effekt auf das Membranpotential von PBC Neuronen altersabhängig ist. Während bei P1 Mäusen Muscimolapplikation bei einem Membranpotential von $-40 \mathrm{mV}$ eine geringfügige Hyperpolarisation auslöste, wurden diese bei negativeren Membranpotentialen wie -70 bzw -100 $\mathrm{mV}$ depolarisiert (s. Abb 15 A). Schon bei vier Tage alten Tieren zeigte sich ein deutlich anderes Bild. Hier bewirkte eine Aktivierung der $\mathrm{GABA}_{\mathrm{A}}$-Rezeptoren eine Hyperpolarisation bei einem vorgebebenen Potential von $-40 \mathrm{mV}$, während sich bei $-70 \mathrm{mV}$ lediglich eine Reduktion in der Amplitude der spontan ausgelösten PSP zeigte. Bei $-100 \mathrm{mV}$ war eine deutliche Depolarisation zu

\section{A) Kontrolle}

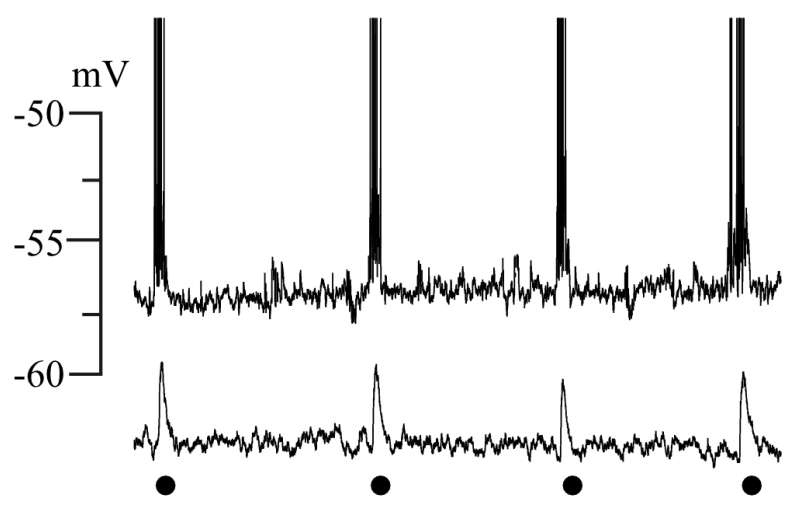

\section{B) Muscimolapplikation}

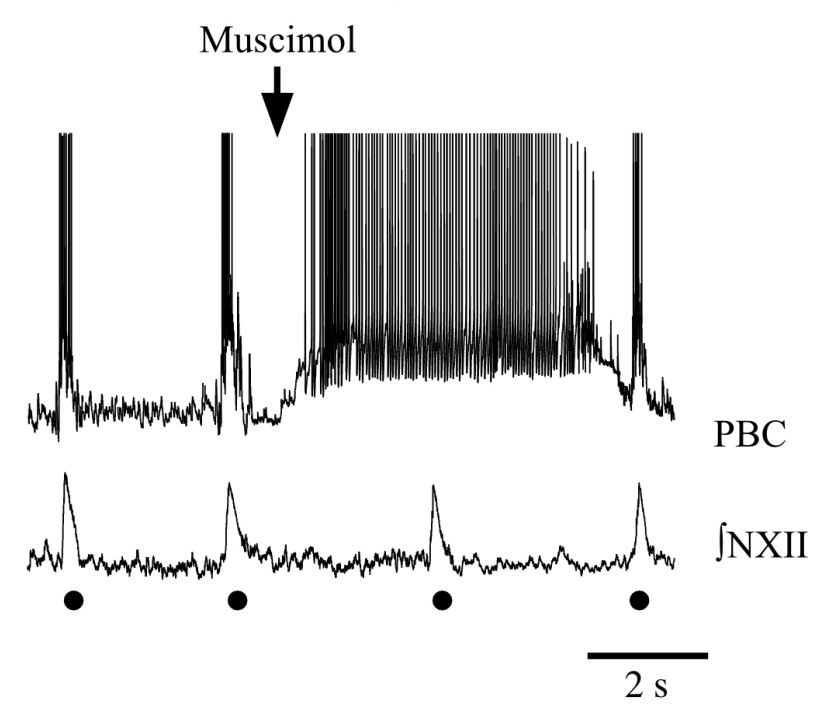

Abb. 14. Muscimolapplikation auf ein rhythmisch aktives Neuron zwei Tage nach der Geburt. A: Gramicidin-perforiertes Neuron des Prä-Bötzinger Komplexes im rhythmisch aktiven Hirnstammschnitt einer zwei Tage alten Maus (obere Spur, Aktionspotentiale abgeschnitten) und gleichzeitige, integrierte Aktivität des zwölften Hirnnerven (untere Spur). B: Druckapplikation von Muscimol (100 $\mu \mathrm{M}$ in ACSF) direkt auf das im current clamp Modus abgeleitete Neuron bewirkt eine vom Rhythmus unabhängige Depolarisation. Die Entladung des zwölften Hirnnerven bleibt unbeeinflußt. In dieser und allen

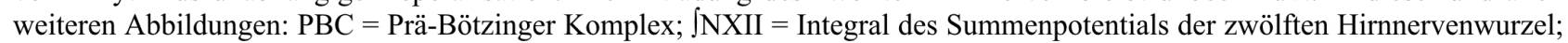
Punkte markieren den respiratorischen Rhythmus; Pfeil markiert Zeitpunkt der Muscimolapplikation; Balken mit entsprechender Zeitangabe. 
beobachten (s. Abb 15 B). Bei älteren Tieren (P8) wurde bei $-70 \mathrm{mV}$ entweder ebenfalls keine Membranpotentialänderung oder eine leichte Hyperpolarisation beobachtet. Ansonsten verhielten sie sich entsprechend den P4 Neuronen s. Abb 15 C). Um das $E_{\text {GABA-A }}$ genau bestimmen zu können, wurde für jedes Neuron die gemessene Potentialänderung bei Muscimolapplikation gegen das vorgegebene Membranpotential aufgetragen. Der Wert des Membranpotentials, an dem die resultierende Regressionsgerade eine Potentialänderung von $0 \mathrm{mV}$ ergab, wurde als $\mathrm{E}_{\mathrm{GABA}-\mathrm{A}}$ angenommen. Ein Beispiel für diese Vorgehensweise zeigt Abbildung $15 \mathrm{D}$ und $\mathrm{E}$. Die hier ermittelten Werte für $\mathrm{E}_{\mathrm{GABA}-\mathrm{A}}$ lagen bei $-42.9 \mathrm{mV}$ für das $\mathrm{P} 1$ und bei $-68.7 \mathrm{mV}$ für das $\mathrm{P} 8$ Neuron.

Die Muscimol-induzierte Membranpotentialänderung war in Neuronen jeglichen Alters durch Zugabe von $10 \mu \mathrm{M}$ Bicucullin zur Badlösung reversibel blockierbar (s. Abb. 16). Selbst wenn eine Muscimolapplikation keine Membranpotentialänderung bewirkte, weil das Membranpotential der Zelle mit dem Gleichgewichtspotential $\mathrm{GABA}_{\mathrm{A}}$-Rezeptor-vermittelter Ströme übereinstimmte, wurde durch sie eine Reduktion spontaner PSP ausgelöst s. Abb. 16 A. Wurden die GABA $^{-}$ Rezptoren mit Bicucullin blockiert, trat auch dieser Effekt von Muscimol nicht auf. Insgesamt

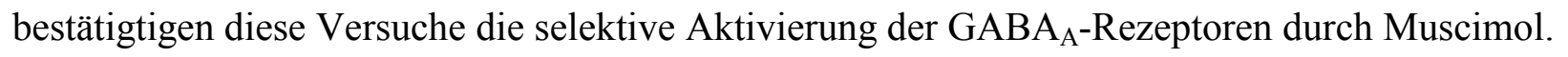



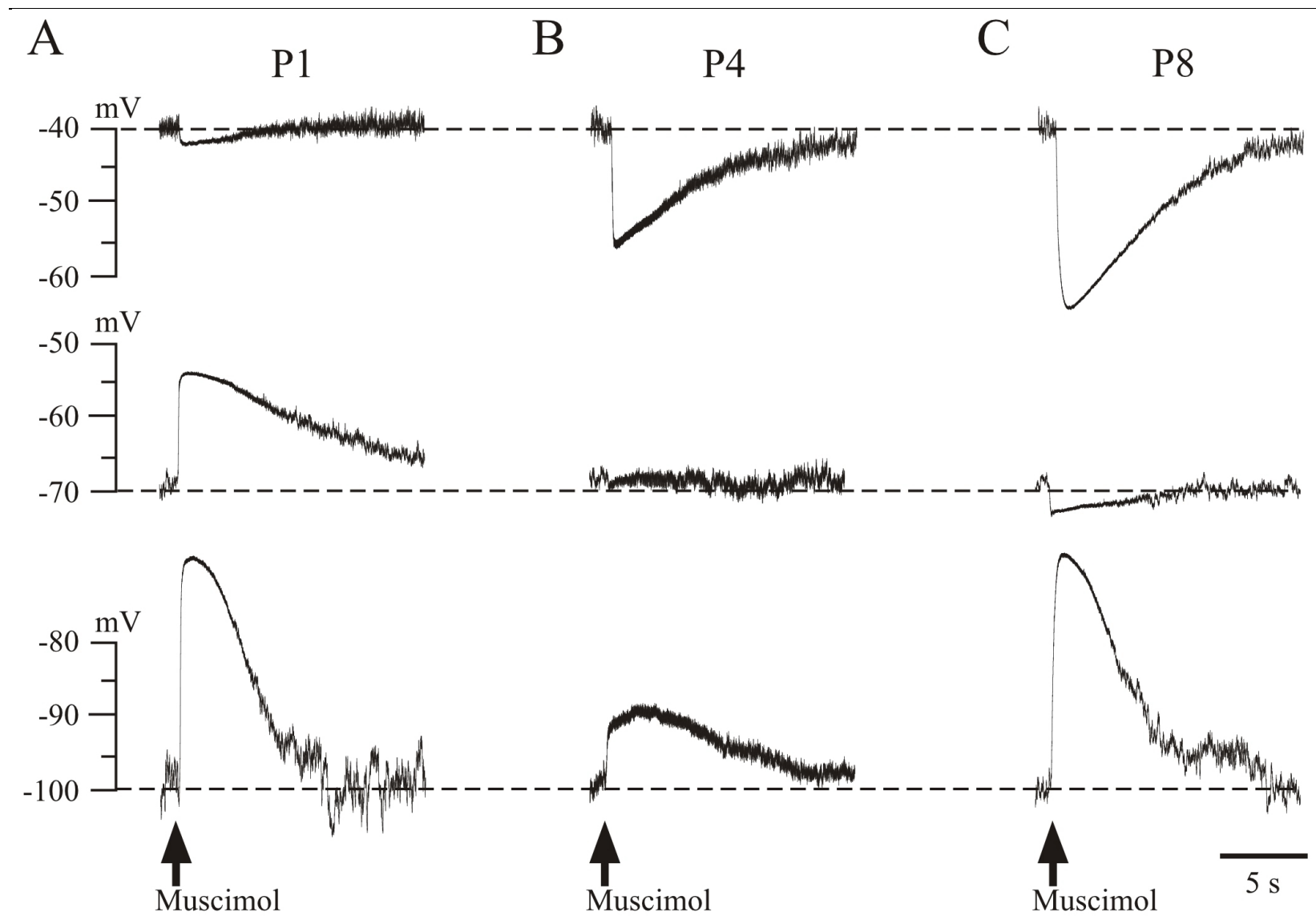

$\mathrm{D}$

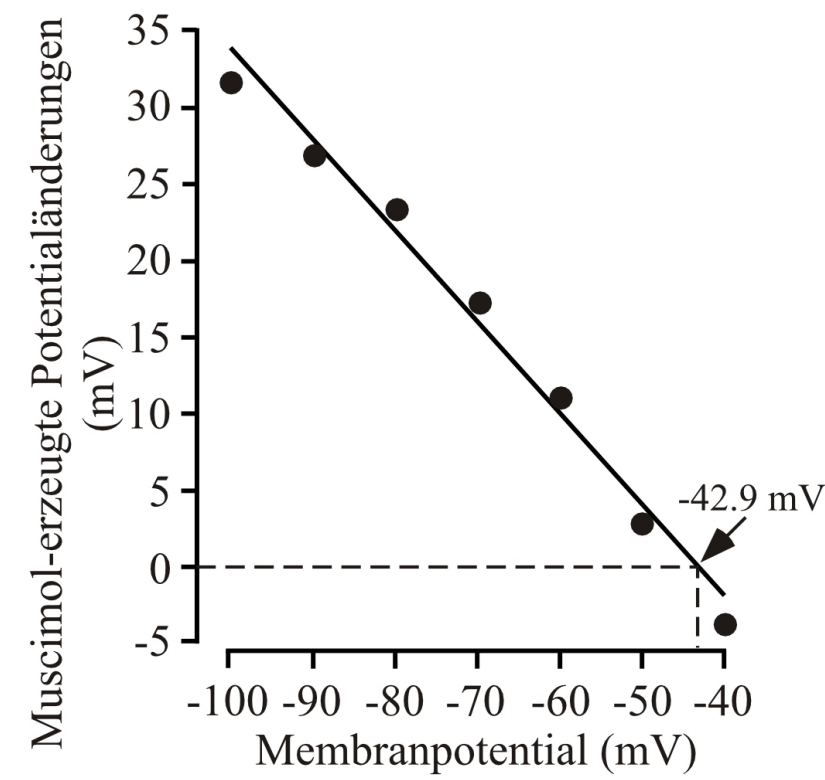

$\mathrm{E}$

P8

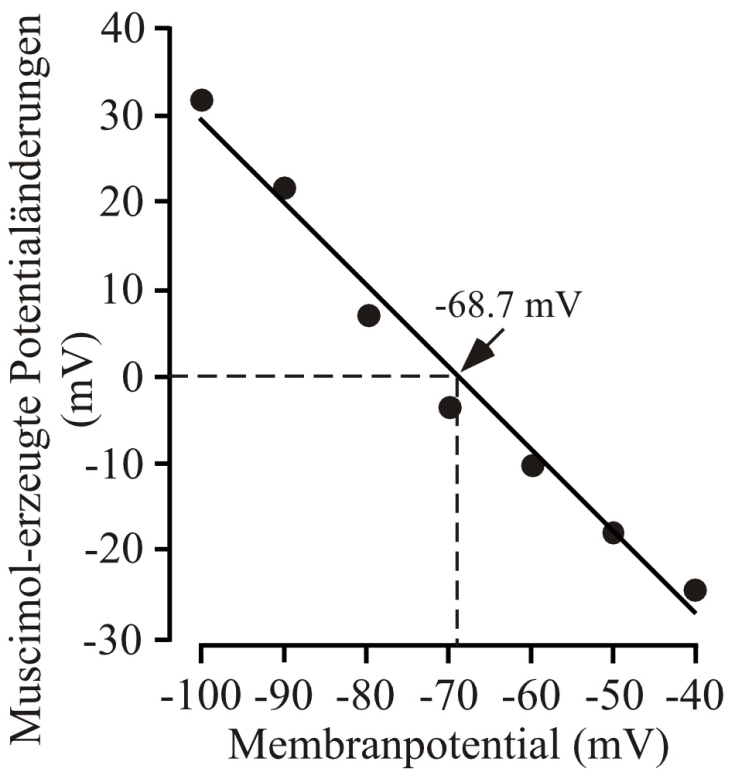

Abb. 15. Muscimol-erzeugte Potentialänderungen sind abhängig vom Alter der untersuchten Maus. A-C: Gramicidin-perforierte Zellen im current clamp Modus wurden mit DC Strömen auf unterschiedliche Ruhemembranpotentiale eingestellt und Muscimol appliziert. A: An P1 zeigt sich bei einem Membranpotential von $-40 \mathrm{mV}$ eine leichte Hyperpolarisation und bei $-70 \mathrm{mV}$ eine Depolarisation, die sich bei $-100 \mathrm{mV}$ verstärkt. B: An P4 werden Neurone bei $-40 \mathrm{mV}$ hyperpolarisiert, während bei $-70 \mathrm{mV}$ nur eine Veränderung der Häufigkeit und Amplitude der postsynaptischen Potentiale zu beobachten ist. Bei $-100 \mathrm{mV}$ wird eine Depolarisation bewirkt. C: An P8 ist die Reaktion ähnlich wie an P4, nur daß bei $-70 \mathrm{mM}$ eine leichte Hyperpolarisation zu beobachten ist. D, E: Werden die Muscimol-erzeugten Potentialänderungen gegen das Ruhemembranpotential aufgetragen, so läßt sich aus der Regressionsgeraden das Potential ermitteln, bei dem keine Potentialänderung bei Muscimolapplikation meßbar ist. Dieses beträgt bei dem hier dargestellten P1 Neuron $-42.9 \mathrm{mV}$ (D), bei dem P4 Neuron $-68.7 \mathrm{mV}$. 


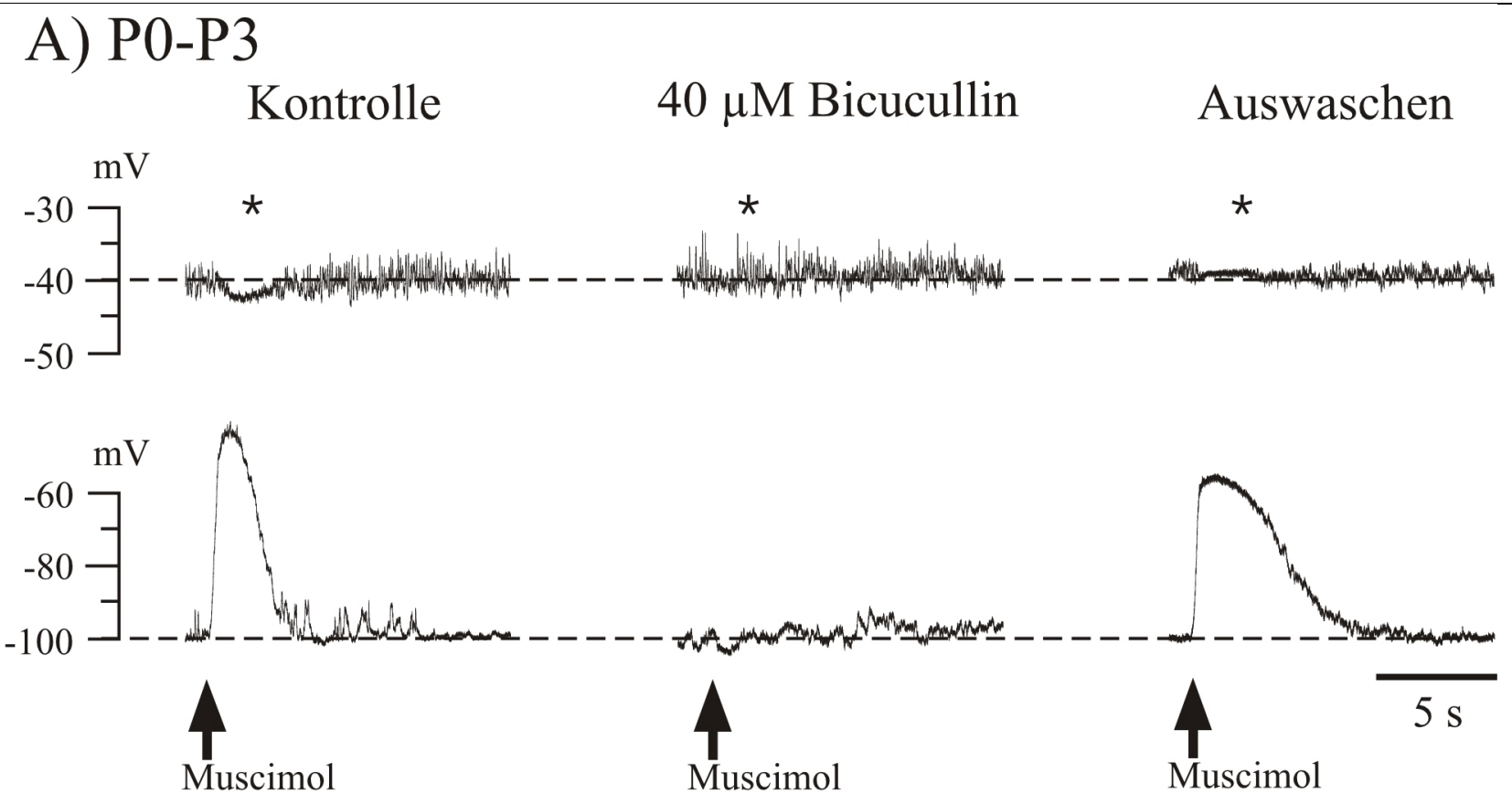

B) P 4-P10

Kontrolle

$40 \mu \mathrm{M}$ Bicucullin

Auswaschen
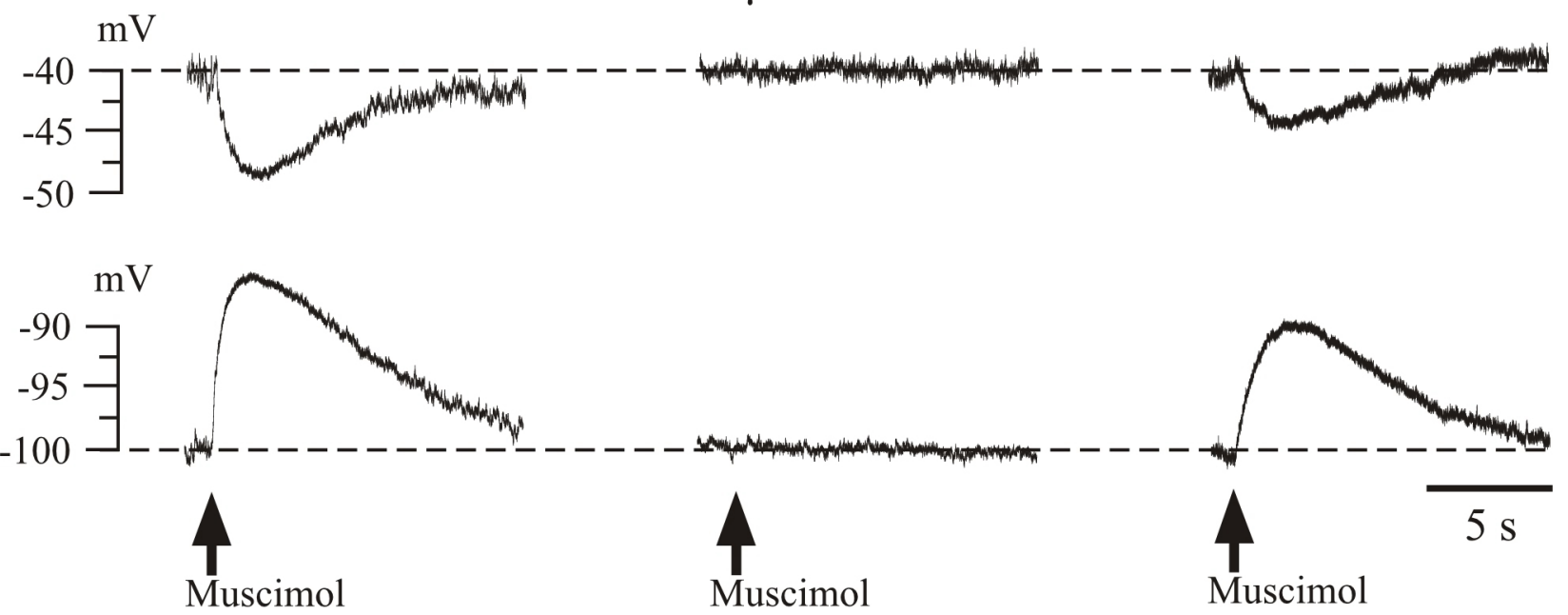

Abb. 16. Muscimol aktiviert spezifisch $\mathrm{GABA}_{\mathrm{A}}$-Rezeptoren. A: Unter Kontrollbedingungen appliziertes Muscimol bewirkt an P0-2 bei einem Membranpotential von $-40 \mathrm{mV}$ kaum eine Potentialänderung, während es das Auftreten von postsynaptischen Potentialen reduziert (Stern). Bei $-100 \mathrm{mV}$ wird die Zelle depolarisiert. Bei Bicucullin in der Badlösung $(40 \mu \mathrm{M})$ bewirkt Muscimol keinerlei Effekte, weder auf das Membranpotential noch auf das Auftreten von postsynaptischen Potentialen (Stern). Die Wirkung von Bicucullin ist nach dem Auswaschen reversibel. B: Obwohl im Alter von P4-10 die Muscimol-evozierten Potentiale verändert sind, sind sie ebenso reversibel durch 40 $\mu \mathrm{M}$ Bicucullin blockierbar. 
Der Durchbruch der Membran und somit die Herstellung des whole-cell Modus bewirkte eine sofortige Abnahme des Signalrauschens aufgrund des verbesserten elektischen Zugangs. Nach der Äquilibrierung des Zellinhaltes mit der Pippettenlösung zeigte sich ein durch die veränderte Ionenverteilung leicht hyperpolarisiertes Membranpotential. Außerdem verschob sich $\mathrm{E}_{\mathrm{GABA}-\mathrm{A}}$ in jüngeren Tieren in Richtung des errechneten $\mathrm{Cl}^{-}$- $̈$ quilibriumpotentials $\left(\left[\mathrm{Cl}^{-}\right]_{\text {innen }}=7 \mathrm{mM} ;\left[\mathrm{Cl}^{-}\right]_{\text {außen }}=\right.$ $131 \mathrm{mM})$ der Pipettenlösung zur Badlösung (-73.6 mV).

Kaila et al. (Bormann, 1991; Kaila, 1994) zeigten an Neuronen der Ratte, daß $E_{\text {GABA-A }}$ nicht ausschließlich von $\mathrm{Cl}^{-}$Ionen, sondern ebenfalls in geringerem Maße von Bicarbonat beeinflußt werden kann. Deshalb wurde in einer weiteren Versuchsreihe die Wirkung des Wechsels von $\mathrm{CO}_{2} / \mathrm{HCO}_{3}{ }^{-}$gepufferter Badlösung zu carbonatfreier, HEPES-gepufferter ACSF auf den Effekt der $\mathrm{GABA}_{\mathrm{A}}$-Rezeptor-Aktivierung untersucht. Dies sollte Aufschluß darüber geben, ob die Leitfähigkeit des $\mathrm{GABA}_{\mathrm{A}}$-Rezeptors für Bicarbonationen wesentlich mitverantwortlich für die durch seine Aktivierung erzeugten Membranpotentialveränderungen ist. Muscimol-Applikation auf PBC Neurone erzeugte bei einem vorgegebenem Membranpotential von $-60 \mathrm{mV}$ in $\mathrm{CO}_{2} / \mathrm{HCO}_{3}{ }^{-}$ haltiger ACSF eine Depolarisation in neonatalen $(\mathrm{P} 0-2, \mathrm{n}=5)$ Tieren, während eine Hyperpolarisation bei älteren Mäusen (P4-10, n=3) bei einem Membranpotential von $-40 \mathrm{mV} \mathrm{zu}$ beobachten war. Diese Membranpotentialänderungen wurden begleitet von einer Reduktion des Eingangswiderstandes, der durch einen $10 \mathrm{~ms}$ andauernden hyperpolarisierenden Strompuls von 1 nA sekündlich dokumentiert wurde. In Mäusen zwischen P0 und P2 erfolgte eine signifikante Reduktion auf $82.7 \pm 17.1 \%$, in älteren auf $79.9 \pm 16.1 \%$ gegenüber den Werten vor der Drogenapplikation s. Abb. 18. Wurde die Badlösung durch HEPES-gepufferte ACSF ersetzt, änderte sich weder das Membranpotential noch der Eingangswiderstand. Auch die bei der Druckapplikation von Muscimol beobachteten Effekte zeigten keine signifikanten Unterschiede (s. Abb 17 C, D.

Abbildung 19 faßt die bisherigen Ergebnisse zusammen. Es zeigte sich eine deutliche, altersabhängige Verschiebung von $\mathrm{E}_{\mathrm{GABA}-\mathrm{A}} \mathrm{zu}$ hyperpolarisierenden Werten. Liegt $\mathrm{E}_{\mathrm{GABA}-\mathrm{A}}$ bei P0 bei $-13.7 \pm 9.8(n=4)$, so sinkt es ab P4 auf Werte von $-73.5 \pm 7.1 \mathrm{mV}(\mathrm{n}=9$; s. Abb 19 A). Vergleicht man $E_{\mathrm{GABA}-\mathrm{A}}$ mit dem durchschnittlichen Ruhemembranpotential (-56.1 $\left.\pm 5.1 \mathrm{mV}\right)$, so zeigt sich, daß $\mathrm{GABA}_{\mathrm{A}}$-Rezeptor-vermittelte Ströme erst ab P3-4 hyperpolarisierende Wirkung auf PBC Neurone ausüben können. 

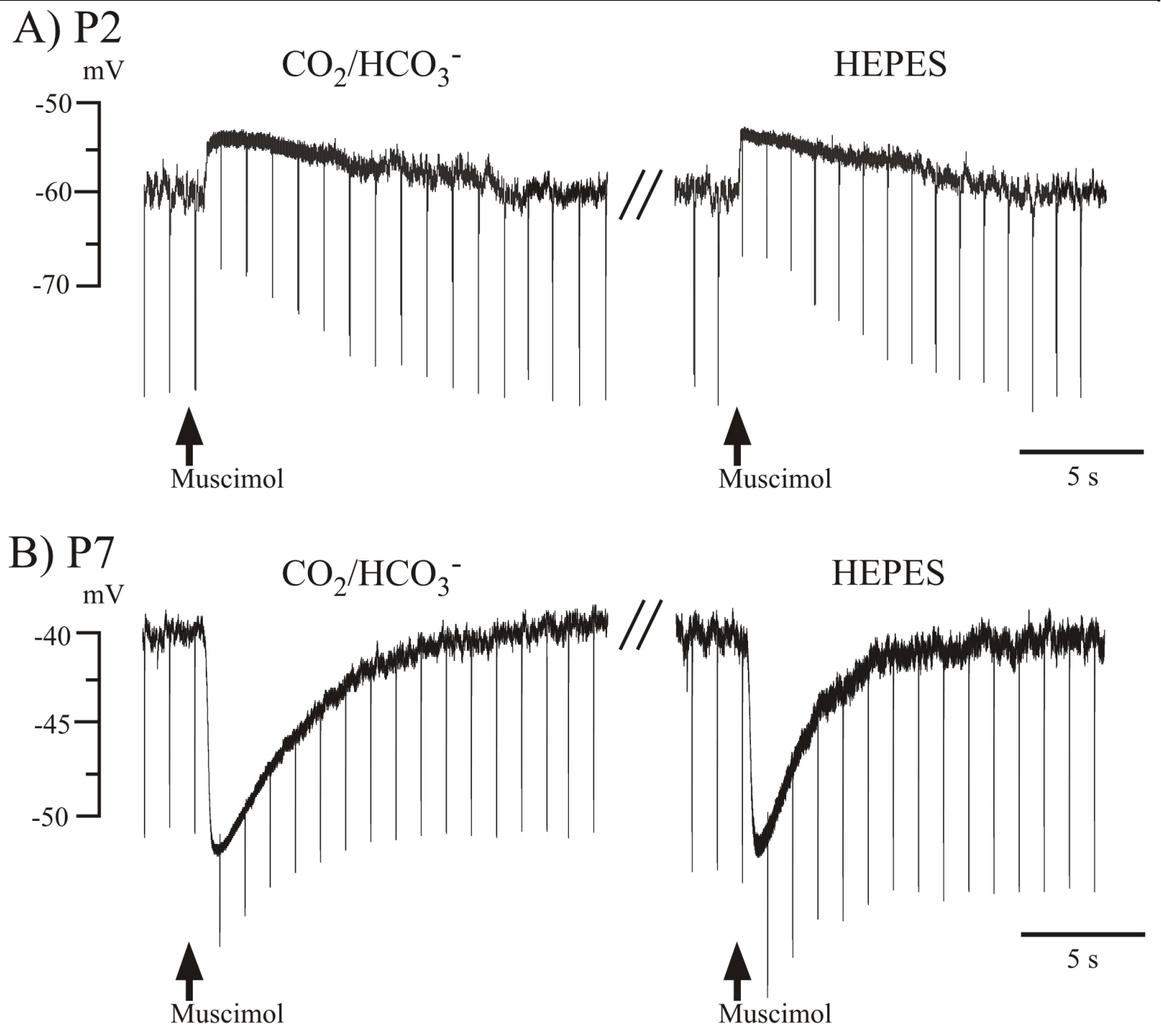

C) $\mathrm{P} 0-3$

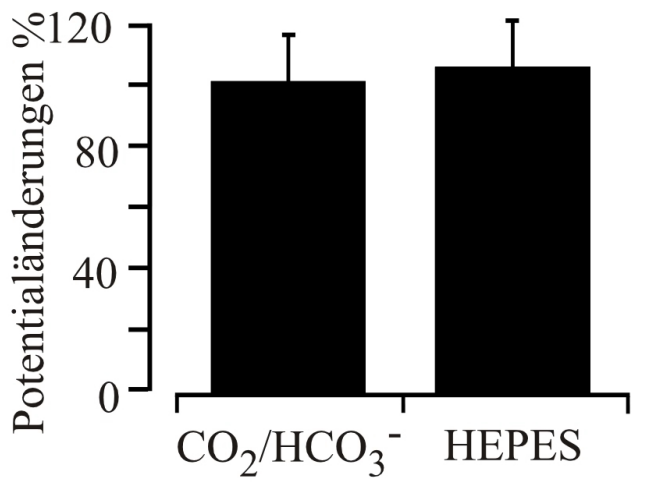

D) P4-10

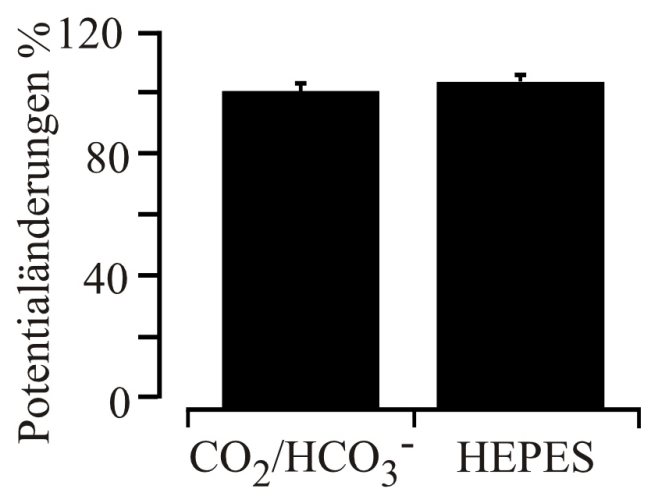

Abb. 17. Veränderungen in der extrazellulären Bicarbonat-Konzentration beeinflussen die Muscimol-Antwort in keinem Alter. A: Bei P2 Mäusen depolarisiert Muscimol PBC Neurone bei $-60 \mathrm{mV}$ in einem $\mathrm{CO}_{2} / \mathrm{HCO}_{3}{ }^{-}$-haltigen Puffer. Des weiteren ist eine verminderte Potentialänderung als Antwort auf einen regelmäßig applizierten Strompuls zu beobachten. Dies zeigt eine Reduktion des Eingangswiderstandes. Wird die Badlösung durch eine HEPES-gepufferte Lösung ersetzt so ist bei derselben Zelle keine Veränderung des Membranpotentials oder der Reaktionen auf Muscimol zu beobachten. B: Trotz veränderter Muscimol-evozierter Potentialänderungen zeigt sich auch im Alter von P7 kein Unterschied in $\mathrm{CO}_{2} / \mathrm{HCO}_{3}^{-}$oder $\mathrm{HEPES}$ haltigem Puffer. C, D: Zusammenfassung mehrerer Versuche in verschiedenen Altersstufen. Die in $\mathrm{CO}_{2} / \mathrm{HCO}_{3}{ }^{-}$gepufferter Badlösung ausgelöste Potentialänderung wurde als 100\% gesetzt und die in HEPES-gepufferter Badlösung entsprechend relativiert. Es zeigte sich keine signifikante Veränderung Muscimol-evozierter Potentialänderungen (P0-3: $n=5 ; P 4-10: n=3)$. 


\section{A) $\mathrm{CO}_{2} / \mathrm{HCO}_{3}^{-}$}

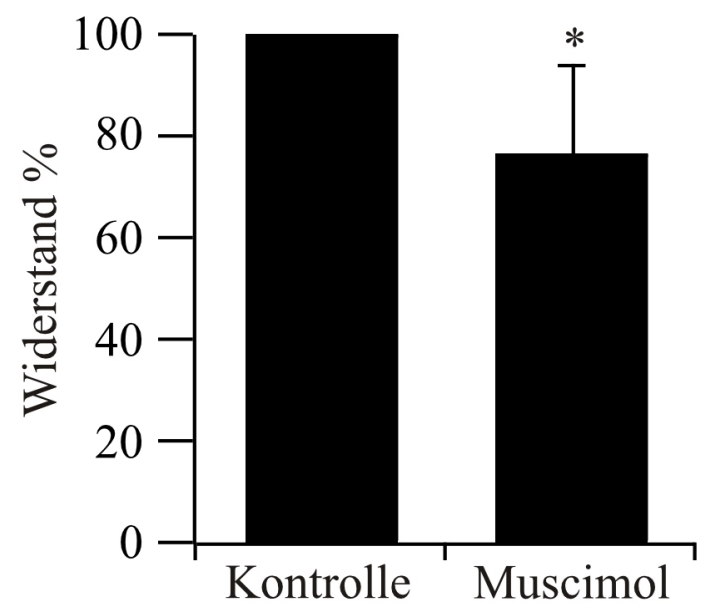

\section{B) Hepes}

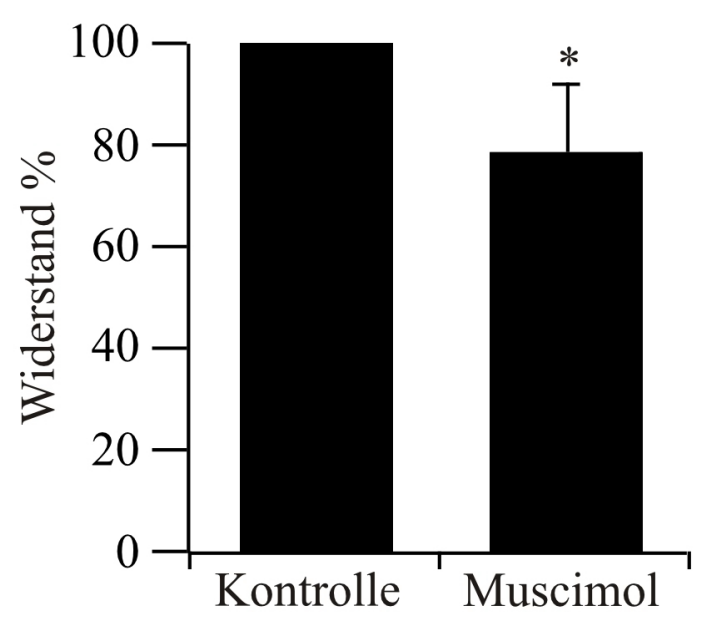

Abb. 18. Reduktion des Membranwiderstandes durch Muscimol in verschiedenen Extrazellulärlösungen. A: Die Applikation von Muscimol reduziert den Eingangswiderstand von PBC Neuronen signifikant (s. auch Abb.17) auf $79.9 \pm 16.1 \%$ des ursprünglichen Wertes in $\mathrm{CO}_{2} / \mathrm{HCO}_{3}{ }^{-}$gepufferter Lösung. B: In HEPES-gepufferter Lösung findet eine Reduktion auf $78.6 \pm 13.7 \%$ statt. Die dargestellten Werte wurde bei P4-7 $(n=3)$ Tage alten Mäusen ermittelt. Bei jüngeren Tieren zeigte sich ein ähnliches Bild.

Das hier ermittelte $E_{\mathrm{GABA}-\mathrm{A}}$ liegt nahe bei $\mathrm{E}_{\mathrm{Cl}^{-}}$, da die $\mathrm{GABA}_{\mathrm{A}}$-Rezeptor vermittelten Ströme überwiegend von $\mathrm{Cl}^{-}$-Ionen getragen werden. Obwohl Bicarbonatströme in den von uns durchgeführten Messungen keine signifikante Bedeutung zur Bildung eines PSP zukommen, finden sie trotzdem statt und gleichen einen Teil der entgegengesetzten $\mathrm{Cl}^{-}$-Ströme aus. Diese versteckten Ströme müssen berücksichtigt werden, um die Konzentration der $\mathrm{Cl}^{-}$-Ionen im Zellplasma berechnen zu können. Die Zellen des PBC besitzen bei einem physiologischen pH-Wert von 7.2 einen intrazellulären Bicarbonat-Gehalt von $20 \mathrm{mM}$ (Ballanyi et al., 1994). Bei einer Öffnung des GABA $_{A}$-Rezeptor-Kanals würde sich bei der hier verwendeten Extrazellulärlösung ein depolarisierender Anionenausstrom ergeben. Berücksichtigt man ein Leitfähigkeitsverhältnis der GABA $_{A}$-Rezeptoren von 1:0.3 (Bormann, 1991; Kaila, 1994) zwischen $\mathrm{Cl}^{-}$-und Bicarbonationen, kann man mit Hilfe der Goldman-Gleichung das $\mathrm{Cl}^{-}$-Konzentrationsgefälle errechnen, das einen entgegengesetzten Strom gleicher Größe erzeugt. Dies würde 5mM entsprechen. Die mit Hilfe der Nernst-Gleichung aus den von uns ermittelten $\mathrm{E}_{\mathrm{GABA}-\mathrm{A}}$ errechneten intrazellulären $\mathrm{Cl}^{-}$Konzentrationen müssen deshalb die um $5 \mathrm{mM}$ gegenüber dem effektiv gemessenen reduziert werden. Somit ergibt sich eine $\mathrm{Cl}^{-}$-Konzentration von 92.0 \pm 34.1 für $\mathrm{P} 0,36.0 \pm 11.5$ für P1 und 22.8 \pm 6.9 für P3. In älteren Tieren schwankte sie zwischen 4 und $7 \mathrm{mM}$ s. Abb. 19 B). Dieser Wert entspricht den von anderen Arbeitsgruppen (Brockhaus \& Ballanyi, 1998) in Ratten ermittelten Werten für die intrazelluläre Konzentration von $\mathrm{Cl}^{-}$-Ionen. 

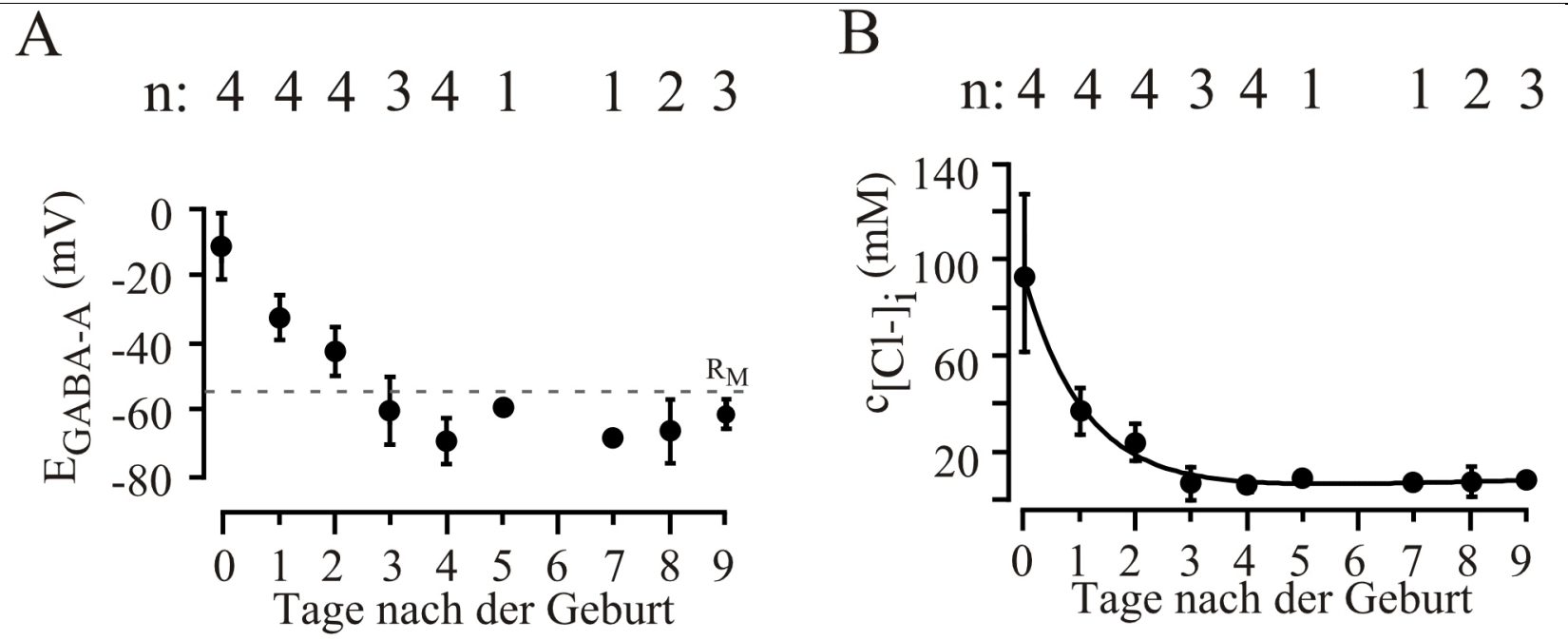

Abb. 19. Entwicklungsbedingte Veränderungen von $\mathrm{E}_{\mathrm{GABA}-\mathrm{A}}$ und intrazellulärer $\mathrm{Cl}^{-}$Konzentration. $\mathrm{A}: \mathrm{GABA}_{\mathrm{A}^{-}}$ Rezeptor-vermittelte Ströme sind erst ab P3-4 hyperpolarisierend. Durch Muscimolapplikation ermitteltes Äquilibriumpotential $\mathrm{GABA}_{\mathrm{A}}$-Rezeptor-vermittelter Ströme $\left(\mathrm{E}_{\mathrm{GABA}-\mathrm{A}}\right)$ gegen das Alter. Die Messwerte sind der Mittelwert der oben angegebenen Anzahl von Versuchen \pm deren Standardabweichung. $\mathrm{E}_{\mathrm{GABA}-\mathrm{A}}$ liegt erst ab P3 unterhalb des durchschnittlichen Ruhemembranpotentials $\left(\mathrm{R}_{\mathrm{M}}\right.$, gestrichelte Linie). B: Mit Hilfe der Nernst-Gleichung und unter Berücksichtigung des physiologischen Bicarbonat-Gehaltes der Zellen ermittelte, intrazelluläre Chloridkonzentration $\left(\mathrm{c}\left[\mathrm{Cl}^{-}\right]_{\mathrm{i}}\right)$ gegen das Alter. Die Messwerte sind der Mittelwert der oben angegebenen Anzahl von Versuchen \pm deren Standardabweichung.

\subsection{Entwicklungsabhängige Funktionsänderungen sind begleitet von Veränderung in der zellulären Verteilung $\operatorname{der} \mathrm{GAB}_{B}$-Rezeptoren}

Wie unter 4.1 .1 gezeigt, ändert sich auch die Funktion des $\mathrm{GABA}_{\mathrm{B}}$-Rezeptors. Während $\mathrm{GABA}_{\mathrm{B}}$ Rezeptoren perinatal in der Vermittlung GABA-induzierter Frequenzreduktion eine wichtige Rolle spielen, nimmt diese im Verlauf der Entwicklung an Bedeutung ab. Auch die elektrophysiologischen Effekte der $\mathrm{GABA}_{\mathrm{B}}$-Rezeptoren auf $\mathrm{PBC}$ Neurone ändern sich grundlegend während dieser Periode. So erhöhen sie zwischen P0-3 den postsynaptischen $\mathrm{Ca}^{2+}$-Einstrom durch $\mathrm{Ca}^{2+}{ }_{\mathrm{T}}-$ Kanäle, während dieser später durch die reduzierte Leitfähigkeit von $\mathrm{Ca}^{2+}{ }_{\mathrm{T} / \mathrm{N} / \mathrm{L}}-\mathrm{Kanälen}$ erschwert wird (Zhang et al., 1999). Des weiteren gibt es Indizien dafür, daß sich die $\mathrm{GABA}_{\mathrm{B}^{-}}$ Rezeptor-vermittelte Modulation der einwärtsgerichteten $\mathrm{K}^{+}$-Ströme $\left(\mathrm{K}_{\mathrm{IR}}\right)$ altersabhängig verändert (Eicke et al., 1999). In der vorliegenden Arbeit sollte die Entwicklung der Expression und Lokalisation der $\mathrm{GABA}_{\mathrm{B}}$-Rezeptoren in der Medulla oblongata im Zeitrahmen der elektrophysiologisch aufgezeigten, funktionellen Veränderungen bis zum Erwachsenenalter dokumentiert werden (P0-66). Darüber hinaus wurden ebenso Sagitalschnitte des gesamten Mäusehirns untersucht, um die Entwicklungen im Hirnstamm mit denen in anderen Gebieten zu vergleichen. 


\subsubsection{Expression des $\mathrm{GABA}_{\mathrm{B}}$-Rezeptors ab der Geburt nachweisbar}

Die Anwesenheit des GABA $_{B}$-Rezeptors konnte bereits am Tag der Geburt in vielen Hirnregionen nachgewiesen werden. Die Neurone der unterschiedlichen Hirnstammkerne waren deutlich markiert, u.a. in den Nuclei ambiguus und hypoglossus ebenso wie im Nucleus vagus s. Abb. 20 AD), im Nucleus roller und in den Nuclei Raphe. In allen untersuchten Hirngebieten zeigte sich hierbei eine diffuse Immunoreaktivität in Somata und größeren, somanahen Dendriten ebenso wie in feinen Dendritenästen.

Im Neocortex war die detektierte Immunoreaktivität der $\mathrm{GABA}_{\mathrm{B}} \mathrm{R} 1$-Untereinheit in erster Linie in den pyramidalen Neuronen aller Cortexschichten lokalisiert (s. Abb. 21 A, B). Im Hippocampus zeigten einige kleine, verstreut liegende Zellen in den Regionen CA1, CA3 und Gyrus dentate, bei denen es sich vermutlich um Interneurone oder Gliazellen handelt, eine ausgeprägte GABA $_{B}$ R1Immunoreaktivität. Ebenso waren die Pyramidalzellen in den oben genannten Hippocampusregionen immunopositiv s. Abb. 21 A, C). Auch wenn nur die bisher erwähnten Hirnregionen des Telenzephalons im Folgenden exemplarisch weiterbehandelt werden sollen, muß erwähnt werden, daß der $\mathrm{GABA}_{\mathrm{B}}$-Rezeptor in vielen Gebieten des Zentralen Nervensystems nachzuweisen war. Eine intensive Immunoreaktivität konnte u.a. im Bulbus olfactorius, Striatum, Habenula und der Substantia nigra detektiert werden. Übereinstimmend mit vorhergehend durch andere Techniken erstellten Studien wurdeeine starke Expression in Soma und Dendriten der Purkinjezellen des Kleinhirns nachgewiesen. Weiterhin war in den Neuronen der granulären Schicht eine weniger intensive Färbung zu beobachten (s. Abb. 22. 


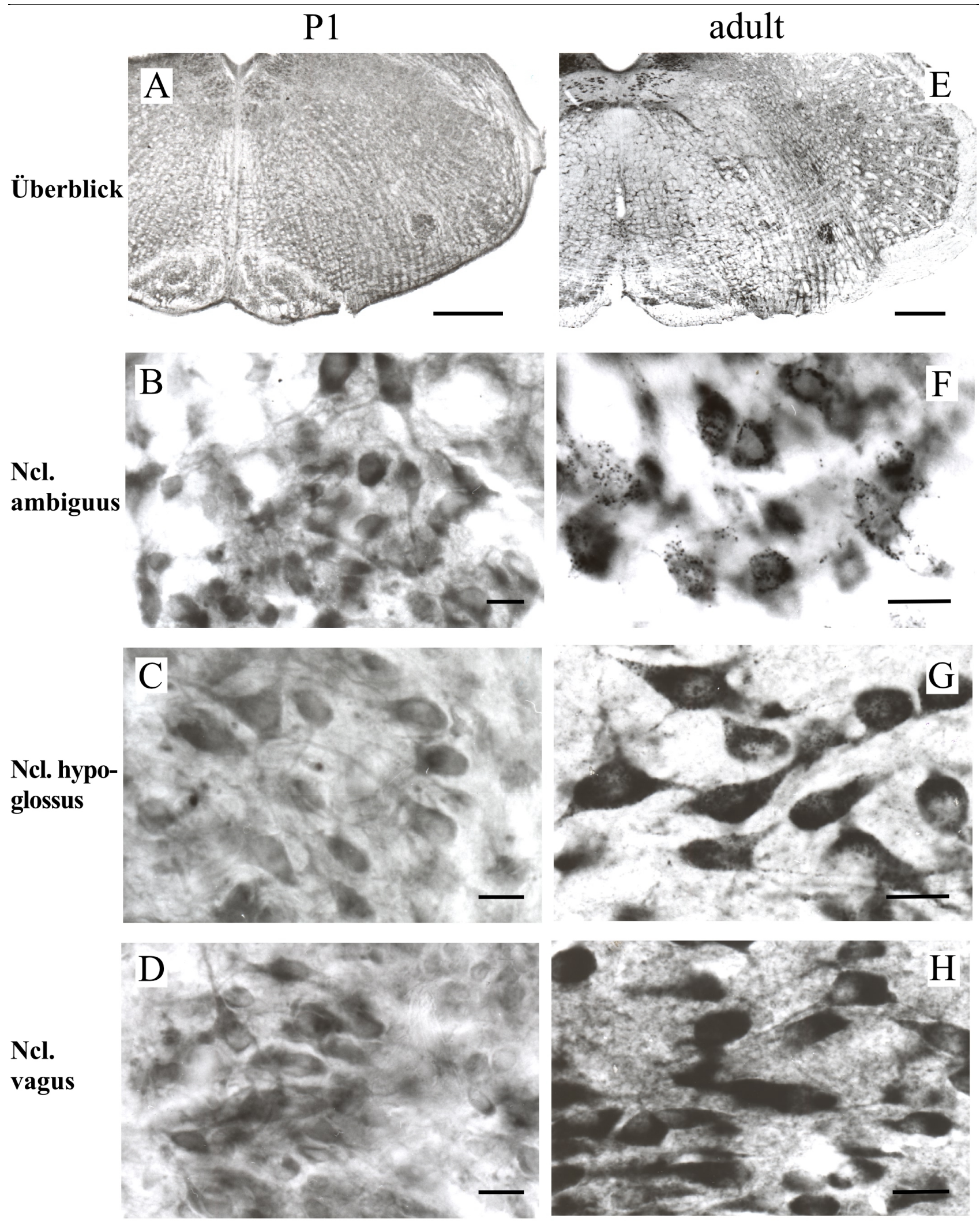

Abb. 20. Intrazelluläre Umverteilung der $\mathrm{GABA}_{\mathrm{B}} \mathrm{R} 1 \mathrm{a} / \mathrm{b}-\mathrm{Imm}$ unoreaktivität in der Entwicklung des Hirnstammes. Immunohistochemische Markierung der carboxiterminalen Endigung der GABA $\mathrm{B} 1 \mathrm{a} / \mathrm{b}$-Untereinheit mittels Diaminobenzidin (DAB)-Färbung. Dargestellt ist jeweils eine Färbung in einer P1 (linke Reihe; A, B, C, D) und einer adulten (P66; rechte Reihe; E, F, G, H) Maus. A, E: Die regionale Verteilung der Immunoreaktivität ändert sich kaum. Stark markierte Gebiete sind die Nuclei ambiguus, hypoglossus und vagus. B, F: Die zuvor diffuse Markierung der Neurone im Nucleus ambiguus wird in adulten Tieren durch eine immunopositive Granula ergänzt oder ersetzt. C, G: Im Ncl. hypoglossus bleibt die diffus verteilte Immunoreaktivität stärker ausgeprägt, immunopositive Granula sind allerdings deutlich erkennbar. D,H: Im Ncl. vagus überdeckt die intensive, flächige Färbung der Neurone auch im adulten Stadium eventuell vorhandene, immunopositive Granula. Der Balken entspricht $300 \mu \mathrm{m}$ in A und E, $30 \mu \mathrm{m}$ in allen anderen Abbildungsteilen. 


\section{P1}
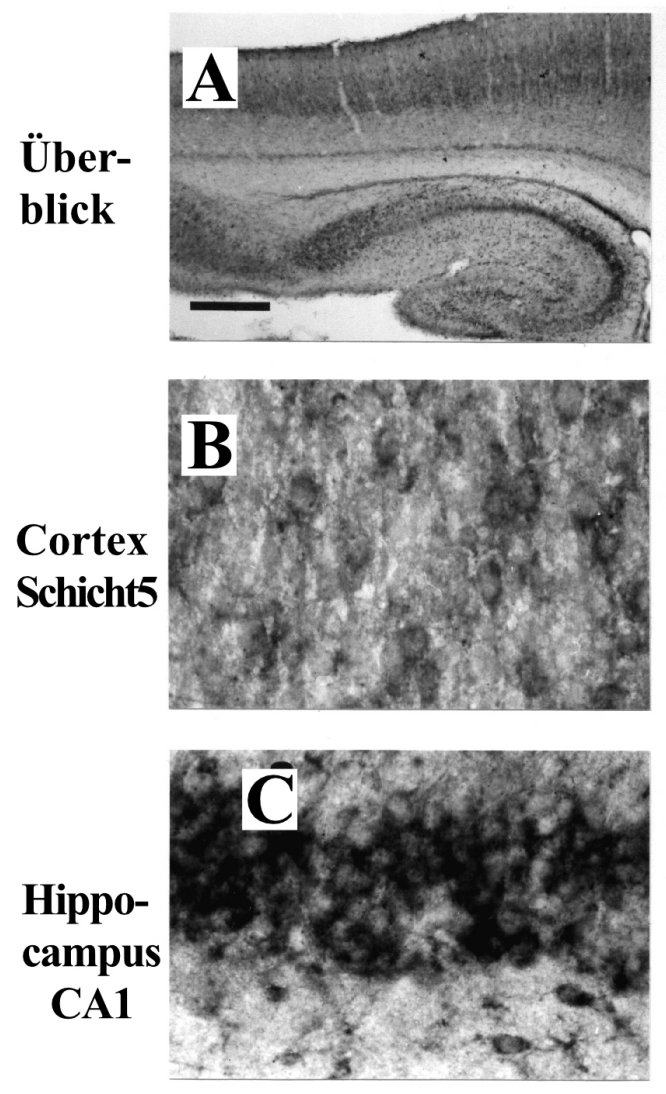

P11
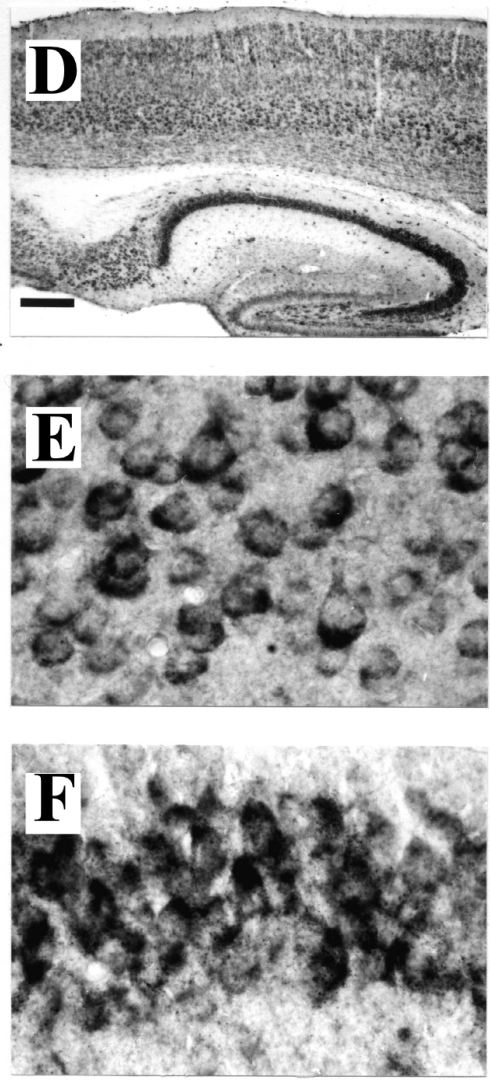

\section{adult}
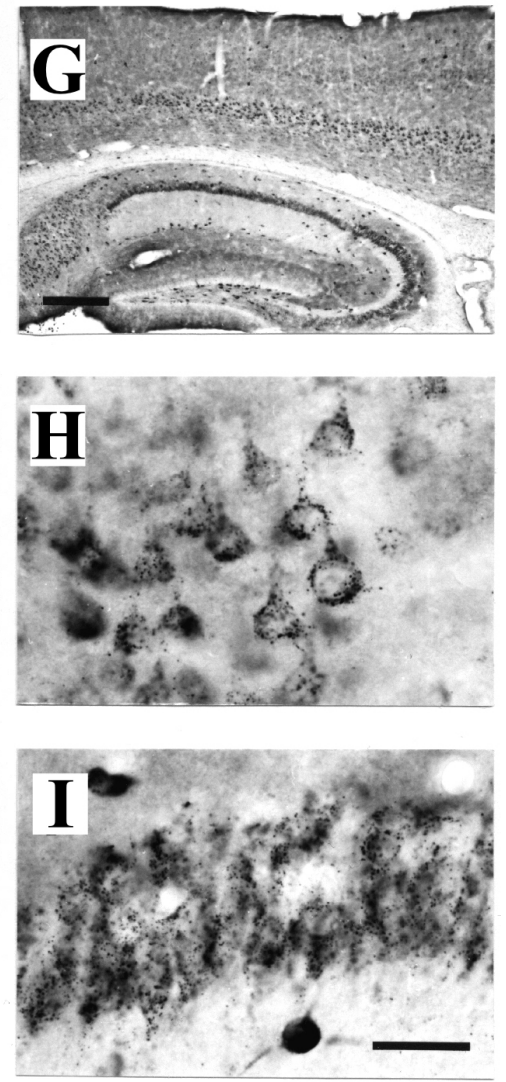

Abb. 21. Intrazelluläre Umverteilung der $\mathrm{GABA}_{B} \mathrm{R} 1 \mathrm{a} / \mathrm{b}$-Immunoreaktivität in der Entwicklung des Telenzephalons.Während sich die regionale Verteilung der $\mathrm{GABA}_{\mathrm{B}} \mathrm{R} 1 \mathrm{a} / \mathrm{b}-\mathrm{Immunoreaktivität} \mathrm{in} \mathrm{der} \mathrm{Entwicklung}$ kaum verändert (A, D, G), treten in den Neuronen der cortikalen Schicht 5 (B, E, H) und des Hippocampus (C, F, I) immunopositive, granuläre Strukturen auf. Im Hippocampus bleiben einige Zellen zu intensiv immunopositiv zur Detektion von Granula. Balken in A, D, G entsprechen $300 \mu \mathrm{m}$; der Balken in I gilt als Skala für die anderen Abbildungsteile und entspricht $30 \mu \mathrm{m}$.
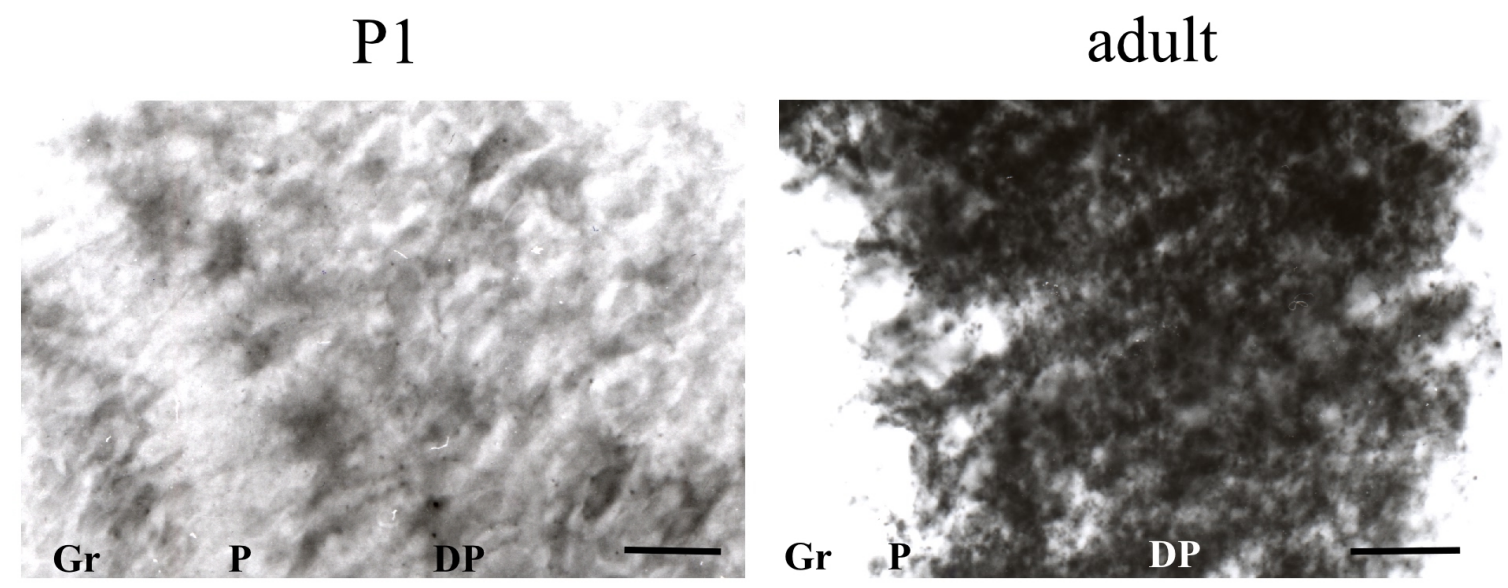

Abb. 22. Intrazelluläre Umverteilung der $\mathrm{GABA}_{\mathrm{B}} \mathrm{R} 1 \mathrm{a} / \mathrm{b}$-Immunoreaktivität in der Entwicklung des Cerebellums. Die diffuse Verteilung der $\mathrm{GABA}_{\mathrm{B}} \mathrm{R} 1 \mathrm{a} / \mathrm{b}$-Immunoreaktivität in der Granularschicht (Gr) ist nur in jungen Tieren zu beobachten. Die Somata der Purkinje Zellen (P) sind nicht gefärbt, während ihre Dendriten (DP) intensiv immunopositiv bleiben. Diese intensive Markierung überdeckt eventuell vorhandene immunopositive Granula. Balken entsprechen $30 \mu \mathrm{m}$. 


\subsubsection{Die intrazelluläre Verteilung des GABA $_{B}$-Rezeptors unterliegt einer postnatalen Veränderung}

Während sich die regionspezifische Expression der $\mathrm{GABA}_{B}$ R1-Untereinheit postnatal kaum veränderte, zeigte sich zwischen P5-10 eine Veränderung in der intrazellulären Rezeptorverteilung. So war ab einem bestimmten Entwicklungsstadium punktförmige, immunopositive Färbungen innerhalb des Zellplasmas detektierbar, während die diffuse Markierung oft abnahm und in einigen Fällen - wie den Pyramidalzellen des Neocortex - ganz verschwand s. Abb. 20 E, H. Nur wenige Zelltypen, wie eine Population relativ kleiner Neurone im Hippocampus, bei der es sich wahrscheinlich um GABAerge Interneurone handelt (s. Abb. 21 F, I), oder die Neurone des Nucleus vagus s. Abb. $20 \mathrm{H}$, behielten eine so intensive, diffus verteilte Färbung bei, daß auch eine eventuell auftretende, punktförmige Färbung überdeckt wurde und nicht erkennbar war. Obwohl diese Entwicklung in vielen Hirnregionen beobachtet werden konnte (u.a. Bulbus olfactorius, Striatum, Habenula, Substantia nigra), war der Zeitpunkt, an dem das Auftreten dieser immunoraktiven, punktförmigen Strukturen - im Folgenden nach Baude et al. immunopositive Granula genannt (Baude \& Shigemoto, 1998) - detektierbar wurde, regionspezifisch. So wurden die ersten immunopositiven Granula in den Hirnstammkernen der Nuclei ambiguus und hypoglossus ab P5, in der CA1 Region des Hippocampus ab P7 und in der fünften neocorticalen Schicht erst ab P8 beobachtet. Abbildung 22 zeigt die Entwicklung des Cerebellums. Hier intensivierte sich die Dendritenbaumfärbung der Purkinjezellen bis zum adulten Stadium, während sie in der granulären Schicht ab P12 nicht mehr zu detektieren war s. Abb. 22.

Zwischen dem Zeitpunkt ihres anfänglichen Auftretens und dem Erwachsenenalter (ca. 2 Monate) wurden die intrazellulären, immunopositiven Granula nicht nur intensiver gefärbt, sie traten auch deutlich vermehrt auf. Um dieses gesteigerte Vorkommen näher zu charakterisieren, wurden in den vier ausgewählten Hirnregionen die Anzahl der Granula pro Soma morphometrisch in optischen Schnitten durch das Präparat bestimmt. Der größte und der kleinste Durchmesser der Somata wurde von Herrn Thorsten Kühn im Rahmen seiner Dissertation mit einem Camera-Lucida-System bestimmt und unter Annahme eines idealen Elipsoiden das Somavolumen abgeschätzt. Auf diese Weise wurde für jede Hirnregion die Dichte der Granula $\left(\right.$ Anzahl $\left./ \mu \mathrm{m}^{3}\right)$ in den unterschiedlichen Altersstufen errechnet. 


\section{A) Nucl. hypoglossus}

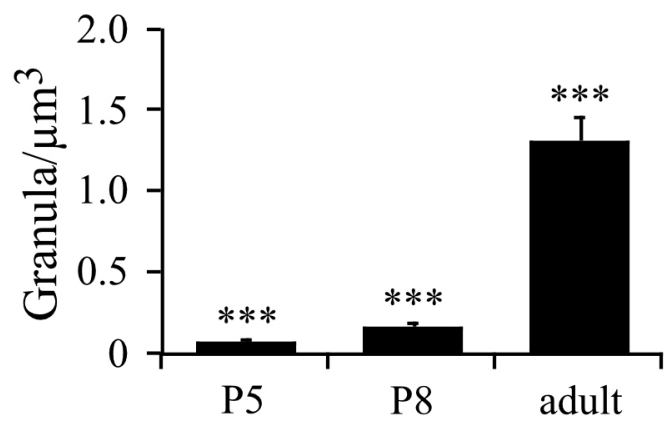

\section{C) Hippocampus (CA1)}

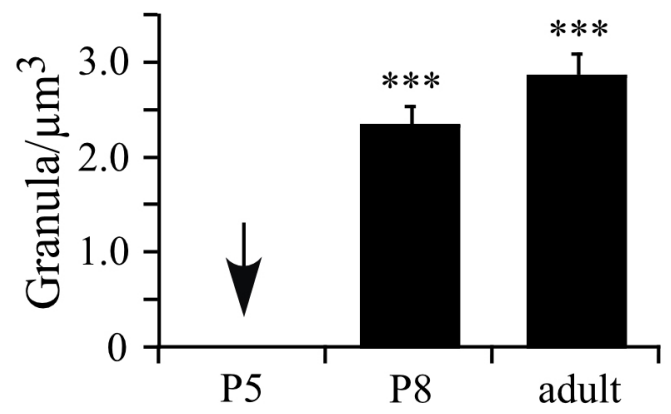

B) Nucl. ambiguus

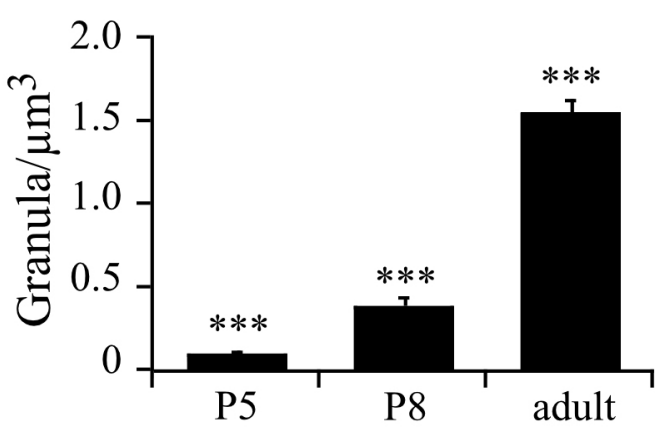

D) Cortex

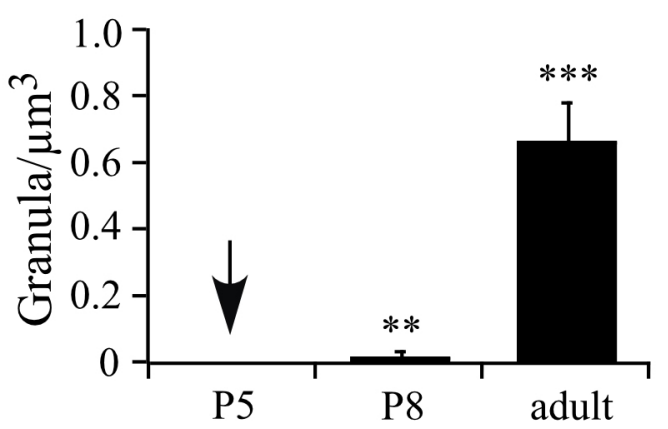

Abb. 23. Die Anzahl immunopositiver Granula pro Somavolumen ist abhängig von Hirnregion und Alter. A,B: In den Nuclei ambiguus und hypoglussus zeigt sich eine geringe Anzahl von Granula pro Soma bereits an P5. Ihre Dichte nimmt bis zum adulten Stadium zu. Es sind jeweils die Mittelwerte von 15-25 Zellen mit ihrer Standardabweichung dargestellt. C,D: In den Pyramidenzellen des Cortex und in der CA1 Region des Hippocampus sind an P5 noch keine immunopositiven Granula zu detektieren (Pfeil). Auch hier steigt ihre Anzahl pro $\mu \mathrm{m}^{3}$ bis zur Reife an. Die Dichte der Granula ist stark hirnregionabhängig. Bitte unterschiedliche Skalen für Granula/ $\mu \mathrm{m}^{3}$ beachten.

Wie Abbildung 23 zeigt, lag der Zeitpunkt des ersten Auftretens gefärbter Granula in unterschiedlichen Regionen an verschiedenen postnatalen Tagen. Während sie im Hirnstamm erstmals an P5 detektierbar waren, verzögerte sich ihr Auftreten im Hippocampus bis P7 und im Neocortex bis P8. Die Zahl der Granula pro Volumen in adulten Tieren war charakteristisch für jede Region. So zeigten die Pyramidenzellen des Neocortex $(n=20,0.67 \pm 0.12)$ eine geringere Granuladichte als die Hirnstammkerne (nucleus hypoglossus: $\mathrm{n}=30,1.32 \pm 0.16$; nucleus ambiguus: $\mathrm{n}=20,1.5 \pm 0.08)$ und die Neurone in der CA1 Region des Hippocampus $(\mathrm{n}=16 ; 3.3 \pm 0.23)$ s. Abb. 23). (in Kooperation, Ritter et al., 2001a)

Die bisher beschriebene intrazelluläre Umverteilung des $\mathrm{GABA}_{\mathrm{B}}$-Rezeptors während der posnatalen Entwicklung der Maus wurde unter Benutzung eines Antikörpers beobachtet, der das konservierte, carboxiterminale Ende der beiden weitverbreitetsten Splicevarianten der GABA $A_{B}$ R1-Untereinheit ( a und b) gleichermaßen erkennt. Um die Ergebnisse zu verifizieren und eine genauere Aussage über die Verteilung der Splicevarianten treffen $\mathrm{zu}$ können, wurden weitere Färbungen mit Splicevarianten-spezifischen Antikörpern und anderen Färbemethoden durchgeführt. Es zeigte sich, 
daß gleichen, immunopositiven Granula mit einem ausschließlich gegen das aminoterminale Ende der $\mathrm{GABA}_{\mathrm{B}} \mathrm{R} 1$ b-Variante gerichteten Antikörper detektiert werden konnten s. Abb. 24).

Ebenso konnten immunopositive Granula in adulten Neuronen unter Benutzung des GABA $_{B}$ R1 a/b-spezifischen Antikörpers und der Fluoreszenzfärbung nachgewiesen werden (s. Abb. 25 A, C). Dieselbe Methode führte beim Einsatz eines Erstantikörpers gegen die GABA $A_{B}$ R-Untereinheit ebenfalls zu einer Detektion punktförmiger Immunoreaktivität mit vergleichbarer intrazellulärer Verteilung s. Abb. 25 B, D].

\section{Hinterhorn}

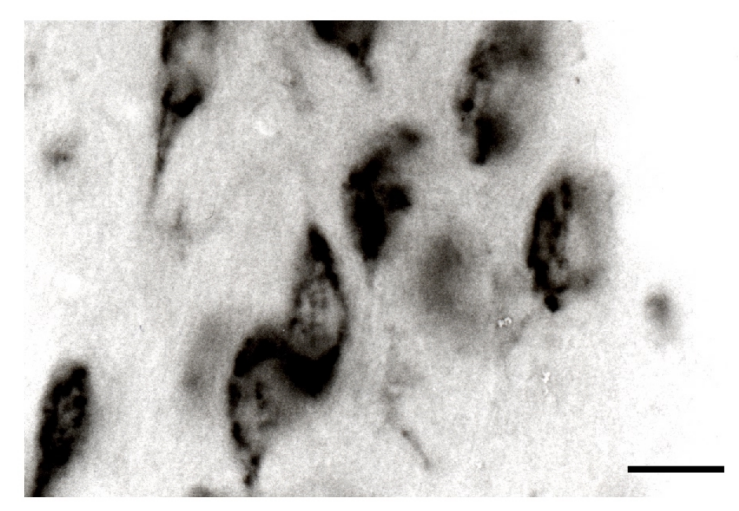

\section{Cerebellum}

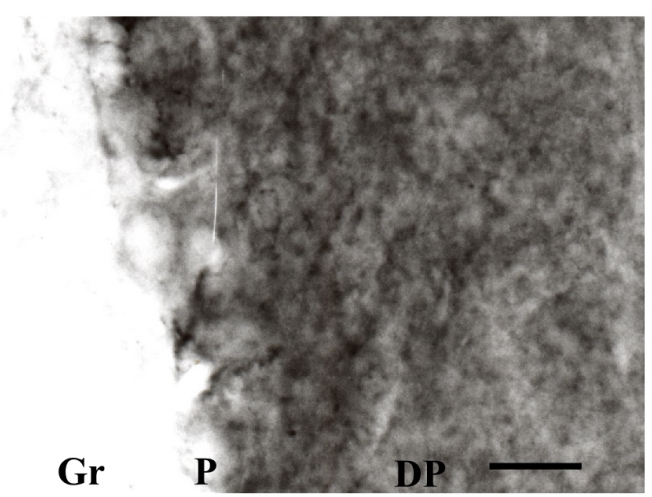

Abb. 24. Verteilung der GABA $\mathrm{B} 1$ b Immunoreaktivität in Rückenmark und Cerebellum adulter Mäuse. In den Neuronen des spinalen Hinterhorns (links) sind immunopositive Granula in Soma und Dendriten zu detektieren. Im Cerebellum (rechts) sind die Dendritenbäume der Purkinjezellen (DP) stark immunopositiv während die Färbung in den Purkinjezellen (P) und der Granularschicht (Gr) kaum erkennbar ist. Die Balken entsprechen $30 \mu \mathrm{m}$.

Um zu klären, welche Zellorganellen und -kompartimente innerhalb eines Neurons den $\mathrm{GABA}_{\mathrm{B}^{-}}$ Rezeptor enthalten, ist die Lichtmikroskopie aus Gründen unzureichender Gewebefixierung und physikalischer Beschränkungen s. Material und Methoden nicht geeignet. Deshalb wurde von Frau Monika Ochojski im Rahmen ihrer Dissertation eine elektronenmikroskopische Studie durchgeführt (Ritter et al., 2001a), in der die intrazelluläre Lokalisation des $\mathrm{GABA}_{\mathrm{B}}$-Rezeptors dargestellt wurde. Hierbei zeigte sich, daß immunoreaktive Granula Gruppen von kleineren, etwa 30-50 nm großen Vesikeln darstellen s. Abb. 36, Diskussion. 


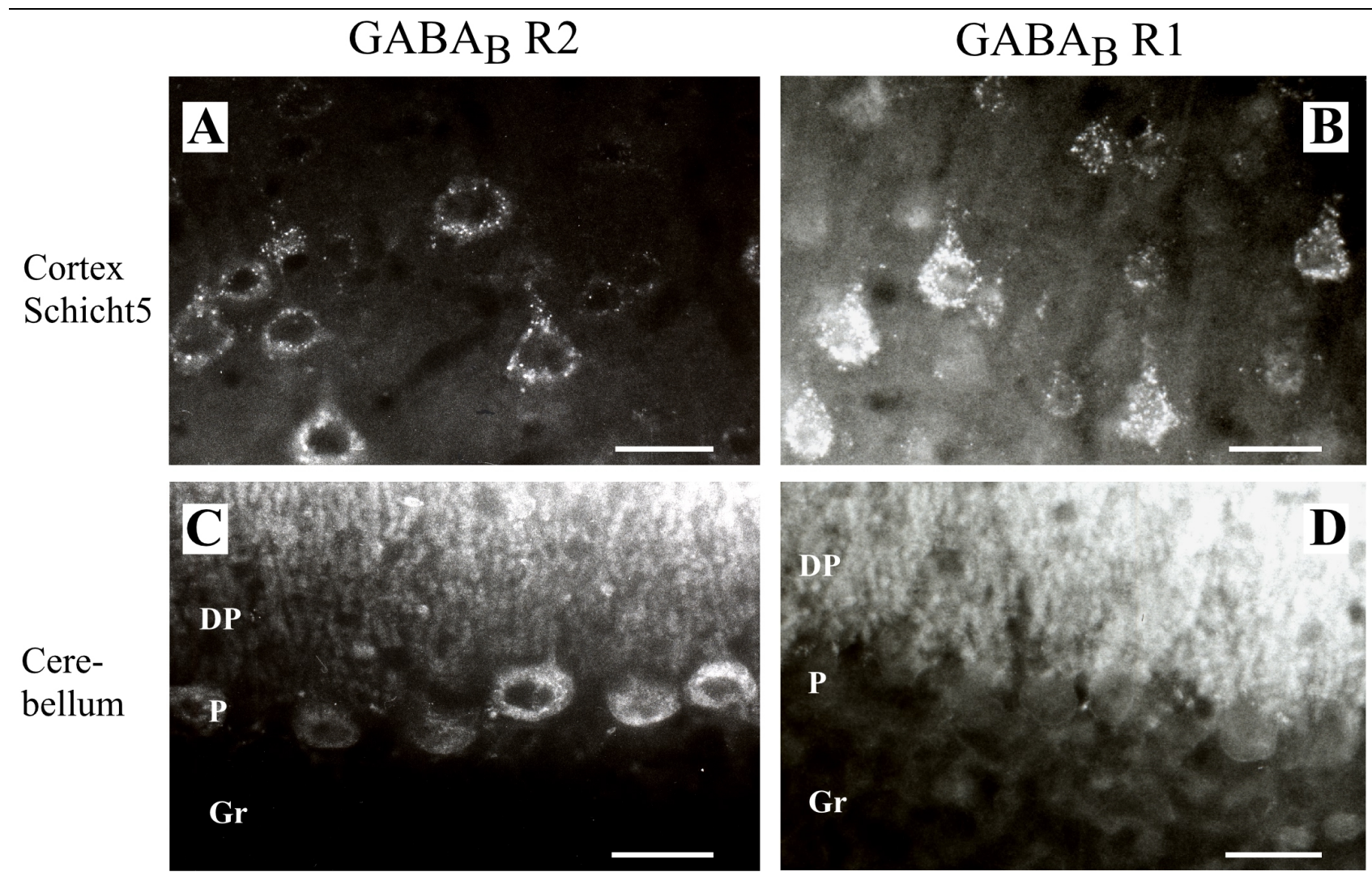

Abb. 25. GABA $A_{B}$ R1- und R2-immunopositive Granula sind mit Fluoreszenzfärbungen zu detektieren. A, B: Fluoreszenzfärbungen von $\mathrm{GABA}_{\mathrm{B}}$ R2 bzw. R1 mit CY3-gekoppeltem Antikörper in der fünften Cortexschicht. Die immunopositiven Granula sind deutlich in Soma und Dendriten zu erkennen. C, D: In den Pyramidenzellen des Cerebellums sind kaum immunopositive Granula detektierbar. $\mathrm{GABA}_{\mathrm{B}} \mathrm{R} 2$ scheint in den Somata häufiger vertreten als GABA $\mathrm{B} 1$. Die Balken entsprechen jeweils $30 \mu \mathrm{m}$. Gr: Granularschicht; P: Somata der Purkinje Zellen; DP: Dendriten der Purkinje Zellen 
4.4 Die intrazelluläre Komplex-Bildung zwischen ATF4 und GABA $A_{\mathrm{B}}$-Rezeptor ändert sich während der postnatalen Entwicklung

Einige Forschungsarbeiten jüngerer Zeit zeigten, daß der $\mathrm{GABA}_{\mathrm{B}}$-Rezeptor nicht nur als Heterodimer seiner beiden Untereinheiten R1 und R2 besteht, sondern wahrscheinlich auch weitere Proteine, wie z.B. Mitglieder der CREB/ATF Familie von Transkriptionsfaktoren binden kann (s. Einleitung). Dies ermöglicht neue Perspektiven, sowohl für die Wirkungsweise des $\mathrm{GABA}_{\mathrm{B}^{-}}$ Rezeptors als auch für seinen Transport innerhalb der Zelle. Doppelfärbungen mit fluoreszierenden Zweitantikörpern zeigten eine Kolokalisation von GABA $_{B}$ R1 a/b- und ATF4-immunopositiven Granula. Zur Markierung des in der Maus exprimierten Transkriptionsfaktors ATF4 wurde ein an einen grün emittierenden Fluofor gekoppelter Zweitantikörper benutzt. Seine Verteilung zeigte sich diffus in Soma und Kern von Neuronen und Gliazellen. Dies galt für gefärbte Gewebeschnitte ebenso wie für primäre hippocampale Zellkulturen. Zusätzlich zu dieser diffusen Färbung zeigten sich verstreute, immunopositive Granula. Addierte man die punktförmige $\mathrm{GABA}_{B}$ R1 a/bImmunoreaktivität so ergaben sich mit diesen Strukturen Kolokalisationen mit gelber Additionsfarbe (s. Abb. 26). Die Färbungen an hippocampalen Zellkulturen wurden in Zusammenarbeit mit Dr. E. Ponimaskin, Institut für Physiologie, Universität Göttingen, durchgeführt. (In Kooperation, Ritter et al., 2001b)

Um diese Ergebnis zu verifizieren, wurde eine Ko-Immunopräzipitation mit entsprechenden Antikörpern aus unterschiedlichen Geweben der Maus durchgeführt. Hierzu wurden Lysate aus
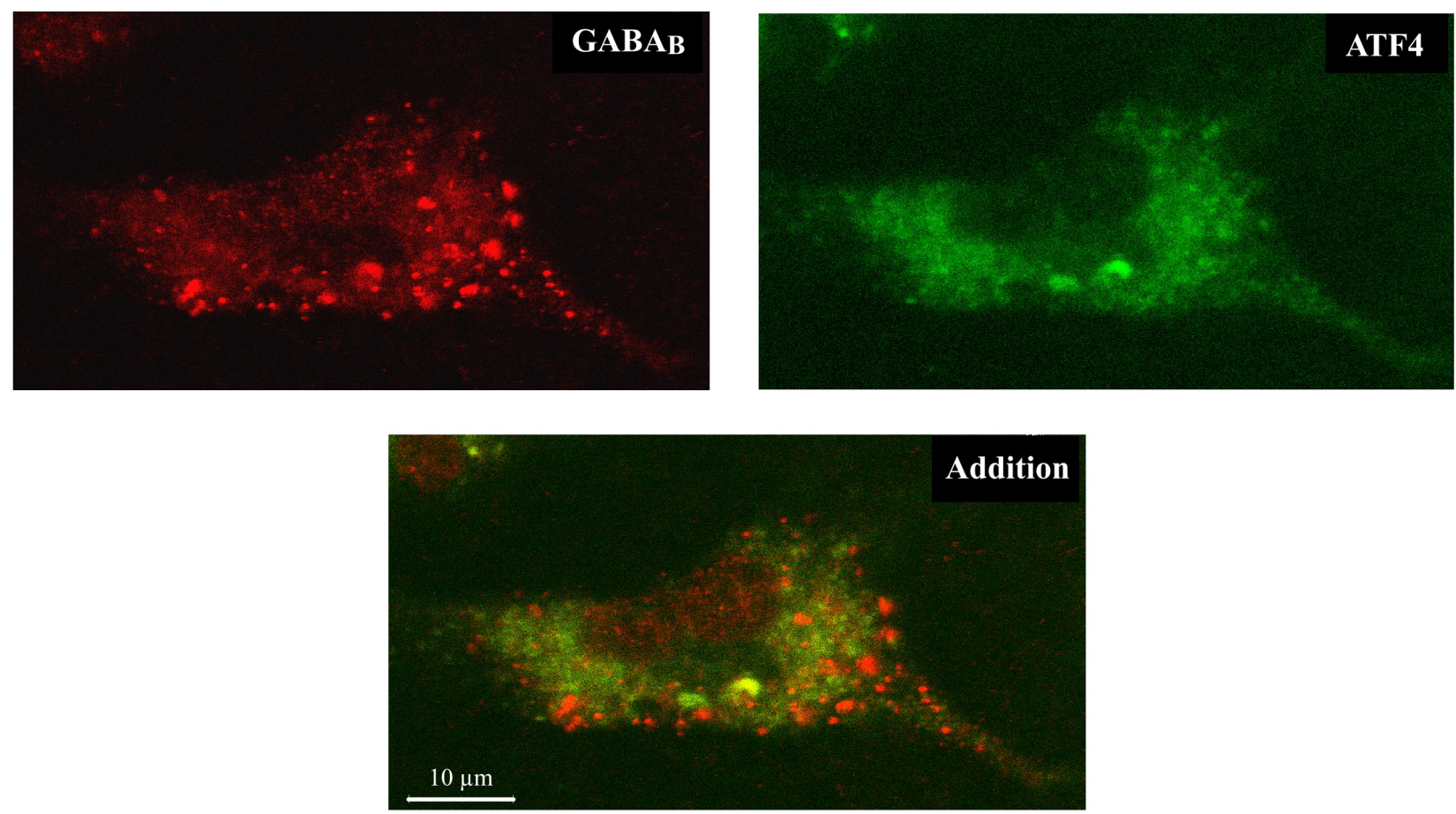

Abb. 26. Fluoreszenz-Doppelfärbung zeigt eine Kolokalisation von GABA $\mathrm{B}$ R1 a/b und ATF4. In kultivierten Zellen des Hippocampus zeigen sich $\mathrm{GABA}_{\mathrm{B}}$-Rezeptor-immunopositive Granula (links). Die Immunoreaktivität für ATF4 ist diffuser verteilt (rechts), es sind jedoch auch intensivere, punktförmige Strukturen zu erkennen. Diese erscheinen in der Addition der Fluoreszenzen als gelbe Färbungen (unten, Mitte), die eine Kolokalisation der gefärbten Antigene anzeigen. Sie beträgt etwa $5 \%$ der GABA $\mathrm{B}^{-R e z e p t o r-}$ immunopositiven Granula. 
verschiedenen Hirngeweben und primären Hippocampus-Zellkulturen erstellt. Die aus ihnen ausgefällten Proteine wurden auf Polyacrylamidgelen aufgetrennt und durch Western BlotVerfahren wurde mit ECL System untersucht, ob neben dem durch den zugegebenen Erstantikörper erkannten Protein weitere zu detektieren waren. Wie Abbildung 27 zeigt, konnte eine Komplexbildung von ATF4 mit beiden GABA $_{B}$-Rezeptor-Untereinheiten in Gesamthirn-Lysat der adulten Maus nachgewiesen werden. Dieser Nachweis gelang sowohl mit einer primären Fällung

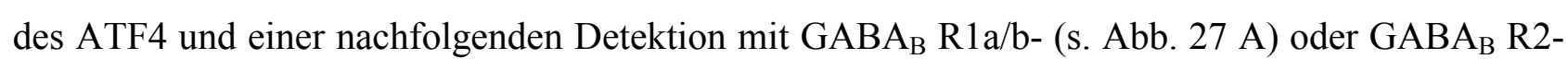
s. Abb. 27 B) spezifischen Antikörper als auch mit einer Fällung einer der GABA $_{B}$-RezeptorUntereinheiten und ATF4-Detektion. Dasselbe Ergebnis zeigte sich bei einer Immunopräzipitation aus kultivierten Hippocampuszellen (s. Abb. 27 A).

A

i) Hirnlysat

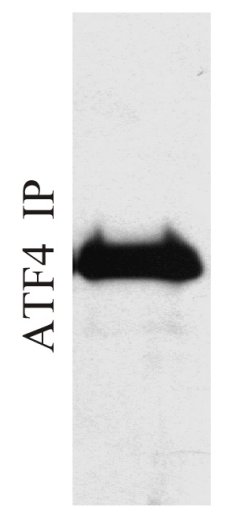

ATF4

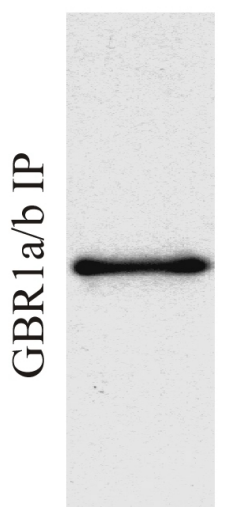

ATF4

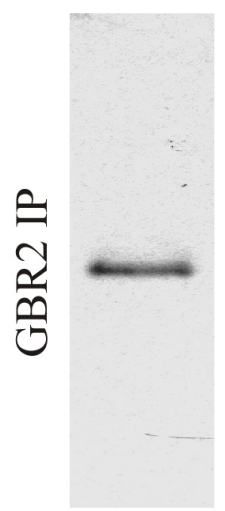

ATF4 ii) Zellkultur $\mathrm{kDa}$

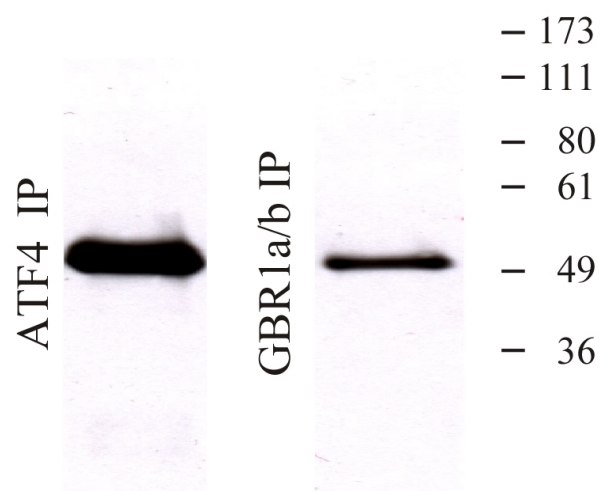

ATF4

ATF4
B

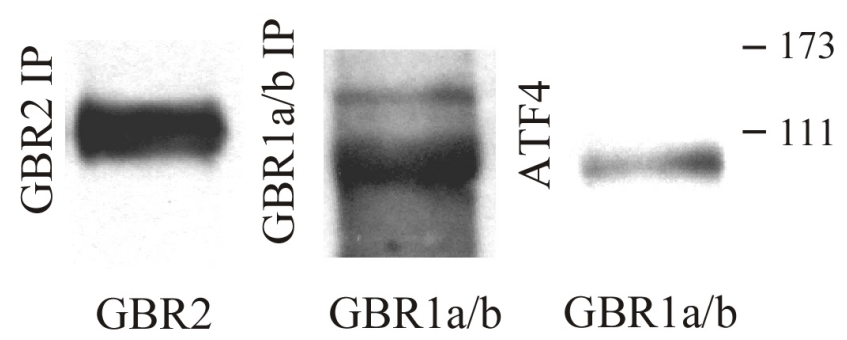

Abb. 27. Ko-immunopräzipitation von $\mathrm{GABA}_{\mathrm{B}} \mathrm{R} 1 \mathrm{a} / \mathrm{b}$ und $\mathrm{GABA}_{\mathrm{B}} \mathrm{R} 2$ mit ATF4 aus Hirnlysat und Lysat aus kultivierten Hippocampuszellen. A: Die mit den links neben den Gelen angegebenen Antikörpern präzipitierten Proteinkomplexe wurden unter reduzierenden Bedingungen auf einem Polyacrylamid-Gel aufgetrennt. Nach der Übertragung auf Nitrozellulose Membranen durch Western-blot wurde ATF4 detektiert. Es zeigte sich, daß sowohl nach Fällung mit GABA $\mathrm{B} 1$ Antikörper als auch mit Antikörper gegen GABA $\mathrm{B} 2$ aus Hirnlysaten (i) ATF4 detektierbar war. Ähnliche Ergebnisse zeigten sich bei einer Fällung aus dem Lysat kultivierter Hippocampuszellen (ii). B: Auch eine Detektion mit GABA $\mathrm{B}$ R1- bzw 2-Antikörpern verlief nach Fällung aus Hirnlysat mit den angegebenen Antikörpern positiv. Es sind repräsentative Gele von sieben unabhängigen Versuchen gezeigt. GBR1a/b $=\mathrm{GABA}_{\mathrm{B}} \mathrm{R} 1 \mathrm{a} / \mathrm{b}$; GBR2 = GABA $\mathrm{B}$ R2; IP = zur Präzipitation benutzter Antikörper

Zur weiteren Charakterisierung der Komplexbildung von GABA - Rezeptoren und ATF4 wurde die Signalintensität der Proteinbanden untereinander verglichen. Hierzu wurde die Intensität der 
Kontrollbande (gleicher Antikörper zu Fällung und zur Detektion, :=100\%) mit der des koimmunopräzipitierten Proteins verglichen. Bei dieser quantitativen Analyse zeigte sich, daß ca. 10\% des gesamten detektierbaren ATF4 mit der GABA $_{B}$ R1-Untereinheit gekoppelt waren. Die Komplexbildung mit der R2-Untereinheit erwies sich als etwas schwächer. Hier konnten nur etwa 5\% des detektierbaren ATF4 in Komplexen nachgewiesen werden. Die Menge von interagierenden ATF4 und $\mathrm{GABA}_{\mathrm{B}} \mathrm{R} 1$ variierte allerdings geringfügig, wenn unterschiedliche Gehirnregionen mit einander verglichen wurden. Während in Lysaten aus dem Hirnstamm und Cerebellum 10-12\% des gesamten ATF4 an einer Bindung beteiligt waren, waren es im Cortex lediglich etwa 6\%. Auch in

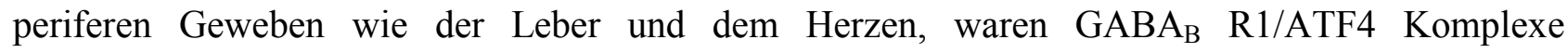
nachweisbar s. Abb. 28.
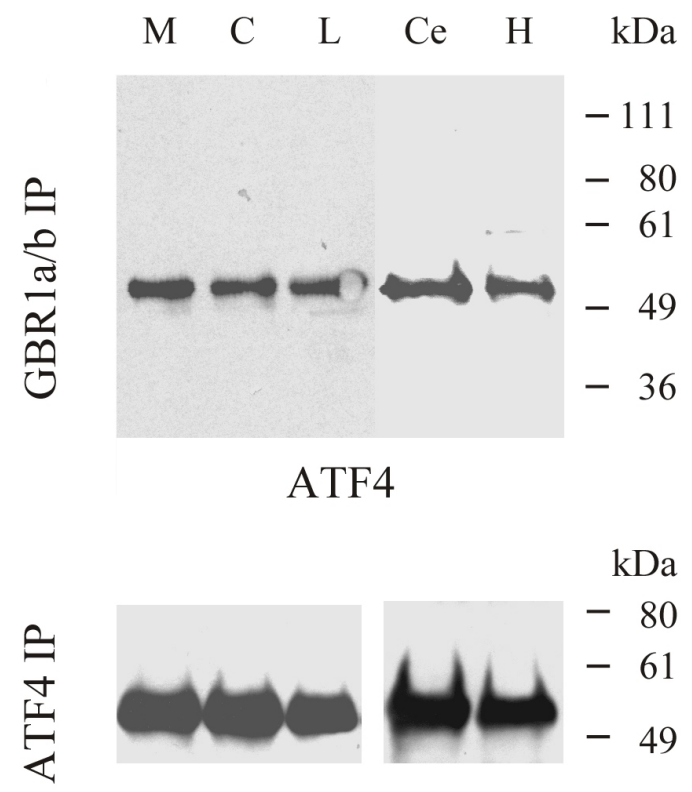

ATF4

Abb. 28. GABA $A_{B}$ R1 a/b und ATF4 ko-immunopräzipitieren in unterschiedlichen Geweben. GABA $\mathrm{B} 1 \mathrm{a} / \mathrm{b}$ (oben) und ATF4 (unten) wurden aus den Lysaten unterschiedlicher Gewebe der Maus immunopräzipitiert und unter reduzierenden Bedingungen auf einem Polyacrylamid-Gel aufgetrennt. Nach der Übertragung auf Nitrozellulose-Membranen durch Western-blot wurde ATF4 mit entsprechenden Antikörpern detektiert. Die gezeigten Ergebnisse konnten in drei Versuchen verifiziert werden. GBR1a/b = GABA $\mathrm{B} 1 \mathrm{a} / \mathrm{b}$; IP = zur Präzipitation benutzter Antikörper; $\mathrm{M}=$ Medulla; $\mathrm{C}=\mathrm{Cortex}$; $\mathrm{L}=\mathrm{Leber}$; Ce = Cerebellum; $\mathrm{H}=$ Herz

Des weiteren wurde die postnatale Entwicklung dieser Komplexbildung untersucht. Hier wurde in Proben gleichen Proteingehaltes aus Lysaten verschieden alter Tiere eine Ko-Immunopräzipitation durchgeführt und die Intensität der Banden verglichen. Die intensivste Bande wurde mit 100\% festgelegt. Es stellte sich für die beiden Untereinheiten ein unterschiedliches Bild dar. Die Intensität der Bindung von ATF4 an die $\mathrm{GABA}_{\mathrm{B}}$ R1-Untereinheit war in allen vier (P0, P5, P15, P20) untersuchten postnatalen Stadien vorhanden, nahm aber während der ersten zwei postnatalen Wochen ab, um zwischen P15 und P20 wieder leicht anzusteigen s. Abb. 29. Auch GABA R2 $^{2}$ ko-immunopräzipitierte in jedem getesteten Alter mit ATF4. Diese Bindung wurde allerdings ausgehend vom Tag der Geburt über die ersten zwei postnatalen Wochen zunächst schwächer und 
$\overline{\text { stieg zur adulten Intensität wieder an. Die gesamte detektierbare Proteinmenge von ATF4, GABA }}$ $\mathrm{R} 1 \mathrm{a} / \mathrm{b}$ und R2 änderte sich während dieser Zeit nicht. Dieses wurde durch die gleichbleibende Intensität der Kontrollbanden (gleicher Antikörper für Fällung und Detektion, s. Abb. 29 A, B untere Gele) verifiziert.

A
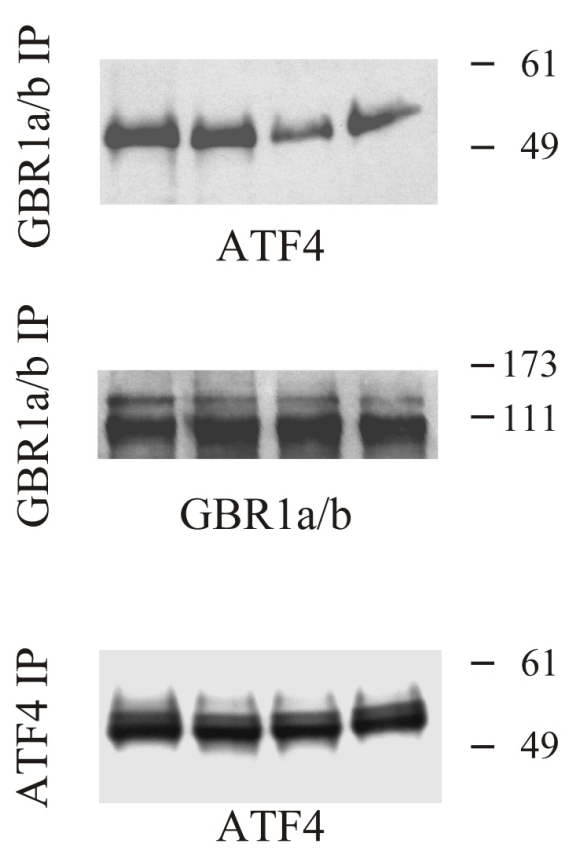

$\mathrm{C}$

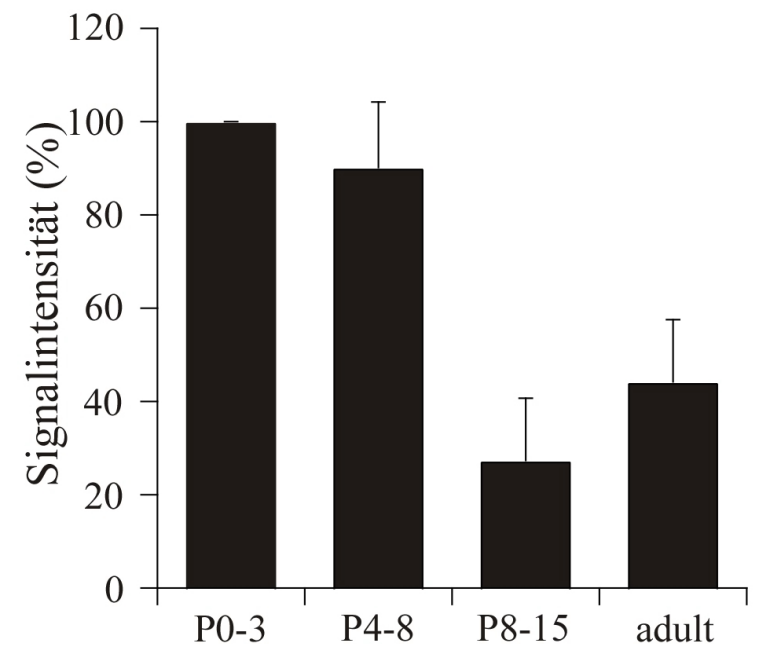

B

P3 $\quad$ P5 $\quad$ P10 P20 $\quad \mathrm{kDa}$

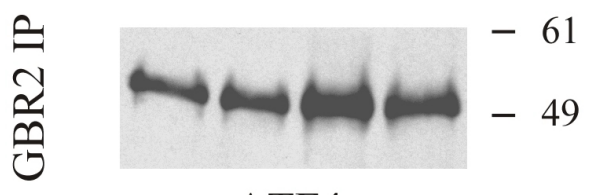

ATF4

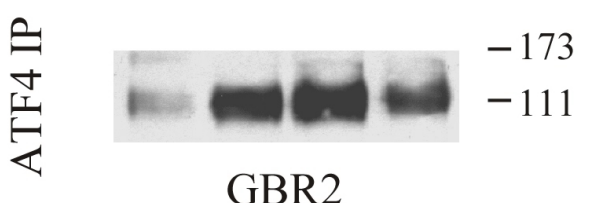

GBR2

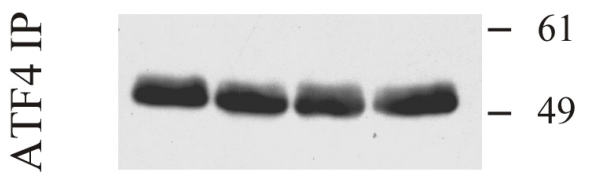

ATF4

$\mathrm{D}$

ATF4 and GBR2

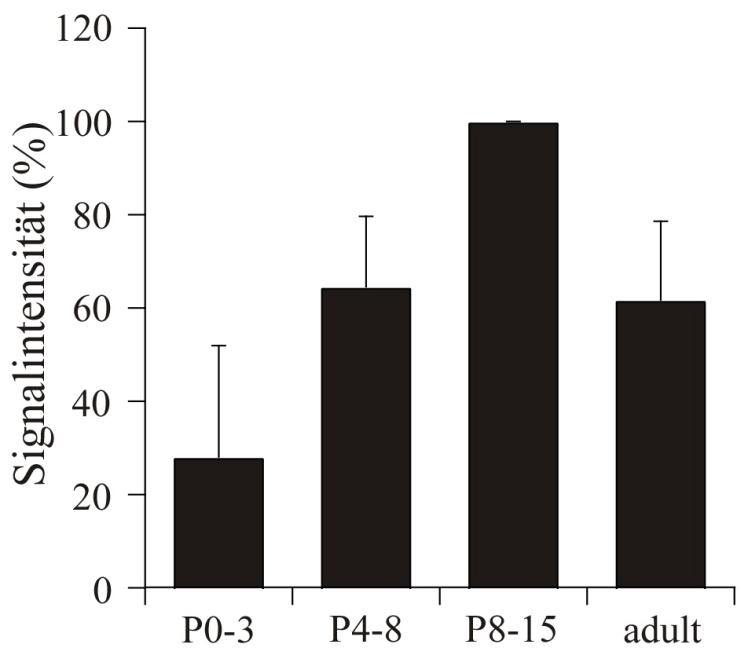

Abb. 29. Entwicklungsbedingte Änderungen in der Interaktion mit ATF4 sind spezifisch für die $G A B A_{B}$-RezeptorUntereinheiten. A, B: GABA $\mathrm{B}$ R1 (A) bzw. GABA $\mathrm{B} 2$ (B) und ATF4 wurden aus den Lysaten des gesamten Hirngewebes mit den links vom Gel angegebenen Antikörpern immunopräzipitiert. Der Gesamtproteingehalt der Proben wurde konstant gehalten. Die ausgefällten Proteine wurden mit den jeweils unter den Gelen angegebenen Antikörpern gefärbt. C, D: Densiometrische Quantifizierungen der unter A und B erhaltenen Signale mit entsprechenden Computerprogrammen zeigen die postnatale Entwicklung der relativ zum höchsten Wert angegebenen Signalstärke des ko-immunopräzipitierten Proteins auf. Die Signalstärke des detektierten ATF4 änderte sich in den untersuchten Altersstadien nicht. Die gezeigten Ergebnisse konnten in drei Versuchen verifiziert werden. GBR1a/b $=G_{A B A}$ R1 a/b; GBR2 = GABA $R 2$; IP = zur Präzipitation benutzter Antikörper. 
4.5 Auswirkungen der Entwicklung des GABAergen Systems auf der Ebene von neuronalen Netzwerken

\subsubsection{GABA $_{A}$-Rezeptoren reduzieren die respiratorische Frequenz erst ab dem Eintritt ihrer hyperpolarisierenden Wirkung}

In den vorausgehenden Untersuchungen wurde gezeigt, daß das ab der Geburt im Hirnstamm von NMRI Mäusen funktionelle GABAerge System vielen ontogenetischen Veränderungen unterliegt. Diese Veränderungen betreffen sowohl den $\mathrm{GABA}_{\mathrm{A}^{-}}$als auch den $\mathrm{GABA}_{\mathrm{B}}$-Rezeptor. Während sich die $\mathrm{GABA}_{\mathrm{A}}$-Rezeptor-vermittelten, postsynaptischen Potentiale von depolarisierend zu hyperpolarisierend verschieben, zeigt der $\mathrm{GABA}_{\mathrm{B}}$-Rezeptor eine intrazelluläre Umverteilung und eine Veränderung seiner relativen Komplexbildungsmenge mit ATF4.

Um festzustellen, wie sich diese Veränderungen auf der Netzwerkebene auswirken, wurden die Effekte selektiver Rezeptorblockade für den respiratorischen Rhythmus im rhytmisch aktiven Hirnstammpräparat untersucht. Zunächst wurde der GABA $_{\mathrm{A}}$-Rezeptor-Antagonist Bicucullin systemisch über die Badlösung appliziert und die Netzwerkaktivität durch die Ableitung des zwölften Hirnnervs (N.XII) dokumentiert. Kleinere Dosen Bicucullin $(0.25 \mu \mathrm{M})$ hatten in P0-3 Mäusen keinen signifikanten Effekt auf die Frequenz oder Amplitude des integrierten Signals der N.XII Aktivität ( $\mathrm{n}=5$ bzw 7: s. Abb. 30 A Abb. 31 A, B). Erst bei einer Bicucullinkonzentration von $5 \mu \mathrm{M}$ konnte eine geringfügige Vergrößerung der Amplitude der integrierten N.XII Aktivität beobachtet werden. Bei Tieren zwischen P4 und P6 zeigte sich auf die Amplitude ein ähnlicher Effekt, allerdings erhöhte schon eine Dosis von $0.5 \mu \mathrm{M}$ Bicucullin die Frequenz des Rhythmus signifikant (n=14; s. Abb. 30 B; Abb. 31 C, D). Er konnte durch eine erhöhte Bicucullin-Gabe (5 $\mu \mathrm{M})$ weiter beschleunigt werden. Die Reaktion von Mäusen in der zweiten postnatalen Woche (P710) war vergleichbar, allerdings deutlicher ausgeprägt $(n=7 ;$ s. Abb. 30 C; Abb. 31 E, F. Die integrierten Signale der N.XII Aktivität zeigten in keinem der untersuchten postnatalen Stadien eine Veränderung in Anstiegszeit und Breite nach einer Blockade der $\mathrm{GABA}_{\mathrm{A}}$-Rezeptoren.

Es fällt auf, daß eine Blockade des $\mathrm{GABA}_{\mathrm{A}}$-Rezeptors bei Mäusen bis zum dritten postnatalen Tag zu einer höheren Unregelmäßigkeit in der Abfolge der respiratorischen bursts führte. Verglich man den sich ergebenden Koeffizient der Variation der Frequenzen in perinatalen und älteren Tieren vor und nach Bicucullin-Gabe, so zeigte sich nur bei P0-P3 eine deutliche Erhöhung s. Abb. 32 A. Dies spricht für eine Rolle des $\mathrm{GABA}_{\mathrm{A}}$-Rezeptors bei der Stabilisierung des Rhythmus in jüngeren Tieren. Der Effekt war ab einer Antagonistkonzentration von 2.5 $\mu \mathrm{M}$ zu beobachten. In P4-6 Mäusen war eine Vergrößerung des Variationskoeffizienten kaum erkennbar, während sich in P710 sogar eine Verringerung andeutete S. Abb. 32 B, C). Zum anderen konnte in drei von sieben Experimenten mit Tieren im Alter von P0-P3 das Auftreten zusätzlicher bursts mit geringerer Amplitude und beschleunigter Frequenz neben der gewohnten Form der rhythmischen Aktivität beobachtet werden s. Abb. 33). Dieses Phänomen trat in keinem der Versuche mit Tieren älter als 
ACSF.

\section{Kontrolle}

A) P1

NXII

$\int$ NXII
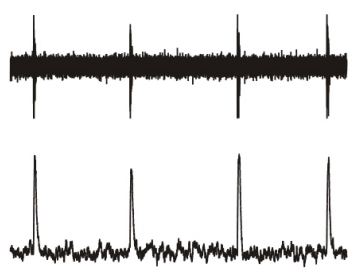

B) P4

NXII

$\int \mathrm{NXII}$

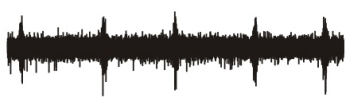

C) P7

NXII

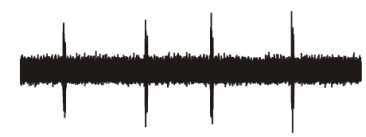

$\int \mathrm{NXII}$

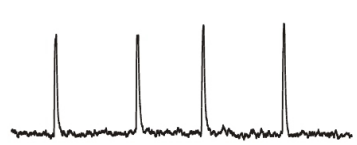

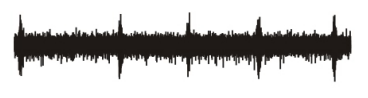

$0.25 \mu \mathrm{M}$

Bicucullin
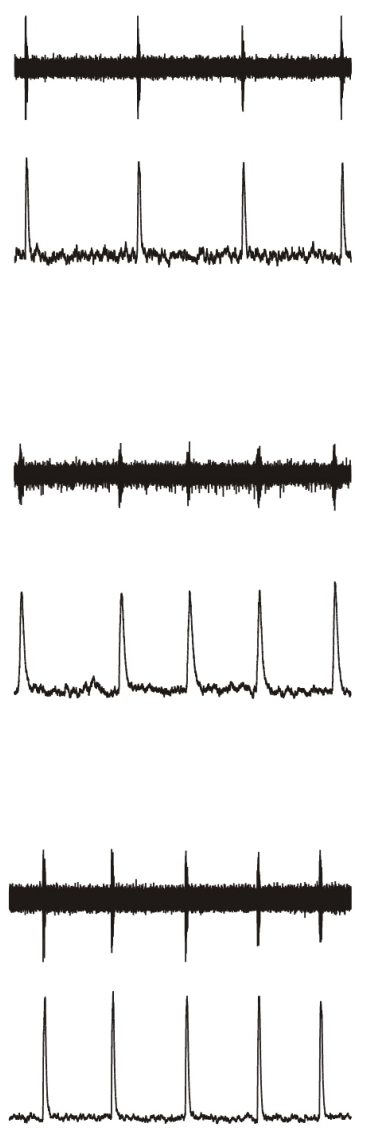
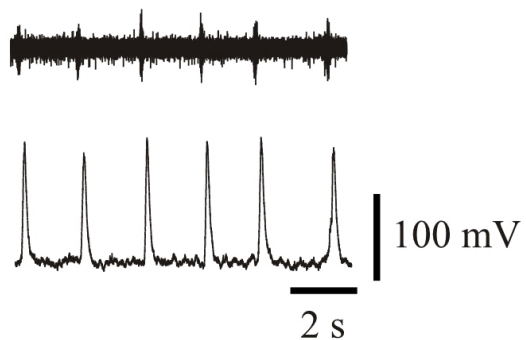

$2.5 \mu \mathrm{M}$

Bicucullin

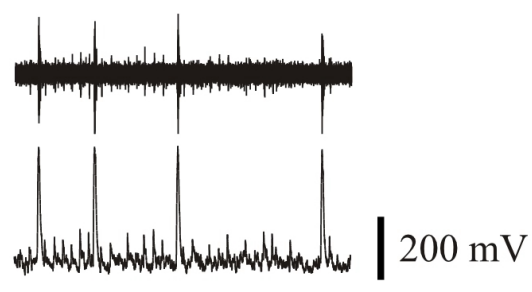

$\overline{4 \mathrm{~s}}$
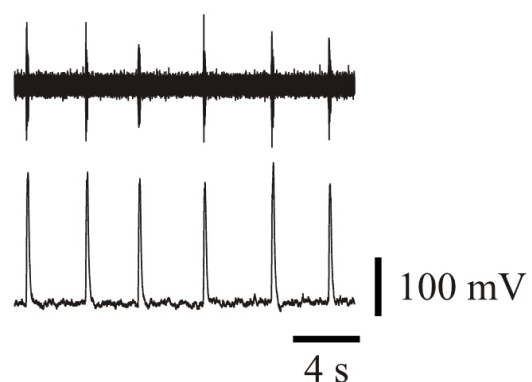

Abb. 30. Einfluß der $\mathrm{GABA}_{\mathrm{A}}$-Rezeptor-Blockade auf den respiratorischen Rhythmus der Maus in unterschiedlichen postnatalen Stadien. A: Extrazelluläre Ableitung der Summenaktivität des zwölften Hirnnerven (NXII) und seines Integrales ( NXII) im Hirnstammpräparat einer P1 Maus. Unterschiedliche Konzentrationen von Bicucullin in der Badlösung vergrößern weder Frequenz noch Amplitude des respirativen Rhythmus. Es zeigt sich allerdings eine Unregelmäßigkeit in den Abständen der auftretenden bursts bei einer Bicucullinkonzentration von $2.5 \mu \mathrm{M}$. B: Im Alter von P4 bewirken $2.5 \mu \mathrm{M}$ Bicucullin sowohl eine Beschleunigung als auch eine Vergrößerung der Amplitude der respiratorischen Aktivität. C: Die bei P4 beobachteten Wirkungen treten an P7 verstärkt und bereits bei geringeren Konzentrationen von Bicucullin $(0.25 \mu \mathrm{M})$ auf. 

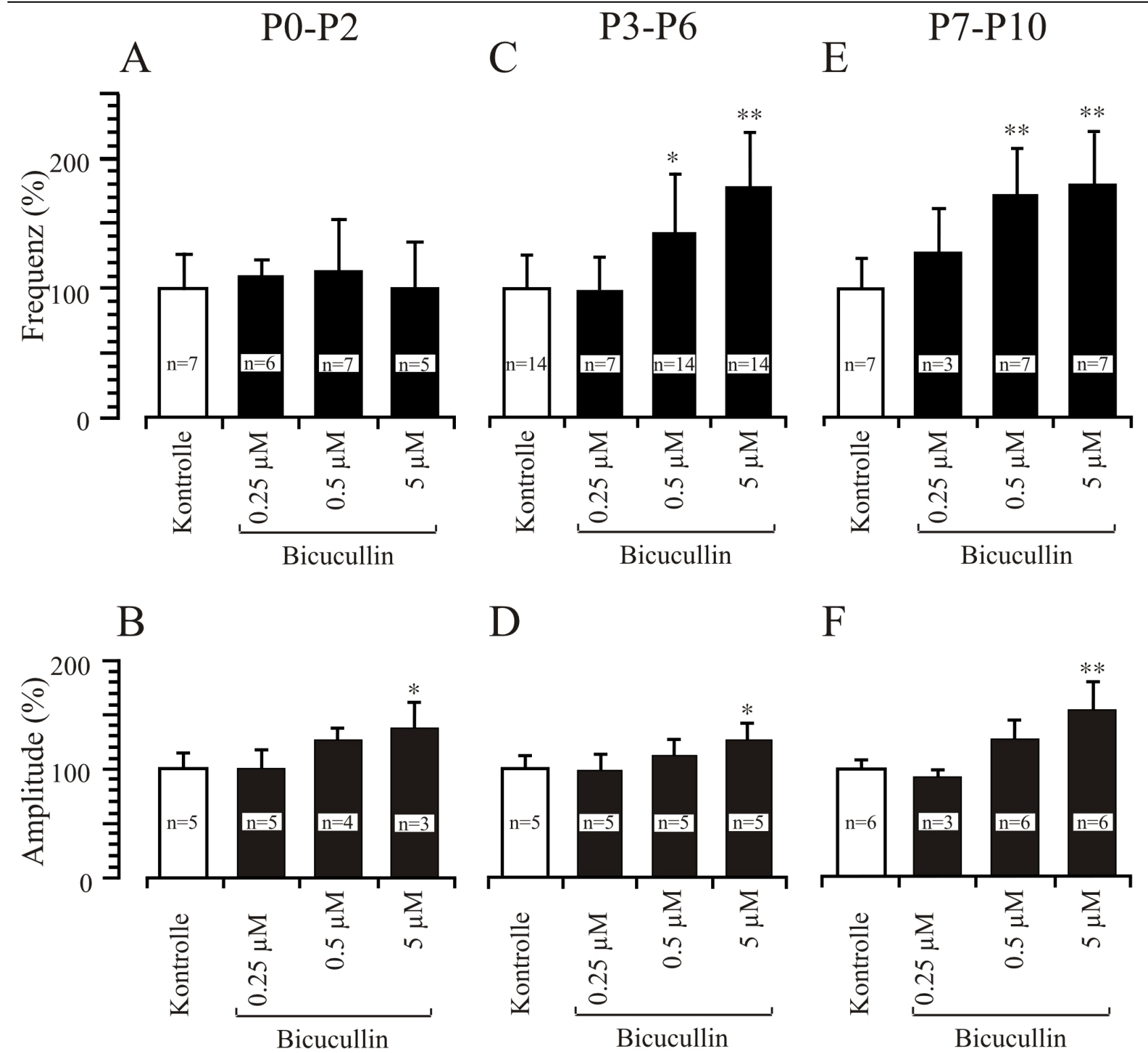

$\mathrm{D}$

$\mathrm{F}$
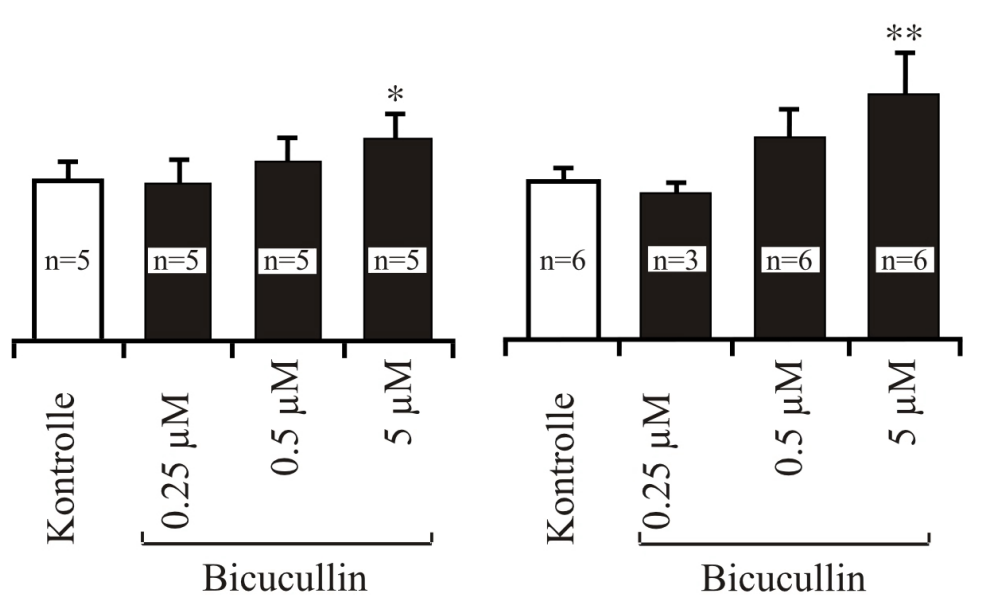

Abb. 31. Statistische Signifikanz der Bicucullin-induzierten Effekte. Die Ergebnisse aus der angegebenen Anzahl von Versuchen wurden mit einem gepaarten ANOVA Test auf signifikante Unterschiede geprüft. Die Frequenz (A) und die Amplitude (B) rhythmischer Aktivität in unterschiedlichen Altersstufen wurde gegen die Konzentration von Bicucullin in der Badlösung aufgetragen. A: Während die Frequenz zwischen P0-2 nicht Bicucullin-sensitiv ist, erhöht sich diese Sensitivität mit zunehmenden Alter. B: In Tieren zwischen P0-2 und P3-6 zeigt nur eine Bicucullinkonzentration von $5 \mu \mathrm{M}$ einen signifikanten Einfluß auf die Amplitude der respiratorischen Aktivität. Zwischen P7 und P10 wird diese Vergrößerung deutlich signifikant. $*=$ signifikant $(\mathrm{P}<0.05) ; * *=$ deutlich signifikant $(\mathrm{P}<0.01)$ 


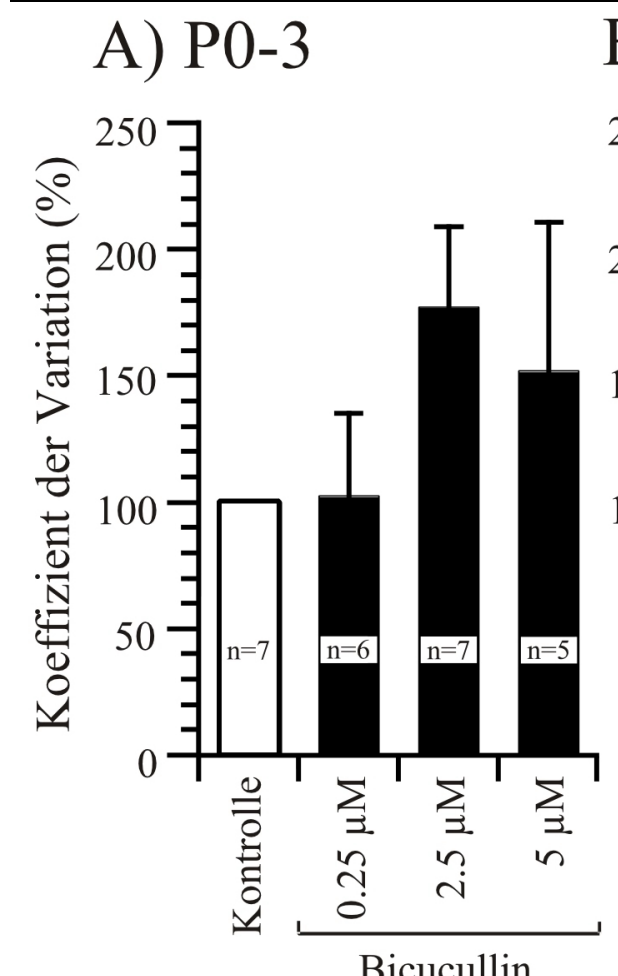

B) P4-6

C) $\mathrm{P} 7-10$

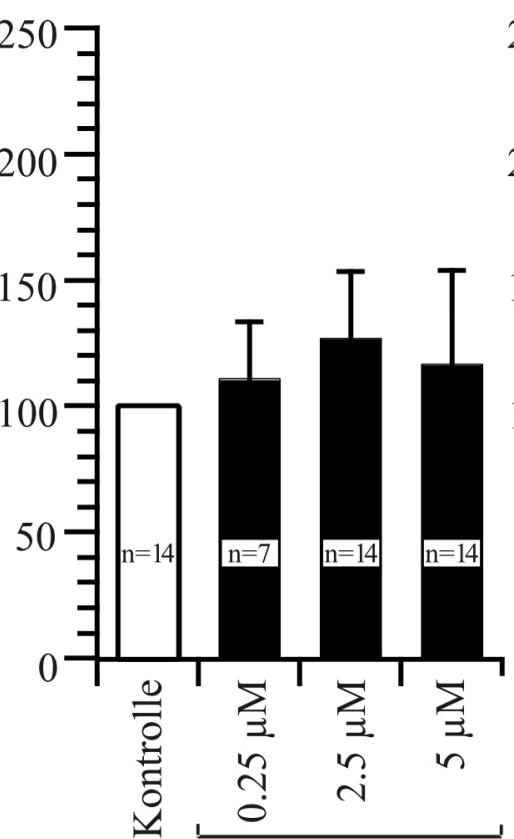

Bicucullin

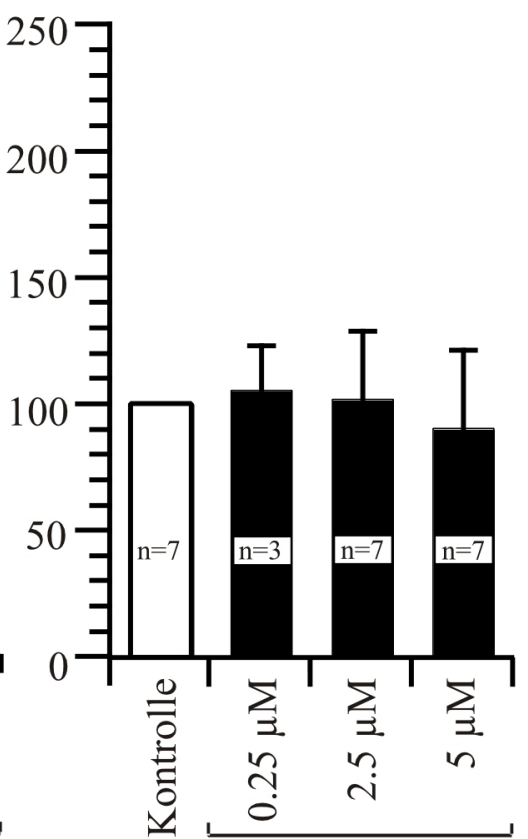

Bicucullin

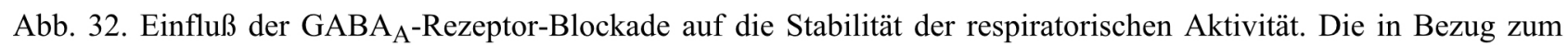
Mittelwert relative Standardabweichung, auch Koeffizient der Variation genannt, wurde als Maß für die Stabilität der rhythmischen Frequenz gegen die Bicucullinkonzentration aufgetragen. Die angegebene Zahl von Versuchen wurde gemittelt. Während Bicucullin den Koeffizient der Variation in Mäusen von P0-3 dosisabhängig erhöhte (A), zeigte sich zwischen P4-6 (B) und P7-10 (C) kaum ein Effekt von Bicucullin auf die Stabilität der Frequenz. 


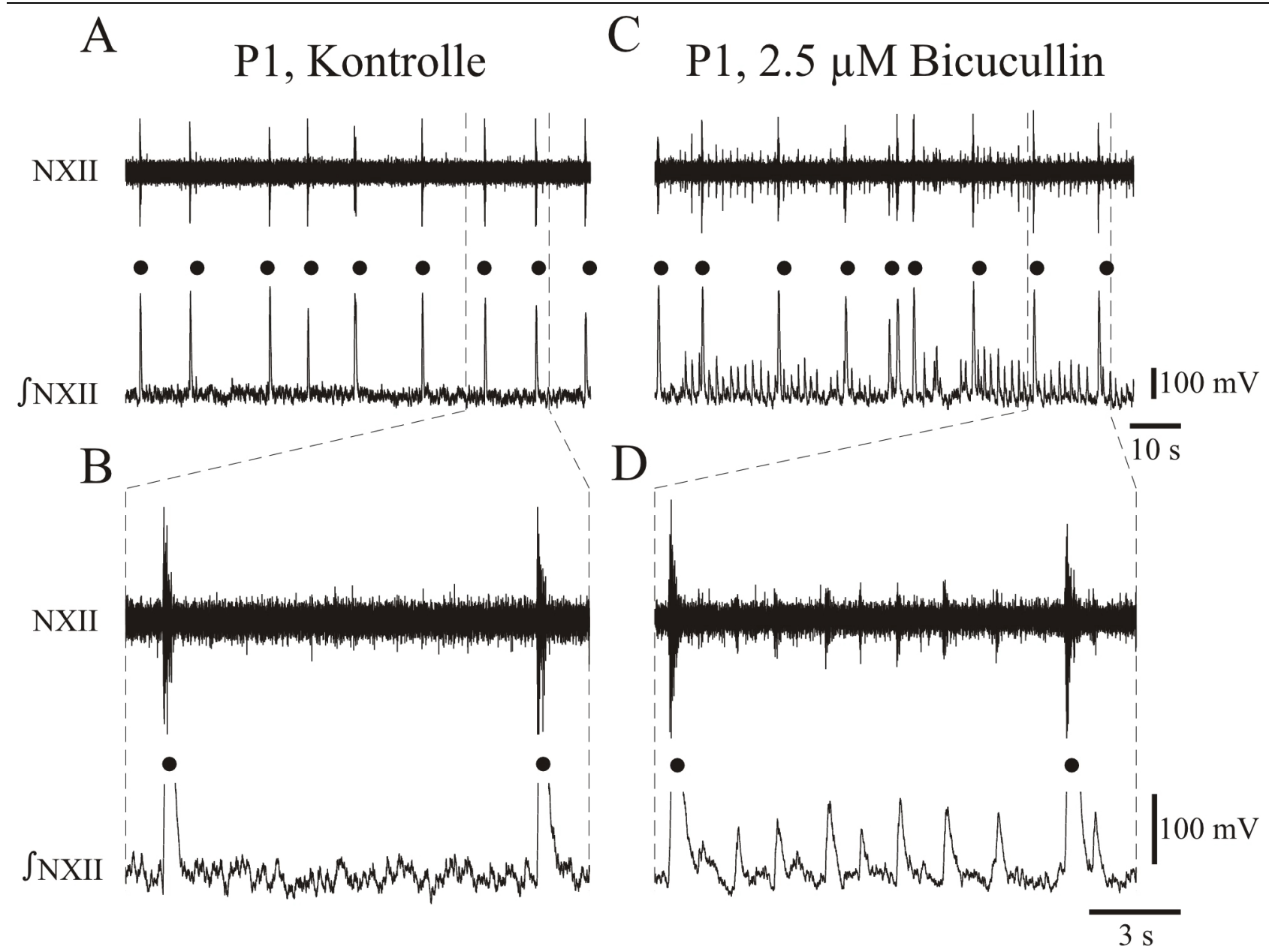

Abb. 33. Bicucullin erzeugt einen zusätzlichen, hochfrequenten Rhythmus geringer Amplitude in jungen Tieren. A: Extrazelluläre Ableitung der Aktivität des zwölften Hirnnerven (NXII) und seine Integration ( (NXII) einer P1 Maus unter Kontrollbedingungen. Die Punkte kennzeichnen den Rhythmus. B: Vergrößerte Ansicht der Region in A innerhalb der gestrichelten Linie. Die Aktivitätsspitzen des integrierten Signals sind abgeschnitten. C: $2.5 \mu \mathrm{M}$ Bicucullin verringert die Regelmäßigkeit des Rhythmus (Punkte) und es erscheint eine zusätzliche rhythmische Aktivität mit größerer Frequenz und geringerer Amplitude. D: Ausschnittsvergrößerung ähnlich B.

\subsubsection{Blockade des GABA $_{\mathrm{B}}$-Rezeptors zeigt eine grundlegend unterschiedliche Wirkung in perinatalen und in älteren Mäusen}

In weiterführenden Versuchen wurde der $\mathrm{GABA}_{\mathrm{B}}$-Rezeptor im rhytmisch aktiven Hirnstammpräparat mit CGP 55845A (5-40 nM) blockiert. In perinatalen (P0-3) NMRI Mäusen zeigte sich ab 20 nM CGP eine signifikante Erhöhung der Rhythmusfrequenz (n=10; s. Abb. 34 C). Zwischen P4-6 erhöhten 40 nM CGP die Frequenz in 4 Präparationen während sie in 4 anderen verringert wurde. Ab P7 reduzierte CGP den respiratorische Frequenz in allen durchgeführten Versuchen (P7-15; n=14; S. Abb. 34 D) bereits bei einer Konzentration von 5 nM. Somit änderte sich nicht nur der Effekt der Blockade, sondern auch die Sensitivität des Rezeptors für CGP. Die Wirkung von CGP war reversibel bei Auswaschen mit Kontrollösung. 
P1

$\mathrm{A}_{1} \quad$ Kontrolle

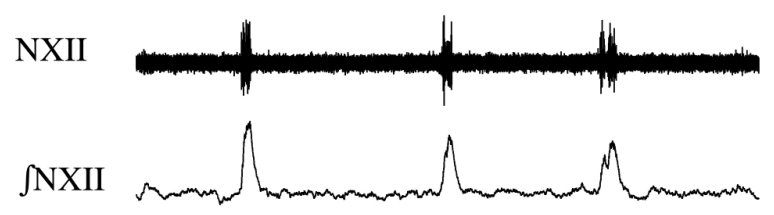

$\mathrm{A}_{2} \quad 40$ nM CGP 55845A

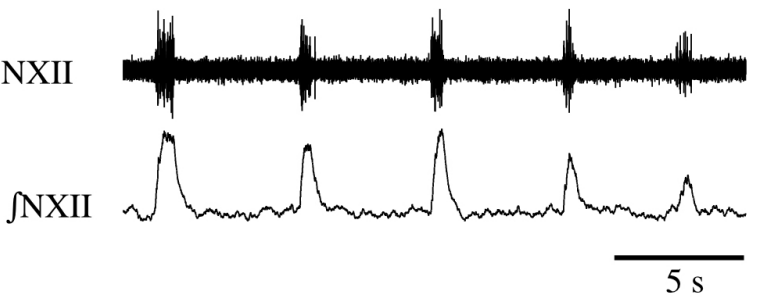

P9

$\mathrm{B}_{1}$ Kontrolle

NXII

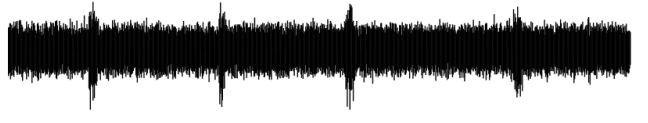

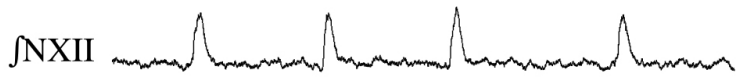

NXII

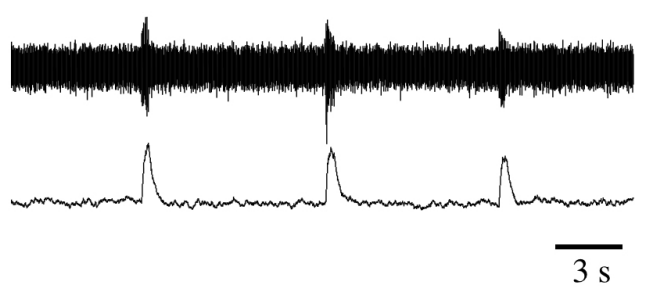

$\mathrm{C}$

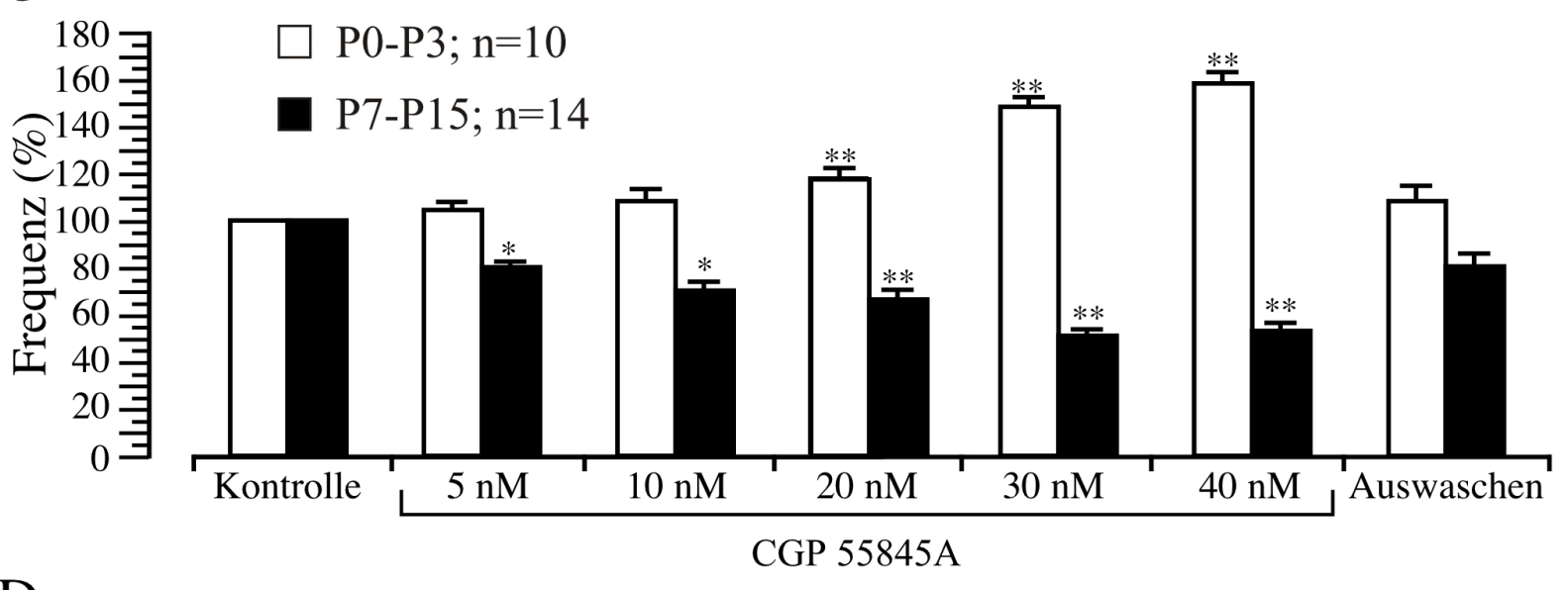

$\mathrm{D}$

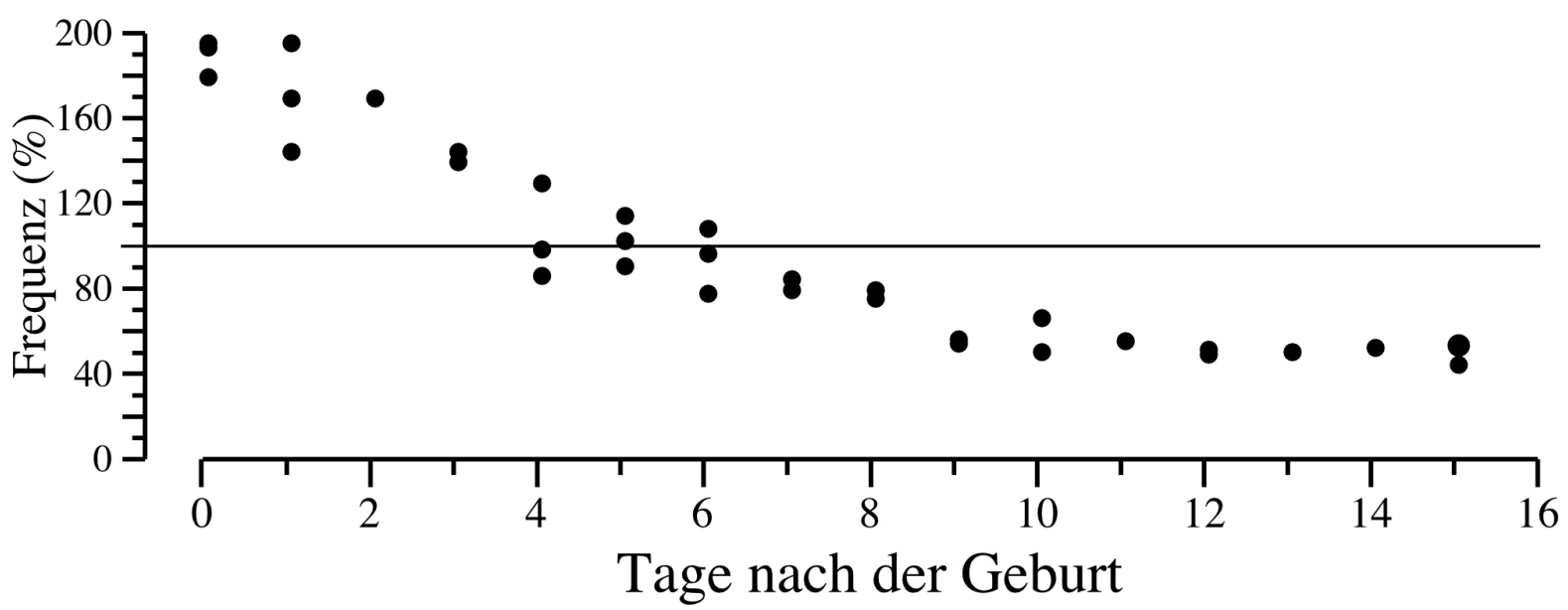

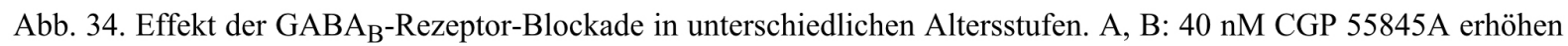
die rhythmische Frequenz an P1 und verringern sie an P9. C: Zusammenfassung des Effektes unterschiedlich konzentrierten CGP (5-40 nM) auf neonatale (P0-3) und ältere (P7-15) Tiere. Die Werte werden relativ zum Kontrollwert angegeben. In neonatalen Tieren wird die Frequenz ab $20 \mathrm{nM}$ CGP signifikant erhöht, in älteren wird sie bereit ab $5 \mathrm{nM}$ signifikant reduziert. Die Wirkung war in jedem Alter reversibel. *= signifikant, $* *=$ deutlich signifikant. D: Detaillierte Aufführung der Wirkung von CGP auf Präparationen unterschiedlichen Alters. Jeder Punkt repräsentiert eine Messung bei einer CGP Konzentration von $40 \mathrm{nM}$. Zwischen P0-3 konnte in jeder Messung eine Steigerung der respiratorischen Frequenz beobachtet werden, von P4-6 in 4 von 8 Experimenten und ab P7 wurde der Rhythmus stets verlangsamt. 
P1

A $1 \quad$ Kontrolle

NXII

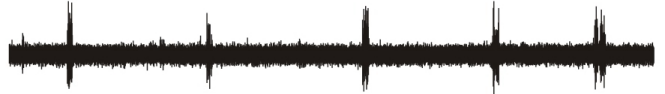

NXII

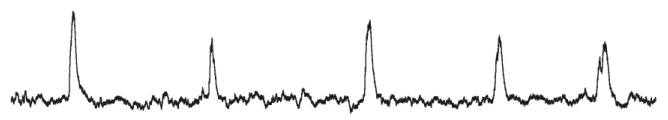

$\mathrm{A}_{2} \quad 2 \mu \mathrm{M} \mathrm{Bic}+2 \mu \mathrm{M} \mathrm{Str}$

NXII

NXII
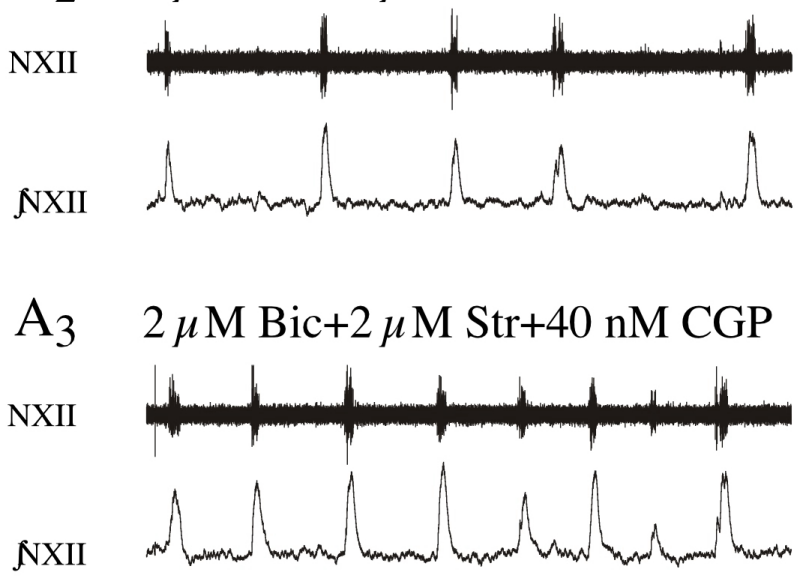

B $1 \quad$ Kontrolle

NXII

NXII

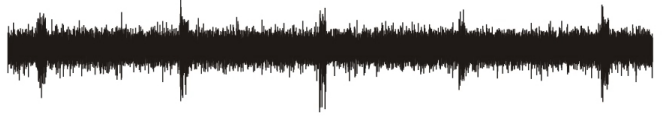

$\mathrm{B}_{2} \quad 2 \mu \mathrm{M} \mathrm{Bic}+2 \mu \mathrm{M} \mathrm{Str}$

NXII

NXII

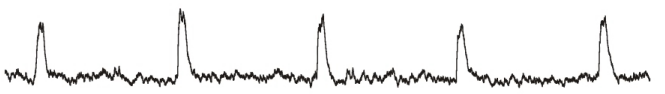

$\mathrm{B}_{3} \quad 2 \mu \mathrm{M} \mathrm{Bic}+2 \mu \mathrm{M} \mathrm{Str}+40 \mathrm{nM}$ CGP

NXII

NXII

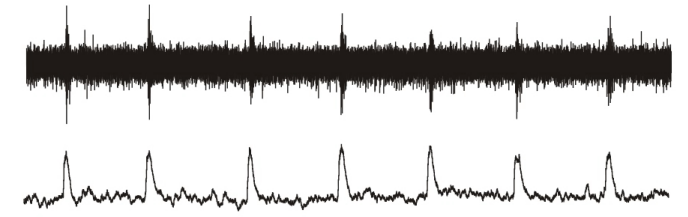

C
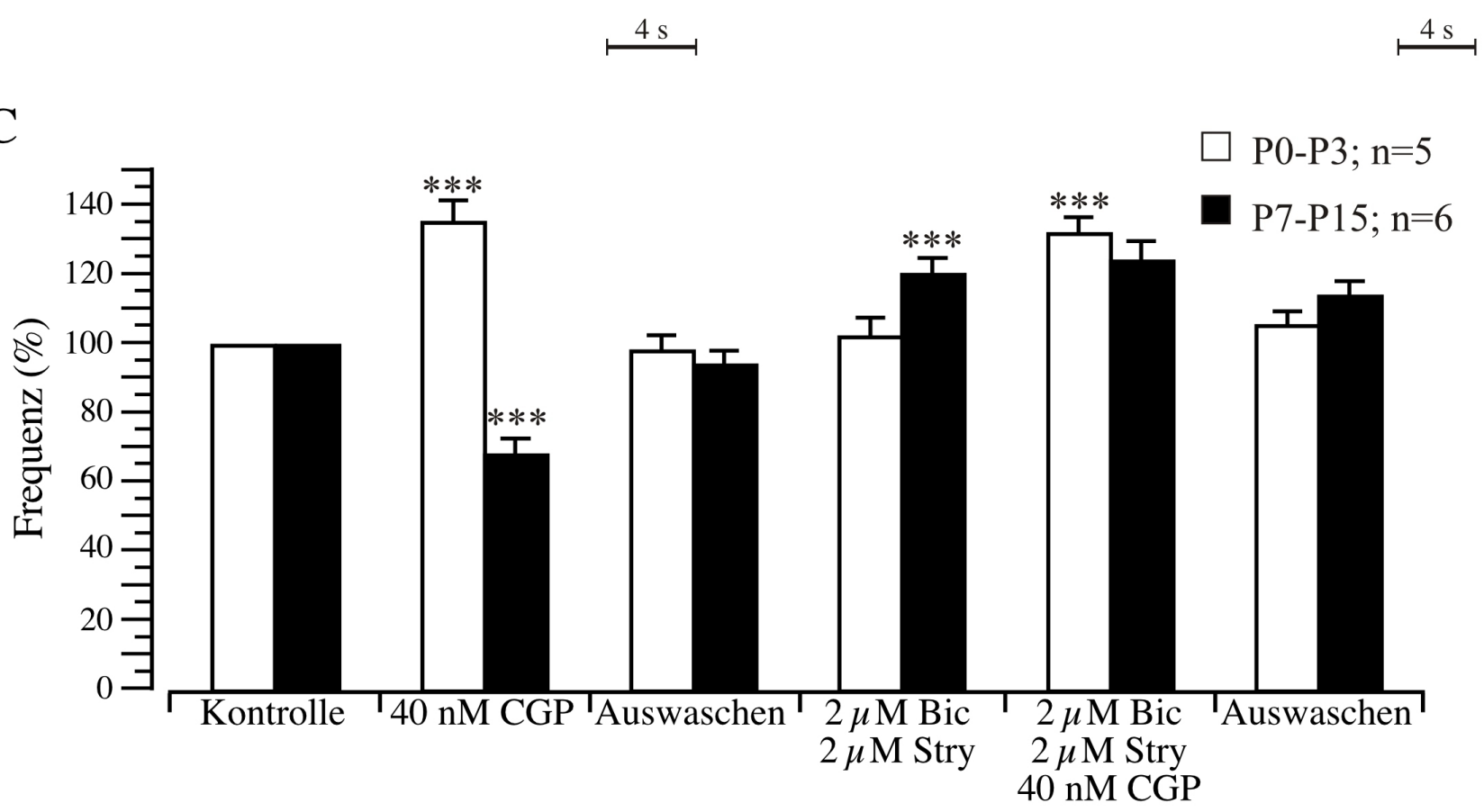

Abb. 35. Einfluß zusätzlicher GABA $A^{-}$und Glycin- Rezeptor-Blockaden auf die Wirkung der $G_{A B A}$-Rezeptor-Blockade. A,B: Beispiele für die Wirkung von $40 \mathrm{nM}$ CGP 55845A nach der Applikation von jeweils $2 \mu \mathrm{M}$ Bicucullin (Bic) und Strychnin (Str). An P1 wird die durch Bic und Str unbeeinflußte respiratorische Frequenz durch CGP erhöht, an P9 verändert CGP die durch Bic und Str erhöhte Frequenz nicht. C: Zusammenfassung der Daten aus 5 bzw 6 Versuchen der Altersgruppen P0-3 bzw P7-15. Werte relativ zum Kontrollwert und \pm Standardabweichung dargestellt. $*=$ signifikant, $* *=$ deutlich signifikant, $* * *=$ extrem signifikant

Abbildung 35 zeigt, daß der Effekt der $\mathrm{GABA}_{\mathrm{B}}$-Rezeptor-Blockade nur in älteren Tieren von einer zusätzlichen Blockade von $\mathrm{GABA}_{\mathrm{A}^{-}}$und Glyzin-Rezeptoren beeinflußt wurde. In den hier dargestellten Versuchen wurde zunächst 40 nM CGP appliziert und der oben beschriebene Effekt in 
neonatalen $(\mathrm{P} 0-3 ; \mathrm{n}=5)$ bzw. älteren $(\mathrm{P} 7-15 ; \mathrm{n}=6)$ Tieren dokumentiert. Nach dem Auswaschen der Droge wurden Bicucullin und der Glycin-Rezeptor-Antagonist Strychnin in einer Konzentration von je $2 \mu \mathrm{M}$ appliziert. Dies bewirkte nur in älteren Tieren eine signifikante Frequenzerhöhung (s. 3.4.1.). Eine zusätzliche Gabe von 40 nM CGP änderte die Frequenz nicht, während in perinatalen Tieren eine extrem signifikante Erhöhung der Frequenz zu beobachten war. Diese Ergebnisse sprechen dafür, daß in älteren Tieren $\mathrm{GABA}_{\mathrm{A}^{-}}$und Glycin-Rezeptoren an der Vermittlung $\mathrm{GABA}_{\mathrm{B}^{-}}$ Rezeptor-induzierter Effekte beteiligt sind. Dies könnte durch eine vorwiegend präsynaptische Lokalisation des Rezeptors während dieser Entwicklungsphase erklärt werden. Eine Aktivierung von $\mathrm{GABA}_{\mathrm{B}}-$ Rezeptoren würde in diesem Fall den Ausstoß von Neurotransmittern wie GABA und Glycin verringern und so eine Verminderung postsynaptischer Inhibition bewirken. 


\section{DISKUSSION}

Die in dieser Arbeit beschriebenen Untersuchungen lieferten experimentelle Indizien für eine umfangreiche postnatale Umorganisation des GABAergen Systems, welche im Wesentlichen wie folgt zusammengefaßt werden kann:

a) Die durchgeführten Versuche deuten darauf hin, daß GABA die Respiration von NMRI Mäusen bereits zum Zeitpunkt der Geburt moduliert. Die von endogen ausgeschüttetem GABA bewirkte Reduktion der respiratorischen Frequenz wird perinatal durch den $\mathrm{GABA}_{\mathrm{B}}$-Rezeptor vermittelt. Erst ab P4 gewinnt der $\mathrm{GABA}_{\mathrm{A}}$-Rezeptor zunehmend an Bedeutung. Ebenfalls während dieser Zeit verschiebt sich das Gleichgewichtspotential $\mathrm{GABA}_{\mathrm{A}}$-Rezeptor-vermittelter $\mathrm{Cl}^{-}$-Ströme von depolarisierend auf hyperpolarisierend.

b) Die zwischen P0-5 diffus in Somata und Dendriten der Neurone vieler Hirnregionen verteilte Immunoreaktivität des $\mathrm{GABA}_{\mathrm{B}}$-Rezeptors wird im Laufe der postnatalen Ontogenese durch intensiv immunopositive Granula ergänzt oder ersetzt. Diese wurden als Gruppen GABA $_{B}$-Rezeptor-haltiger Vesikel identifiziert. Der Beginn dieser intrazellulären Umverteilung ist Hirnareal-spezifisch und spiegelt die sich später in der postnatalen Entwicklung vollziehende Reifung höherer Hirnstrukturen wider.

c) Die in unterschiedlichen Hirngebieten nachweisbare Komplexbildung von GABA $_{B}$ R1 und R2 mit dem Transkriptionsfaktor ATF4 (CREB2) ist einer Untereinheit-spezifischen postnatalen Entwicklung unterworfen.

d) Die Auswirkungen der dokumentierten Entwicklungen zeigen sich auf der Ebene des respiratorischen Netzwerks durch eine unterschiedliche Auswirkung der Rezeptorblockaden auf den respiratorischen Rhythmus. Während die Blockade des $\mathrm{GABA}_{\mathrm{A}}$-Rezeptors erst ab P4 zu einer signifikanten Erhöhung der Rhythmusfrequenz führte, steigerte eine $G_{A B} A_{B}$-Rezeptor-Blockade diese zwischen P0-3 und reduzierte sie von P7-15.

\subsection{Inhibition in der frühpostnatalen Phase}

Die Nervenzellen innerhalb eines neuronales Netzwerks sind sowohl exzitatorisch als auch inhibitorisch miteinander verbunden. Im adulten Zentralen Nervensystem wird ein großer Teil der Inhibition durch die ionotropen $\mathrm{GABA}_{\mathrm{A}^{-}}$bzw. Glycin-Rezeptoren über eine $\mathrm{Cl}^{-}$-Ion-getragenen Hyperpolarisationen vermittelt. In der peri- und frühpostnatalen Entwicklung ist die Situation in vielen Hirnregionen z.B. der Ratte grundlegend anders, da in dieser Phase die $\mathrm{Cl}^{-}$-vermittelte Inhibition noch nicht funktionsfähig ist. Die Frage, ob synaptische Inhibition dennoch ein essentieller Bestandteil des unreifen Gehirns ist oder die neuronalen Netzwerke während dieser Phase gänzlich ohne synaptische Inhibition auskommen, ist bis heute Gegenstand kontroverser Diskussionen. 


\subsubsection{Die Funktion GABA $\mathbf{A}_{\mathrm{A}}$-Rezeptor vermittelter Depolarisation in neuronalen Netzwerken}

In dieser Arbeit wurde gezeigt, daß eine Aktivierung des $\mathrm{GABA}_{\mathrm{A}}$-Rezeptors im respiratorischen Netzwerk der Maus erst ab P4 hyperpolarisierende PSP erzeugt. Somit wurde demonstiert, daß das respiratorische Netzwerk der Maus perinatal ohne $\mathrm{Cl}^{-}$-getragene Hyperpolarisation funktionieren kann. Da die Respiration aus vitalem Grund von der Geburt an stabil und effizient funktionieren muß, ist die Frage nach dem Aufbau eines neuronalen Netzwerks unter diesen Umständen besonders brisant.

Es wurde schon früher von unterschiedlichen Forschungsgruppen die Frage nach dem Vorhandensein der $\mathrm{Cl}^{-}$-getragenen Hyperpolarisation im perinatalen respiratorischen Netzwerk gestellt. Sie berichteten, daß sowohl im respiratorischen Netzwerk von Ratten (Brockhaus \& Ballanyi, 1998; Shao \& Feldman, 1997) als auch in Katzen (Lawson et al., 1992) die $\mathrm{GABA}_{\mathrm{A}^{-}}$ Rezeptor-vermittelte Hyperpolarisation bereits zum Zeitpunkt der Geburt zu beobachten ist. In anderen Hirngebieten der Ratte konnte hingegen perinatal eine $\mathrm{GABA}_{\mathrm{A}}$-Rezeptor vermittelte Depolarisation gezeigt werden. Sie wurde z.B im Hippocampus (Ben-Ari et al., 1997; Cherubini et al., 1991; Cherubini et al., 1990; Staley \& Mody, 1992), Hypothalamus (Chen et al., 1996), auditorischem Hirnstamm (Kandler \& Friauf, 1995), spinalen Hinterhorn (Reichling et al., 1994) und spinalen Motoneuronen (Wu et al., 1992) postnatal nachgewiesen. Diese Unterschiede deuten darauf hin, daß der Zeitpunkt des Auftretens der $\mathrm{Cl}^{-}$-vermittelten Inhibition eine hirngewebespezifische Funktion ist. Darüber hinaus könnte die allgemeine Reife des Gehirns zum Zeitpunkt der Geburt eine Rolle spielen. So ist die Tragzeit der Ratte (21-23 Tage) länger als bei der hier verwendeten NMRI Maus (18-21 Tage), und somit werden Ratten vermutlich reifer geboren als Mäuse.

Die Ergebnisse dieser Studie zeigen, daß die beobachteten Veränderungen $\mathrm{GABA}_{\mathrm{A}}$-Rezeptorvermittelter Ströme tatsächlich auf eine ontogenetische Verschiebung des $\mathrm{Cl}^{-}$-Gradienten über der Neuronenmembran zurückzuführen sind. Erfolgte nach einem Experiment an Gramicidinperforierten Neuronen ein Durchbruch durch die Zellmembran, so ergaben die anschließend im whole cell Modus durchgeführten Messungen eine Verschiebung von $\mathrm{E}_{\mathrm{GABA}-\mathrm{A}}$ in Richtung des für den nun gegebenen $\mathrm{Cl}^{-}$-Gradienten berechneten, hyperpolarisierten Wert. Die intrazelluläre $\mathrm{Cl}^{-}$Konzentration in ausgereiften Neuronen konnte auf ca 4 bis $7 \mathrm{mM}$ berechnet werden. Dieser Wert stimmt mit der in der adulten Ratte ermittelten intrazellulären $\mathrm{Cl}^{-}$-Konzentration überein (Brockhaus \& Ballanyi, 1998; Shao \& Feldman, 1997). Zusätzlich wurde durch Veränderungen des extrazellulären Bicarbonatgehaltes gezeigt, daß diese Ionen anders als in den Arbeiten von Kaila et al (Bormann, 1991; Kaila, 1994) in keinem untersuchten postnatalen Stadium einen wesentlichen Einfluß auf $\mathrm{E}_{\mathrm{GABA}}$ ausübten. Auch dies stimmt mit den von Brockhaus et al. am respiratorischen System der Ratte erzielten Ergebnissen überein (Brockhaus \& Ballanyi, 1998). 
Die Funktion GABA $_{\mathrm{A}}$-Rezeptor vermittelter Depolarisation wird unterschiedlich diskutiert. Allgemein wird eine trophische Rolle angenommen, da die Expression von $\mathrm{GABA}_{\mathrm{A}}$-Rezeptoren und die von ihnen vermittelten Depolarisationen in einigen Fällen ontogenetisch noch vor der Ausbildung von Synapsen stattfinden (Coyle \& Enna, 1976; Rozenberg et al., 1989). Im Hippocampus der Ratte wurde die Entwicklung der GABA $_{A}$-Rezeptor-vermittelten Ströme und ihre Funktion von der Arbeitsgruppe Ben Ari et al. untersucht. Sie wiesen GABA in der postnatalen Phase als den vorherrschenden exzitatorischen Neurotransmitter in dieser Region nach. Die durch GABA ausgelösten Depolarisationen ersetzen die Effekte des in frühpostnatalen Phase noch nicht funktionellen non-NMDA-Glutamat-Rezeptors. Sie ermöglichen die rhythmische Aktivität dieses Netzwerkes (Ben-Ari et al., 1997). Darüber hinaus wird durch sie das $\mathrm{Mg}^{2+}$-Ion, daß den NMDAGlutamat-Rezeptor blockiert, entfernt und bei gleichzeitiger Aktivierung dieses Rezeptors ein Einstrom von vorwiegend $\mathrm{Na}^{+}$und $\mathrm{Ca}^{2+}$ ermöglicht. Die so erhöhte intrazelluläre $\mathrm{Ca}^{2+}$ Konzentration kann die Frühphase von Langzeitpotenzierungen (long term potentiation, LTP) einleiten. Somit kommt der $\mathrm{GABA}_{\mathrm{A}}$-Rezeptor vermittelten Depolarisation eine wichtige Rolle nicht nur in der Aufrechterhaltung der Netzwerkoszillation sondern auch in der Stabilisierung aktiver Synapsen und der Synapsenneubildung zu (Ben-Ari et al., 1997).

In der vorliegenden Studie bewirkte eine Blockade des $\mathrm{GABA}_{\mathrm{A}}$-Rezeptors mit Bicucullin während der ersten drei postnatalen Tage im Gegensatz zu seiner Wirkung in späteren postnatalen Stadien keine signifikante Erhöhung der respiratorischen Frequenz. Dieses Resultat stimmt mit den Beobachtungen anderer Forschungsgruppen überein (Brockhaus \& Ballanyi, 1998; Feldman \& Smith, 1989; Onimaru et al., 1990; Ramirez \& Richter, 1996). Darüber hinaus wird in der Literatur berichtet, daß im PBC anders als im Hippocampus der Ratte die non-NMDA-Glutamat-Rezeptoren bei Geburt bereits funktionell sind, da bei ihrer Blockade durch den spezifischen Antagonisten 6Cyano-7-nitroquinoxalin-2,3-dion (CNQX) der respiratorische Rhythmus zum Erliegen kommt

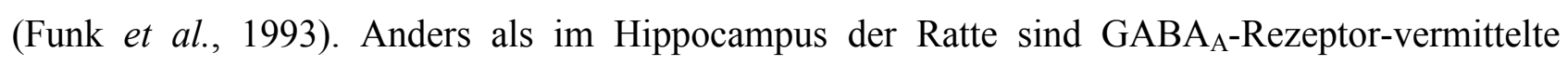
Depolarisationen im respiratorischen Netzwerk dementsprechend nicht essentiell an der Generierung des Rhythmus beteiligt. Es konnte allerdings ein stabilisierender Effekt auf die Rhythmusfrequenz nachgewiesen werden.

Es ist beschrieben, daß die perinatal vom $\mathrm{GABA}_{\mathrm{A}}$-Rezeptor-vermittelten PSP trotz ihrer depolarisierenden Natur durch die Erniedrigung der Impedanz der postsynaptischen Membran (shunting, s. Einleitung) einen Beitrag zur Abschwächung der exzitatorischen PSPs leisten. In diesem Fall ist zusätzlich die $\mathrm{Cl}^{-}$-getragene Hyperpolarisation nicht vorhanden. Folglich fehlt auch die de-inaktivierende Funktion an spannungsabhängigen Kationen-Kanälen in der Phase zwischen den Aktionspotentialsalven. 


\subsection{2 $\mathrm{K}^{+}$- vermittelte Inhibition während der frühpostnatalen Phase}

Da die $\mathrm{Cl}^{-}$-getragene Inhibition in der frühpostnatalen Phase in vielen Hirngebieten nicht oder nur eingeschränkt funktionstüchtig ist, stellt sich die Frage, wie Inhibition während dieser Zeit vermittelt wird. Eine Möglichkeit besteht darin, daß sie durch Kationen-getragene Ströme ausgeübt wird. Da, wie in dieser Arbeit gezeigt, GABA die rhythmische Aktivität des respiratorischen Hirnstammes in jedem untersuchten Alter verlangsamt, bietet sich der $\mathrm{GABA}_{B}$-Rezeptor als Vermittler Kationen-getragener Inhibition in perinatalen Mäusen an.

Es wurde in unterschiedlichen neuronalen Netzwerken demonstriert, daß der GABA B Rezeptor bereits zum Zeitpunkt der Geburt exprimiert wird und eine funktionelle Rolle einnimmt (Gaiarsa et al., 1995b; Zhang et al., 2001; Zhang et al., 1999). In der hier vorliegenden Arbeit konnte demonstriert werden, daß eine Blockade des $\mathrm{GABA}_{B}$-Rezeptors den respiratorischen Rhythmus neonataler Mäuse beschleunigt. Da dieser Effekt unabhängig vom Glycin oder dem $\mathrm{GABA}_{\mathrm{A}^{-}}$ Rezeptor vorhanden war, ist anzunehmen, daß er durch postsynaptisch lokalisierte $\mathrm{GABA}_{\mathrm{B}^{-}}$ Rezeptoren vermittelt wird. Die Arbeit von Pfeiffer-Eicke et al. (Pfeiffer-Eicke et al., 1999) hat zusätzlich gezeigt, daß der $\mathrm{GABA}_{\mathrm{B}}$-Rezeptor von Geburt an die einwärtsgerichteten $\mathrm{K}^{+}{ }^{-}$Ströme aktivieren kann.

Es wurde von mehreren Arbeitsgruppen demonstriert, daß die Lokalisation von $\mathrm{GABA}_{\mathrm{B}}$-Rezeptoren an prä- und postsynaptischen Membranen altersbedingten Veränderungen unterliegt (Gaiarsa et al., 1995b; Koulen et al., 1998). So zeigten z.B. Gaiarsa et al. an Neuronen der CA1 Region im Hippocampus der neonatalen Ratte, daß die Applikation des $\mathrm{GABA}_{\mathrm{B}}$-Rezeptor-Agonisten Baklofen präsynaptisch die Transmitterfreisetzung reduziert (Gaiarsa et al., 1995a; Gaiarsa et al., 1995b). Ebenso modulieren $\mathrm{GABA}_{\mathrm{B}}$-Rezeptoren die Leitfähigkeiten von $\mathrm{Ca}^{2+}$-Kanälen im neonatalen Hippocampus der Ratte (Guyon \& Leresche, 1995). Im repiratorischen System der Maus wurde dieser Aspekt von Frau Anke Barnbrock in ihrer medizinischen Dissertation ausführlich untersucht (Barnbrock, 2000; siehe auch Zhang et al., 2001). Sie konnte demonstrieren, daß GABA $\mathrm{B}^{-}$ Rezeptoren zwischen P0-3 vorwiegend post- und später (P4-10) vorwiegend präsynaptisch lokalisiert sind. Diese Ergebnisse werden durch die Befunde dieser Arbeit unterstützt, nämlich daß die $\mathrm{GABA}_{\mathrm{B}}$-Rezeptor Blockade ab P4 den respiratorischen Rhythmus beschleunigen kann und dieser Effekt nur in der Anwesenheit postsynaptischer GABA $_{\mathrm{A}^{-}}$und/oder Glyzin-Rezeptoren zu beobachten ist.

\subsection{Entwicklungsbedingte Veränderungen des $G A B A_{B}$-Rezeptors}

Die Ontogenese des $\mathrm{GABA}_{\mathrm{A}}$-Rezeptors ist von vielen Arbeitsgruppen unter verschiedenen Gesichtspunkten untersucht worden. So ändert sich im Laufe der Entwicklung seine Expressionsrate, seine Untereinheitenzusammensetzung und die Auswirkung der durch ihn vermittelten Ströme (s. Einleitung, Tab. 1). Im Gegensatz zu diesen detaillierten Kenntnissen über 
die ontogenetischen Veränderungen des $\mathrm{GABA}_{\mathrm{A}}$-Rezeptors wissen wir noch sehr wenig über die des $\mathrm{GABA}_{\mathrm{B}}$-Rezeptors.

Bisher ist es noch keiner Arbeitsgruppe gelungen, den $\mathrm{GABA}_{\mathrm{B}}$-Rezeptor in der synaptischen Membran nachzuweisen, obwohl extrasynaptisch lokalisierte GABA $_{B}-$ Rezeptoren mehrfach beobachtet worden sind (Fritschy et al., 1999; Ige et al., 2000). Die von Frau Monika Ochojski während ihrer Dissertation erstellte, elektronenmikroskopische Studie zeigte, daß auch in dieser Arbeit nur ein intrazellulärer Vesikelpool angefärbt werden konnte s. Abb. 36. Eine Erklärung für diese Schwierigkeiten könnte eine intensive Bindung von $\mathrm{GABA}_{\mathrm{B}}$-Rezeptoren an ein Ankerprotein sein, wie sie für andere Rezeptoren wie den $\mathrm{GABA}_{\mathrm{A}^{-}}$oder den Glycin-Rezeptor an Gephyrin gezeigt wurde (Kirsch \& Betz, 1993; Kirsch et al., 1995; Kneussel et al., 1999). Eine solche Interaktion könnte die durch die erhältlichen Antikörper zu bindenden Epitope maskieren. Eine weitere Schwierigkeit stellt die Gewebefixierung dar, bei der Proteine chemisch vernetzt und somit auch verändert werden. In der Elektronenmikroskopie werden zusätzlich die Membranstrukturen durch eine Verknüpfung der Lipide untereinander konserviert. Darüber hinaus werden mehrere Kontrastierungsschritte durchgeführt, die zwar die Zellstrukturen leichter erkennbar machen, aber eine Detektion des gesuchten Epitops erschweren können. Da die Suche nach immer effektiveren Antikörpern gegen wechselnde Epitope des $\mathrm{GABA}_{\mathrm{B}}$-Rezeptors noch lange nicht abgeschlossen ist, bleibt auf einen Erfolg in naher Zukunft zu hoffen. Eine solche Färbemöglichkeit könnte dazu dienen, die elektrophysiologisch gezeigte $\mathrm{GABA}_{\mathrm{B}}$-Rezeptor Lokalisation und ihre Entwicklung während der Ontogenese zu verifizieren.

5.2.1 Unterschiedliche intrazelluläre Verteilung des GABA $A_{B}$-Rezeptors in der Ontogenese: ein Phänomen des Rezeptor-Transportes oder der Rezeptor-Internalisierung?

Die durchgeführten immunohistochemischen Untersuchungen zeigten eine postnatale Umverteilung des intrazellulären $\mathrm{GABA}_{\mathrm{B}}$-Rezeptors, welche sowohl spezifisch für das betrachtete Hirngebiet als auch für das jeweilige Alter der untersuchten Maus spezifisch ist. Um die Möglichkeit eines Artefaktes auszuschliessen, wurden die Ergebnisse in dieser Arbeit durch Anwendung von Antikörper gegen verschiedene Epitope und unterschiedlichen Färbemethoden mit verschiedenen zweiten Antikörpern verifiziert. So wurden $\mathrm{GABA}_{\mathrm{B}}$-Rezeptor-haltige Granula sowohl mit der Färbung durch Diaminobenzidin-Umsatz als auch mit Fluoreszenzfärbungen nachgewiesen. Des Weiteren sind intrazelluläre, immunopositive Granula mit Antikörpern gegen die $\mathrm{GABA}_{B} \mathrm{R} 1 \mathrm{a} / \mathrm{b}$ Untereinheit, gegen ausschließlich die $\mathrm{GABA}_{\mathrm{B}} \mathrm{R} 1 \mathrm{~b}$-Untereinheit und die $\mathrm{GABA}_{\mathrm{B}}$ R2-Untereinheit detektierbar.

In der höheren Auflösung des Elektronenmikroskopes zeigten sich diese immunopositiven Granula als eine Ansammlung von immunopositiven Ringen, die ein helleres Zentrum umgaben s. Abb. 36, vgl. Dissertation Frau Monika Ochojski Ritter et al., 2001a). Diese können aus folgenden Gründen 
als $\mathrm{GABA}_{\mathrm{B}}$-Rezeptor enthaltende Vesikel interpretiert werden. Beim Transport von Membranproteinen in Vesikeln weisen in der Zellmembran zum Zellplasma ausgerichteten Bereiche nach außen, während die putativ extrazellulären Domänen im Innern des Vesikels liegen s. Abb 37 A. Dies resultiert bei einer Verschmelzung des Vesikels mit der Zellmembran in der richtigen Orientierung des Proteins (Stenoien \& Brady, 1999). Die gleiche Orientierung ergibt sich bei endozytotischer Aufnahme von proteinhaltigen Membranabschnitten als Vesikel ins Zellplasma. Da in der hier beschriebenen elektronenmikroskopischen Studie ein Antikörper benutzt wurde, der die C-terminalen, in der Zellmembran intrazellulär gelegenen Bereiche der $\mathrm{GABA}_{\mathrm{B}} \mathrm{R} 1 \mathrm{a} / \mathrm{b}$ Untereinheit erkennt, würde man sowohl in Transport- als auch in endozytotischen Vesikeln die oben beschriebene Verteilung der Immunoreaktivität erwarten. Auch in den veröffentlichen immunohistochemischen Färbungen anderer Arbeitsgruppen (Billinton et al., 2000; Nehring et al., 2000) sind diese intrazellulären, immunopositiven Granula zu erkennen, allerdings wurden sie von keiner dieser Arbeitsgruppen in ihrer Verteilung und Entwicklung näher beschrieben.

Da der $\mathrm{GABA}_{\mathrm{B}}$-Rezeptor funktionell nur als Heterodimer vorliegt (Jones et al., 1998; Kaupmann et al., 1998a; White et al., 1998), ist die Frage von großer Bedeutung, in welcher Form der GABA $\mathrm{B}^{-}$ Rezeptor in den Versikel vorkommt. Eine Studie von Billinton et al. (Billinton et al., 2000) zeigt eine weitgehende Kolokalisation der $\mathrm{GABA}_{\mathrm{B}} \mathrm{R} 1$ und R2-Untereinheit in den von ihnen untersuchten Hirngebieten (visueller Cortex, Hippocampus, Thalamus, Cerebellum) auch in immunopositiven Granula (Cerebellum, Billinton et al., 2000). Dies spricht dafür, daß in den meisten immunopositiven Granula der detektierte $\mathrm{GABA}_{\mathrm{B}}$-Rezeptor als Heterodimer vorliegt.

Die elektrophysiologischen Experimente unserer Arbeitsgruppe haben gezeigt, daß im respiratorischen System der Maus eine funktionelle präsynaptische Inhibition erst am Ende der ersten postnatalen Woche (P5) präsent ist, obwohl die postsynaptische Inhibition von Geburt an

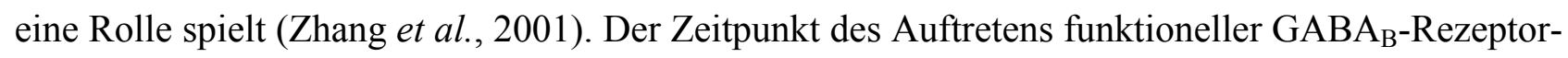
vermittelter präsynaptischer Inhibition koinzidiert mit dem oben beschriebenen Eintritt $\mathrm{GABA}_{\mathrm{A}^{-}}$ Rezeptor vermittelter Hyperpolarisation und mit der erster immunopositiver Granula in Neuronen der Ncl. hypoglossus und ambiguus. Dies deutet darauf hin, daß zwischen dem Auftreten von $\mathrm{GABA}_{\mathrm{A}}$-Rezeptor-vermittelter Hyperpolarisation, präsynaptischer $\mathrm{GABA}_{\mathrm{B}}$-Rezeptor-vermittelter Inhibition und dem vermehrten Auftreten von $\mathrm{GABA}_{\mathrm{B}}$-immunopositiver Vesikel ein Zusammenhang bestehen könnte. So kann das vermehrte Auftreten von immunopositiven Granula im Zellplasma ein Zeichen für eine geringere Verweildauer des Rezeptors in der Membran (erhöhter turnover) und einen intensivierten Transport unter veränderten funktionellen Anforderungen gedeutet werden (s. Abb 37A, Baude \& Shigemoto, 1998). 

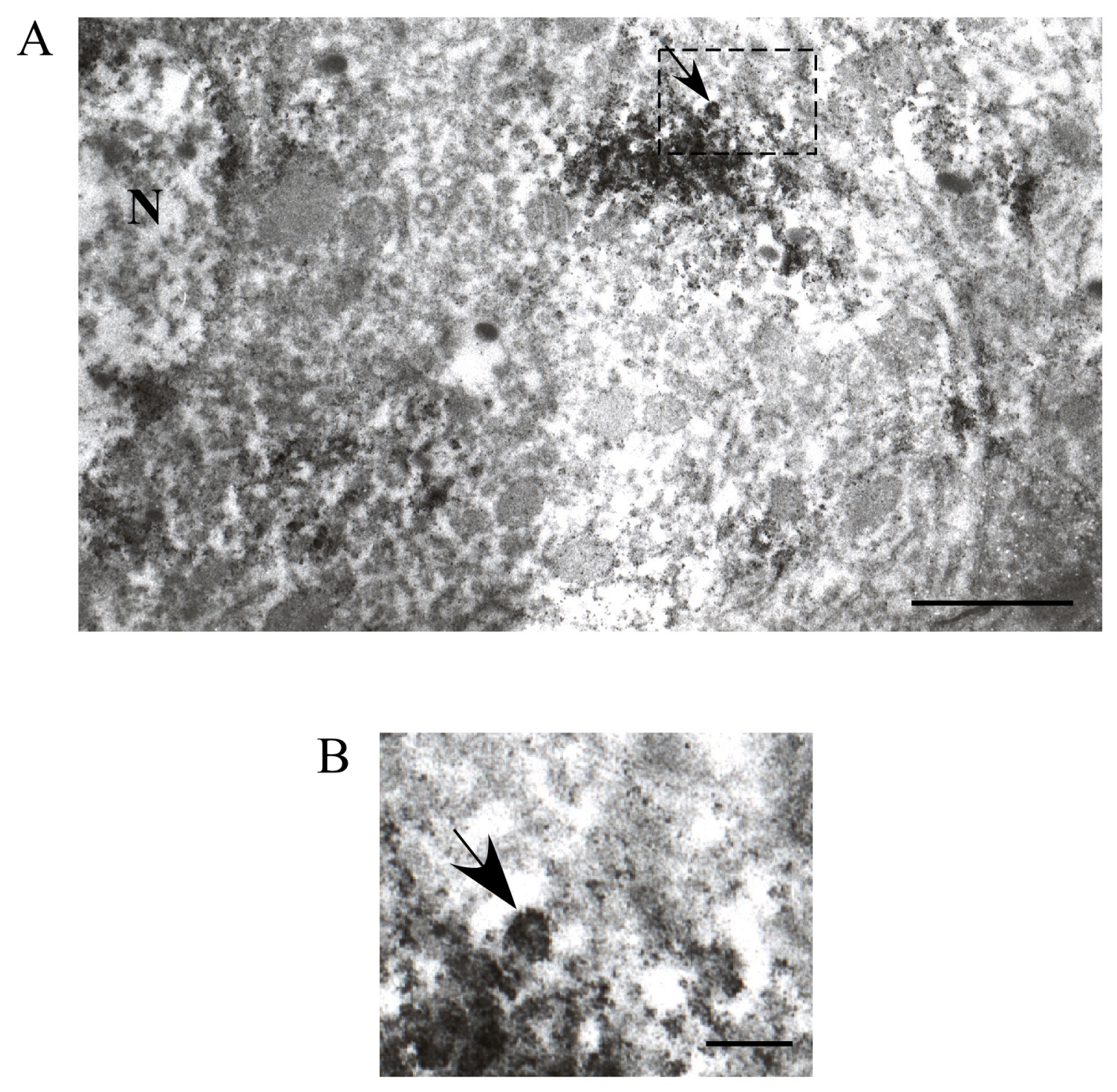

Abb. 36. Granuläre Strukturen zeigen sich im Elektronenmikroskop als Gruppen immunopositiver Vesikel. A: Ausschnitt einer DAB-Färbung aus einem Neuron der CA 1 Region des Hippocampus. Die vesikulären Strukturen (Pfeil) weisen ein helles Zentrum und einen stärker immunopositiven, dunkleren Außenrand auf. Der Balken entspricht 200 nm. N markiert den Zellkern. B: Ausschnittsvergrößerung des in A durch den gestrichelten Kasten markierten Bereiches. Balken entspricht $40 \mathrm{~nm}$. Diese Abbildung wurde von Frau Monika Ochojski zur Verfügung gestellt.

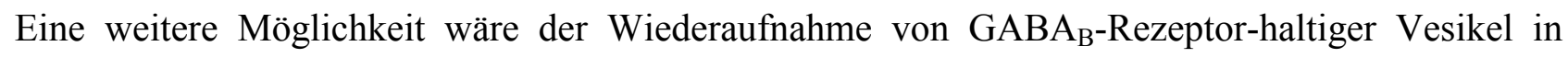
einen intrazellulären Pool ('recycling' Endosom, s. Abb 37 B). Eine solche Desensitisierung GProtein- gekoppelter Rezeptoren wurde u.a. für den $\beta_{2}$-adrenergen-Rezeptor als Möglichkeit zur schnellen Inaktivierung nach Ligandenbindung gezeigt (s. Rewiev Tsao et al., 2001). Dieser intrazelluläre Pool ist nicht unbedingt eine Vorstufe zum Rezeptorabbau. Die Rezeptor-haltigen Vesikel können ebenso wieder mit der Membran verschmelzen und den Rezeptor so wieder zur Verfügung stellen. Für diese Variante zur Erklärung $G_{A B A}-$ Rezeptor positiver Vesikel spricht die Beobachtung, daß keine $\mathrm{GABA}_{\mathrm{B}}$-Rezeptor-Immunoreaktivität in Zellkompartimenten der Proteindegradation wie den Lysosomen detektiert werden konnte.

\subsection{Interaktion von GABA $A_{B}$-Rezeptoren mit ATF4}

Mit Hilfe einer Doppelimmunofluoreszenzfärbung in fixierten Hirngewebe der Maus konnte beobachtet werden, daß in einem gewissen Anteil der $\mathrm{GABA}_{B} \mathrm{R} 1$ a/b-haltigen Vesikel der 
ansonsten diffus in Zellplasma und Kern verteilte ATF4 verstärkt vertreten ist. Dies stimmt mit den von anderen Gruppen in kultivierten Neuronen oder im Gewebe von transgen mit floureszierenden Sequenzen (tags) versehenen Creb2 (ATF4) exprimierenden Ratten erzielten Ergebnissen überein (Nehring et al., 2000; White et al., 2000).

Der Anteil ebenfalls ATF4 immunopositiver Granula wurde in dieser Arbeit als etwa 5-10\% der gesamt $\mathrm{GABA}_{\mathrm{B}}$-Rezeptor-haltigen Vesikel bestimmt. Da ATF4 an dieselbe C-terminale Helixstruktur bindet, an der auch die Interaktion der $\mathrm{GABA}_{\mathrm{B}}$-Rezeptor Untereinheiten miteinander stattfindet (Nehring et al., 2000; White et al., 2000), können zwei verschiedene Mechanismen diskutiert werden, durch die ein Transport eines solchen Komplexes zur Zellmembran durchgeführt werden könnte. Es ist denkbar, daß ATF4 die Bindung von $\mathrm{GABA}_{\mathrm{B}} \mathrm{R} 2$ an $\mathrm{GABA}_{\mathrm{B}} \mathrm{R} 1$ ersetzt und so einen voneinander unabhängigen Transport der beiden Untereinheiten zur Zellmembran erlaubt s. Abb. 37 A). Ob diese dann in der Membran dimerisieren oder getrennt voneinander ihre Funktion ausüben, ist ungeklärt. In diesem Falle nehmen die 5-10\% doppelt immunopositiven Vesikel eine Sonderstellung innerhalb des $\mathrm{GABA}_{\mathrm{B}}$-enthaltenden Vesikelpools ein, deren Großteil nach Billinton et al. (Billinton et al., 2000) bereits $\mathrm{GABA}_{B} \mathrm{R} 1$ und R2-Untereinheiten enthalten.

Da sehr wenig Informationen über die Funktion der $\mathrm{GABA}_{\mathrm{B}}$-Rezeptor/ ATF4 Interaktion vorliegen, ist die Diskussion darüber in hohem Maße spekulativ. Es ist durchaus möglich, daß die drei Komponenten - $\mathrm{GABA}_{\mathrm{B}} \mathrm{R} 1, \mathrm{R} 2$ und ATF4 - durch eine Dreifachhelix-Struktur miteinander in einem Versikel interagieren (Nehring et al., 2000). In einer Reihe von Versuchen konnte die Arbeitsgruppe White et al. (2000) zeigen, daß eine Aktivierung des $\mathrm{GABA}_{\mathrm{B}}$-Rezeptors in einigen Fällen zu einer Wanderung doppelt immunopositiver Vesikel zum Kern und nachfolgender Transkriptionsregulation von ATF4-sensitiven Reportergenen führt, die u.a. die für die Bildung von Neurotransmittern benötigten Proteine kodieren (Barthel et al., 1996). Ob ATF4 bei Aktivierung des Rezeptors bereits gebunden sein muß oder sich bei seiner Aktivierung anlagert, ist unklar. Ebenso steht auch hier die Möglichkeit offen, daß ATF4 mit Rezeptormonomeren in der Membran interagiert (s. Abb 37 B). Diese hätten dann nicht die Funktion, einen elektrophysiologischen Effekt auszulösen, sondern dienten als Sensor für die GABAerge Aktivität.

Bei Immunopräzipitation des ATF4 mit GABA $A_{B}$ 1 und R2 aus Hirngewebe unterschiedlich alter Mäuse konnte ein Untereinheiten-spezifischer Zeitverlauf der an der Interaktion beteiligten Proteinmenge aufgezeigt werden. Während die Bindung von $\mathrm{GABA}_{\mathrm{B}} \mathrm{R} 1$ an ATF4 innerhalb der ersten drei postnatalen Wochen leicht abnahm, um zum adulten Niveau wieder zu steigen, zeigte die Wechselwirkung mit $\mathrm{GABA}_{\mathrm{B}} \mathrm{R} 2$ einen umgekehrten Verlauf. 

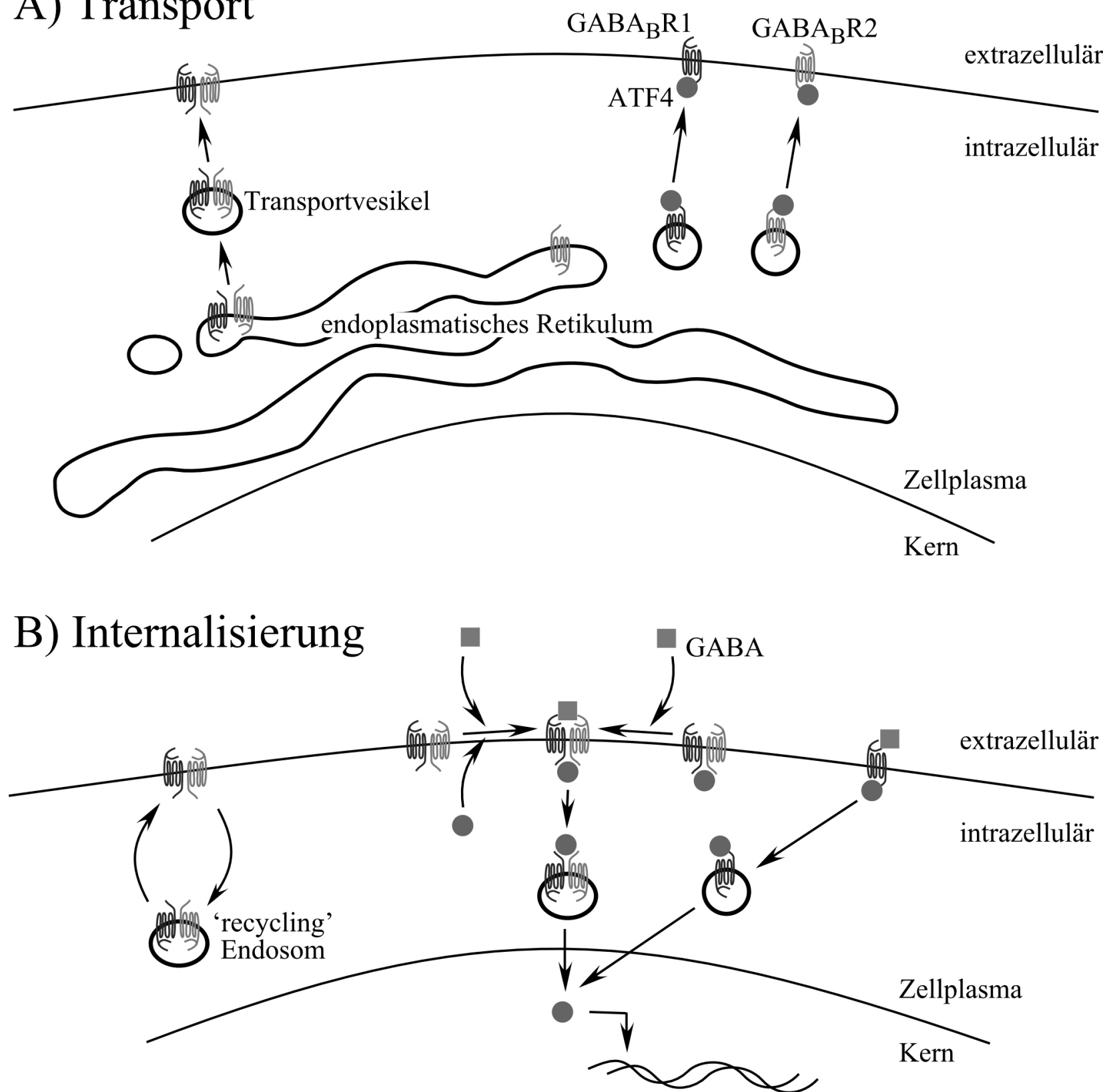

DNA

Abb. 37. Intrazelluläre Umverteilung des $G_{A B A}$-Rezeptors: Möglichkeiten für Transport und Internalisierung. A: Transportvesikel mit heterodimeren $\mathrm{GABA}_{\mathrm{B}}$-Rezeptor werden vom endoplasmatischen Retikulum abgeschnürt und verschmelzen mit der Zellmembran (links). Die C-terminale Endigung der Proteine ist dabei stets dem Zellplasma zugewandt. Im rechten Abbildungsteil wird dargestellt, daß ATF4 die zweite Untereinheit ersetzen kann und so Monomer-haltige Vesikel zur Membran transportiert werden können. Eine Bindung von ATF4 an ein Heterodimerhaltiges Transportvesikel kann jedoch nicht ausgeschlossen werden. B: Links wird gezeigt, wie $\mathrm{GABA}_{\mathrm{B}}$-Rezeptoren durch Endozytose von 'recycling'-Endosomen in einen intrazellulären Pool aufgenommen werden können. Sie können bei Bedarf wieder in die Membran eingebaut werden. Nach Bindung von GABA kann der $\mathrm{GABA}_{\mathrm{B}}$-Rezeptor auch zusammen mit ATF4 internalisiert werden (rechts). Ob ATF4 bei oder nach der Stimulation mit dem Rezeptor interagiert oder ob ein Heterodimer benötigt wird, ist unklar. ATF4 gelangt danach in den Kern und reguliert die Gentranskription.

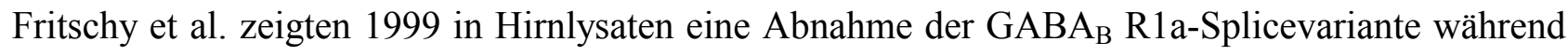
der Entwicklung. Im Gegensatz dazu stieg die Expression der GABA $_{B}$ R1 b-Variante bis zur zweiten postnatalen Woche an, um dann bis zum Erwachsenenstadium wieder leicht abzufallen 
(Fritschy et al., 1999). Diese Regulation der GABAB R1-Splicevarianten wird im Zusammenhang mit der prä- und postsynaptischen Lokalisation des Rezeptors diskutiert (Billinton et al., 1999). Sie spricht dafür, daß die funktionellen Änderungen des $\mathrm{GABA}_{B}$-Rezeptors begleitet sind von einer ontogenetischen Kontrolle der Untereinheitenexpression, wie sie ausführlich für andere Rezeptoren wie z.B. den $\mathrm{GABA}_{\mathrm{A}}$-Rezeptor dokumentiert sind. Auch die hier gezeigte entwicklungsbedingte Interaktion von $\mathrm{GABA}_{\mathrm{B}} \mathrm{R} 1$ und R2 mit ATF4 könnte für eine $\mathrm{GABA}_{\mathrm{B}} \mathrm{R} 1$ bzw R2 spezifische, ontogenetische Expressionsregulation sprechen. Die verschiedenen Untereinheiten könnten als Monomer an ATF4 binden und eine Rolle im Transport (s. Abb. 37 A) oder der Internalisierung (s. Abb. 37 B) spielen. Eine andere Möglichkeit wäre, daß R1 bzw R2 während der Entwicklung mit unterschiedlichen, bisher noch nicht charakterisierten $\mathrm{GABA}_{\mathrm{B}}$-Rezeptor-Untereinheiten (Mohler \& Fritschy, 1999) interagieren und ATF4 in einer Dreifachhelix-Struktur binden.

\subsection{Ausblick}

Im adulten Zentralen Nervensystem der Säugetiere kann es unter pathologischen Bedingungen zu einem Ausfall anionengetragener Inhibition kommen, die mit der Situation während der Entwicklung zu vergleichen ist. So ist es beim Menschen z.B. in der Ischämie möglich, daß gravierende Störungen der $\mathrm{Cl}^{-}$-getragenen Inhibition und ihrer Rezeptoren auftreten (Hansen \& Nedergaard, 1988). Wenn hier das über Kationen inhibierende System - z.B. über $\mathrm{GABA}_{\mathrm{B}}$ - oder Serotoninrezeptoren - gestärkt werden könnte, wäre dies ein möglicher Kompensationsmechanismus. Eine ähnliche Hypothese wurde bereits von Misgeld 1995 geäußert, der vermutete, daß bei einem Ausfall entweder des $\mathrm{GABA}_{\mathrm{A}^{-}}$oder des $\mathrm{GABA}_{\mathrm{B}}$-Rezeptors der jeweils andere die Rolle des ausgefallenen übernimmt. Er nannte diese These 'weakening of the one may strengthen the other' (Misgeld et al., 1995).

Die indirekte Steuerung der Genexpression über intrazelluläre Signalwege ist seit langem für unterschiedliche Rezeptoren der Zellmembran bekannt. So reguliert ATF4 die Transkription von Neurotransmittern wie z.B. von Proenkephalin und Somatostatin ebenso wie von ThyrosinHydrolase-abhängigen Neurotransmittern (Barthel et al., 1996). Über die Interaktion des $\mathrm{GABA}_{\mathrm{B}}$ Rezeptors mit dem Transkriptionsfaktor ATF4 (CREB2) eröffnet sich die Möglichkeit einer schnelleren Steuerung. Somit könnte es sich bei der GABA $_{B}$-Rezeptor/ATF4 Interaktion um einen Sensor für die Aktivität des GABAergen Systems handeln, der direkt die Transkriptionsrate von Neurotransmittern beeinflußt und somit die für die Aktivität des Nervensystems zur Verfügung stehende Neurotransmittermenge mitbestimmt. 


\section{LITERATUR}

Anderson, R. A. \& Mitchell, R. (1985) Evidence for GABAB autoreceptors in median eminence. Eur J Pharmacol, 118, 355-358.

Archibald, K., Molnar, E. \& Henley, J. M. (1999) Differential changes in the subcellular distribution of alpha-amino-3- hydroxy-5-methyl-4-isoxazole propionate and N-methyl-Daspartate receptors in neonate and adult rat cortex. Neurosci Lett, 270, 49-52.

Ballanyi, K., Muckenhoff, K., Bellingham, M. C., Okada, Y., Scheid, P. \& Richter, D. W. (1994) Activity-related $\mathrm{pH}$ changes in respiratory neurones and glial cells of cats. Neuroreport, 6, 3336.

Barnbrock, A., 2000, Frühpostnatale Entwicklung der GABAB-Rezeptor-vermittelten prä- und postsynaptischen Inhibition im respiratorischen Netzwerk der Maus, in: Zentrum Physiologie und Pathophysiologie (Georg August Universität Göttingen, Göttingen) p. 57.

Barthel, F., Kienlen Campard, P., Demeneix, B. A., Feltz, P. \& Loeffler, J. P. (1996) GABAB receptors negatively regulate transcription in cerebellar granular neurons through cyclic AMP responsive element binding protein- dependent mechanisms. Neuroscience, 70, 417-427.

Baude, A. \& Shigemoto, R. (1998) Cellular and subcellular distribution of substance P receptor immunoreactivity in the dorsal vagal complex of the rat and cat: a light and electron microscope study. J Comp Neurol, 402, 181-196.

Ben-Ari, Y., Cherubini, E., Corradetti, R. \& Gaiarsa, J. L. (1989) Giant synaptic potentials in immature rat CA3 hippocampal neurones. J Physiol (Lond), 416, 303-325.

Ben-Ari, Y., Khazipov, R., Leinekugel, X., Caillard, O. \& Gaiarsa, J. L. (1997) GABAA, NMDA and AMPA receptors: a developmentally regulated 'menage a trois'. Trends Neurosci, 20, 523529.

Bettler, B., Kaupmann, K. \& Bowery, N. (1998) GABAB receptors: drugs meet clones. Curr Opin Neurobiol, 8, 345-350.

Bianchi, A. L., Denavit-Saubie, M. \& Champagnat, J. (1995) Central control of breathing in mammals: neuronal circuitry, membrane properties, and neurotransmitters. Physiol Rev, 75, $1-45$.

Billinton, A., Ige, A. O., Wise, A., White, J. H., Disney, G. H., Marshall, F. H., Waldvogel, H. J., Faull, R. L. \& Emson, P. C. (2000) GABA(B) receptor heterodimer-component localisation in human brain. Brain Res Mol Brain Res, 77, 111-124.

Billinton, A., Upton, N. \& Bowery, N. G. (1999) GABA(B) receptor isoforms GBR1a and GBR1b, appear to be associated with pre- and post-synaptic elements respectively in rat and human cerebellum. Br J Pharmacol, 126, 1387-1392.

Bischoff, S., Leonhard, S., Reymann, N., Schuler, V., Shigemoto, R., Kaupmann, K. \& Bettler, B. (1999) Spatial distribution of GABA(B)R1 receptor mRNA and binding sites in the rat brain. J Comp Neurol, 412, 1-16.

Bittiger, H., Froestl, W., Mickel, S. \& Olpe, H. R. (1993) GABAB receptor antagonists: from synthesis to therapeutic applications. Trends Pharmacol Sci, 14, 391-394. 
Borden, L. A. (1996) GABA transporter heterogeneity: pharmacology and cellular localization. Neurochem Int, 29, 335-356.

Bormann, J. (1991) Electrophysiological characterization of diazepam binding inhibitor (DBI) on GABAA receptors. Neuropharmacology, 30, 1387-1389.

Bowery, N. G., Hill, D. R. \& Hudson, A. L. (1983) Characteristics of GABAB receptor binding sites on rat whole brain synaptic membranes. Br J Pharmacol, 78, 191-206.

Bowery, N. G., Price, G. W., Hudson, A. L., Hill, D. R., Wilkin, G. P. \& Turnbull, M. J. (1984) GABA receptor multiplicity. Visualization of different receptor types in the mammalian CNS. Neuropharmacology, 23, 219-231.

Brockhaus, J. \& Ballanyi, K. (1998) Synaptic inhibition in the isolated respiratory network of neonatal rats. Eur J Neurosci, 10, 3823-3839.

Castro-Lopes, J. M., Malcangio, M., Pan, B. H. \& Bowery, N. G. (1995) Complex changes of GABAA and GABAB receptor binding in the spinal cord dorsal horn following peripheral inflammation or neurectomy. Brain Res, 679, 289-297.

Champagnat, J. \& Richter, D. W. (1994) The roles of K+ conductance in expiratory pattern generation in anaesthetized cats. $J$ Physiol, 479, 127-138.

Chen, G., Trombley, P. Q. \& van den Pol, A. N. (1996) Excitatory actions of GABA in developing rat hypothalamic neurones. $J$ Physiol (Lond), 494, 451-464.

Cherubini, E., Gaiarsa, J. L. \& Ben-Ari, Y. (1991) GABA: an excitatory transmitter in early postnatal life. Trends Neurosci, 14, 515-519.

Cherubini, E., Rovira, C., Gaiarsa, J. L., Corradetti, R. \& Ben Ari, Y. (1990) GABA mediated excitation in immature rat CA3 hippocampal neurons. Int J Dev Neurosci, 8, 481-490.

Connolly, C. N., Wooltorton, J. R., Smart, T. G. \& Moss, S. J. (1996) Subcellular localization of gamma-aminobutyric acid type A receptors is determined by receptor beta subunits. Proc Natl Acad Sci US A, 93, 9899-9904.

Couve, A., Filippov, A. K., Connolly, C. N., Bettler, B., Brown, D. A. \& Moss, S. J. (1998) Intracellular retention of recombinant GABAB receptors. J Biol Chem, 273, 26361-26367.

Coyle, J. T. \& Enna, S. J. (1976) Neurochemical aspects of the ontogenesis of GABAnergic neurons in the rat brain. Brain Res, 111, 119-133.

Crunelli, V. \& Leresche, N. (1991) A role for GABAB receptors in excitation and inhibition of thalamocortical cells. Trends Neurosci, 14, 16-21.

Davies, C. H., Starkey, S. J., Pozza, M. F. \& Collingridge, G. L. (1991) GABA autoreceptors regulate the induction of LTP. Nature, 349, 609-611.

Deisz, R. A., Billard, J. M. \& Zieglgansberger, W. (1997) Presynaptic and postsynaptic GABAB receptors of neocortical neurons of the rat in vitro: differences in pharmacology and ionic mechanisms. Synapse, 25, 62-72.

Deisz, R. A. \& Lux, H. D. (1985) gamma-Aminobutyric acid-induced depression of calcium currents of chick sensory neurons. Neurosci Lett, 56, 205-210. 
Ebihara, S., Shirato, K., Harata, N. \& Akaike, N. (1995) Gramicidin-perforated patch recording: GABA response in mammalian neurones with intact intracellular chloride. J Physiol (Lond), 484, 77-86.

Eicke, A., Ritter, B. \& Zhang, W. (1999) GABAB-receptor-activated inwardly rectifying K+currents emerge after the third postnatal day in brain stem of mouse. Neurobiologentagung Göttingen,

Enna, S. \& Bowery, N. (1997) The GABA receptors (Humana Press, Totowa).

Enna, S. J., Harstad, E. B. \& McCarson, K. E. (1998) Regulation of neurokinin-1 receptor expression by GABA(B) receptor agonists. Life Sci, 62, 1525-1530.

Feldman, J. L. \& Smith, J. C. (1989) Cellular mechanisms underlying modulation of breathing pattern in mammals. Ann N Y Acad Sci, 563, 114-130.

Fritschy, J. M., Benke, D., Johnson, D. K., Mohler, H. \& Rudolph, U. (1997) GABAA-receptor alpha-subunit is an essential prerequisite for receptor formation in vivo. Neuroscience, 81, 1043-1053.

Fritschy, J. M., Meskenaite, V., Weinmann, O., Honer, M., Benke, D. \& Mohler, H. (1999) GABAB-receptor splice variants GB1a and GB1b in rat brain: developmental regulation, cellular distribution and extrasynaptic localization. Eur J Neurosci, 11, 761-768.

Fritschy, J. M. \& Mohler, H. (1995) GABAA-receptor heterogeneity in the adult rat brain: differential regional and cellular distribution of seven major subunits. J Comp Neurol, 359, 154-194.

Fritschy, J. M., Paysan, J., Enna, A. \& Mohler, H. (1994) Switch in the expression of rat GABAAreceptor subtypes during postnatal development: an immunohistochemical study. $J$ Neurosci, 14, $5302-5324$.

Funk, G. D., Smith, J. C. \& Feldman, J. L. (1993) Generation and transmission of respiratory oscillations in medullary slices: role of excitatory amino acids. $J$ Neurophysiol, 70, 1497 1515.

Gahwiler, B. H. \& Brown, D. A. (1985) GABAB-receptor-activated K+ current in voltage-clamped CA3 pyramidal cells in hippocampal cultures. Proc Natl Acad Sci U S A, 82, 1558-1562.

Gaiarsa, J. L., McLean, H., Congar, P., Leinekugel, X., Khazipov, R., Tseeb, V. \& Ben-Ari, Y. (1995a) Postnatal maturation of gamma-aminobutyric acid A- and B-mediated inhibition in the CA3 hippocampal region of the rat. J Neurobiol, 26, 339-349.

Gaiarsa, J. L., Tseeb, V. \& Ben-Ari, Y. (1995b) Postnatal development of pre- and postsynaptic GABAB-mediated inhibitions in the CA3 hippocampal region of the rat. $J$ Neurophysiol, 73, 246-255.

Greer, J. J., Smith, J. C. \& Feldman, J. L. (1992) Respiratory and locomotor patterns generated in the fetal rat brain stem-spinal cord in vitro. J Neurophysiol, 67, 996-999.

Grillner, S., Ekeberg, El Manira, A., Lansner, A., Parker, D., Tegner, J. \& Wallen, P. (1998) Intrinsic function of a neuronal network - a vertebrate central pattern generator. Brain Res Brain Res Rev, 26, 184-197. 
Gunther, U., Benson, J., Benke, D., Fritschy, J. M., Reyes, G., Knoflach, F., Crestani, F., Aguzzi, A., Arigoni, M., Lang, Y. \& et al. (1995) Benzodiazepine-insensitive mice generated by targeted disruption of the gamma 2 subunit gene of gamma-aminobutyric acid type A receptors. Proc Natl Acad Sci US A, 92, 7749-7753.

Guyon, A. \& Leresche, N. (1995) Modulation by different GABAB receptor types of voltageactivated calcium currents in rat thalamocortical neurones. $J$ Physiol, 485, 29-42.

Haji, A., Remmers, J. E., Connelly, C. \& Takeda, R. (1990) Effects of glycine and GABA on bulbar respiratory neurons of cat. J Neurophysiol, 63, 955-965.

Haji, A., Takeda, R. \& Remmers, J. E. (1992) Evidence that glycine and GABA mediate postsynaptic inhibition of bulbar respiratory neurons in the cat. $J$ Appl Physiol, 73, 23332342 .

Hansen, A. J. \& Nedergaard, M. (1988) Brain ion homeostasis in cerebral ischemia. Neurochem Pathol, 9, 195-209.

Hayashi, F. \& Lipski, J. (1992) The role of inhibitory amino acids in control of respiratory motor output in an arterially perfused rat. Respir Physiol, 89, 47-63.

Ige, A. O., Bolam, J. P., Billinton, A., White, J. H., Marshall, F. H. \& Emson, P. C. (2000) Cellular and sub-cellular localisation of $\operatorname{GABA}(\mathrm{B} 1)$ and $\mathrm{GABA}(\mathrm{B} 2)$ receptor proteins in the rat cerebellum. Brain Res Mol Brain Res, 83, 72-80.

Isomoto, S., Kaibara, M., Sakurai-Yamashita, Y., Nagayama, Y., Uezono, Y., Yano, K. \& Taniyama, K. (1998) Cloning and tissue distribution of novel splice variants of the rat GABAB receptor. Biochem Biophys Res Commun, 253, 10-15.

Jarolimek, W., Bijak, M. \& Misgeld, U. (1994) Differences in the Cs block of baclofen and 4aminopyridine induced potassium currents of guinea pig CA3 neurons in vitro. Synapse, 18, 169-177.

Jarolimek, W. \& Misgeld, U. (1992) On the inhibitory actions of baclofen and gamma-aminobutyric acid in rat ventral midbrain culture. $J$ Physiol, 451, 419-443.

Johnston, G. A. (1996) GABAc receptors: relatively simple transmitter -gated ion channels? Trends Pharmacol Sci, 17, 319-323.

Jones, K. A., Borowsky, B., Tamm, J. A., Craig, D. A., Durkin, M. M., Dai, M., Yao, W. J., Johnson, M., Gunwaldsen, C., Huang, L. Y., Tang, C., Shen, Q., Salon, J. A., Morse, K., Laz, T., Smith, K. E., Nagarathnam, D., Noble, S. A., Branchek, T. A. \& Gerald, C. (1998) $\mathrm{GABA}(\mathrm{B})$ receptors function as a heteromeric assembly of the subunits $\mathrm{GABA}(\mathrm{B}) \mathrm{R} 1$ and GABA(B)R2. Nature, 396, 674-679.

Jungling, S., Cibelli, G., Czardybon, M., Gerdes, H. H. \& Thiel, G. (1994) Differential regulation of chromogranin B and synapsin I gene promoter activity by cAMP and cAMP-dependent protein kinase. Eur J Biochem, 226, 925-935.

Kaila, K. (1994) Ionic basis of GABAA receptor channel function in the nervous system. Prog Neurobiol, 42, 489-537.

Kandler, K. \& Friauf, E. (1995) Development of glycinergic and glutamatergic synaptic transmission in the auditory brainstem of perinatal rats. $J$ Neurosci, 15, 6890-6904. 
Karpinski, B. A., Morle, G. D., Huggenvik, J., Uhler, M. D. \& Leiden, J. M. (1992) Molecular cloning of human CREB-2: an ATF/CREB transcription factor that can negatively regulate transcription from the cAMP response element. Proc Natl Acad Sci U S A, 89, 4820-4824.

Kaupmann, K., Huggel, K., Heid, J., Flor, P. J., Bischoff, S., Mickel, S. J., McMaster, G., Angst, C., Bittiger, H., Froestl, W. \& Bettler, B. (1997) Expression cloning of GABA(B) receptors uncovers similarity to metabotropic glutamate receptors [see comments]. Nature, 386, 239246.

Kaupmann, K., Malitschek, B., Schuler, V., Heid, J., Froestl, W., Beck, P., Mosbacher, J., Bischoff, S., Kulik, A., Shigemoto, R., Karschin, A. \& Bettler, B. (1998a) GABA(B)-receptor subtypes assemble into functional heteromeric complexes. Nature, 396, 683-687.

Kaupmann, K., Schuler, V., Mosbacher, J., Bischoff, S., Bittiger, H., Heid, J., Froestl, W., Leonhard, S., Pfaff, T., Karschin, A. \& Bettler, B. (1998b) Human gamma-aminobutyric acid type B receptors are differentially expressed and regulate inwardly rectifying $\mathrm{K}+$ channels. Proc Natl Acad Sci U S A, 95, 14991-14996.

Kerr, D. I. \& Ong, J. (1995) GABAB receptors. Pharmacol Ther, 67, 187-246.

Kirsch, J. \& Betz, H. (1993) Widespread expression of gephyrin, a putative glycine receptor-tubulin linker protein, in rat brain. Brain Res, 621, 301-310.

Kirsch, J., Kuhse, J. \& Betz, H. (1995) Targeting of glycine receptor subunits to gephyrin-rich domains in transfected human embryonic kidney cells. Mol Cell Neurosci, 6, 450-461.

Kneussel, M., Brandstatter, J. H., Laube, B., Stahl, S., Muller, U. \& Betz, H. (1999) Loss of postsynaptic GABA(A) receptor clustering in gephyrin-deficient mice. J Neurosci, 19, 92899297.

Koulen, P., Malitschek, B., Kuhn, R., Bettler, B., Wassle, H. \& Brandstatter, J. H. (1998) Presynaptic and postsynaptic localization of GABA(B) receptors in neurons of the rat retina. Eur J Neurosci, 10, 1446-1456.

Krogsgaard-Larsen, Frolund \& Ebert, 1997, GABAA receptor agonists, partial agonists and antagonists. In Humana Press, Totowa.

Krogsgaard-Larsen, P., Frolund, B. F. \& Falch, E. (1998) Inhibitors of gamma-aminobutyric acid transport as experimental tools and therapeutic agents. Methods Enzymol, 296, 165-175.

Kyrozis, A. \& Reichling, D. B. (1995) Perforated-patch recording with gramicidin avoids artifactual changes in intracellular chloride concentration. J Neurosci Methods, 57, 27-35.

Lawson, E. E., Schwarzacher, S. W. \& Richter, D. W. (1992) Postnatal development of the medullary respiratory network of cat. Proceedings of the 20th Göttingen Neurobiology Conference, Thieme, 1:P. 69.

Liang, G. \& Hai, T. (1997) Characterization of human activating transcription factor 4, a transcriptional activator that interacts with multiple domains of cAMP- responsive elementbinding protein (CREB)-binding protein. J Biol Chem, 272, 24088-24095.

Lu, J., Karadsheh, M. \& Delpire, E. (1999) Developmental regulation of the neuronal-specific isoform of $\mathrm{K}-\mathrm{Cl}$ cotransporter $\mathrm{KCC} 2$ in postnatal rat brains. J Neurobiol, 39, 558-568. 
Maric, D., Maric, I., Wen, X., Fritschy, J. M., Sieghart, W., Barker, J. L. \& Serafini, R. (1999) GABAA receptor subunit composition and functional properties of $\mathrm{Cl}$ - channels with differential sensitivity to zolpidem in embryonic rat hippocampal cells [In Process Citation]. $J$ Neurosci, 19, 4921-4937.

Marshall, F. H., Jones, K. A., Kaupmann, K. \& Bettler, B. (1999) GABAB receptors - the first 7TM heterodimers. Trends Pharmacol Sci, 20, 396-399.

Mertens, S., Benke, D. \& Mohler, H. (1993) GABAA receptor populations with novel subunit combinations and drug binding profiles identified in brain by alpha 5- and delta-subunitspecific immunopurification. J Biol Chem, 268, 5965-5973.

Mironov, S. L., Langohr, K., Haller, M. \& Richter, D. W. (1998) Hypoxia activates ATP-dependent potassium channels in inspiratory neurones of neonatal mice. $J$ Physiol, 509, 755-766.

Misgeld, U., Bijak, M. \& Jarolimek, W. (1995) A physiological role for GABAB receptors and the effects of baclofen in the mammalian central nervous system. Prog Neurobiol, 46, 423-462.

Mohler, H. \& Fritschy, J. M. (1999) GABAB receptors make it to the top--as dimers. Trends Pharmacol Sci, 20, 87-89.

Mohler, H., Fritschy, J. M., Luscher, B., Rudolph, U., Benson, J. \& Benke, D. (1996) The GABAA receptors. From subunits to diverse functions. Ion Channels, 4, 89-113.

Nehring, R. B., Horikawa, H. P., El Far, O., Kneussel, M., Brandstatter, J. H., Stamm, S., Wischmeyer, E., Betz, H. \& Karschin, A. (2000) The Metabotropic GABAB Receptor Directly Interacts with the Activating Transcription Factor 4 (ATF-4). J Biol Chem.

Newberry, N. R. \& Nicoll, R. A. (1984) Direct hyperpolarizing action of baclofen on hippocampal pyramidal cells. Nature, $\mathbf{3 0 8}, 450-452$.

Numberger, M. \& Draguhn, A. (1996) Patch-Clamp-Technik (Spektrum Akademischer Verlag, Heidelberg, Berlin, Oxford).

Nusser, Z., Sieghart, W. \& Somogyi, P. (1998) Segregation of different GABAA receptors to synaptic and extrasynaptic membranes of cerebellar granule cells. $J$ Neurosci, 18, 1693-1703.

Onimaru, H., Arata, A. \& Homma, I. (1990) Inhibitory synaptic inputs to the respiratory rhythm generator in the medulla isolated from newborn rats. Pflugers Arch, 417, 425-432.

Onimaru, H. \& Homma, I. (1987) Respiratory rhythm generator neurons in medulla of brainstemspinal cord preparation from newborn rat. Brain Res, 403, 380-384.

Paysan, J. \& Fritschy, J. M. (1998) GABAA-receptor subtypes in developing brain. Actors or spectators? Perspect Dev Neurobiol, 5, 179-192.

Pfeiffer-Eicke, A., Ritter, B. \& Zhang, W. (1999) GABAB-receptor-activated inwardly-rectifying $\mathrm{K}+$-currents appear at the end of the first postnatal week in brain stem of mouse. Neurobiologentagung,

Plotkin, M. D., Snyder, E. Y., Hebert, S. C. \& Delpire, E. (1997) Expression of the Na-K-2Cl cotransporter is developmentally regulated in postnatal rat brains: a possible mechanism underlying GABA's excitatory role in immature brain. $J$ Neurobiol, 33, 781-795. 
Ramirez, J. M. \& Richter, D. W. (1996) The neuronal mechanisms of respiratory rhythm generation. Curr Opin Neurobiol, 6, 817-825.

Reichling, D. B., Kyrozis, A., Wang, J. \& MacDermott, A. B. (1994) Mechanisms of GABA and glycine depolarization-induced calcium transients in rat dorsal horn neurons. J Physiol (Lond), 476, 411-421.

Richter, D., 1995, Rhythmogenese der Atmung und Atemregulation. In Springer-Verlag, Berlin.

Richter, D. W., Ballanyi, K. \& Schwarzacher, S. (1992) Mechanisms of respiratory rhythm generation. Curr Opin Neurobiol, 2, 788-793.

Ritter, B., Ochojski, M., Kühn, T., Schwarzacher, S. \& Zhang, W. (2001a) Differential cellular and subcellular distribution of GABAB R1a and $b$ receptors in mouse brain during postnatal development. in preparation.

Ritter, B., Zhang, W., Richter, D. \& Ponimaskin, E. (2001b) The GABAB receptor subunits R1 and R2 interact differentially with the activating transcription factor ATF4 in mouse brain during the postnatal development. in preparation.

Rivera, C., Voipio, J., Payne, J. A., Ruusuvuori, E., Lahtinen, H., Lamsa, K., Pirvola, U., Saarma, M. \& Kaila, K. (1999) The K+/Cl- co-transporter KCC2 renders GABA hyperpolarizing during neuronal maturation [In Process Citation]. Nature, 397, 251-255.

Rozenberg, F., Robain, O., Jardin, L. \& Ben-Ari, Y. (1989) Distribution of GABAergic neurons in late fetal and early postnatal rat hippocampus. Brain Res Dev Brain Res, 50, 177-187.

Schmid, K., Bohmer, G. \& Gebauer, K. (1989) GABAB receptor mediated effects on central respiratory system and their antagonism by phaclofen. Neurosci Lett, 99, 305-310.

Selverston, A. I. \& Moulins, M. (1985) Oscillatory neural networks. Annu Rev Physiol, 47, 29-48.

Shao, X. M. \& Feldman, J. L. (1997) Respiratory rhythm generation and synaptic inhibition of expiratory neurons in pre-Botzinger complex: differential roles of glycinergic and GABAergic neural transmission. J Neurophysiol, 77, 1853-1860.

Sieghart, W. (1995) Structure and pharmacology of gamma-aminobutyric acidA receptor subtypes. Pharmacol Rev, 47, 181-234.

Smith, J. C., Ellenberger, H. H., Ballanyi, K., Richter, D. W. \& Feldman, J. L. (1991a) PreBotzinger complex: a brainstem region that may generate respiratory rhythm in mammals. Science, 254, 726-729.

Smith, J. C., Ellenberger, H. H., Ballanyi, K., Richter, D. W. \& Feldman, J. L. (1991b) PreBotzinger complex: a brainstem region that may generate respiratory rhythm in mammals. Science, 254, 726-729.

Snead, O. C., 3rd (1994) The ontogeny of [3H]gamma-hydroxybutyrate and [3H]GABAB binding sites: relation to the development of experimental absence seizures. Brain Res, 659, 147-156.

Sodickson, D. L. \& Bean, B. P. (1996) GABAB receptor-activated inwardly rectifying potassium current in dissociated hippocampal CA3 neurons. J Neurosci, 16, 6374-6385. 
Staley, K. J. \& Mody, I. (1992) Shunting of excitatory input to dentate gyrus granule cells by a depolarizing GABAA receptor-mediated postsynaptic conductance. J Neurophysiol, 68, 197212.

Stenoien, D. L. \& Brady, S. T., 1999, Axonal transport. In Lippincott-Raven, Philadelphia,

New York pp. 565-587.

Steriade, M. \& Deschenes, M. (1984) The thalamus as a neuronal oscillator. Brain Res, 320, 1-63.

Taguchi, J., Kuriyama, T., Ohmori, Y. \& Kuriyama, K. (1989) Immunohistochemical studies on distribution of GABAA receptor complex in the rat brain using antibody against purified GABAA receptor complex. Brain Res, 483, 395-401.

Taveira da Silva, A. M., Hartley, B., Hamosh, P., Quest, J. A. \& Gillis, R. A. (1987) Respiratory depressant effects of GABA alpha- and beta-receptor agonists in the cat. J Appl Physiol, 62, 2264-2272.

Thews, G., 1995, Lungenatmung. In Springer-Verlag, Berlin.

Tsao, P., Cao, T. \& von Zastrow, M. (2001) Role of endocytosis in mediating downregulation of Gprotein-coupled receptors. Trends Pharmacol Sci, 22, 91-96.

Turgeon, S. M. \& Albin, R. L. (1994) Postnatal ontogeny of GABAB binding in rat brain. Neuroscience, 62, 601-613.

White, J. H., McIllhinney, R. A., Wise, A., Ciruela, F., Chan, W. Y., Emson, P. C., Billinton, A. \& Marshall, F. H. (2000) The GABAB receptor interacts directly with the related transcription factors CREB2 and ATFx [In Process Citation]. Proc Natl Acad Sci U S A, 97, 13967-13972.

White, J. H., Wise, A., Main, M. J., Green, A., Fraser, N. J., Disney, G. H., Barnes, A. A., Emson, P., Foord, S. M. \& Marshall, F. H. (1998) Heterodimerization is required for the formation of a functional GABA(B) receptor [see comments]. Nature, 396, 679-682.

Wojcik, W. J. \& Neff, N. H. (1984) gamma-aminobutyric acid B receptors are negatively coupled to adenylate cyclase in brain, and in the cerebellum these receptors may be associated with granule cells. Mol Pharmacol, 25, 24-28.

Wu, W. L., Ziskind-Conhaim, L. \& Sweet, M. A. (1992) Early development of glycine- and GABA-mediated synapses in rat spinal cord. J Neurosci, 12, 3935-3945.

Xia, Y. \& Haddad, G. G. (1992) Ontogeny and distribution of GABAA receptors in rat brainstem and rostral brain regions. Neuroscience, 49, 973-989.

Zhang, W., Barnbrock, A., Gajic, S., Pfeiffer, A. \& Ritter, B. (2001) Differential ontogeny of GABAB receptor-mediated pre- and postsynaptic inhibition in respiratory rhythm generating network of mouse. The Journal of Physiology, revised.

Zhang, W., Elsen, F., Barnbrock, A. \& Richter, D. W. (1999) Postnatal development of GABAB receptor-mediated modulation of voltage- activated $\mathrm{Ca} 2+$ currents in mouse brain-stem neurons. Eur J Neurosci, 11, 2332-2342. 


\section{DANKSAGUNG}

Ich danke Herrn Prof. Dr. D.W. Richter für die Überlassung dieses interessanten Themas und die großzügige Bereitstellung der Mittel, die für die Fertigstellung dieser Arbeit notwendig waren.

Mein Dank gilt Herrn Prof. Dr. Schürmann für die freundliche und hilfsbereite Übernahme der Betreuung meiner Doktorarbeit. Ebenso danke ich meinem Koreferenten Herrn Prof. Hustert und meinen Prüfern Herrn Prof. Dr. Heldt und Herrn Prof. Dr. Zippel sowie den anderen Mitgliedern meiner Prüfungskomission für ihr Interesse.

Mein besonderer Dank gilt Herrn Dr. Weiqi Zhang. Unter seiner Betreuung im Labor waren drei Jahre intensiver Arbeit mit überraschend wenig intensivem Streß verbunden. Ohne seine Ansprechbarkeit auf alle wichtigen Fragen des Anfangs (Weiqi, was macht man, wenn der Computer mitten während der Messung abstürzt?) bis zu den wichtigen Fragen des Abschlusses (Was soll ich dem Refery denn darauf antworten?) und all den wichtigen Fragen dazwischen (Wie kommt man von Gamla Stan nach Djurgarden? Hast Du wieder neue Fotos?) kann ich mir diese Arbeit beim besten Willen nicht vorstellen.

Des Weiteren bedanke ich mich bei Herrn Dr. Swen Hülsmann, dessen Fachwissen über Computer - und sein kreativer Umgang mit Krisen - mir eine große Hilfe waren.

Ebenso danke ich Herrn Dr. Stefan Schwarzacher für seine geduldige und intensive Einführung in die Schönheit und die Tücken immunohistochemischer Färbungen.

Mein Dank gilt auch Herrn Dr. Evgeni Ponimaskin für seine tatkräftige Hilfe auf dem Feld der Molekularbiologie. Ich habe sogar beinahe russisch gelernt! Na, ja - wie gesagt, fast.

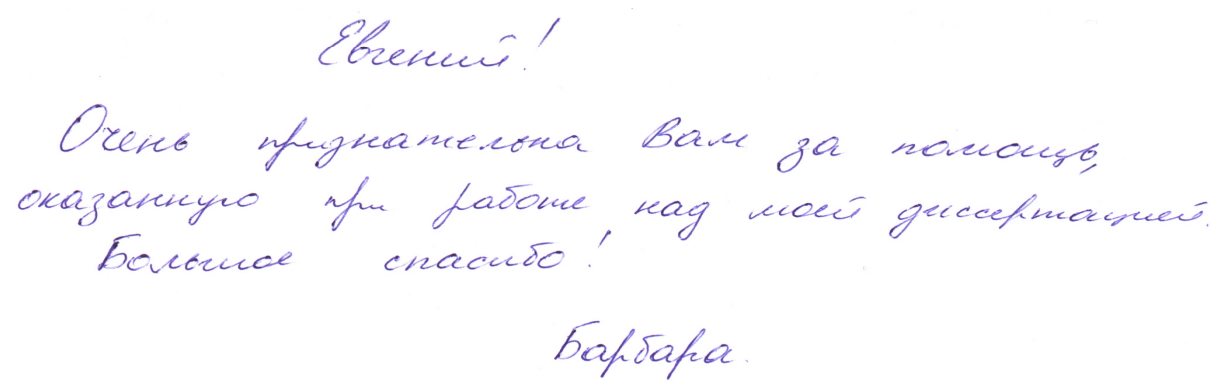


Des Weiteren bedanke ich mich bei denen, die das Labor und die Aufgabe, eine Doktorarbeit zu verfassen, mit mir geteilt haben. Bei Anke, Juliana und Almut, bei Monika und Torsten, bei Sasa und Thorsten, bei Anja, Jana und Korinna und bei Marco und Dennis. Eure Geduld mit meinen dummen Sprüchen war phänomenal! Und natürlich eure Phantasie mit noch dümmeren zu antworten.

Für geübte technische Assistenz und eine gute Zusammenarbeit sei hier Frau Christine Bartje, Frau Christina Patzelt und Frau Gabi Klaehn gedankt.

Außerdem sei an dieser Stelle allen denen gedankt, die mir sehr lehrreiche - und sehr schöne Auslandsaufenthalte ermöglicht haben, um die Türen zur Elektronenmikroskopie und zur Immunofluoreszenz-Doppelfärbung zu öffnen. Dies waren Herr Dr. Lennard Brodin zusammen mit Jenny Gustafson im Karolinska Institut Stockholm und Herr Dr. Jean-Marc Fritschy im Institut für Pharmakologie in Zürich. 


\section{LEBENSLAUF}

14.01.1970 geboren in Waltrop als drittes Kind der Eheleute Karl-Josef und Adelheid Ritter, geborene Schroer

Staatsangehörigkeit: Deutsch

1976 - 1980 Besuch der Grundschule am Heikenberg in Lünen, Westfalen

1980 - 1989 Besuch des städtischen Gymnasiums Altlünen in Lünen, Westfalen

Mai 1989 Abitur

Oktober 1989 Beginn des Studiums der Biologie an der Ruhr-Universität Bochum

Oktober 1990 Wechsel des Studienfaches

Beginn des Studiums der Biochemie an der Ruhr-Universität Bochum

1995 - 1996 Diplomarbeit: “Änderung der Proteinexpression bei Synapsenbildung in Zellkultur" am Lehrstuhl für Molekulare Neurobiochemie, RuhrUniversität Bochum (Priv. Doz. I.D. Dietzel-Meyer)

09.12.1996 Diplom in Biochemie

Januar - $\quad$ Tätigkeit als Wissenschaftliche Mitarbeiterin am Lehrstuhl für Oktober 1997 Molekulare Neurobiochemie, Ruhr-Universität Bochum

November 1997 Tätigkeit als Wissenschaftliche Mitarbeiterin im Zentrum für - Juni 2001 Physiologie und Pathophysiologie, Georg August Universität Göttingen Promotionsstudiengang in Biologie, Georg August Universität Göttingen

Anfertigung der Promotionsarbeit:

"Postnatale Entwicklung des GABAergen Systems im Gehirn der Maus" 